\title{
Ghana: Poverty Reduction Strategy Paper
}

Poverty Reduction Strategy Papers (PRSPs) are prepared by member countries in broad consultation with stakeholders and development partners, including the staffs of the World Bank and the IMF. Updated every three years with annual progress reports, they describe the country's macroeconomic, structural, and social policies in support of growth and poverty reduction, as well as associated external financing needs and major sources of financing. This country document for Ghana, dated November 2005, is being made available on the IMF website by agreement with the member country as a service to users of the IMF website.

To assist the IMF in evaluating the publication policy, reader comments are invited and may be sent by e-mail to publicationpolicy@imf.org.

$$
\begin{gathered}
\text { Copies of this report are available to the public from } \\
\text { International Monetary Fund • Publication Services } \\
70019^{\text {th }} \text { Street, N.W. • Washington, D.C. } 20431 \\
\text { Telephone: (202) 623-7430 • Telefax: (202) 623-7201 } \\
\text { E-mail: publications@imf.org • Internet: http://www.imf.org }
\end{gathered}
$$

Price: $\$ 15.00$ a copy

\section{International Monetary Fund Washington, D.C.}





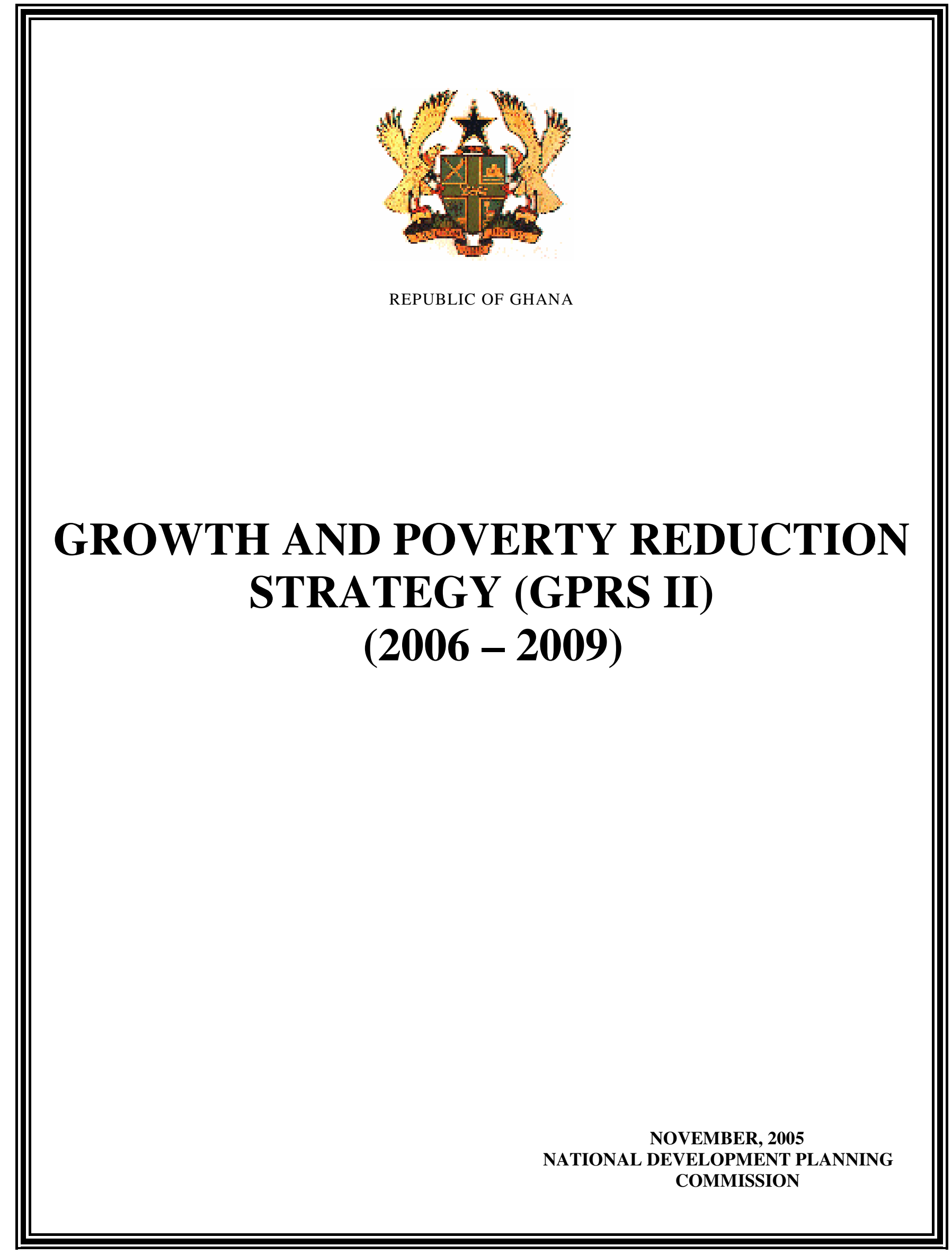




\section{PREFACE}

\section{Economic Development and Poverty Reduction in Ghana}

\section{Widening Opportunities, New Strategic Choices}

1. With this 2005 version of Ghana's Poverty Reduction Strategy papers, the nation is called upon to define anew the programmes of National Development that it wishes to pursue in support of its current social and political aspirations. The turn-around in Ghana's economic fortunes which has come about with the new century, offers the opportunity to achieve faster the existing goals of development policy, or to enlarge them or to do both. But the march of history and ideas also moves us to consider whether entirely new goals have come within our grasp, or that our priorities should be substantially re-ordered.

2. The previous strategy paper GPRS I, issued in 2003, reflected a policy framework that was directed primarily towards the attainment of the anti-poverty objectives of the UN's Millennium Development Goals (MDGs). The present paper, GPRS II, is intended to introduce a shift of strategic focus, even though many of the actual programmes which will be implemented under it between 2006 and 2009 will be in the same areas. The central goal of the new policy is to accelerate the growth of the economy so that Ghana can achieve middle-income status within a measurable planning period. It is necessary to place such a far-reaching change in the focus of development policy into a perspective of Ghana's economic history which is much longer than the recent past when we began writing periodic policy papers of this sort.

3. Ghana is already on course to meet the targets of the MDGs, and acceleration of economic growth will permit us to implement them even more fully. For instance, in the case of basic education for all, government has undertaken not only to meet the numerical targets of the MDGs but also to put the lost quality back into the basic education that is offered to children in deprived and rural areas. Aside from this, government has gone beyond the MDGs and set educational targets that are more related to the manpower needs of a future middle-income Ghana than simply to the fundamental human right of our children to receive at least a basic-level of education from the society. (This is discussed more fully below).

\section{A Tradition of High Expectations}

4. The post-war Gold Coast, 1945-1957, was a model colony of the British Empire, endowed with a relatively advanced network of infrastructure and social service institutions in health and education. These facilities had been financed with the proceeds of a previous cocoa boom in the 1920s. Indeed, that boom had been so remunerative that Governor Gordon Guggisberg had felt emboldened to write a long-term development plan, the first in the history of the colony, with considerable assurance that it would be successfully financed and implemented. The 1930s global depression and the disruption of exports during the Second World War marked a decade-long pause 
in the economic progress of the colony.

5. But the British Government had made arrangements for the continuing purchase of the cocoa crop throughout the war years while opportunities for spending those earnings were restricted by war-time rationing. The result was that by 1945 the Gold Coast emerged as one of the biggest holders of reserves in the Sterling Area system, with assets of a value which today would put Ghana in the position of an oil-exporting country.

6. It was against this background of accumulated national savings that the colony was able to finance a university for itself as early as 1947, and nationalist leaders were able to set their sights equally high in every aspect of development planning. By the time Dr. Nkrumah was deposed in 1966 he had placed social aspirations such as free education and public health, mass housing and municipal transport, firmly onto the development agenda of the new Ghana. In the field of infrastructure he had already delivered such impressive monuments as the new harbour and industrial city of Tema, the Volta River power system, and even a concrete motorway to link Accra and Tema. An incipient industrialisation was also being simultaneously financed from public coffers by the time he left.

7. Side by side with this 20-year transformation of Ghana's social and economic infrastructure, an explosive population boom had got underway, fuelled by the classic rural-urban drift of younger people. All these costs of social change were being paid for out of the profits from a long cyclical boom in the cocoa industry, a guaranteed bullion gold price, and a newly emerging timber export business. The haunting question in economic policy-making was what would happen to all this if the cocoa bubble were to burst.

\section{Economic Structure and the Sustainability of Development}

8. And that was precisely what it did: in 1965/66 when, saturated by Ghana's own success in raising the volume of cocoa production to a then-record level of 550, 000 tons, the market collapsed and the vulnerability of a mono-crop economy was starkly exposed. Since then, the economic fortunes of this country have shown a highly unstable pattern of cyclical fluctuation, depending on the ups and downs in the markets for the triad of primary products - cocoa, timber and gold - upon which, even now, the economy depends so completely. Economic security and steady progress in national development have constantly eluded us. In the forty years since the days of Nkrumah, economic policy-making in Ghana has had to contend with a popular sense of grievance over an arrested national development which is still blocked by an unfair international trading system.

9. The need for a rapid and radical transformation of the structure of Ghana's internal production and foreign trade is one of the most widely-shared beliefs among intelligent laymen, who must own and support this GPRS II programme, as well as the professional and political lenders. In the face of the widening development opportunities offered by the rehabilitated Ghana economy of 2005, this universal ideology informs the decision to re-focus policy in this GPRS II. The nation must now aim for strategic objectives beyond the minimal goals of poverty reduction as envisaged under GPRS I, even though faster growth and structural diversification will themselves 
provide the resources to more than meet the MDG objectives of GPRS I. It is essential for Ghana to dialogue freely with its development partners on these political / ideological issues so that the implementation of GPRS II is not obstructed by hidden political reservations.

10. In the early 1960s, the supply of educated manpower and the availability of industrial development credits from both sides in the global cold war had enabled the Government of Dr. Nkrumah to develop serious ambitions for the industrialisation of the country in order to correct its structural lop-sidedness. For various reasons, among them principally deficiencies in managerial capacity in state-owned industries and errors in technological choices, together with the cyclical fluctuations of Ghana's export earnings, that incipient reform of the structure of Ghana's economy has yielded meagre returns. But almost unanimously Ghanaians believe that the road to economic emancipation lies through diversifying away from the cocoa-gold-timber structure and adding an element of industrialisation, technology and high productivity to the pattern of Ghana's economy. GPRS II aims to set Ghana on that road.

\section{Political Stability and National Development}

11. To compound the difficulties of remoulding the economy, and driving it to serve the rising needs of a rapidly growing population, Ghana proceeded, during the period after we had exhausted our financial reserves under Dr. Nkrumah, to saddle itself with the additional handicap of political instability and a long-range deterioration in the standards of governance. Against that background, not only did the volume of new investment continue to stagnate or even decline, but the maintenance of existing assets was systematically neglected. And capital flight rather than capital inflow became the normal condition in Ghana's balance of payments picture.

12. Unsurprisingly, by the time that a semblance of democratic governance was restored under the 1992 Constitution, average productivity, and hence the real incomes of all classes of Ghanaian citizens, had fallen to very low levels. During the 1980s, the Multilateral Financial Institutions in Washington had guided Ghana into adopting successive programmes of "Structural Adjustment" supported with substantial amounts of credit. But the composition of internal production and external trade remained largely unchanged. For twenty years no new industrial enterprise of any size was established in Ghana, and the farming community adopted no new major crop to add to the list of exports or the staples of domestic consumption.

13. And the restoration of competitive democratic politics in the 1990s seemed paradoxically to work against economic stabilisation. At each of the elections in 1992, 1996, and 2000, an incipient stabilisation of the fiscal and monetary environment suffered a relapse. And in the latter years inflation and exchange rate deterioration seemed to spin out of control. It says a great deal for the growing robustness of the economy and its management that for the elections of 2004 Ghana was able to avoid the recurrence of that 4-yearly syndrome financial dislocation. 


\section{From the Economics of Reconstruction to the Economics of Growth}

14. At the nadir of economic stress in 2000 - 2001 the government was compelled to seek relief from the unsustainable burden of debt servicing, and other elements of external imbalance, which were fuelling an oppressive combination of inflation and stagnation. In return for the reliefs then granted, the association of Ghana's creditors required of us the adoption of "safety net" budgetary policies by government, plus a monetary regime that was principally aimed at fighting inflation. Thus, the framework of policy which was formally agreed with Ghana's creditors prescribed on the one hand a defensive and protective bias of national development expenditures in favour of building up the basic social services and securing the welfare of the most handicapped and excluded elements of society. On the other hand, it also prescribed a sharp overall redistribution of public financial resources in favour of the lower segments of income-earners.

15. The Millennium Development Goals had been adopted at the UN at the turn of the century to help Third World countries construct a dyke wall against the flood of rising impoverishment which could have sucked so many Third World citizens into permanent depths of poverty. Ghana subscribed voluntarily to the MDGs at the UN as a member of the general comity of nations. But under the HIPC compact these MDGs were transformed into the mandatory framework of domestic economic policy in return for the grant of debt relief.

16. In the past four years, the policies and instruments of defensive economic strategy under Structural Adjustment and HIPC have finally begun to produce a measure of economic stability and steadily improving social equality. Inflation has come under control despite the challenges of soaring energy prices and incidences of low rainfall / poor grain crops. The value of the Cedi has steadied on the exchanges, and has even begun to appreciate against some major currencies.

17. The proportionate allocation of budgetary resources to basic pro-poor services, such as primary education, water supply and public health, has continued to grow. Pernicious indicators of unacceptable deprivation in some corners of the social structure, such as low school enrolment in the rural and savannah areas, and high drop-out rates for the girl school-child, are being overcome. This year 2005 Ghana is embarking on the ambitious project of a Universal Health Insurance System, financed out of general taxes as well as beneficiary contributions, in order to protect all citizens against preventable and manageable diseases such as malaria, tuberculosis and HIV/AIDS. The indicators in other areas such as maternal and infant mortality and provision of clean water supply all seem set on a steady curve of improvement. Thus, at the beginning of this planning period 2006 -2009 both macro-economic stability and the pursuit of basic MDGs seem to have become securely entrenched. The nation can now move on with assurance from the economics of reconstruction and rehabilitation to the economics of accelerated growth.

\section{Setting New Targets of Development}

18. During the 40 years of Ghana's meandering in the economic wilderness, the world has of course not stood still. Today, comparing the economic status of Ghana with that of similar third world countries which have managed their affairs with greater maturity and skill, our people feels 
themselves left unacceptably far behind in the natural development stakes. Korea, Taiwan, Malaysia, Botswana, Kenya, Mauritius, Seychelles, Jamaica, Tunisia, Morocco, even the desertbound Namibia -- all of which had comparable, sometimes lower, levels of per capita production than Ghana at the beginning 50 years ago -- now have considerably higher levels of per capita income. The brightest stars of contemporary economic development, India and China, were prey to recurrent mass famine at the time when Ghana was reasonably well-fed and liberally provided with social services.

19. It is in the light of these comparisons that the discerning Ghanaian electorate feels compelled to raise its sights from the minimal ambitions of preventing gross poverty and distress, and instead aim at sharing in the commonly observed standards of living in the early 2000-Global Economy. With the present instalment of strategising in development policy, government is offering leadership for the nation to embark on the quest for that higher destiny. This is to be done by achieving the status of a middle-income economy. Accordingly, even though the present document is the second in the series of "poverty reduction" programmes, its strategic focus is being steered in a significantly different direction. Government believes that with the platform of macroeconomic stability and international credits-worthiness that has been achieved, it is now appropriate for Ghana to aim for the attainment of middle-income status in the medium-term.

20. The average intelligent citizen need not concern himself with the technical definition of economic concepts like "per capita GDP" and "middle-income country" in order to be able to take part in the public debate on the management of the nation's economy in which the Government is hereby inviting every citizen to participate through the publication of this document.

\section{Towards Middle-Income Status}

21. The internationally accepted definition of a middle-income country is highly elastic, ranging from the lower limits of an average income of $\$ 750$ per capita per annum (as measured by the prevailing methods of calculation) to as much as \$3,000 per head per annum. In the current 2005 practice of the World Bank, countries are categorised into two classes: those which are considered wealthy enough and therefore have to borrow on the quasi-commercial terms of the Bank itself, and on the other hand those lower income countries which are permitted to borrow on the concessionary terms of the Bank's IDA, soft-window, branch.

22. Leaving aside certain technical overlaps, the World Bank's cut-off line between poorer IDA and middle income - IBRD borrowers currently translates into countries with per capita national income above $\$ 2,000$ per annum and those with less. In other words, the World Bank continues to support many countries in the lower segments of middle-income status with concessionary development loans even though they have passed the conventional threshold of middle-income status. On this scale, Ghana will be already on the fringes of stable middle-income status when we move to the level of $\$ 1,000$ per capita per annum, and would be comfortably installed among the majority of progressive developing countries when our per capita income has risen above $\$ 1,500$ per annum. 
23. In setting our economic growth targets the important thing is to ensure that the nation will be moving forward at a fast enough pace that, even with our still rapidly rising population, would allow majority of Ghanaians to see that their real standard of living -- their access to better food, housing, clothing, water, education, health, transport facilities - have become significantly better every few years when they look back. Too often, the technical numbers get in the way of such intelligent assessment. People live well or poorly not in proportion to "GDP growth rates" or \$X per head per annum, but in relation to their access to these tangible goods and services.

24. With this present instalment of the NDPC's development strategy document we have symbolically changed the name of the programme from the "Ghana Poverty Reduction Strategy" (GPRS I) to the Growth and Poverty Reduction Strategy (GPRS II) -- the same initials, GPRS, but with a fundamentally different focus and content. This is not simply a matter of acronyms, but of basic intent and policy.

\section{Human Resource Development: The Focal Point of Strategy}

25. The educational sector reform policy of government most sharply illustrates the intended change in strategic focus between GPRS I and GPRS II. The objectives of the UN's MDG compact, which are reflected in the original poverty reduction proposals of GPRS I, included raising the access of all the nation's children and youth to a defined minimum of basic education, unhampered by the particular economic circumstances of their parents or guardians.

26. In an educational programme which was simply focussed on poverty reduction, the standard way to meet this target was to improve and equalise access to a six-year basic education for all children up to the age of around 12 years. In Ghana's GPRS II it has been decided to eventually make school attendance obligatory for all children for 11 years -- from 4 to 15 -including two years of Kindergarten, and three years of Junior High School with a genuine secondary school content. The plan also includes improving the physical environment of schooling, and assuring the quality standards, especially in basic numeracy and literacy. In the last four years, Government has already built nearly 4,000 units of new primary / JSS school blocks, and rehabilitated thousands of older ones including the raising of all teacher training colleges to diploma-awarding institutions, and the retraining of Cert A, Cert B and many thousands of untrained teachers, thanks in part to the technological opportunities of distance-learning School. The levels of teacher education are being rapidly improved; Curricula are being reshaped at every level so as to raise the standard targets of educational attainment for the bulk of Ghana's youth and to bring them eventually up to standards around the world.

27. The reason for going so far beyond the internationally covenanted obligations in the provision of universal basic education as simply our children's human right is that government has absorbed the most important lesson of contemporary economic history. The lesson is that the single most crucial key to the attainment of economic success is the educational quality of a nation's work force. Government has accordingly decided that Ghana must nurture a workforce which is equipped with more than the basic levels of educational attainment, as defined in the MDG goals. 
This is so in order to support an economy which can then realistically aim to achieve rapid progress in the income status of its citizens.

28. In particular, the long-neglected areas of technical and vocational training for youngsters from 15 to 18 years, and a structured system of apprenticeship to cater for the even larger numbers who under a basic MDG programme would not go through any formal training beyond the age of 12 years, are to be brought into much sharper focus. Besides, Government is determined that Ghana should go after the proven benefits that early childhood education confers, so that the entire working force is much more open to the absorption of modern high-productivity, high income technology.

29. The logic and the evidence in favour of the ambitious goals in educational development are totally irresistible. But the strategy will be very expensive to pursue. Even though the eventual cost/benefit ratio undoubtedly speaks for its adoption, the process of moving from where we are today to where we want to be tomorrow, is bound to be very painful, costly and turbulent.

30. In our evolving relations with those countries and institutions which are our developing partners, there is no more crucial area than this in which we should be calling on them to supplement the meagre financial resources that the economy of Ghana can generate itself, to support the government's new educational programme. Fortunately, in the most recent reassessments of donor country policies towards the development programmes of countries such as Ghana, and especially in the lead-up to the Gleneagles Summit of the G8 in July 2005, it has been recognised that the absorption and application of a great deal more science and technology than is presently deployed is a critical ingredient for successful growth in the third world. And that means a much better educated workforce in place of the old concepts of cheap, sweatshop labour.

31. Fortunately, many donor countries and agencies have now reconsidered their attitudes towards tertiary education, and the promotion of science and technology in third world countries.

32. When out-dooring the strategic objectives of the new Government in his State-of-the-Nation address to Parliament on $23^{\text {rd }}$ January 2005, President J. A Kufour placed in the number one position "the development of Ghana's human resources". That should unambiguously settle the issue of priorities in the nation's development plans for the next four years.

33. There is one aspect of Human Resources Development to which the Government has paid particular attention, for very good reasons. And that is the development of a public service that can be relied on to manage the nation's business with efficiency and dispatch. The groundwork has been laid and, with the help of our development partners we expect to deepen the reforms so that the public sector becomes once again the icon by which Ghana was judged for many years.

34. In the area of improving the social and living conditions of Ghanaians another example can be cited to illustrate the change of strategic focus which is being introduced as between GPRS I and GPRS II. In the first four years after the government established for the first time a dedicated Cabinet-level ministry to look after Women and Children's Affairs, the nation can proudly record the rescuing and rehabilitation of more than 3,000 'street children', including many young girls, 
who had been living and sleeping rough in Ghana's principal cities. In the new phase of social policy under GPRS II, however, Government is moving beyond that. By launching in September 2005 the first mass housing project for working family people that has been attempted in Accra for the past 25 years, government has raised the focus and standards in the field of the provision of shelter by many notches beyond the rescuing of homeless youth under GPRS I.

\section{The Modernisation of Agriculture and Strengthening of Infrastructure}

35. The ensuing pages of this GPRS II document contain exhaustive details of programmes for the rationalisation and modernisation of Ghana's agriculture and agro-based/processing industry. The majority of Ghana's working population continues to depend upon farming activities for their livelihood, and typically they cultivate small acreages. It stands to reason therefore that no significant progress can be made in raising the average real incomes of Ghanaians as a whole without significant improvements in the productivity of the small-scale farmer and farm labourer. The means for securing such increases in productivity range from improving the complement of equipment and tools with which the small-scale woman farmer earns her living, through many intermediate stages of applying scientific and technological improvements to the farming practices of medium-scale agriculturists, and going up to the most sophisticated systems of irrigation, high value horticultural production, and scientific fish farming.

36. These processes of agricultural modernisation constitute the second most important leg of the strategic priorities that have been established under GPRS II. It has the potential of yielding benefits, in terms of accelerating overall growth rates, in a much shorter timeframe than the programs to be taken under the first strategic priority, which is Human Resource Development. But in turn, long-range improvement in the productivity of farm work will depend upon success in the area of enhanced manpower training and the application of research, science and technology to agriculture. The two strategies must be intimately linked together. And indeed the strengthening of agricultural training institutions in the second cycle is one of important innovations in the educational reform policy.

37. The problem of infrastructure development has always sat awkwardly with the overall strategic model of poverty reduction and the MDGs. Typically, Infrastructure development has two characteristic features. First, the unit cost of projects - whether in energy, water, roads or communications - tends to be very large in relation to the cost of the typical, individual project in agriculture, education or health, which are seen as the classical props for poverty alleviation and the fight against extreme deprivation. Secondly, the beneficiaries of many of these infrastructure projects are as likely to be higher-income citizens and corporate enterprises as the lower-income and disadvantaged sectors who are the prime targets of the classic poverty reduction strategy, including the MDG model.

38. The role of investment in a development strategy which is firmly focussed on accelerating growth cannot be over-estimated. Government will continue to promote a financial sector that deepens the process of intermediation and promotes local savings, even as we look for external finance, especially foreign direct investment. The banks and other entities in the financial services 
sector have greater need than most other participants to make far-reaching changes both in the mind-set of their decision-makers and in their practices and policies in order to measure up to their responsibilities in bringing Ghana rapidly up to middle-income status.

\section{Uniting Behind Our National Programme}

39. A national development programme such as the GPRS II is more important for its implementation than for its technical or intellectual merits. The formulation of GPRS II commenced in 2004. This was at a time when the strategic direction was still dominated by the MDG goals. The Government of Ghana, the principal executing departments, and Ghana's foreign partners were organised in a working consensus based on the implementation of the MDGs agenda. By the time GPRS II was finalised, Ghana's HIPC programme had come to an end, and the macroeconomic rehabilitation of the economy, had been substantially accomplished. Government judged that a turning point in the nation's path of development had been reached whose consequences had to be taken on board in formulating a new national development programme. The Government itself had gone through far-reaching evolution in various aspects of its thinking on development policy reflecting also the evolving aspirations of the Ghanaian electorate and contemporary achievements of other countries with no greater development potential than Ghana. This is a continuing process which hopefully will accelerate and deepen. But for administrative purposes it is necessary at this stage to halt and try to systematise the present consensus, so that all partners can assess its financial implications and lay out the practical details of its implementation.

40. This first volume of the GPRS II, covering the general policy framework of current thinking, will be accompanied by two volumes outlining how much it would cost and what specific projects and programmes it would take to realise those ideas. It is emphasised that this is a temporary stage of stock taking in a continuous evolution of public policy. Even while we are summarising the present set of conclusions, major new issues are arising, such as the connectivity between economic management in Ghana and the international capital market which must soon be called in to supplement the development resources of the nation in a substantial fashion. Preparations, which started with the acquisition of credit market ratings from international agencies, are afoot to float Government of Ghana instruments on the international market.

41. On the other hand, with the completion of the more rigid HIPC stage of Ghana's utilisation of IMF resources to the economic stabilisation programme, the modalities of policy dialogue with the Washington institutions have to be restructured. And the connection between development policy here and the exclusive pursuit of the MDGs has to go through a process of transition, taking into account also the outcome of the recent G8 Summit and any new institutional arrangements arising therefrom.

\section{Consultation and Participation}

42. In the lead-up to preparing the present GPRS document, there has already been completed an extensive program of consultation with elements of civil society, economic interest groups and 
government agencies, all of which are needed to rally behind the programme in order to assure its success. Now that there is a text, the dialogue with Ghana's development partners and professional groups will be particularly intensified. But in the long run the vast body of the citizenry must unite behind the programme if it is to succeed, and in that process the content of the programme itself should be flexibly open to modification and improvement in response to the tides of responsible opinion.

43. This document therefore is presented very much as work-in-progress. Before the end of the year 2006, the consensus that has been reached on the "poverty reduction" subset of a larger national development agenda would be carried over into a new document that will be presented by government to Parliament and the people of Ghana as a Comprehensive Programme of National Development in accordance with the provisions of Article 36 (5) of the 1992 Constitution of Ghana.

September, 2005
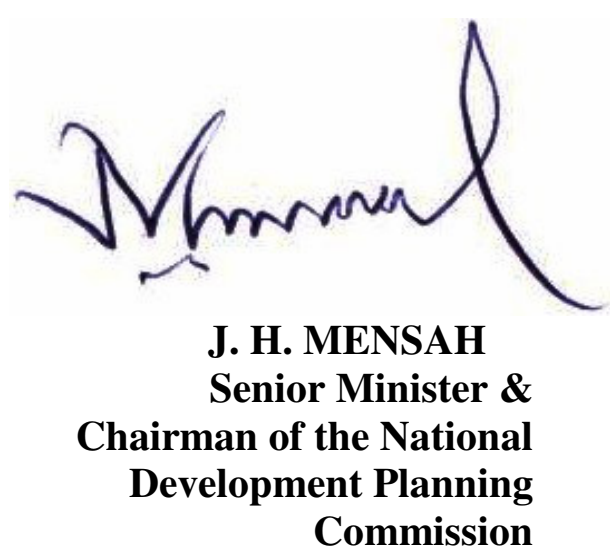


\section{TABLE OF CONTENTS}

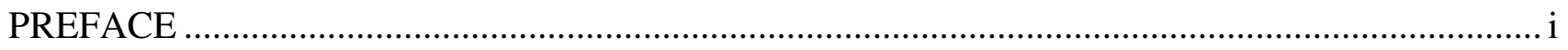

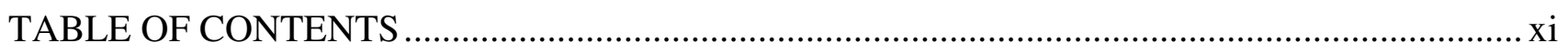

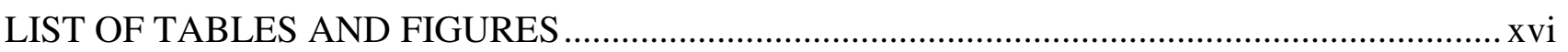

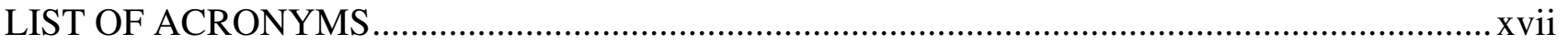

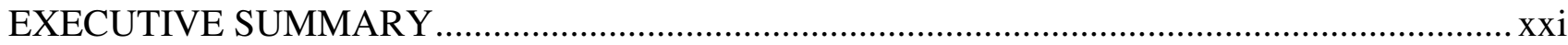

CHAPTER ONE: GPRS II: OUTLINE OF CONTENTS AND POLICIES ...................................... 1

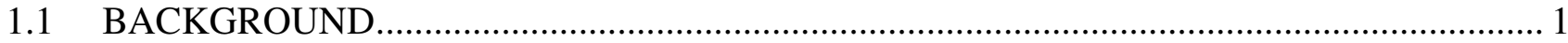

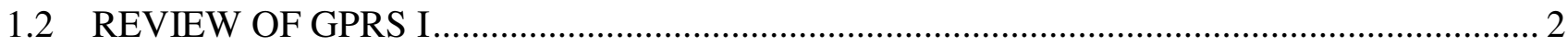

1.4 GROWTH AND POVERTY REDUCTION STRATEGY (GPRS II) ……………................ 4

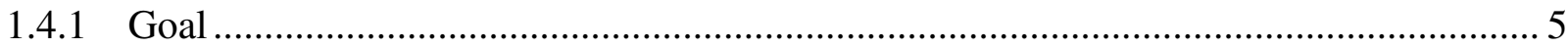

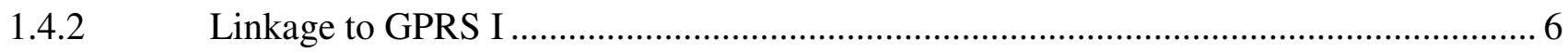

1.4.3 Ghana's Progress towards achieving the Millennium Development Goals (MDGs) ….. 7

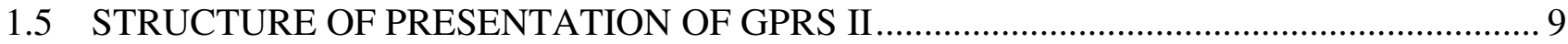

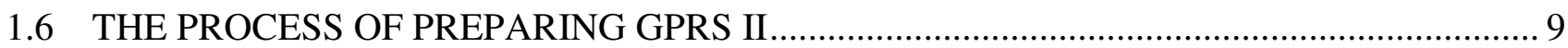

1.6.1 Composition and Terms of Reference of Cross Sectoral Planning Groups (CSPGs)................ 10

1.6.2 The Public Consultation Process............................................................................................ 11

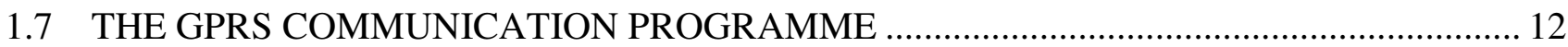

CHAPTER TWO: MACROECONOMIC CONTEXT AND STRATEGIC DIRECTION ................. 14

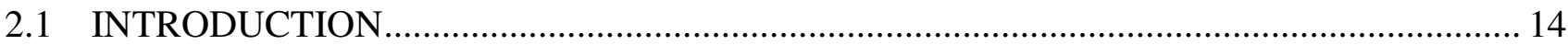

2.2 REVIEW OF MACROECONOMIC PERFORMANCE UNDER GPRS I .............................. 14

2.2.1 Economic Performance by Sectors …………………................................................. 15

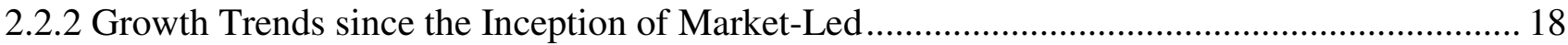

2.3 MACROECONOMIC POLICIES, STRATEGIES AND TARGETS FOR GPRS II ................ 20

2.3.1 Growth Target for GPRS II............................................................................................. 20

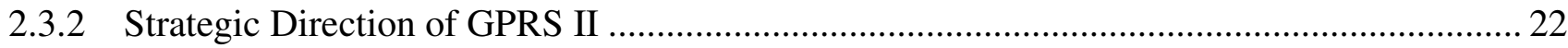

2.3.3 Agriculture as Basis for Economic Growth and Structural Transformation.................. 23

2.3.4 Weaknesses and Threats to an Agriculture-Led Strategy ............................................ 24 
CHAPTER THREE: PRIORITIES FOR PRIVATE SECTOR COMPETITIVENESS.................... 29

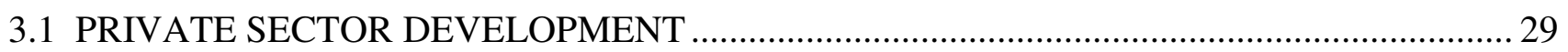

3.1.1 Improve Ghana's access to global and regional markets ....................................... 30

3.1.2 Enhance efficiency and accessibility to national markets ....................................... 30

3.2 IMPROVING THE BUSINESS AND INVESTMENT ENVIRONMENT FOR

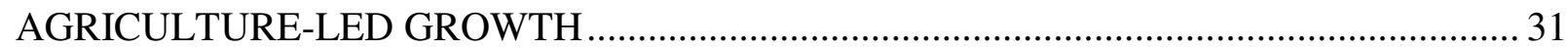

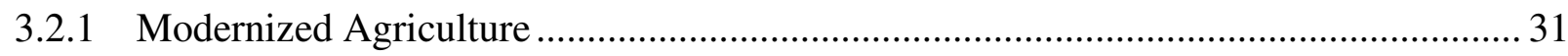

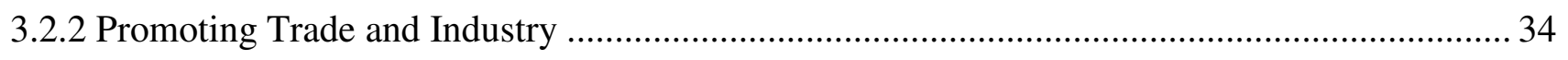

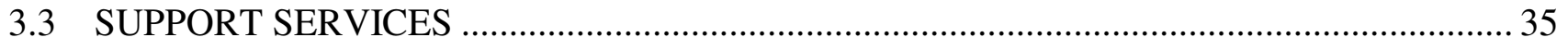

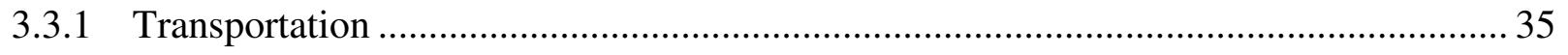

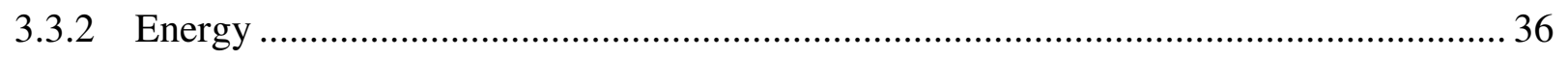

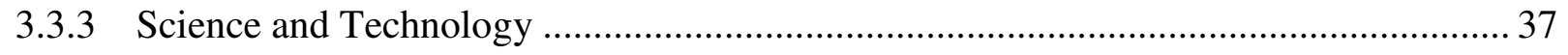

3.4 DEVELOPING ADDITIONAL SECTORS TO SUPPORT GROWTH............................... 37

3.4.1 Developing Information and Communication Technology (ICT) ........................... 37

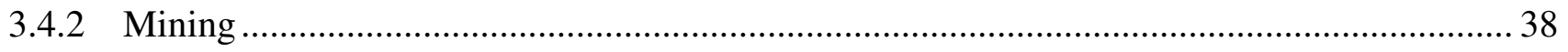

3.4.3 Developing the Tourism Sector for Revenue and Employment Generation................. 38

3.4.4 The Music and Film Industry for Growth and Job Creation ...................................... 39

3.5 EMPLOYMENT GENERATION AND IMPROVEMENT AND

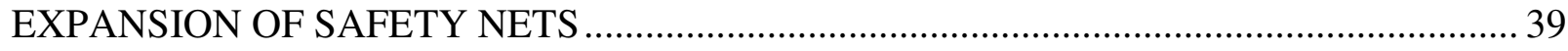

CHAPTER FOUR: HUMAN RESOURCE DEVELOPMENT ............................................... 41

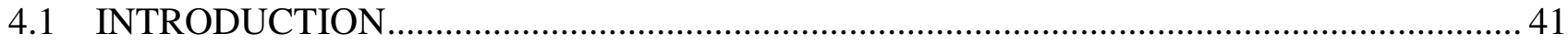

4.2 REVIEW OF HUMAN RESOURCE DEVELOPMENT UNDER GPRS I ........................ 41

4.3 EDUCATION, SKILLS, MANPOWER AND SPORTS DEVELOPMENT FOR

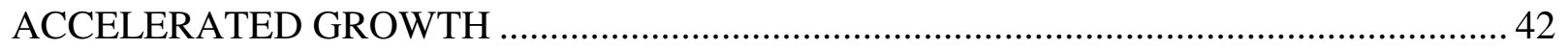

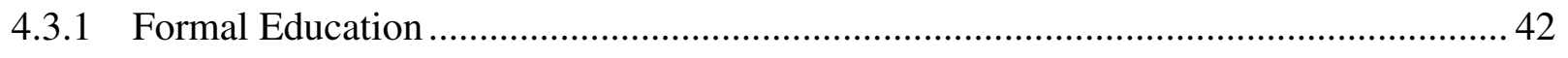

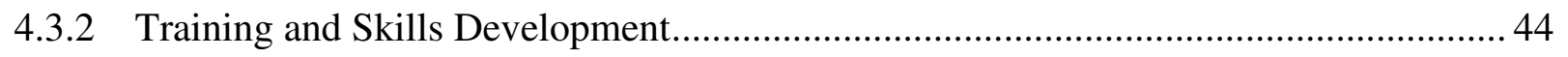

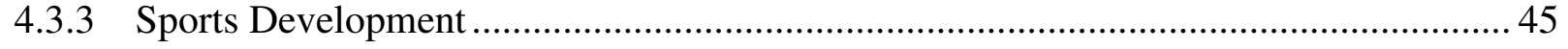




\subsection{IMPROVED ACCESS TO HEALTH CARE, MALARIA CONTROL AND PREVENTION}

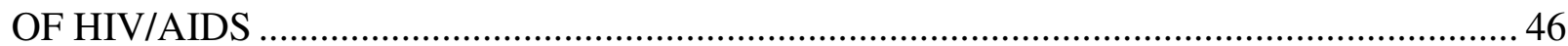

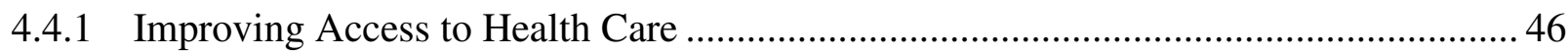

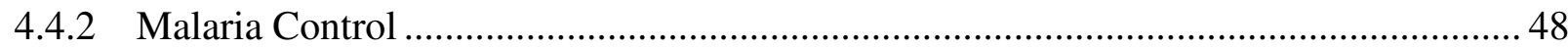

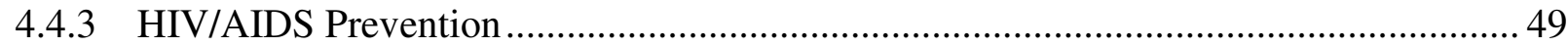

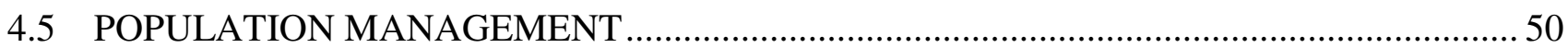

4.6 SAFE WATER AND ENVIRONMENTAL SANITATION ………………………….......... 51

4.7 URBAN DEVELOPMENT, HOUSING AND SLUM UPGRADING/URBAN

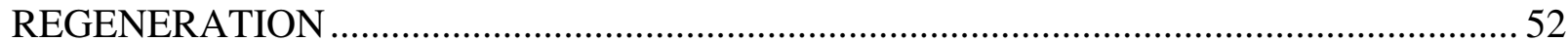

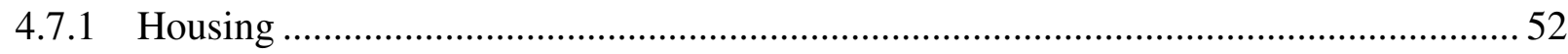

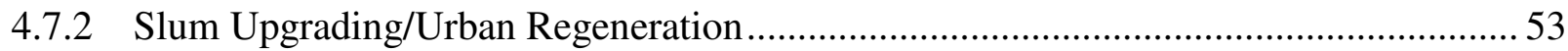

4.8 SOCIAL POLICY FRAMEWORK FOR MAINSTREAMING THE VULNERABLE AND

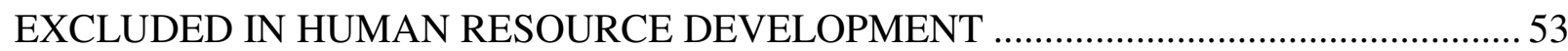

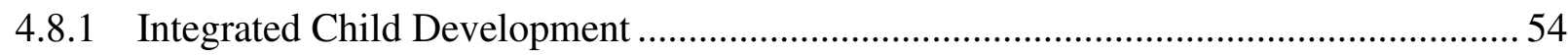

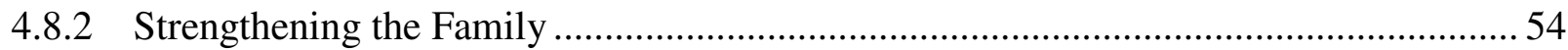

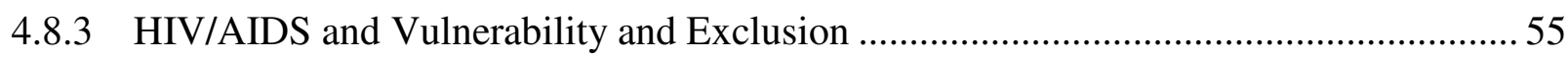

4.8.4 Capacity Development in Social Work and Volunteerism ..............................................55

4.8.5 Database on the Vulnerable and Excluded Groups ........................................................5 55

4.8.6 Institutional Strengthening, Linkages and Coordination ................................................ 55

CHAPTER FIVE: GOOD GOVERNANCE AND CIVIC RESPONSIBILITY .................................57

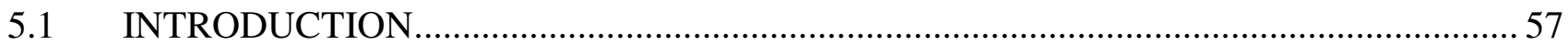

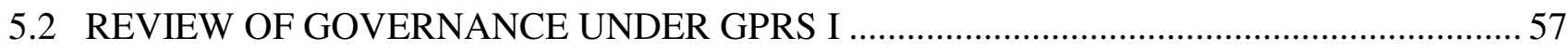

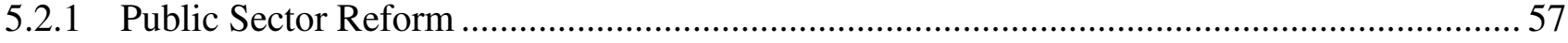

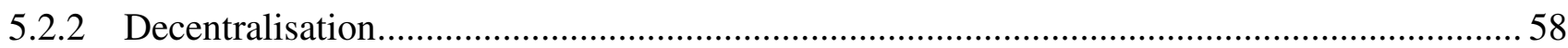

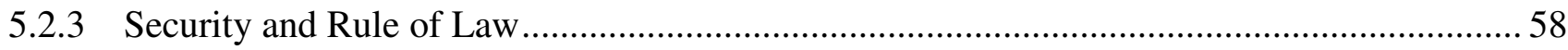

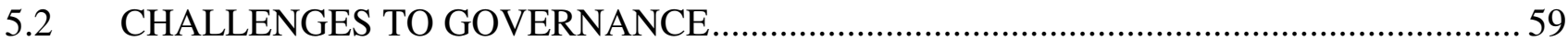

5.3.1 Strengthening the process of democratization ................................................................59

5.3.2 Improving existing institutional, legal and policy environment .....................................59

5.3.3 Evidence-based decision-making and public dialogue .......................................................... 60 


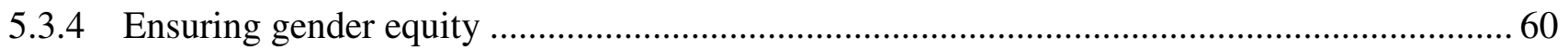

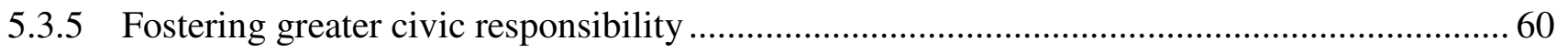

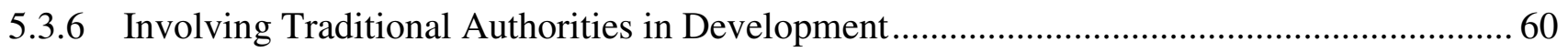

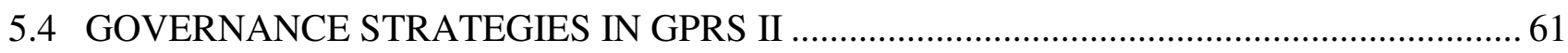

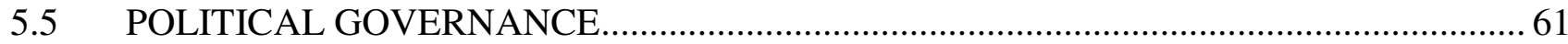

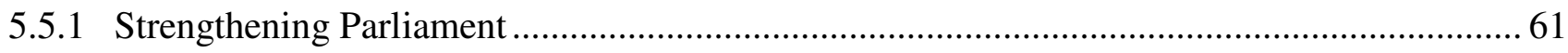

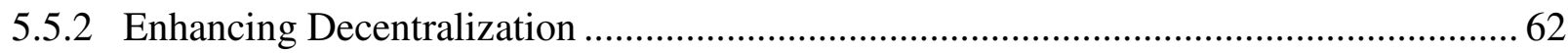

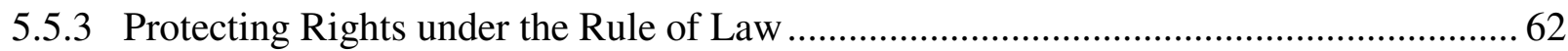

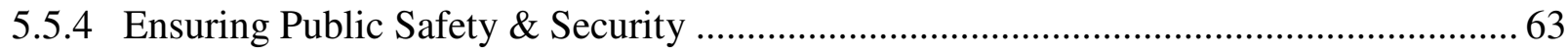

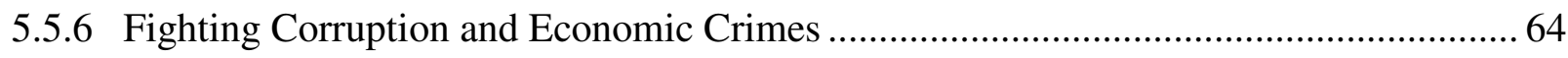

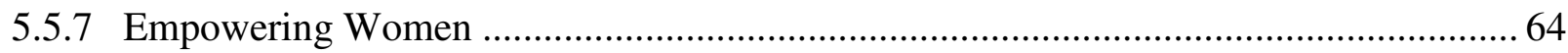

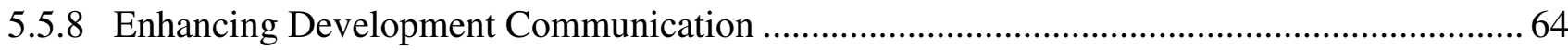

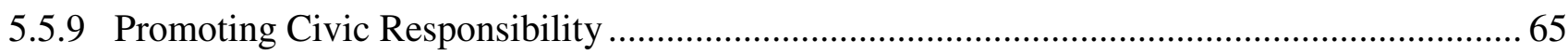

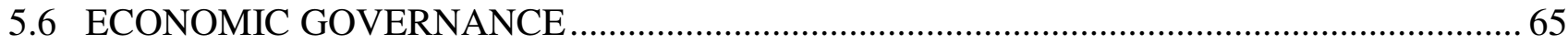

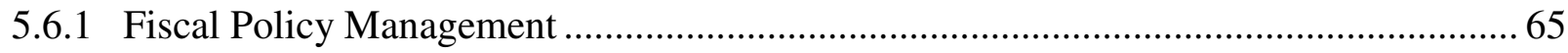

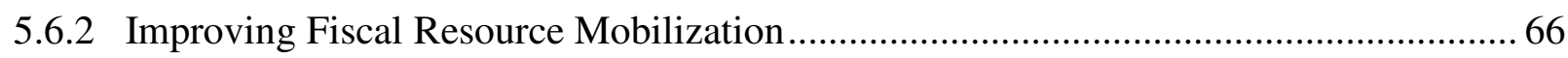

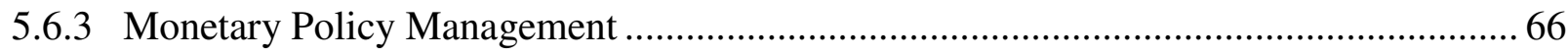

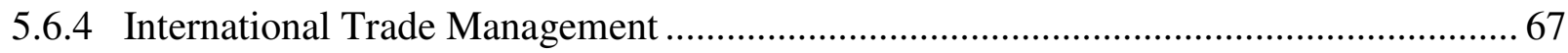

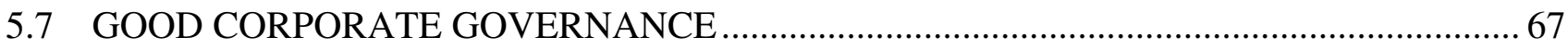

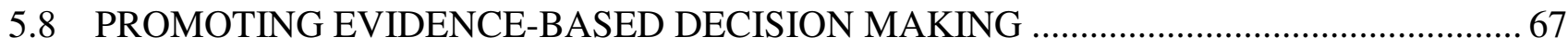

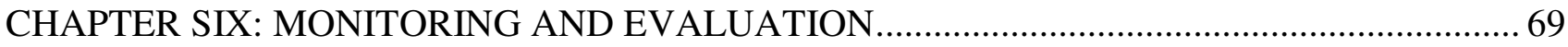

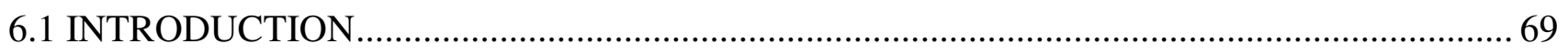

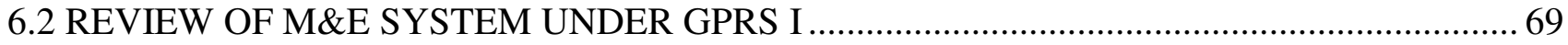

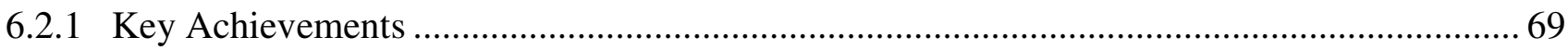

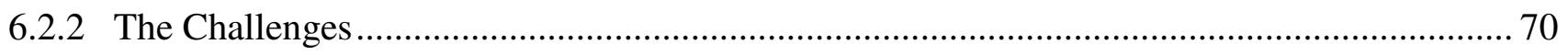

6.3 STRENGTHENING THE M\&E SYSTEM UNDER GPRS II ………...................................... 70

6.3.1 Reinforcing institutional arrangements ...................................................................... 71

6.3.2 Strengthening and effective coordination of existing mechanisms................................. 71

6.3.3 Evolving an efficient system for evidence-based monitoring and evaluation: ................ 71 


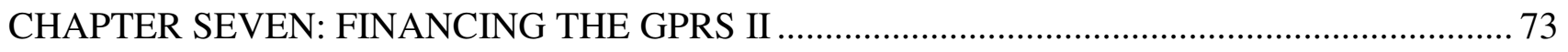

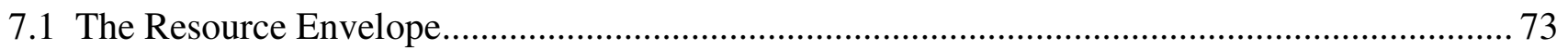

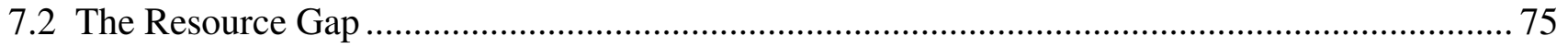

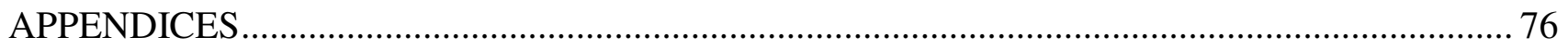

APPENDIX 1: $\quad$ Ranking of Poverty Incidence by Region and by Districts ............................... 76

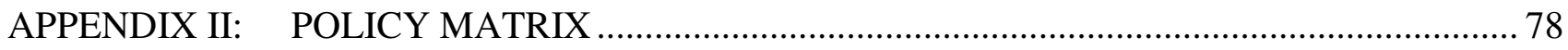

APPENDIX I1A: PRIORITIES FOR PRIVATE SECTOR COMPETITIVENESS....................... 78

APPENDIX I1B: HUMAN DEVELOPMENT AND BASIC SERVICES ............................... 117

APPENDIX 1IC: GOOD GOVERNANCE AND CIVIC RESPONSIBILITY .......................... 133 


\section{LIST OF TABLES AND FIGURES}

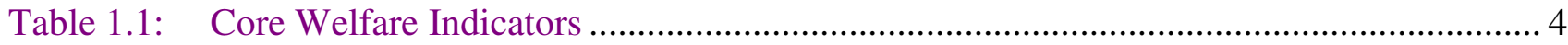

Table 1.2: Ghana's Progress towards Achieving the Millennium Development Goals................... 8

Table 1.3: Chronology of Activities............................................................................. 13

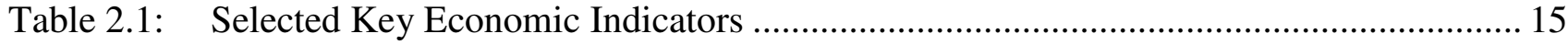

Table 2.2: $\quad$ Structure of GDP by Kind of Economic Activity in Percentages .............................. 16

Table 2.3: GDP by Kind of Economic Activity: Growth Rates at Constant 1993 Prices .............. 17

Table 2.4: $\quad$ Projected Real GDP versus Actual Real GDP Growth Rates: 1995 - 2004 ................ 19

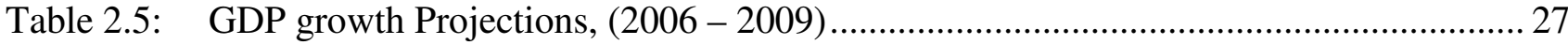

Table 2.6: Gross Domestic Product by Kind of Economic Activity at Constant 1993 Prices Historical and Projected Growth Rates for GPRS II (2006 - 2009)............................ 28

Table 7.1: $\quad$ Medium Term Expenditure Framework - 2005-2009 …...................................... 74

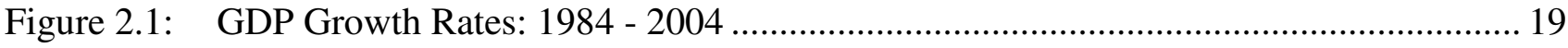




\section{LIST OF ACRONYMS}

ADF

AGOA

APR

APRM

ASSI

BAF

BOG

$\mathrm{CBO}$

CEPS

CHPS

CHRAJ

CPI

CSIR

CSOs

CSPGs

CWSA

DFR

DMHIS

DPs

DSW

DUR

DVLA

EC

ECG

ECOWAS

EDIF

EIC

EPA

FBOs

FCUBE

FDI

FIDA

FINSSP

FUSMED

GAEC

GDP
African Development Foundation

African Growth and Opportunity Act

Annual Progress Report

Africa Peer Review Mechanism

Association of Small-Scale Industries

Business Assistance Fund

Bank of Ghana

Community-Based Organizations

Customs, Excise and Preventive Service

Community-based Health Planning and Services

Commission for Human Rights and Administrative Justice

Consumer Price Index

Council For Scientific and Industrial Research

Civil Society organizations

Cross-Sectoral Planning Groups

Community Water and Sanitation Agency

Department of Feeder Road

District Mutual Health Insurance Scheme

Development Partners

Department of Social Welfare

Department of Urban Roads

Driver's and Vehicle Licensing Authority

Energy Commission

Electricity Corporation of Ghana

Economic Community of West African States

Export Development and Investment Fund

Extension Information Centers

Environmental Protection Agency

Farmer Based Organizations

Free Compulsory Universal Basic Education

Foreign Direct Investment

Association of Women Lawyers

Financial Sector Strategic Plan

Fund for Medium and Small-Scale Enterprises Development

Ghana Atomic Energy Commission

Gross Domestic Product 


\begin{tabular}{|c|c|}
\hline GEPC & Ghana Export Promotion Council \\
\hline GES & Ghana Education Service \\
\hline GFTZB & Ghana Free Trade Zone Board \\
\hline GHAPOHA & Ghana Ports and Harbours Authority \\
\hline GIPC & Ghana Investment Promotion Centre \\
\hline GLSS & Ghana Living Standard Survey \\
\hline GNCC & Ghana National Commission on Culture \\
\hline GPRS & Ghana Poverty Reduction Strategy \\
\hline GPRTU & Ghana Private Road and Transport Union \\
\hline GSB & Ghana Standards Board \\
\hline GSMF & Ghana Social Marketing Foundation \\
\hline GTB & Ghana Tourists Board \\
\hline HIPC & Heavily Indebted Poor Country \\
\hline HIV/AIDS & Human Immunodeficiency Virus/Acquired Immune Deficiency Syndrome \\
\hline HR & Human Resource \\
\hline HRD & Human Resource Development \\
\hline HSD & Health Service Delivery \\
\hline ICT & Information and Communication Technology \\
\hline IRS & Internal Revenue Service \\
\hline ITTUs & Intermediate Technology Transfer Units \\
\hline JSS & Junior Secondary School \\
\hline LPG & Liquefied Petroleum Gas \\
\hline MCA & Millennium Challenge Account \\
\hline MDAs & Ministries, Departments and Agencies \\
\hline MDBS & Multi Donor Budget Support \\
\hline MDGs & Millennium Development Goals \\
\hline MLFM & Ministry of Land, Forestry and Mines \\
\hline MLGRD & Ministry of Local Government and Rural Development \\
\hline MOT \& MCC & Ministry of Tourism and Modernization of the Capital City \\
\hline MMYE & Ministry of Manpower, Youth and Employment \\
\hline MOCT & Ministry of Communication and Technology \\
\hline MOE & Ministry of Energy \\
\hline MES & Ministry of Environment and Science \\
\hline MOFI & Ministry of Fisheries \\
\hline MOFA & Ministry of Food and Agriculture \\
\hline MOFEP & Ministry of Finance and Economic Planning \\
\hline $\mathrm{MOH}$ & Ministry of Health \\
\hline MOH-GHS & Ministry of Health-Ghana Health Services \\
\hline MOI & Ministry of Information \\
\hline MOJ & Ministry of Justice \\
\hline
\end{tabular}




$\begin{array}{ll}\text { MOTI } & \text { Ministry of Trade and Industry } \\ \text { MOWAC } & \text { Ministry of Women and Children's Affairs } \\ \text { MPHR } & \text { Ministry of Ports, Harbours and Railways } \\ \text { MPSD \& PSI } & \text { Ministry of Private Sector Development and Presidential Special Initiatives } \\ \text { MRT } & \text { Ministry of Road Transport } \\ \text { MSMEs } & \text { Small and Medium Size Enterprises } \\ \text { MTEF } & \text { Medium Term Expenditure Framework } \\ \text { MMTC } & \text { Metro Mass Transit Company } \\ \text { MTTU } & \text { Motor Traffic and Transport Unit } \\ \text { MWRWS } & \text { Ministry of Water Resources, Works and Housing } \\ \text { NACP } & \text { National Aids Control Programme } \\ \text { NADMO } & \text { National Disaster Management Organization } \\ \text { NBSSI } & \text { National Board For Small Scale Industry } \\ \text { NCA } & \text { National Communication Authority } \\ \text { NCCE } & \text { National Commission on Civic Education } \\ \text { NCWD } & \text { National Commission on Women and Development } \\ \text { NDPC } & \text { National Development Planning Commission } \\ \text { NED } & \text { National Economic Dialogue } \\ \text { NEPAD } & \text { New Partnership for Africa's Development } \\ \text { NGOs } & \text { Non Governmental Organizations } \\ \text { NHIC } & \text { National Health Insurance Commission } \\ \text { NHIS } & \text { National Health Insurance Scheme } \\ \text { NPA } & \text { National Petroleum Authority } \\ \text { PEF } & \text { Private Enterprise Foundation } \\ \text { PLWHA } & \text { People Living With HIV/AIDs } \\ \text { PRSC } & \text { Poverty Reduction Support Credit } \\ \text { PSI } & \text { President's Special Initiatives } \\ \text { PSIA } & \text { Poverty and Social Impact Analysis } \\ \text { PURC } & \text { Public Utility Regulatory Commission } \\ \text { PWDs } & \text { Persons With Disabilities } \\ \text { RBM } & \text { Roll Back Malaria } \\ \text { SEA } & \text { Strategic Environmental Assessment } \\ \text { S\&T } & \text { Science and Technology } \\ \text { SHEP } & \text { Self-Help Electrification Programme } \\ \text { SSNIT } & \text { Social Security and National Insurance Trust } \\ \text { SSS } & \text { Senior Secondary School } \\ \text { STDs } & \text { Sexually Transmitted Diseases } \\ \text { STEP } & \text { Skill Training and Entrepreneurship Programme } \\ \text { STIs } & \text { Sexually Transmitted Infections } \\ \text { TUC } & \text { Trades Union Congress } \\ & \end{array}$


VLTC

VRA

WAJU

WHO

WTO
Volta Lake Transport Company

Volta River Authority

Women and Juvenile Unit

World Health Organization

World Trade Organization 


\section{EXECUTIVE SUMMARY}

\subsection{INTRODUCTION}

With the attainment of relative macroeconomic stability and modest economic growth under GPRS I, the overarching goal of Ghana's current socio-economic development agenda is to attain middle income status (with a per capita income of at least US\$1000) by the year 2015 within a decentralized democratic environment. This is to be complemented by the adoption of an overall social protection policy, aimed at empowering the vulnerable and excluded, especially women to contribute to and share in the benefits of growth of the economy, thus ensuring sustained poverty reduction

However, there are two broad sets of constraints to achieving accelerated wealth creation and poverty reduction. These are the vulnerability of the economy due to the persistent reliance on the export earnings from a few primary commodities and the social structure which comprises a high proportion of children and youth with the attendant high dependency ratio, low level of literacy and skills, especially among women and the rural population.

Accordingly, emphasis is placed on changing the structure of the economy by developing the private sector, diversifying the export base and increasing agricultural productivity and rural incomes.

While the GPRS I focused on poverty reduction programmes and projects, the emphasis of GPRS II is on the implementation of growth-inducing policies and programmes which have the potential to support wealth creation and sustainable poverty reduction. GPRS II is therefore anchored on pursuing the following priorities:

- continued macroeconomic stability

- accelerated private sector-led growth

- vigorous human resource development

- good governance and civic responsibility

\subsection{MACROECONOMIC POLICIES, STRATEGIES AND TARGETS}

The strategy is guided by the goal of doubling the size of the economy \{in terms of real production\} within the next decade, and bringing the per capita income of the average Ghanaian to middle income level by 2015 . This is expected to reflect in positive social change and improvement in the quality of life of the population. It is in this regard that the growth targets are made taking cognizance of the corresponding objectives of NEPAD and MDGs.

The economic growth targets derived from the current level of development and the feasible expectations for the long term perspective of the economy are based on the following assumptions:

- The population growth rate will not exceed 2.6 per cent per annum, through the population 
management policies and strategies outlined in the sections on human resources development (section 4.5).

- Continued macroeconomic stability, especially by containing inflation within single digit as from 2006, up from the rate of about 14.7 percent (August 2005). Accordingly, it is expected that the average annual change in the GDP deflator will not exceed 9 percent.

- A stable Cedi/ Dollar exchange rate with prudent management that will keep the Cedi depreciation below a 4 percent per annum ceiling.

- Reduced cost of investment loans as incentives for stimulating investment in support of private sector-led growth. This is expected to be the dividend from sound macroeconomic management, and also reflect the reduction in risk factors that make loans to SMEs unattractive to banks.

- Containment of fiscal deficits and preventing them from being a major source of monetary instability and price inflation. Two years after gaining a very favourable rating from leading agencies, Ghana is preparing to tap into the international capital market to supplement access to developmental resources. Prudent, debt management will entail taking into account the maturity profiles of debt against public sector borrowing requirements.

- An aggressive domestic revenue mobilization and its efficient use in driving the prioritized development targets. This is to be attained through administrative measures and capacity enhancement of existing tax collection instruments and personnel.

- An efficient expenditure re-prioritization in favour of development expenditure and to ensure efficiency in the use of public resources.

- Growth in aggregate investment, especially from packaged programmes such as the Millennium Challenge Account Compact with its integrated agro projects

Within these general assumptions, it is targeted that the economy grows at an annual rate which will rise from 6 percent to 8 percent towards the realization of middle income status by 2015; but this must be firmly situated within the perspective of changing the inherent structure of production.

GPRS II will therefore continue with the implementation of policies that will enhance and sustain the gains made in macroeconomic stability under GPRS I by ensuring:

- prudent fiscal policy management

- a monetary policy that is flexible enough to respond to external shocks, promote growth and ensure price stability

- real interest rates that enhance effective mobilisation of savings and make credits affordable to the private sector

- relatively stable real exchange rates that promote international trade 


\subsection{PRIVATE SECTOR COMPETITIVENESS}

\section{Challenges to the Capacity of the Private Sector}

The main challenge is to systematically address a number of structural constraints at the policy and institutional levels that hamper private-sector competitiveness in the agricultural sector in the medium term and in the industrial and other sectors over the long term.

Primary among these are:

- complexity and non-transparency of regulations

- inadequate information on existing regulations

- lack of access to finance, especially for small-scale women farmers

- falling but still fairly high interest rates

- weak and inadequate capacity within the public sector to formulate, implement, monitor and evaluate private sector policies that explicitly take into account the specific needs of enterprises (especially the interests of micro, small and medium scale enterprises)

- weak commercial dispute resolution system

- insecurity and vulnerability in the informal sector where the youth and women predominate

- weak linkages between the informal and formal sector activities

- lack of social protection for men and women in the informal sector

- weak institutional and regulatory framework for small business management.

Additionally a number of technical constraints to agricultural development exist. These include:

- low crop yield and output due to low soil fertility and over-dependency on rainfall

- unsustainable agricultural practices including low exploitation of water for irrigation purposes

- low productivity and low disease-resistant breeds of livestock

- high incidence of livestock diseases and poor disease surveillance systems

- inappropriate husbandry practices

- inadequate infrastructure for aquaculture and low levels of fish production from existing water bodies

- limited value addition and high post-harvest losses

- limited access to marketing centres due to poor conditions of the road network

\section{Policy Interventions}

The capacity of the private sector will be strengthened to effectively perform as the engine of growth and poverty reduction by improving Ghana's access to global and regional markets; enhancing the efficiency and accessibility of national markets; strengthening of firms' competency and capacity to operate effectively and efficiently; enhancing government capacity for private sector policy formulation, implementation, monitoring and evaluation; facilitating private sector access to capital; improving the institutional and legal bottlenecks; supporting adoption of technological innovation and entrepreneurship; enhancing the quality of public services and 
accelerating the development of other sectors that are strategic to the attainment of private sectorled growth.

Accordingly, the following broad areas have been identified for priority interventions in the agricultural sector:

- reform to land acquisition and property rights

- accelerating the provision of irrigation infrastructure

- enhancing access to credit and inputs for agriculture

- promoting selective crop development

- modernising livestock development

- improving access to mechanised agriculture

- increasing access to extension services

- provision of infrastructure for aquaculture

- restoration of degraded land and environment

In line with the long term vision of developing an agro-based industrial economy, the interventions in agriculture will be complemented with appropriate interventions in the trade and industry sector. The policy objectives and strategies outlined to achieve this include:

- ensure proper integration of the nation's production sectors into the domestic market

- promote agro-processing

- improve agricultural marketing

- enhance access to export markets

- increase industrial output and improve the competitiveness of domestic industrial products

- facilitate the development of commercially viable export and domestic market oriented enterprises in the rural areas

- $\quad$ promote industrial sub-contracting and partnership exchange

- promote the development of the craft industry for export

- ensure the health, safety and economic interest of consumers

\section{Support Services:}

Strategic support services that would be developed to facilitate improved productivity in agriculture and agro-industry are transportation, energy, science and technology.

The broad policy objectives here are to ensure the provision, expansion and maintenance of the appropriate transport infrastructure which strategically links the rural production and processing centres to the urban centres, while ensuring the provision of affordable and accessible transport system that recognises the needs of people with disabilities.

Policy interventions within the energy sector will focus on ensuring increased access to alternatives forms of energy by the poor and vulnerable; modernisation and expansion of power infrastructure; improving the regulatory environment in the power sector, ensuring full cost recovery for power supply and delivery while protecting the poor; promoting productive and efficient use of energy and minimising the environmental impacts of energy supply and consumption through increased energy 
efficient technologies.

The policy objective under Science and Technology is therefore to promote the adoption of appropriate technologies, both local and foreign, with the capacity to improve productivity and efficiency in the agricultural, industrial and services sectors especially for small and medium-scale rural enterprises.

\section{Additional sectors to support accelerated growth:}

Other sectors which are targeted for accelerated growth and development in view of their employment creation and income generation potentials include: mining (especially exploration and exploitation of the lesser developed minerals such as salt); Information and Communication Technology (ICT), tourism, music and film industry, as well as the development and production of commodities under the Special Initiatives for export including garments and textiles.

\section{Employment generation and improved safety nets:}

The broad objective of employment creation will be to ensure that the benefits of accelerated growth impact positively on increased job opportunities for all. The attainment of this objective will significantly contribute to reducing poverty among the rural and urban poor. Strategies in this direction will include adoption of a national policy for enhancing productivity and income/wages with equal opportunities for men and women, ensuring the existence and implementation of a coherent employment policy for the youth, the vulnerable and excluded including people living with disabilities and adopting a policy for comprehensive and integrated employment monitoring and evaluation

\subsection{HUMAN RESOURCE DEVELOPMENT}

The main goal of Human Resource Development under GPRS II is to ensure the development of a knowledgeable, well-trained and disciplined labour force with the capacity to drive and sustain private sector-led growth.

\section{Policy Interventions}

The following broad policy areas have been identified to drive the development of the necessary human resources for accelerated economic growth: The promotion of formal education and training and skills development; improved access to health care; malaria control and HIV/AIDS prevention and treatment; access to safe water and adequate sanitation; housing and slum upgrading and population management. The strategy will also include a vigorous health education campaign on the adoption of healthy environmental practices and lifestyles. In addition relevant issues relating to vulnerability and exclusion will be mainstreamed in the human resource development strategy 


\section{$\underline{\text { Education }}$}

Priority policy interventions that will deepen and sustain the progress made in the sector under GPRS I and accelerate growth include the following:

- increase access to and participation in education and training at all levels

- bridge gender gaps in access to education in all districts

- improve the quality of teaching and learning;

- improve efficiency in the delivery of education services

- promote science and technology education at all levels with particular attention to increased participation of girls.

Training, skills and entrepreneurial development will be guided by the following priorities:

- provision of skills and entrepreneurial training in a gender responsive and equitable manner

- promotion of dialogue between industry and skills/professional training institutions to produce skilled labour required by industry

- strengthening of and support HR training institutions

- promotion of training in apprenticeship;

- promotion of the adoption of the National Youth Policy and enactment of the Disability Bill

\section{$\underline{\text { Health }}$}

In order to accelerate access to quality health services, the health sector will continue to deepen efforts and focus on the three broad policy objectives. These are:

- bridge equity gap in access to quality health and nutrition services

- ensure sustainable financing arrangements that protect the poor

- enhance efficiency in service delivery

In Ghana, malaria remains the leading cause of morbidity, accounting for about $40 \%$ of all out patients attendance. It is also the leading cause of deaths, especially among children under five years old and pregnant women. Malaria is more than a health issue as it adversely affects productivity in all sectors of the economy through workdays lost due to illness and the cost of treatment. The following priority interventions in the Roll Back Malaria (RBM) plan will be promoted and strengthened in GPRS II: improve malaria case management; multiple prevention; improved partnership; and focused research.

In addition to the malaria menace, HIV/AIDS pandemic at the prevalence rate of $3.4 \%$ has a negative impact on productivity, loss of productive assets, high treatment costs and the break in the transfer of valuable livelihood knowledge from one generation to the next. To effectively address this issue, the following strategies will be adopted to prevent the spread of HIV/AIDS in order to keep the prevalence rate below 5\%: reduce new HIV/STI transmission; reduce the impact of HIV/AIDS related vulnerability, morbidity and mortality; enhance the coordination and management of the national HIV/AIDS response. 


\section{Safe water and environmental sanitation:}

The following priorities will guide the delivery of safe water and sanitation in the next four years: accelerate provision of safe water in rural and urban areas; accelerate the provision of adequate sanitation; improve environmental sanitation in urban and rural areas.

\section{Urban housing and slum upgrading:}

The ultimate goal of Shelter Policy is to provide adequate and affordable stock of housing with the requisite infrastructure and basic services to satisfy the basic needs of the people. GPRS II treats the provision of housing as a strategic area for stimulating economic growth while at the same time improving the living conditions of Ghanaians. The very activity of providing housing contributes to economic growth through its multiplier effect on job creation and the local building material industry.

\section{Population management:}

Even though the population growth rate in Ghana has reduced from its previously high level of about $3 \%$ in 1994 to $2.7 \%$ in 2000, it continues to outstrip the provision of social services and infrastructure. The high fertility rate has also resulted in a youthful population with a high dependency ratio. The immediate challenge to human resources development under GPRS II is to formulate appropriate strategies to manage the population to ensure that population growth rate is maintained at a level that will support economic growth and social development.

Population management will be based on the following priorities:

- promote access to and utilization of family planning services

- educate the youth on sexual relationship, fertility regulation, adolescent health, marriage and child bearing

- promote sexual health, delayed marriage and child bearing

- promote compulsory education for children especially the girl-child up to secondary

- promote compulsory and universal birth registration as a basic right and population management measure

- integrate population variables into the GPRS at the national, regional and district levels and improve population database for the GPRS

- promote the integration of HIV/AIDS into sexual and reproductive health programmes

- strengthen the multi-sectoral, multi-disciplinary institutional co-ordination, collaboration and networking for population management.

\section{Mainstreaming the Vulnerable and Excluded in Human Resource Development:}

Issues relating to vulnerability and exclusion have been mainstreamed in the GPRS II. A comprehensive Social Policy Framework to update existing policies where necessary and provide guidelines for improved social development performance to bolster economic growth will be developed and adopted to strengthen the process of empowering the vulnerable and excluded to 
reduce their risks, protect their rights and enhance their contribution to national development.

Priority policy issues to be resolved, besides education and health, include:

- integrated child development

- $\quad$ strengthening of the family

- HIV/AIDS

- capacity development in social work and volunteerism;

- updating the database on vulnerable and excluded groups; and

- strengthening institutional linkages and better coordination.

\subsection{GOOD GOVERNANCE AND SOCIAL RESPONSIBILITY}

The broad objective of good governance and civic responsibility is to empower state and non-state entities to participate in the development process and to collaborate effectively in promoting peace and stability. Measures towards attaining this objective include the promotion of an effective, responsible and accountable state machinery with improved capacity to engage the productive private sector and civil society in formulating strategies for accelerated growth and poverty reduction.

The priority areas for the promotion of political governance under GPRS I included public sector reform, decentralisation, and security and rule of law. Although considerable progress was made in terms of these objectives under GPRS I, the following still present challenges to good governance:

- strengthening the process of democratisation

- further improving existing institutional capacities in the legislative and policy environment

- strengthening the data management system to support evidence-based decision making

- ensuring gender equity

- integrating traditional authorities into formal institutional structure for governance

- fostering greater civic responsibility

Strategies for Political Governance under the GPRS II therefore include strengthening Parliament, enhancing decentralisation, protecting rights under rule of law, ensuring public safety and security, managing public policy, empowering women and the vulnerable group, enhancing development communication, ensuring good corporate governance, increasing access to information, and promoting civic responsibility. Priorities for enhancing Economic Governance under GPRS II will focus on improved management of fiscal, monetary and international trade policies.

Strategies for improved fiscal policy management will focus on public expenditure management, promoting effective debt management, and improving fiscal resource mobilization. Monetary Policy management will continue to focus on price and exchange rate stability. GPRS II will promote international trade by reducing the constraints associated with export and import procedures; minimizing the incidence of "dumping"; diversifying and increasing the export base, promoting new areas of competitive advantage, taking full advantage of Ghana's preferential access to international markets (AGOA, EU-ACP), engaging fully in multi-lateral trade negotiations, and 
establishment of an effective information system to track and measure progress.

\subsection{MONITORING AND EVALUATION}

The goal of the M\&E System under GPRS II is to facilitate the tracking of progress and effectiveness as well as to identify bottlenecks associated with the implementation of the Strategy. The proposed system, which forms an integral part of the GPRS II, will build on the progress made under GPRS I and would involve the following key strategies:

- $\quad$ reinforce institutional arrangements that can support and sustain monitoring and evaluation processes

- $\quad$ evolve an efficient system for evidence-based monitoring and evaluation

- $\quad$ strengthen and effectively coordinate existing mechanisms

- $\quad$ evolve an efficient system for generating relevant, reliable and timely quantitative and qualitative information

- $\quad$ manage an effective feedback mechanism that makes statistical information available in useable form to government and civil society

- ensure a holistic and participatory approach to M\&E including consultative mechanisms such as the APRM

Enhanced efforts to implement the M\&E Plan will focus on strengthening institutional capacities to link $M \& E$ results to national policy and decision-making and budgeting. The outputs from the M\&E efforts will be documented and widely disseminated through the Annual Progress Reports

\subsection{FINANCING THE GPRS II}

The estimated total resources required to finance the GPRS II is \$ 8.06 billion (2006-2009). These costs exclude wages and salaries and administrative expenses associated with project and programme implementation. They consist primarily of investment and service costs. As reflected in the macro-economic framework, the budgeted expenditures for investments and services over the same period only amount to $\$ 6.27$ billion indicating an overall funding gap of $\$ 1.79$ billion which is expected to be filled by external inflows and resources from the capital market.

External inflows are expected to be harnessed from HIPC savings, debt cancellation and Millennium Challenge Account to complement domestic resources. Given Ghana's favourable sovereign ratings, augmented by good governance, additional resources could be sourced from the international capital market. 


\section{CHAPTER ONE}

\section{GPRS II: OUTLINE OF CONTENTS AND POLICIES}

\subsection{BACKGROUND}

Ghana's economy, which is largely agro-based, has in the past been characterised by high rates of inflation, continuous depreciation of the cedi, dwindling foreign reserves, an excessive public debt burden and fluctuating growth. Extensive implementation of liberalization and adjustment policies in the 1980s produced some growth in services and mining but did little to induce and sustain growth in agriculture and manufacturing. Both growth and incomes remained stagnant, resulting in deepening poverty.

During the 1990s, the levels of public expenditure on social development programmes for poverty reduction such as health and education were at 2.0 percent and 2.8 percent of GDP respectively. These levels of spending were much lower than what prevailed in other African countries, constraining poverty reduction and effective social change and development. Although general poverty levels decreased in the 1990s, certain areas of Ghana experienced growing and deepening incidence of poverty, with evidence of intensification of vulnerability and exclusion ${ }^{1}$ among certain social groups. This was particularly noticeable in the savannah and transitional zones in northern Ghana and in some coastal areas in the Central and Greater Accra regions. In the country as a whole, some large occupational groups such as small-scale food farmers, especially women, remained stuck below the poverty line, and the chances of survival of many children and youth remained precarious.

The first programmes under the Ghana Poverty Reduction Strategy (GPRS I) were formulated against the backdrop of a general economic crisis in which virtually all of Ghana's key macroeconomic indicators were spiralling out of control. The focus of that programme was accordingly to re-align the macroeconomic situation as a necessary condition for the implementation of sectoral policies specifically targeted towards reducing the incidence of poverty as observed in the 1990s. In the meantime Ghana had applied for debt relief under the HIPC initiative, and had to observe the classical conditionality of that scheme, namely, that the savings from debt relief would be applied

\footnotetext{
1 Defining Vulnerability and Exclusion
}

Vulnerability is a state of deprivation based on poverty or lack of enjoyment of other rights and entitlements; it is therefore multi-dimensional. It leads to the exclusion of disadvantaged groups of men, women and children and persons with disability from active participation in the economic, political and social life of their society, leaving them with little or no defence against exploitation and risks.

Definition of Exclusion

Invariably persistent vulnerability leads to exclusion. It can be looked at from social, economic, political or human ecological perspectives. Exclusion arising from such distinctive features may lead to the following conditions:

- Inability to participate in decision making in political, and socio-cultural affairs

- Inability to compete or participate in an event due to discrimination 
solely to "poverty alleviation" which in turn translated into the pursuit of the United Nations Millennium Development Goals. Indeed, the need to submit a PRSP was the immediate occasion for producing GPRS I and subsequent versions were envisaged at fitting into the same trajectory of national development policy.

At the onset, it became obvious that apart from HIPC savings, policies under GPRS had to address the issue of how to create wealth by restructuring the economy towards accelerated growth, so that the objectives of poverty reduction and the protection of the vulnerable and excluded could be sustained. The principal social objectives that were added to these related to improved governance, including the decentralization of government and reform of the public services to partner the private sector in national economic development within a decentralized democratic environment.

\subsection{REVIEW OF GPRS I}

For the three years under GPRS I, the main thrust of the government's policy initiatives was aimed at maintaining macroeconomic stability. This was achieved through prudent fiscal and monetary policies aimed at reducing inflation, driving interest rates down to levels conducive to increased investments but still attractive enough to mobilize savings, ensuring stable but yet competitive exchange rates, and maintaining a fiscally sustainable debt regime. In the real economy a moderate rate of economic growth was to be achieved through the creation of an enabling environment for improved agricultural productivity and private sector-led agro-industrial development. As a result of the availability of HIPC savings the manifestations, and at the same time the causes, of the deepest poverty were to be directly attacked through greater investments in health, education, safe water and sanitation. Feeder roads and other transport infrastructure could be financed to facilitate distribution of agricultural products and services in favour of the rural poor. The main political objective of the GPRS I of ensuring that in the promotion and protection of civil liberties no Ghanaian was excluded from participating in decisions that affected their lives, has been pursued through HIPC supplementation of the resources available under the District Assemblies Common Fund and the Ghana Educational Trust Fund.

Considerable progress has been made towards achieving the objectives of GPRS I. The economy has been characterized by relative stability, with all the targeted macroeconomic indicators registering positive trends. Despite a series of major fuel price adjustments to absorb petroleum debt and respond to a fast-rising crude oil market, the overall consumer price index declined dramatically over the period, interest rates eventually fell and exchange rates stabilized. GDP grew at an average rate of 5 percent during the period, because it coincided with the dissemination of new high-productivity technologies in the all-important cocoa sector. As a result, unlike the classical pattern of sectoral contributions to growth in an emerging economy, Ghana's economic growth under GPRS I (2002 - 2004) was led by the agricultural sector with 6\% average growth rate, followed by industry and services respectively with $5 \%$ and $4.7 \%$.

Generally in the social development circles there were increased expenditure outlays in support of the medium-term priorities of GPRS I with regard to special programmes targeted at the vulnerable and excluded. These included the rehabilitation of street children, increased access to legal aid 
services for the poor, integration of Persons With Disabilities (PWDs) into mainstream production and employment, and increased access of economically marginalized women to credit through the establishment of the government's micro-credit scheme and the Women's Development Fund supported by the government of Japan.

Despite these achievements, as was characteristic of the poverty reduction strategies sponsored by creditor institutions in that epoch, there was little room in the 2001 - 2005 programme for addressing issues, such as urbanisation, industrialisation, technical/vocational training, technology research and development - that must now engage greater attention in policy-making in Ghana as it aspires to join the ranks of the fast growing economies.

GPRS I has a number of limitations and bottlenecks. These included service delivery constraints and the persistence of regional differences in the distribution of some key outcomes in the health and educational sectors. The educational sector continues to be confronted with insufficient progress in primary school enrolment as well as geographical and gender disparities. In spite of the efforts made, gender disparities can be observed in all sectors including education, health, production, employment and access to and control over land.

Economic policy and management under GPRS I has been criticised for concentrating on macroeconomic stability rather than providing a clear policy direction which recognises a stable macroeconomic environment as a platform upon which to generate economic growth as a means to poverty reduction. Another criticism relates to the ineffectiveness of the participatory process adopted during its preparation and the implication for national ownership. The inability to involve more districts and local communities, and the limited engagement of Parliament and the private sector, have been cited as weaknesses in the process. A further criticism is the insufficiency of gender focus specification when addressing various poverty issues in the diagnostic, in the thematic areas, and in the policy matrices, as well as in the monitoring and evaluation framework.

While taking note of the shortcomings of GPRS I, government has taken even more significant initiatives in basic components of a strategy for the short term protection and improvement of living standards and the longer-term emancipation of people from the stranglehold of inherited poverty. A National Health Insurance System has been brought into effect in 2005 to guarantee every Ghanaian access to a professional health care from "cradle to grave" at affordable cost. In 2004 government promulgated an Educational Reform Programme which does not only assure every young Ghanaian the right to free basic education as prescribed by the National Constitution and the UN's Millennium Development Goals, but will eventually give them the unrestricted opportunity to participate fully as members of a productive work force of a modernised, technological, and wealthcreating economy.

\subsection{POVERTY SITUATION}

In formulating GPRS I, the incidence of poverty was analyzed and categorized on broad regional basis and this resulted in limitations in targeting poverty reduction interventions. However, further analysis of income poverty based on available data presents a clearer picture of poverty at district 
level as depicted in Appendix 1. This has provided the basis for more direct targeting of poverty reduction measures under GPRS II.

Table 1.1 shows the movement of some of the core welfare indicators for periods 1998/99 and 2003.

Table 1.1: Core Welfare Indicators

\begin{tabular}{|c|c|c|c|}
\hline Population Defined as Poor (Welfare measures) & & 1998/99 & 2003 \\
\hline Males who never attended school & & $21 \%$ & $25.9 \%$ \\
\hline Females who never attended school & & $41 \%$ & $37.4 \%$ \\
\hline Males Literacy rate & & $63.0 \%$ & $66.2 \%$ \\
\hline Females Literacy rate & & $36.0 \%$ & $42.5 \%$ \\
\hline Literacy rate in urban areas & & $63.0 \%$ & $69.9 \%$ \\
\hline Literacy rate in rural areas & & $40.0 \%$ & $40.1 \%$ \\
\hline Children aged 6-15 attending school & & $80.0 \%$ & $85.4 \%$ \\
\hline \multirow[t]{2}{*}{ Nearest Health Facility is at least 30 minutes away } & Urban & $20.0 \%$ & $21.4 \%$ \\
\hline & Rural & $61.0 \%$ & $57.4 \%$ \\
\hline \multirow[t]{2}{*}{ Supervised delivery assistance (doctor, nurse, midwife) } & Urban & $79.0 \%$ & $83.4 \%$ \\
\hline & Rural & $33.0 \%$ & $34.7 \%$ \\
\hline \multirow[t]{2}{*}{ Access to Safe Source of water } & Urban & $92.3 \%$ & $87.3 \%$ \\
\hline & Rural & $52.1 \%$ & $63.0 \%$ \\
\hline Prevalence rate of HIV/AIDS - National & & $3.6 \%$ & $2.0 \%$ \\
\hline Households Using Electricity & & $41.4 \%$ & $48.3 \%$ \\
\hline Population employed in agriculture & & $55.0 \%$ & $44.5 \%$ \\
\hline Population employed in trading & & $18.3 \%$ & $22.5 \%$ \\
\hline Population employed in manufacturing & & $11.7 \%$ & $6.4 \%$ \\
\hline
\end{tabular}

Source: CWIQ $1997 \& 2003$

\subsection{GROWTH AND POVERTY REDUCTION STRATEGY (GPRS II)}

The design and preparation of GPRS II (2006-2009) is thus guided by practical lessons and experiences drawn from the preparation and implementation of GPRS I (2003-2005). However, going beyond these, the government and the nation itself have also adopted developmental goals and vision based on the proposition that Ghana has now positioned itself to attain the social and economic status of emerging middle income countries within the next decade.

In place of the former Ghana Poverty Reduction Strategy (GPRS I), Government is accordingly launching a new Growth and Poverty Reduction Strategy (GPRS II 2006-2009). The change in name reflects the new direction of government policy which places more emphasis on growth. This document presents a set of coordinated national programme of social and economic development -that set which illustrates how much a national programme can be purposefully steered to eliminate 
the worst manifestations of poverty, social deprivation and economic injustice, from Ghanaian society. Essentially, it integrates the otherwise disparate development agenda and sectoral commitments that compete for inclusion in the annual national budget into one comprehensive development policy framework to serve the basic objective of guaranteeing every Ghanaian a decent livelihood, especially for the most vulnerable and deprived (who are disproportionately made up of women, children and unemployed youth). It incorporates the relevant development strategies/policy documents of all the various sectors such as the Basic Education Improvement Programme and the 2004 White Paper in Education Reform, the Private Sector Development Strategy, Ghana Trade Policy, the Food and Agricultural Sector Development Programme and the National Gender and Children's Policy.

GPRS II also seeks to operationalise various international agreements which are relevant to the poverty reduction objectives and of which Ghana is signatory. Principal among these are the Millennium Development Goals (MDGs), the New Partnership for African Development (NEPAD) and the African Peer Review Mechanism (APRM), the Convention on the Elimination of all forms of Discrimination Against Women (CEDAW) and the African and Beijing Platforms for Action. It is also consistent with the relevant ongoing programmes which government is pursuing with development partners.

\subsubsection{Goal}

The overarching goal of Ghana's current socio-economic development agenda is to attain middle income status (with a per capita income of at least US\$1000) by the year 2015 within a decentralized, democratic environment. This is to be complemented by the adoption of an overall social protection policy, aimed at empowering the vulnerable and excluded, especially women to contribute to and share in the benefits of growth of the economy, thus ensuring sustained poverty reduction.

This document reviews GPRS I, analyses growth trends, and defines the strategic direction and interventions aimed at achieving the basic poverty reduction goals prescribed in the MDGs framework and, beyond that, bringing Ghana within the threshold of middle income countries.

The technical computation of these goals in terms of the traditional indicators of "per capita gross national income" expressed in current United States dollars is at present inhibited by a number of professional constraints. First, greater portion of business in Ghana is conducted using the national currency - the Cedi. In the recent period of extreme turbulence in the relative value of the Cedi against the Dollar, translating the value of the nation's entire production of goods and services into meaningful dollar terms is obviously a difficult and controversial exercise. Besides that complication of the exchange rate, our economists have also to cope with the influence of domestic price changes, including periods of hyper-inflation, on the measurement of the value of Ghana's total economic output in real terms. A further difficulty is posed by challenges to data inaccuracies relating to the conduct of ten-year national population census.

The combined effect of the above factors is that depending on the methodologies and assumptions 
that have been employed by various agencies, estimates of the value of the productive work that is averagely done by every living Ghanaian today in a year, range from US\$380 per head on the current World Bank rankings, to US \$430 according to some local experts and to US\$480 per head according to some internationally reputed rating agencies. These figures will be refined and the differences narrowed down as a result of the professional advances that are envisaged in the technical standards of governance under GPRS II.

The contemporary debate on the status of national income or demographic statistics not withstanding, what matters is that as a nation we are able to think through, agree upon and vigorously implement a realistic plan to bring about the vast improvements in our living standards such as are warranted by Ghana's own endowments of human and material resources backed by the technological possibilities of the world that we share.

\subsubsection{Linkage to GPRS I}

With the attainment of relative macroeconomic stability under GPRS I, the direction of GPRS II is to accelerate economic growth and poverty reduction by assisting the private sector as much as possible to create wealth and by shaping the acts and policies of government deliberately so as to generate the maximum opportunities for additional employment.

However, there are two broad sets of constraints to achieving accelerated wealth creation and poverty reduction. The first is the vulnerability of the economy due to the persistent reliance on the export earnings from a few primary commodities. The second is the social structure which comprises a high proportion of children and youth. The attendant high dependency ratio is aggravated by the low level of literacy, working skills, and productivity especially among women and the rural population.

Accordingly, emphasis in this GPRS II is placed on measures to change the structure of the economy by developing the private sector, diversifying the export base and increasing agricultural productivity, processing and rural incomes.

While the GPRS I focused on poverty reduction programmes and projects, the emphasis of GPRS II is on growth-inducing policies and programmes as which have the potential to support wealth creation and poverty reduction. GPRS II is therefore anchored on pursuing the following priorities:

- continued macroeconomic stability

- accelerated private sector-led growth

- vigorous human resource development

- good governance and civic responsibility

Continued macroeconomic stability will be realized by ensuring prudent fiscal policy management, effective monetary policy, and a well-managed debt and international trade regime. It is accepted however that the highly reserved posture of macroeconomic policy which was appropriate to the convalescent economy under GPRS I has to be modified to meet the needs of a more expansionary thrust of policy under GPRS II. The Bank of Ghana is already leading the way by introducing 
measures such as the reduction in banks' reserve requirements and the lowering of the cost of credit to business on a broad front.

But GPRS II should make its greatest impact in the real economy of agricultural and industrial production. Accelerated growth will be achieved through the development of a vibrant private sector with adequate capacity to lead the growth of agriculture and other emerging sectors including ICT and tourism. After decades of development effort, some of the most basic advances in production technologies have eluded Ghana. We did not need to overcome the terrible scourge of mass famine, but Ghana today has not even achieved basic food security in its traditional staple diet. The peasant woman who feeds this country is still using the same technology of cutlass and hoe which her grandmother used to feed a population one-fifth the size of today's population.

Ghana's timber industry is yet to derive optimum value for the nation from the forest resources which are in the meantime being exploited to exhaustion. A significant portion of wood material ends up as off-cuts and sawdust because of low investment in the technology of timber utilisation. The emerging success in Ghana's textile industry has turned sour: the exportable surplus of cotton production has long disappeared, and now not only is the textile weaving industry in a state of crisis but even printing on imported cloth seems to be losing its competitiveness.

Overall, the contribution of modern industry to the modestly fast growth of the economy in the most recent years has been unacceptably low, mirroring a relatively stagnant inflow of foreign direct investment. The years of GPRS II should serve as a transition period when a basic platform of agro-industrial production and technology is built up to match the successes that have been achieved in the area of macroeconomic reform. Vigorous human resource development, good governance and civic responsibility will be pursued both to support growth and as important developmental goals in themselves.

\subsubsection{Ghana's Progress towards achieving the Millennium Development Goals (MDGs)}

The MDGs span the critical development issues of poverty and hunger, education, health (especially child and maternal mortality), gender equality and women's empowerment, environmental sustainability and global partnership for development, and thus provide an important subsidiary framework for defining specific objectives for GPRS II.

Ghana has, since 2000 adopted the targets of the MDGs as the minimum requirements for socioeconomic development and poverty reduction. Accordingly, Ghana began the monitoring of progress towards achieving the MDGs from 2002 even prior to the formal launching of GPRS I.

The initial findings were that though some progress had been made, achieving the goals of the MDGs by 2015 would require additional effort particularly in the area of reducing maternal mortality.

Since then government has focused on removing the constraints hindering the realization of the MDGs. Table 1.2 below shows the progress that Ghana has made towards achieving the Millennium Development Goals. 
Table 1.2: Ghana's Progress towards Achieving the Millennium Development Goals

\begin{tabular}{|c|c|c|c|c|c|c|c|c|}
\hline Goals & Will go & be reach & & & State & supp & tive enviror & iment \\
\hline $\begin{array}{l}\text { Extreme poverty and hunger } \\
\text { Halve the proportion of people below the } \\
\text { national poverty line by } 2015\end{array}$ & Probably & Potentially & Unlikely & $\begin{array}{l}\text { Lack of } \\
\text { data }\end{array}$ & $\underline{\text { Strong }}$ & Fair & $\begin{array}{l}\text { Weak but } \\
\text { improving }\end{array}$ & Weak \\
\hline $\begin{array}{l}\text { Halve the proportion of people who suffer } \\
\text { from hunger }\end{array}$ & Probably & Potentially & $\underline{\text { Unlikely }}$ & $\begin{array}{l}\text { Lack of } \\
\text { data }\end{array}$ & Strong & $\underline{\text { Fair }}$ & $\begin{array}{l}\text { Weak but } \\
\text { improving }\end{array}$ & Weak \\
\hline $\begin{array}{l}\text { Universal primary education } \\
\text { Achieve universal access to primary } \\
\text { education by } 2015\end{array}$ & Probably & Potentially & Unlikely & $\begin{array}{l}\text { Lack of } \\
\text { data }\end{array}$ & Strong & Fair & $\begin{array}{l}\text { Weak but } \\
\text { improving }\end{array}$ & Weak \\
\hline $\begin{array}{l}\text { Ender equality } \\
\text { Eliminate gender disparity in primary and } \\
\text { junior secondary education by } 2005\end{array}$ & Probably & Potentially & Unlikely & $\begin{array}{l}\text { Lack of } \\
\text { data }\end{array}$ & Strong & $\underline{\text { Fair }}$ & $\begin{array}{l}\text { Weak but } \\
\text { improving }\end{array}$ & Weak \\
\hline $\begin{array}{l}\text { Achieve equal access for boys and girls to } \\
\text { senior secondary by } 2005\end{array}$ & Probably & Potentially & $\underline{\text { Unlikely }}$ & $\begin{array}{l}\text { Lack of } \\
\text { data }\end{array}$ & Strong & Fair & $\frac{\text { Weak but }}{\text { improving }}$ & Weak \\
\hline $\begin{array}{l}\text { Under-five mortality } \\
\text { Reduce under-five mortality by two-thirds } \\
\text { by } 2015\end{array}$ & Probably & Potentially & Unlikely & $\begin{array}{l}\text { Lack of } \\
\text { data }\end{array}$ & $\underline{\text { Strong }}$ & Fair & $\begin{array}{l}\text { Weak but } \\
\text { improving }\end{array}$ & Weak \\
\hline $\begin{array}{l}\text { Maternal mortality } \\
\text { Reduce maternal mortality ratio by three- } \\
\text { quarters by } 2015\end{array}$ & Probably & Potentially & $\underline{\text { Unlikely }}$ & $\begin{array}{l}\text { Lack of } \\
\text { data }\end{array}$ & Strong & Fair & $\begin{array}{l}\text { Weak but } \\
\text { improving }\end{array}$ & Weak \\
\hline $\begin{array}{l}\text { HIV/AIDS \& Malaria } \\
\text { Halt and reverse the spread of HIV/AIDS } \\
\text { by } 2015\end{array}$ & Probably & $\underline{\text { Potentially }}$ & Unlikely & $\begin{array}{l}\text { Lack of } \\
\text { data }\end{array}$ & $\underline{\text { Strong }}$ & Fair & $\begin{array}{l}\text { Weak but } \\
\text { improving }\end{array}$ & Weak \\
\hline Halt and reverse the incidence of malaria & Probably & Potentially & Unlikely & $\underline{\text { Lack of }}$ & Strong & $\underline{\text { Fair }}$ & $\begin{array}{l}\text { Weak but } \\
\text { improving }\end{array}$ & Weak \\
\hline $\begin{array}{l}\text { Ensure Environmental Sustainability } \\
\text { Integrate the principles of sustainable } \\
\text { development into country policies and } \\
\text { programmes and reverse loss of } \\
\text { environmental resources }\end{array}$ & Probably & $\underline{\text { Potentially }}$ & Unlikely & $\begin{array}{l}\text { Lack of } \\
\text { data }\end{array}$ & Strong & $\underline{\text { Fair }}$ & $\frac{\text { Weak but }}{\text { improving }}$ & Weak \\
\hline $\begin{array}{l}\text { Halve the proportion of people without } \\
\text { access to safe drinking water by } 2015\end{array}$ & $\underline{\text { Probably }}$ & Potentially & Unlikely & $\begin{array}{l}\text { Lack of } \\
\text { data }\end{array}$ & Strong & $\underline{\text { Fair }}$ & $\begin{array}{l}\text { Weak but } \\
\text { improving }\end{array}$ & Weak \\
\hline $\begin{array}{l}\text { By } 2020 \text { a significant improvement would } \\
\text { have been achieved in the lives of at least } \\
100 \text { million slum dwellers }\end{array}$ & Probably & Potentially & Unlikely & $\underline{\text { Lack of }}$ & Strong & Fair & $\begin{array}{l}\text { Weak but } \\
\text { improving }\end{array}$ & Weak \\
\hline Improving the lives of slum dwellers & & & & & & & & \\
\hline $\begin{array}{l}\text { Global partnership for development } \\
\text { Deal comprehensively with debt and } \\
\text { make debt sustainable in the long term }\end{array}$ & Probably & $\underline{\text { Potentially }}$ & Unlikely & $\begin{array}{l}\text { Lack of } \\
\text { data }\end{array}$ & $\underline{\text { Strong }}$ & Fair & $\begin{array}{l}\text { Weak but } \\
\text { improving }\end{array}$ & Weak \\
\hline
\end{tabular}

Source: NDPC 2004

* Lack of data implies inability to score appropriately 


\subsection{STRUCTURE OF PRESENTATION OF GPRS II}

GPRS II is presented in two volumes; Volume I, which is the policy framework of the Growth and Poverty Reduction Strategy analyses the macroeconomic context and the development policy choices that should be made to attain the goals of GPRS II. It includes a policy matrix, which outlines issues, policy objectives, and strategies, and also identifies the agencies responsible for implementing each component of the strategy. Volume II is a four-year framework of costed policies and strategies.

This document is organized into six chapters. Chapter 1 is the introduction which includes a discussion of recent experiences and future goals in national development, especially as they bear on the issues of poverty reduction. It also outlines the process of preparing the GPRS and the strategy for mass citizen involvement in the GPRS II process in as much as there is need to mobilise the whole body politic to assure its success. Chapter 2 presents the Macroeconomic Context and Policy choices, while Chapter 3 discusses the policies for Growth through Private Sector Development. Chapter 4 contains policies for Vigorous Human Resource Development, Chapter 5 deals with Good Governance and Civic Responsibility and, in Chapter 6 the plan for monitoring and evaluating the implementation of the GPRS II is presented. Finally Chapter 7 presents the financing arrangements for the implementation of the GPRS II.

The GPRS II document is not designed to present a set of cut and dried policies and programmes. It rather represents a medium term framework which offers a platform for maximising social dialogue with civil society and development partners in order to arrive at the best long term solutions to national development challenges.

The extensive process of consultation which has preceded this publication will be followed by a further and even more comprehensive programme of dialogue within the government itself, with Parliament, civil society, various interest groups, and development partners so that the crucial tasks of consolidation of policies and programmes under GPRS II can be accomplished. During the period of excessive debt dependency, the management of the development dialogue has seemed to be a duet between the Government establishments and its multilateral and bilateral foreign creditors. The ordinary mass of the people, whose future and fortunes were being decided, had no part or opinion in the process. The inevitable result was that all those programmes achieved scant success - because there was an insufficient conviction of "ownership" among either the state or the non-state partners in the implementation of the planned development programmes.

The processes of consultation that have already been conducted in the lead up to this publication are outlined below.

\subsection{THE PROCESS OF PREPARING GPRS II}

During the four year term of implementing this GPRS II it is imperative to institute procedures and relationships that will enhance the probability of attaining the objectives for national development and poverty reduction. The first requirement is that Ghanaians themselves will own and drive 
forward the process of development.

Accordingly the preparation of GPRS II has involved broad participation to ensure that diverse shades of opinion and experiences are reflected at all stages of the process. The planning process began with the formation of technical working teams, known as Cross-Sectoral Planning Groups (CSPGs) organized around the five thematic areas of GPRS I, namely:

- Macroeconomic Stability

- Production and Gainful Employment

- Human Development and Provision of Basic Services

- Vulnerability and Exclusion and

- Good Governance

These five CPSGs metamorphosed into three at the later stages of the process on the basis of the three priority areas of Government, namely Private Sector Competitiveness, Human Resource Development and Good Governance.

\subsubsection{Composition and Terms of Reference of Cross Sectoral Planning Groups (CSPGs)}

CSPGs were composed of state and non-state actors drawn from Ministries, Departments and Agencies (MDAs), Professional Bodies, Tertiary Institutions, Research Institutions and Think Tanks, Non-Governmental Organizations (NGO), Community-Based Organizations (CBO), Private Sector, Organised Groups and Associations (TUC, Federation for the Blind \& Disabled etc), Specialized Institutions, outstanding individuals with expertise in relevant fields as well as Development Partners.

Each CSPG was chaired by an individual selected by the group and was facilitated by a consultant who provided the technical backstopping and expertise, assisted by a research associate. Consistent with the MDGs requirement to ensure integration of environment in country's policies and programmes (MDG 7 - Target 9), the SEA team of EPA/NDPC was represented on each CSPG. Each CSPG formed a core working group who collated reports on deliberations of that particular CSPG and drafted the report of the CSPG. Coordination of the process was done by technical staff of the NDPC secretariat

Issues relating to gender and the vulnerability and exclusion were mainstreamed into each of the thematic areas.

The Broad Terms of Reference of each CSPG were to:

- determine the programmes, policies and plans to be rolled over from GPRS I to the updated GPRS 2006-2009

- review the policies, programmes and projects with a view to identifying any missing links, and propose new initiatives

- take into consideration recommendations from the Annual Progress Report (APR), the Poverty and Social Impact Analysis (PSIA), the Strategic Environmental Assessment (SEA), and other existing sector strategies and studies 
- mainstream cross-cutting issues such as the environment, employment, ICT, disability, HIV/AIDS, and population into the thematic areas

- integrate international commitments such as the MDGs, the Millennium Challenge Account (MCA) NEPAD, PRSC, and MDBS into the various thematic areas.

- identify national priorities for the theme under consideration

- develop relevant strategies for achieving the objectives in the GPRS II.

\subsubsection{The Public Consultation Process}

The public consultations strategy for GPRS II was aimed at consolidating the gains made in the dissemination of GPRS I through the use of vigorous print and electronic media campaigns as well as other communications media to achieve the twin objectives of creating awareness about the GPRS, and soliciting the views of a large segment of the Ghanaian population as input into the GPRS II.

\section{The Strategic Objectives for Public Consultations Programme}

The strategic objectives for the public consultation programme were to:

- inform the public on the Government's Growth and Poverty Reduction Agenda

- highlight the new policy areas of GPRS II for stakeholders

- $\quad$ solicit their views on priorities for GPRS II,

- promote ownership of GPRS II by all Ghanaians.

From the Public Consultation Process, broad consensus was obtained on the following priorities which should drive the design and implementation of GPRS II

- private Sector Competitiveness

- human Resource Development

- good Governance and Civic Responsibility

The policies and strategies related to the Vulnerable and Excluded were mainstreamed among other cross-cutting issues.

\section{Scope and Methodology for the Public Consultation Process}

The scope and method used for the public consultation process included:

- National, Regional, District and community level workshops

- Use of the electronic media (radio and television)

- Public fora

- Focus group discussions 


\section{Groups Targeted in the Consultation Process}

- Regional Ministers

- Sector Ministers and their Deputies

- Sector Ministers and their deputies

- Council of State

- Regional Coordinating Directors

- Regional Planning Coordinating Units

- District Chief Executives

- District Planning Coordinating Units

- District Assembly members

- Traditional Authorities

- Community Based Organizations

- Community Groups

- The Communications Media

- Professional Bodies
- Student Unions

- Women leaders/Coalition of Women's Groups and Women's organizations

- NGOs in Service Delivery and Religious Bodies

- National Association of Local Authorities

- Ghana Employers Association

- Association of Ghana Industries

- The Trades Union Congress

- Research Institutions and Policy Think Tanks

- Parliament

- Political parties

- Development partners

\subsection{THE GPRS COMMUNICATION PROGRAMME}

Feedback from the dissemination of the GPRS I and the Annual Progress Reports as well as the public consultations have been integrated in GPRS II. Communications under GPRS II will be enhanced through the continued implementation of the Communications Strategy to deepen ownership and to ensure effective implementation, monitoring and evaluation of the strategy.

The Communications Programme will focus on the following:

- development of popular versions of GPRS II (in English and major local languages)

- expansion of sales outlets of GPRS II throughout the country

- extensive dissemination of GPRS II through a variety of media to targeted audiences outlined in the Communications Strategy.

- forging and strengthening of strategic partnerships with state and non state actors for effective coordination of the dissemination of GPRS II and its Annual Progress Reports, management of expectations and feedback for the policy review process, and

- deepening of development communications programmes and processes to foster the necessary attitudinal change in support of growth and poverty reduction. 
Table 1.3: Chronology of Activities

\begin{tabular}{|c|c|c|c|}
\hline \multicolumn{2}{|r|}{ ACTIVITY } & \multirow{2}{*}{$\begin{array}{l}\text { PARTICIPANTS } \\
\text { MDAs, CSOs, CBOs, NGOs, Private Sector, } \\
\text { Professional Associations, Tertiary \& Research } \\
\text { Institutions, Development Partners, etc. }\end{array}$} & \multirow{2}{*}{$\begin{array}{l}\text { DATE } \\
\text { September } 2004 \text { - May } \\
2005\end{array}$} \\
\hline 1. & $\begin{array}{l}\text { Formation and meetings of Cross Sectoral } \\
\text { Planning Groups (CSPGs) }\end{array}$ & & \\
\hline 2. & $\begin{array}{l}\text { Preparation of initial report for each } \\
\text { thematic area }\end{array}$ & CSPG core working groups and consultants & $\begin{array}{l}\text { September - December } \\
2004\end{array}$ \\
\hline 3. & $\begin{array}{l}\text { First review and validation by Steering } \\
\text { Committee }\end{array}$ & NDPC members & December 2004 \\
\hline 4. & $\begin{array}{l}\text { Second validation and review by Steering } \\
\text { Committee }\end{array}$ & NDPC members & January 2005 \\
\hline 5. & $\begin{array}{l}\text { Gender Mainstreaming stakeholder } \\
\text { workshop }\end{array}$ & $\begin{array}{l}\text { Gender focal persons in MDAs, DPs, Groups, } \\
\text { CSOs, NGOs }\end{array}$ & February 2005 \\
\hline 6 & Preparation of zero draft of GPRS II & CSPG core groups and consultants & March 2005 \\
\hline 7. & $\begin{array}{l}\text { Validation by Policy Management teams of } \\
\text { MDAs, DPs and Specialists }\end{array}$ & $\begin{array}{l}\text { MDAs, DPs, Specialists institutions and } \\
\text { individuals }\end{array}$ & April 2005 \\
\hline 8. & $\begin{array}{l}\text { Review of Gender input into thematic } \\
\text { reports }\end{array}$ & Gender Consultative Groups & April - May 2005 \\
\hline 9. & $\begin{array}{l}\text { Third review and validation by Steering } \\
\text { Committee }\end{array}$ & NDPC members & April 2005 \\
\hline 10 & Submission of zero draft to Parliament & All Members of Parliament & April 2005 \\
\hline 11. & Regional and District level Consultations & $\begin{array}{l}\text { RCCs, DAs, CSOs ( Professional Associations, } \\
\text { labour unions, trade association, women's } \\
\text { organisations, NGOs, etc and Traditional } \\
\text { authorities }\end{array}$ & May - June 2005 \\
\hline 11 & $\begin{array}{l}\text { Consultative workshop for Parliamentary } \\
\text { select committees }\end{array}$ & $\begin{array}{l}\text { Parliamentary sub-committees on Finance and } \\
\text { Poverty Reduction }\end{array}$ & June 2005 \\
\hline 12. & Training workshop for 2006 budget & Budget Officers, Ministry of Finance & June 2005 \\
\hline 13. & $\begin{array}{l}\text { Policy review workshop with MTEF/ } \\
\text { Budget Division }\end{array}$ & Budget officers of MDAs & June 2005 \\
\hline 14. & $\begin{array}{l}\text { Fourth review and validation by Steering } \\
\text { Committee }\end{array}$ & NDPC members & June 2005 \\
\hline 15. & $\begin{array}{l}\text { Review and validation of Gender } \\
\text { mainstreaming into draft GPRS II }\end{array}$ & UNIFEM Mission & July 2005 \\
\hline 16. & National level Consultations & $\begin{array}{l}\text { Student un ions, FBOs, Labour unions, Trade } \\
\text { associations, Professional associations, National } \\
\text { House of Chiefs, Council of State, Media }\end{array}$ & July - October 2005 \\
\hline 17. & Consultative workshop & Ghana Federation of the Disabled (GFD) & July 2005 \\
\hline 18 & $\begin{array}{l}\text { Fifth review and validation by Steering } \\
\text { Committee }\end{array}$ & NDPC members & July 2005 \\
\hline 19 & $\begin{array}{l}\text { Review and validation by experts and } \\
\text { private sector }\end{array}$ & $\begin{array}{l}\text { Policy think thanks, ISSER, private consultants, } \\
\text { PEF, Financial institutions }\end{array}$ & August 2005 \\
\hline 19. & $\begin{array}{l}\text { Validation workshop for Parliamentary } \\
\text { select Committee }\end{array}$ & $\begin{array}{l}\text { Members of Parliamentary select committee on } \\
\text { Poverty Reduction }\end{array}$ & August 2005 \\
\hline 20 & $\begin{array}{l}\text { Submission of Final Draft to Cabinet } \\
\text { Committees }\end{array}$ & Oversight, Finance and Economy Committees & August 2005 \\
\hline 21 & Costing of programmes and projects & MDAs organised around the three main pillars & April - November, 2005 \\
\hline 22. & National indicator workshops & MDAs (CSPG members) and Group consultants & Aug. 2005 - January 2006 \\
\hline 23 & Submission of Final Draft to Cabinet & Full Cabinet & September 2005 \\
\hline 24 & Meeting with Development Partners & Heads of Missions and Agencies & September 2005 \\
\hline 25 & Submission to Parliament & All Members of Parliament & October 2005 \\
\hline 26 & Consultative Group Meeting & DPs, GOG, MPs CSOs, NGos, Private sector & November 2005 \\
\hline
\end{tabular}




\section{CHAPTER TWO}

\section{MACROECONOMIC CONTEXT AND STRATEGIC DIRECTION}

\section{$2.1 \quad$ INTRODUCTION}

This chapter sets the macroeconomic context and strategic direction for the implementation of GPRS II based on a review of the performance of the macro-economy in the recent past and identifies critical areas of intervention that would have maximum impact on accelerated growth and poverty reduction.

\subsection{REVIEW OF MACROECONOMIC PERFORMANCE UNDER GPRS I}

The policy thrust of the macroeconomic framework under GPRS I was towards promoting macroeconomic stability for sustainable economic growth and poverty reduction. Substantial progress was made towards the realization of macroeconomic stability. Indicators point to a reduction of inflation (year on year), from 40.5 percent in December 2000 to 11.8 percent by December 2004. Interest rates fell and the prime rate was reduced from 24 percent in 2003 to 15.5 percent by the third quarter of 2005. This decline in the prime rate has been accompanied by consequential reduction in the rates on other money market instruments including the 91-day treasury bill. The exchange rate was stable, depreciating at 2.2 percent against the dollar in 2004 as compared to 49.8 percent in 2000 , the lowest since the foreign exchange market was liberalised. GDP grew at an average rate of 5 percent during the four-year period (2001-2004) compared with 4.1 percent in the preceding three years. This growth was led by the agricultural sector (5.5 percent), followed by industry (5.0 percent) and services ( 4.7 percent).

Relative stability of the economy was achieved in spite of the fact that Ghana's main exports, cocoa and gold, as well as its major import, crude oil, have been subject to the volatile movements in international commodity pricing. Table 2.1 shows trends in selected macroeconomic indicators for the 2001-2004 period. 
Table 2.1: Selected Key Economic Indicators

\begin{tabular}{|l|c|c|c|c|}
\hline Selected Key Economic Indicator $(\boldsymbol{\%})$ & $\mathbf{2 0 0 1}$ & $\mathbf{2 0 0 2}$ & $\mathbf{2 0 0 3}$ & $\mathbf{2 0 0 4}$ \\
\hline End-Period CPI Inflation Rate & 21.3 & 15.2 & 23.6 & 11.8 \\
\hline Nominal Exchange rate of Depreciation $(\phi / \$)$ & 3.7 & $15 . .9$ & 4.9 & 2.2 \\
\hline Real Savings Rate of Interest & -6.8 & $-2-2$ & -12.25 & -2.81 \\
\hline Tax Revenue/GDP & 17.2 & 18.2 & 20.2 & 21.8 \\
\hline Budget Deficit Excluding Grants/GDP & 13.1 & 7.9 & 7.7 & 3.2 \\
\hline BOG Financing of Deficit/Tax Revenue & 0.0 & 12.1 & 0.0 & 2.5 \\
\hline Gross International Reserves & 1.2 & 2.7 & 4.2 & 3.9 \\
\hline GDP Growth Rate & 4.2 & 4.5 & 5.2 & 5.8 \\
\hline
\end{tabular}

Source: Bank of Ghana, Economic and Financial Review, January 2005, Monetary Policy Committee Papers Ghana Statistical Service

\subsubsection{Economic Performance by Sectors}

\section{(i) Agriculture}

Tables 2.2 and 2.3 show the relative structure of Gross Domestic Product by economic activity between 2000 and 2004 (in percentages and growth rates at constant 1993 prices). Agriculture remains the largest contributor to GDP, followed by the services and industrial sectors respectively. Within the agricultural sector, the cocoa and forestry sub-sectors have made significant gains in relative shares, while the crops sub-sector has marginally lost share.

In spite of the progress made in agriculture, the stagnation of technologies and in some areas the wide gender inequalities in access to and control over land and agricultural inputs, including extension services, as well as adverse environmental factors such as climate variability and land/soil degradation, continue to be challenges posed to the growth potential of the agricultural sector.

\section{(ii) Industry}

The industrial sector exhibited low performance, against the projected targets in GPRS I. Despite the overall poor performance of the sector, the construction, mining and quarrying sub-sectors made significant strides. This was the result of increased investments, especially in the roads and real estates sub-sectors of the economy where funding support from both local financial markets and remittances as well as Government and donor sources were available.

Growth in the mining sub-sector, particularly gold, was largely due to substantial infusion of capital from both local and external sources aided by the stable environment created by the institution of 
policies that have insulated earnings and costs from foreign exchange controls.

The manufacturing sub-sector continued to decline due largely to high costs of production and the influx of cheaper imports. While the liberalization of trade has increased access to imported inputs, weak enforcement of laws and regulations at the nation's entry points has resulted in increasingly unfair trade practices. As a result, locally manufactured products have become increasingly uncompetitive, both in terms of price and quality.

\section{(iii) Services}

The services sector also contributed to the modest gains in GDP growth. This sector is driven by the wholesale and retail trade, as well as restaurants and hotels sub-sectors, which together accounts for about 60 percent of the contribution of all services to total production in the economy.

Table 2.2: Structure of GDP by Kind of Economic Activity in Percentages

\begin{tabular}{|c|c|c|c|c|c|}
\hline Economic Sector & 2000 & 2001 & 2002 & 2003 & 2004 \\
\hline \begin{tabular}{|l|} 
Agriculture \\
\end{tabular} & 35.27 & 35.24 & 35.15 & 36.38 & 37.94 \\
\hline Crops And Livestock & 22.01 & 22.25 & 22.43 & 22.35 & 22.12 \\
\hline Cocoa Sub-sector & 4.81 & 4.58 & 4.36 & 5.77 & 7.60 \\
\hline Forestry \& Logging & 3.89 & 3.92 & 3.94 & 3.95 & 3.98 \\
\hline Fishing & 4.57 & 4.49 & 4.42 & 4.30 & 4.24 \\
\hline Industry & 25.40 & 25.22 & 25.28 & 25.10 & 24.74 \\
\hline Mining \& Quarrying & 4.98 & 4.72 & 4.72 & 4.68 & 4.59 \\
\hline Manufacturing & 9.02 & 9.00 & 9.03 & 8.94 & 8.75 \\
\hline Electricity \& Water & 2.69 & 2.70 & 2.69 & 2.66 & 2.59 \\
\hline Construction & 8.71 & 8.79 & 8.83 & 8.79 & 8.8 \\
\hline Services & 28.82 & 29.16 & 29.21 & 28.94 & 28.65 \\
\hline Transport, Storage \& Communication & 4.29 & 4.36 & 4.41 & 4.41 & 4.44 \\
\hline Wholesale, Retail Trade Restaurants \& Hotels & 6.72 & 6.80 & 6.87 & 6.82 & 6.81 \\
\hline Financial \& Business Services and Real Estate & 4.26 & 4.28 & 4.32 & 4.30 & 4.29 \\
\hline Government Services & 10.06 & 10.17 & 10.08 & 9.92 & 9.69 \\
\hline Community, Social \& Personal Services & 2.56 & 2.62 & 2.62 & 2.58 & 2.56 \\
\hline Producers Of Private Non-private Services & 0.94 & 0.93 & 0.92 & 0.90 & 0.87 \\
\hline Net Indirect Taxes & 10.51 & 10.38 & 10.36 & 9.14 & 8.66 \\
\hline GDP In Purchasers Value & 100.00 & 100.00 & 100.00 & 100.00 & 100 \\
\hline
\end{tabular}

Source: Ghana Statistical Service 
Table 2.3: GDP by Kind of Economic Activity: Growth Rates at Constant 1993 Prices

\begin{tabular}{|c|c|c|c|c|c|}
\hline Economic Sector & 2000 & 2001 & 2002 & 2003 & 2004 \\
\hline \begin{tabular}{|l|} 
Agriculture \\
\end{tabular} & 2.1 & 4 & 4.4 & 6.1 & 7.5 \\
\hline Crops And Livestock & 1.1 & 5 & 5.2 & 5.3 & 5.3 \\
\hline Cocoa Sub-sector & 6.2 & -1 & -0.5 & 16.4 & 29.9 \\
\hline Forestry \& Logging & 11.1 & 4.8 & 5 & 6.1 & 5.8 \\
\hline Fishing & -1.6 & 2 & 2.8 & 3 & 3.5 \\
\hline Industry & 3.8 & 2.9 & 47 & 5.1 & 5.1 \\
\hline Mining \& Quarrying & 1.5 & -1.6 & 4.5 & 4.7 & 4.5 \\
\hline Manufacturing & 3.8 & 3.7 & 4.8 & 4.6 & 4.6 \\
\hline Electricity \& Water & 4.5 & 4.2 & 4.1 & 4.2 & 3.7 \\
\hline Construction & 5.1 & 4.8 & 5 & 6.1 & 6.6 \\
\hline Services & 5.4 & 5.1 & 4.7 & 4.7 & 4.7 \\
\hline Transport, Storage \& Communication & 6 & 5.5 & 5.7 & 5.8 & 5.8 \\
\hline Wholesale, Retail Trade Restaurants \& Hotels & 4 & 5.1 & 5.6 & 5 & 4.9 \\
\hline Financial \& Business Services and Real Estate & 5 & 4.5 & 5.6 & 5.2 & 4.8 \\
\hline Government Services & 6 & 5 & 3.6 & 4 & 4.4 \\
\hline Community, Social \& Personal Services & 6.9 & 6.5 & 4.4 & 4.1 & 4.2 \\
\hline Producers Of Private Non-private Services & 3.1 & 3.2 & 3.1 & 3.2 & 3.5 \\
\hline Net Indirect Taxes & 5 & 5.4 & 4.3 & 4.4 & 4.3 \\
\hline GDP In Purchasers Value & 3.7 & 4.2 & 4.5 & 5.2 & 5.8 \\
\hline
\end{tabular}

Source: Ghana Statistical Service

Although the financial services sub-sector made significant gains between 2001-2004, this did not impact sufficiently on the agricultural and manufacturing sectors. Generally the financial institutions have considered local manufacturing and agricultural enterprises as risky undertakings; this is of particular concern because of the adverse effect on small-scale farmers, especially women, who constitute the majority of the rural poor. On the other hand, the bulk of bank credit has been channelled to commercial activities, especially those involving import trade, at the expense of those sectors which could potentially serve as growth points to lead the required accelerated growth ${ }^{2}$.

To ensure the availability of credit to the potential growth points of the economy, government has

\footnotetext{
${ }^{2}$ The most recent trend however indicates that credit to the manufacturing sector is on the increase. A number of banks are now setting up specialized SME units to coordinate financial support to local industry and agriculture.
} 
established special institutions such as Export Development and Investment Fund (EDIF), the Presidential Special Initiatives (PSIs), the Micro Credit Unit and the Women's Development Fund (WDF) to support financially marginalized enterprises. Although these schemes are yet to show fully their potential impact on overall economic growth, they indicate the fact that institutional credit is not sufficiently available to most micro, small and medium scale enterprises in Ghana, particularly those that involve women and the rural population.

\subsubsection{Growth Trends since the Inception of Market-Led Development Strategy}

Figure 2.1 shows real GDP growth rates for the period 1984-2004 following the inception of market-led development strategy in 1983. For the period 2002-2004 under GPRS I, the annual average growth rate of real GDP was 5.2 per cent. This is a marked improvement on the historical trend, and equal only to the average of the period 1984-1992.

Table 2.4 shows government's targeted real GDP growth rates against realized rates between 1995 and 2004. The trend in real GDP growth rates shows marked shortfalls between the targets and performance from 1995 till 2000. Between 2001 and 2004, actual real GDP growth rates either equaled or exceeded the targets. In 2004, the target was 5.2 percent while the actual growth rate was 5.8 percent, the most impressive performance since the 8.6 percent real GDP growth rate recorded in 1984. This indicates a potential for achieving higher rates in GDP growth.

From these analyses, the following observations are made:

- the high economic growth rates was led by the agricultural sector under GPRS I.

- within the Agricultural sector cocoa was the dominant contributor to growth while other branches remained relatively stagnant.

- overall, the basic structure of the economy has not changed and Ghana's economy is still fragile and vulnerable to external shocks

- the level of growth which occurred has not been sufficiently high enough to support a mark reduction of poverty

- the growth points of the various sectors of the economy do not have effective inter- sectoral linkages within the domestic economy. In particular, the agriculture- industry - consumer value chain remains weak and has not generated much opportunity for additional employment.

- cocoa, forestry, mining, wholesale and retail trading, and hotels/tourism, which have been the principal growth points in the economy are largely linked to the external sector, and are subject to potential risks and shocks arising from international price movement.

- it can however be argued, in retrospect, that the growth targets for 2001-2004 have not been ambitious enough when measured against the 4.8 per cent annual average already been attained in the 1984-2004 period as a whole.

These observations inform the formulation of macroeconomic policies and growth strategies for GPRS II. 
Figure 2.1: GDP Growth Rates: 1984 - 2004

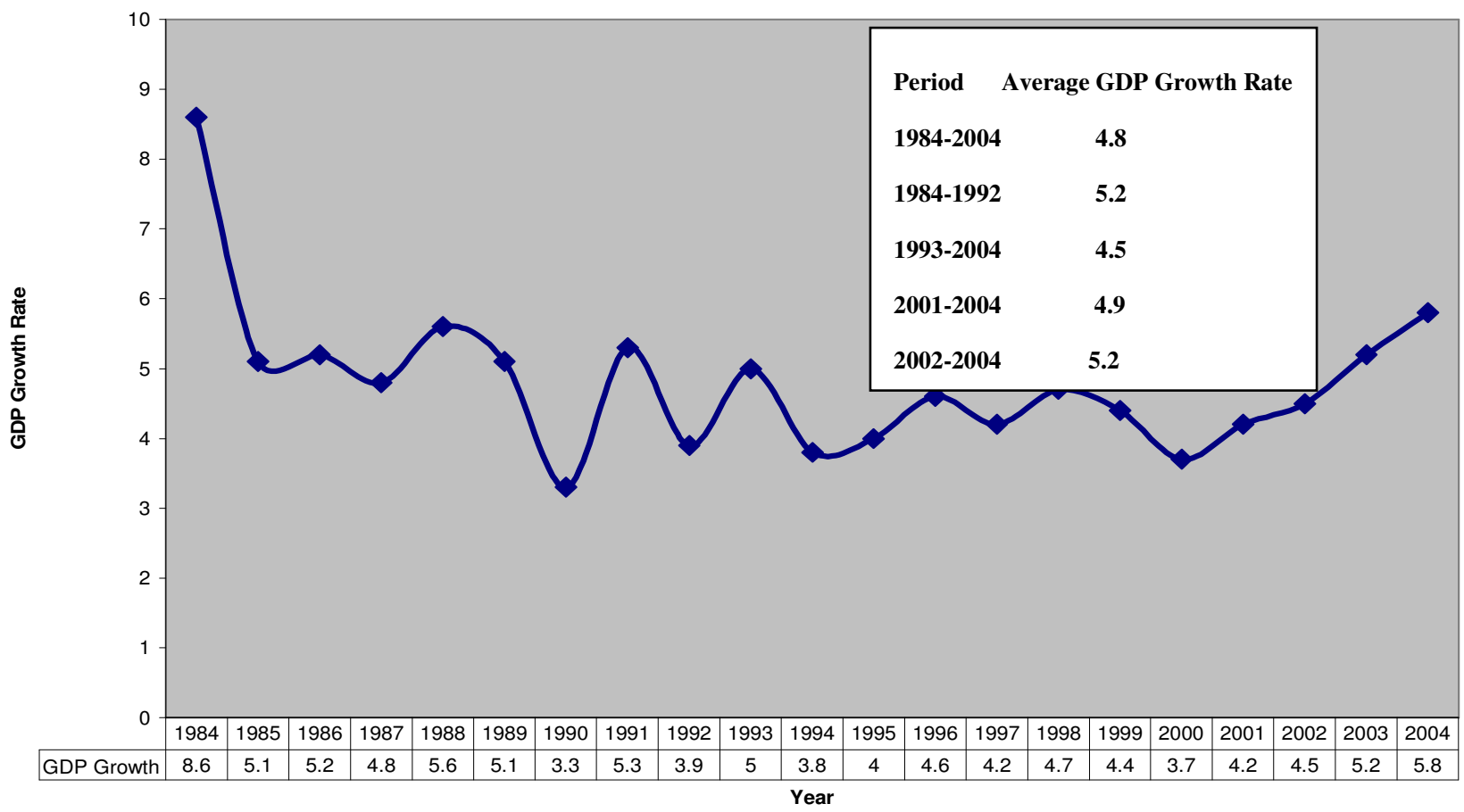

Source: Budget Statement and Economic Policy Statement, Various Years

Table 2.4: Projected Real GDP versus Actual Real GDP Growth Rates: 1995 - 2004

\begin{tabular}{|l|l|l|c|}
\hline Year & $\begin{array}{l}\text { Projected Real GDP } \\
\text { Target }\end{array}$ & $\begin{array}{l}\text { Actual Real GDP Growth } \\
\text { Rate }\end{array}$ & $\begin{array}{l}\text { Difference Between } \\
\text { Estimate And Actual }\end{array}$ \\
\hline 1995 & 5 & 4 & -1 \\
\hline 1996 & 5 & 4.6 & -0.4 \\
\hline 1997 & 5.5 & 4.2 & -1.3 \\
\hline 1998 & 5.6 & 4.7 & -0.9 \\
\hline 1999 & 5.5 & 4.4 & $-1-1$ \\
\hline 2000 & 5 & 3.7 & -2.3 \\
\hline 2001 & 4 & 4.2 & 0.2 \\
\hline 2002 & 4.5 & 4.5 & 0 \\
\hline 2003 & 4.7 & 5.2 & 0.5 \\
\hline 2004 & 5.2 & 5.8 & 0.6 \\
\hline
\end{tabular}

Source: Ghana Statistical Service 


\subsection{MACROECONOMIC POLICIES, STRATEGIES AND TARGETS FOR GPRS II}

\subsubsection{Growth Target for GPRS II}

GPRS II is guided by the overall objective of doubling the size of the Ghana economy (in terms of real production) within the next decade, and bringing the per capita income of the average Ghanaian to middle income level by 2015. This is expected to reflect in positive social change and improvement in the quality of life for all. It is in this regard that the growth targets are made taking cognizance of the corresponding objectives of NEPAD and MDGs, all of which specify some qualitative indices. These qualitative improvements are the really important objectives of the process of national development for the enhancement of human welfare and are the real substance of development policy.

As a guide to target setting, the current World Bank practice draws the line for concessionary IDAlending, which is for the benefit of "low-income" countries at US\$965 per capita per annum. Above that level (with a few marginal exceptions) countries are regarded as "middle-income" and only eligible to borrow from the Bank on IBRD terms which are only a modification of the terms of credit on the private capital markets. On the World Bank scale Ghana is today rated at a level of $\$ 380$, which reveals the challenging gap which must be overcome in attaining middle income status.

In developmental terms, middle income countries are characterized not only by the relatively high dollar value of their production, but also the following attributes:

i. achieved international competitiveness in one or multiple aspects of the global trade in industrial or service products

ii. supported by a significant level of "scientific autonomy" which is reflected in their application of science and technology in their production processes and their ownership of intellectual property

iii. attainment of critical mass in economic propulsion, with high rates of domestic savings and investments, and the ability to tap into the worldwide pools of equity and loan capital

A narrow definition of our growth targets for the GPRS II period is $6-8 \%$ GDP per annum, but this must be firmly situated within the perspective of changing the inherent structure of production and joining the march of technological progress.

\section{Assumptions}

The economic growth targets derived from the current level of development and the feasible expectations in the long term perspective of the economy are based on the following assumptions:

- the population growth rate will not exceed 2.6 per cent per annum, through the population management policies and strategies outlined in the sections on human resources 
development

- macroeconomic stability, especially by containing inflation within single digit as from 2006 from the current rate of about 14.7 percent (August 2005). Accordingly, it is expected that the average annual change in the GDP deflator will not exceed 9 percent

- a stable Cedi/ Dollar exchange rate with prudent management that will keep the Cedi depreciation below a 4 percent per annum ceiling

- reduced cost of investment loans as incentives for stimulating investment in support of private sector-led growth. This is expected to be the dividend from sound macroeconomic management, and also reflect the reduction in risk factors that make loans to SMEs unattractive to banks

- containment of fiscal deficits and preventing them from being a major source of monetary instability and price inflation. Two years after gaining a very favourable rating from leading agencies, Ghana is preparing to tap into the international capital market to supplement access to developmental resources. Prudent, debt management will entail taking into account the maturity profiles of debt against public sector borrowing requirements

- an aggressive domestic revenue mobilization and its efficient use in driving the prioritized development targets. This is to be attained through administrative measures and enhancing the capacity of existing tax collection instruments and personnel

- an efficient expenditure re-prioritization in favour of development expenditure and to ensure efficiency in the use of public resources

- growth in aggregate investment, especially from packaged programmes such as the Millennium Challenge Account Compact with its integrated agro-based projects

The strategies for realizing these macroeconomic assumptions are outlined in section 5.6

\section{Targets}

Within the parameters of these general assumptions, it is targeted that the economy grows at an annual rate which will rise from 6 percent to 8 percent towards the realization of middle income status by 2015 (Table $2.5 \& 2.6$ ). The narrow definition of our growth targets for the GPRS II must be firmly situated within the perspective of changing the inherent structure of production and joining the march of technological progress.

Compared to the realized average growth rate of 4.9 percent for the period 2001-2004, the targeted average growth rate of 6 to 8 percent and the sub-sectoral growth rates that could lead to middle income status pose a challenge to Ghanaians. These targeted growth rates are achievable with the 
right macroeconomic policies, incentive structures and the input requirements to support the private sector as the engine of wealth creation and poverty reduction.

Above all, whether Ghana realises the higher or only the lower ends of her growth potential will depend on two factors, namely,

i. the implementation of a broad-based human resource development strategy including the measures envisaged in both the education and public sector reform programmes.

ii. opening of the channels between Ghana and the global capital markets so that both loanable funds, and equity investment which carries in its train the skills of management, science and technology, will flow more freely into the economy.

\subsubsection{Strategic Direction of GPRS II}

Accelerated growth of the economy will result from continued macroeconomic stability, a vibrant private sector, vigorous human resource development underpinned by deepening good governance and civic responsibility.

GPRS II will continue with the implementation of policies that will enhance and sustain the gains made in macroeconomic stability under GPRS I by ensuring:

- prudent fiscal policy management

- a monetary policy that is flexible enough to respond to external shocks, promote growth and ensure price stability

- real interest rates that enhance effective mobilisation of savings and make credits affordable to the private sector

- relatively stable real exchange rates that promote international trade

GPRS II will further address the structural constraints at the policy and institutional levels that impede increased productivity, adoption of technology and competitiveness of the private sector in relation to agriculture, industry and service sectors. This will empower the private sector to effectively play its role as the engine of wealth creation and poverty reduction.

Although the implementation of the proposed macroeconomic measures will contribute to achieving the growth targets it is recognised that their impact on various groups may not be at the same level. To improve upon macroeconomic policy design, poverty and social impact analysis (PSIA) will be conducted to asses the impact of policies on the poor. All impact analysis will contain a gender dimension.

While projections of sectoral contributions to GDP generally assume that natural assets will continue to contribute significantly to economic growth, an ongoing study to determine the costs of degradation of 
some renewable natural resources in relation to GDP points to the fact that the country may be losing about US $\$ 475$ million annually which is approximately $5.5 \%$ of GDP. There is the therefore need to recognise the problem and initiate steps to reverse this trend in order to sustain the agriculture-led accelerated growth strategy envisaged in this framework.

\subsubsection{Agriculture as Basis for Economic Growth and Structural Transformation}

Economic growth and structural transformation is to be propelled by the agricultural sector in order to maximize the benefits of accelerated growth. The emphasis on agriculture-led growth strategy is predicated on a number of factors.

First, agriculture is the highest contributor to GDP and provides employment for over 60 percent of the population. Consequently growth in the sector will impact directly on growth of the economy as well as employment. Conversely, the economy cannot make overall progress unless the mass of small-scale food producers achieve significant improvement in their productivity through increased investment and changes in technology.

Secondly, the bulk of the poor, especially women, are engaged in agriculture - food crops, livestock and fisheries. Therefore accelerated development in agriculture will have direct benefit on poverty reduction in the villages and help to slow-down the rural-urban drift.

Thirdly, increased productivity in agriculture will ensure food security and contribute immensely to health and well being of the population.

Fourthly, modernized agriculture will also prepare the ground for structural transformation between agriculture and industry. The demands of the markets for agricultural produce in whose production Ghana has comparative advantage entail the achievement of additional steps: the occurrence of volume and quality, packaging and conservation, marketing and delivery. Only through these can Ghana's farmers realize higher incomes from both local and foreign sources

Fifth, while the rural areas can be expected to lose population share to urban areas as part of the long-range perspective of economic growth, a pressing social problem of Ghana today is the acute shortage of employment opportunities for the youth. Given the pervasive shortage of capital the quickest route to the solution of a problem that cannot wait is to absorb a maximum number of these in higher productivity and higher income farming pursuits.

Thus in the next few years the growth of the economy is planned to be led by the agricultural sector, which will provide the necessary inputs for a vibrant agro-processing industrial sector in the medium to long term. The security of Ghana's domestic food supply is itself yet to be attained. But in addition, the areas of Ghana's comparative advantage in agricultural production should be enhanced and transformed into competitive advantage in the sub-regional and more distant markets.

For agriculture to lead growth in the short term, the economy must diversify into other crops apart from the traditional cocoa, especially cereals and other cash crops for export markets including 
mangoes, papaya, pineapples, cashew nuts and vegetables. Cocoa will still be significant in the economy for decades yet to come. The recent spurt in Ghana's cocoa production, arising in part from the rapid adoption of improved technology by the farmers, illustrates the developmental potential of our cocoa entrepreneurs, land and workers. Besides, new scientific evidence on the nutritional and health properties of cocoa, present opportunities which Ghana should prepare herself to exploit.

Nevertheless, more attention has to be given to these other crops. The decline in Ghana's fisheries which still provides the major part of the national protein intake has to be reversed by increased investments in aqua-culture among other technological improvements. All these will contribute to the structural transformation of the economy, but more importantly the objective is to target the bulk of the poor farmers who are in the non-cocoa sectors of agriculture, and thereby realize better shared growth. Given the immensity of Ghana's underutilized resources available for agriculture land, sunlight, water and able-bodied youth - some of these targets in the diversification of agriculture could be rapidly implemented. The urgency of this is reinforced by the need to develop mechanisms to absorb the shocks arising from variability in the world pricing mechanism, especially of raw material and petroleum.

\section{Box 2.1: Converting Comparative Advantage in Crop Production into Competitive Advantage}

Ghana has demonstrated that it can convert its comparative advantage into strong competitive advantage in crop production, especially as regards cashew nuts, mangoes, pineapple, papaya and vegetables. For instance in the 2005 Budget it was announced that in order to improve crop production, the Ministry of Food And Agriculture provided farmers with improved seeds and planting materials under the 5 Donor Assisted projects, currently being implemented in the crop sub-sector. About 9,000 plantlets of the MD2 pineapple cultivars were distributed to farmers to help Ghanaian farmers compete in the new popular MD2 variety of pineapple, which has gained European market share. Similarly, a total of 23 tonnes of improved cashew seeds were distributed to farmers. These will go to boost Ghana's crop production for exports. Indications are that papaya is another excellent crop for Ghana's competitive potential. Europe is currently importing approximately 40,000 tons of golden papaya per year and Brazil supplies 9 percent of this market. Market trends show that these 40,000 tons will increase to about 100,000 tons in the next five years which is worth hundreds of millions of dollars. The potential to capture a sizeable portion of the market exist. Not only is Ghana closer to Europe than Brazil, but has sweeter golden specie of papaya and can therefore focus on the European market. Ghana can convert its comparative advantage into competitive advantage through improved shipment, compliance with GhanaGap, large-scale irrigation production, and infrastructure development to enhance supply chain etc. and capture a significant portion of the European market for papaya.

\subsubsection{Weaknesses and Threats to an Agriculture-Led Strategy}

A number of factors limit optimal production in agriculture, especially production of crops, livestock and fisheries. Agriculture as a whole will always be dependent on natural conditions. Rainfall is unreliable with regard to its onset, duration, intensity and amount, and can disrupt food crop production. The failure of development policy over decades is that Ghana has not 
implemented accessible and easily affordable technologies to overcome these deficits. Ghana is not in the Sahel zone. There is no shortage of rain volumes even in the driest savannah for abundant and secure food production year after year. What is lacking is a systematic policy to conserve and utilise ample rainfall in all parts of the country. Some efforts in this direction have been frustrated by the choice of inappropriate technology. The example of Burkina Faso shows that simpler and cheaper technologies for the harvesting and use of our rain water endowments could yield Ghana immense benefits in agricultural productivity and poverty reduction. Additional risks in an agriculture-based strategy include bushfires, post harvest losses and uncertainties, storage, transportation and marketing problems. An equally important constraint is the dearth of affordable credit in agriculture. Even in the flagship of the cocoa sector, the only credit that was ever available from the organised bank in the system was via the short-term seasonal credit of the foreign buying companies. Food crops still do not have adequate marketing and financial support. For the producers, this makes crop farming a high-risk enterprise and in a vicious circular relationship, it also makes a high-risk field for its traders and bankers. Strenuous government intervention is the only way to break the cycle and attenuate the risks on both sides so that the private sector moves in our present development paradigm can successfully perform their roles in moving Ghana's agriculture forward.

Variability in the natural conditions also adversely affect the livestock and fisheries sub-sectors in ways similar to that of crop farming. Under the GPRS II many interventions have to be carried out at public expense to overcome the disabilities that hinders growth.

Consequently, in order to achieve accelerated growth in Ghana's agriculture a number of key interventions will be initiated to support agricultural productivity. These include strategic research and development activities, appropriate financing for the sector, value addition and improved marketing, efficient organization of production, and enhanced capacity of producers.

In the area of crop production in particular, the following measures will be pursued:

- ensure women's access to and control over land and agricultural inputs, including extension services

- promote and support large scale farming and nucleus out-grower schemes for production of targeted/selected crops

- enhance the productivity of small scale farmers by securing their access to extension, storage, price stability, credit, markets and land. Women small holder producers of food crops will be given needed impetus to improve their livelihood and assisted to benefit from the potential positive effects of linkages between agriculture, industry and exports

- develop and use improved seeds/planting materials

- intensify research-extension-farmer linkages to ensure that technologies are developed and disseminated appropriately to meet world-wide market standards

- promote and support the use of weights and measures as well as grades and standards in the marketing of commodities so as to enhance commercial efficiency

- strengthen farmer-based organizations, with full participation of women farmers, to enhance access to credit and other services. The emasculation of the Ghana Cooperative movement, which had previously attained a pre-eminent position in cocoa marketing and the national 
savings

- improve storage/warehousing and distribution network, including refrigerated transport systems and cold storage facilities at the ports

- improve rural infrastructural network, particularly road-rail linkages

- promote the culture of community-based irrigation in order to move agriculture from reliance on the vagaries of the weather to a more scientifically managed systems of assuring water

- improve data collection, collation, analysis and dissemination of results within the industry.

For completeness of the strategy, attention will be paid to cross-cutting issues such as gender, environment, human resource development and capacity building to complement and reinforce production and increased productivity for accelerated growth. Accordingly, the next chapter focuses on the issues and policies that will enhance private sector competitiveness to deliver growth, reduce poverty and improve overall quality of life.

\subsubsection{Other Sectors}

Although the growth process under GPRS II is expected to be propelled by the agricultural sector, attention will also be given to some strategic sectors that have long-term growth potentials. These include tourism, ICT, light industrialization based on textiles, garments and value addition to metallic and non-metallic minerals. Presently, most of these activities are gradually being developed within the framework of the selected Special Initiatives. 
Table 2.5: GDP growth Projections, (2006 - 2009)

\begin{tabular}{|c|c|c|c|c|c|c|c|c|c|c|c|}
\hline Year & $\begin{array}{l}\text { Per Capita } \\
\text { GDP In US \$ }\end{array}$ & $\begin{array}{l}\text { Population } \\
\text { In Millions }\end{array}$ & $\begin{array}{l}\text { Population } \\
\text { Growth } \\
\text { Rate }\end{array}$ & $\begin{array}{l}\text { Nominal } \\
\text { GDP In US \$ }\end{array}$ & $\begin{array}{l}\text { Exchange Rate } \\
\text { Cedis/\$ }\end{array}$ & $\begin{array}{l}\text { Exchange Rate } \\
\text { Depreciation }\end{array}$ & $\begin{array}{l}\text { Nominal GDP } \\
\text { Billions Cedis }\end{array}$ & $\begin{array}{l}\text { GDP } \\
\text { Deflator } \\
1993=100\end{array}$ & $\begin{array}{l}\% \text { Change } \\
\text { In Deflator }\end{array}$ & $\begin{array}{l}\text { Real GDP } \\
\text { Billion } \\
\text { Cedis }\end{array}$ & $\begin{array}{l}\text { Real GDP } \\
\text { Growth rate }\end{array}$ \\
\hline 2002 & 318 & 19 & 2.6 & 6161.4 & 7944.3 & & 48862.0 & 872.4 & & 5600.9 & \\
\hline 2003 & 384 & 20 & 2.6 & 7637.3 & 8680.5 & 9.3 & 66158.0 & 1122.3 & 28.65 & 5894.9 & 5.25 \\
\hline 2004 & 434 & 20 & 2.6 & 8869.2 & 9020.6 & 3.9 & 79804.0 & 1280.7 & 14.11 & 6231.3 & 5.80 \\
\hline 2005 & 492 & 21 & 2.6 & 10305.0 & 9381.4 & 4.0 & 96675.4 & 1466.4 & 14.50 & 6592.7 & 5.80 \\
\hline 2006 & 538 & 21 & 2.6 & 11565.7 & 9756.7 & 4.0 & 112843.2 & 1613.0 & 10.00 & 6995.7 & 6.11 \\
\hline 2007 & 584 & 22 & 2.6 & 12887.4 & 10146.9 & 4.0 & 130768.2 & 1766.3 & 9.50 & 7403.6 & 5.83 \\
\hline 2008 & 635 & 23 & 2.6 & 14360.2 & 10552.8 & 4.0 & 151540.4 & 1929.9 & 9.26 & 7852.3 & 6.06 \\
\hline 2009 & 686 & 23 & 2.6 & 15916.4 & 10974.9 & 4.0 & 174681.9 & 2104.2 & 9.03 & 8301.7 & 5.72 \\
\hline Average & & & 2.6 & & & 4.0 & & & 9.44 & & 6.00 \\
\hline
\end{tabular}


Table 2.6: Gross Domestic Product by Kind of Economic Activity at Constant 1993 Prices Historical and Projected Growth Rates for GPRS II (2006 - 2009)

\begin{tabular}{|c|c|c|c|c|c|c|c|c|c|}
\hline Economic Activity By Type & 2001 & 2002 & 2003 & 2004 & 2005 & 2006 & 2007 & 2008 & 2009 \\
\hline Broad Agriculture & 4.02 & 4.36 & 6.06 & 7.49 & 6.50 & 5.24 & 6.71 & 5.18 & 6.60 \\
\hline Crops and livestock & 5.00 & 5.20 & 5.30 & 5.30 & 6.00 & 6.11 & 5.83 & 6.92 & 4.88 \\
\hline Cocoa production and marketing & -1.01 & -0.51 & 16.44 & 29.90 & 13.20 & 2.99 & 2.62 & 2.75 & 2.31 \\
\hline Forestry and logging & 4.78 & 5.03 & 6.09 & 5.83 & 5.60 & 3.86 & 4.85 & 6.06 & 5.72 \\
\hline Fishing & 2.02 & 2.81 & 2.97 & 3.51 & 3.60 & 3.90 & 4.71 & 4.92 & 5.72 \\
\hline Broad Industry & 2.93 & 4.73 & 5.06 & 5.13 & 5.80 & 6.11 & 5.83 & 6.06 & 5.72 \\
\hline Mining and quarrying & -1.57 & 4.48 & 4.69 & 4.52 & 4.90 & 3.22 & 4.84 & 4.66 & 4.91 \\
\hline Manufacturing & 3.69 & 4.80 & 4.60 & 4.59 & 5.50 & 5.53 & 6.53 & 7.11 & 7.10 \\
\hline Electricity and water & 4.23 & 4.06 & 4.18 & 3.75 & 4.50 & 6.11 & 5.83 & 6.06 & 5.72 \\
\hline Construction & 4.79 & 5.01 & 6.10 & 6.61 & 7.00 & 6.11 & 7.19 & 7.40 & 7.71 \\
\hline Broad Services & 5.07 & 4.70 & 4.68 & 4.73 & 5.40 & 5.75 & 5.90 & 5.99 & 5.72 \\
\hline Transport storage and communication & 5.51 & 5.69 & 5.79 & 5.61 & 5.80 & 6.11 & 5.83 & 5.47 & 5.27 \\
\hline $\begin{array}{l}\text { Wholesale and retail trade, } \\
\text { restaurants and hotels }\end{array}$ & 5.09 & 5.60 & 5.00 & 4.91 & 6.10 & 6.11 & 5.83 & 6.06 & 5.72 \\
\hline $\begin{array}{l}\begin{array}{l}\text { Finance, insurance, real estate and } \\
\text { business services }\end{array} \\
\end{array}$ & 4.50 & 5.48 & 5.24 & 4.78 & 5.60 & 6.06 & 5.83 & 5.81 & 5.97 \\
\hline Government services & 4.99 & 3.61 & 4.00 & 4.40 & 5.00 & 5.13 & 5.83 & 5.57 & 6.02 \\
\hline $\begin{array}{l}\begin{array}{l}\text { Community, social and personal } \\
\text { services }\end{array} \\
\end{array}$ & 6.47 & 4.44 & 4.07 & 4.17 & 4.30 & 5.54 & 5.83 & 5.72 & 5.72 \\
\hline Produce of private nonprofit services & 3.21 & 3.11 & 3.21 & 3.50 & 3.80 & 4.92 & 5.59 & 5.09 & 5.36 \\
\hline Indirect taxes & 5.40 & 4.30 & 4.40 & 4.30 & 4.50 & 6.11 & 5.83 & 6.06 & 5.72 \\
\hline Real GDP Growth rate & 4.20 & 4.50 & 5.20 & 5.80 & 5.80 & 6.11 & 5.83 & 6.06 & 5.72 \\
\hline
\end{tabular}




\section{CHAPTER THREE}

\section{PRIORITIES FOR PRIVATE SECTOR COMPETITIVENESS}

\subsection{PRIVATE SECTOR DEVELOPMENT}

The objective of GPRS II is to achieve accelerated growth through modernised agriculture, led by a vibrant and competitive private sector. The challenge to the attainment of this objective is to how to systematically address the structural constraints at the policy and institutional levels that hamper private-sector competitiveness in agriculture in the medium term and in the industrial and other sectors over the long term.

\footnotetext{
Box 3.1: Overview of the private sector under GPRS I (2002 - 2004)

Among the key strategies of the GPRS I (2003-2005) was to strengthen the private sector and enhance its capacity to function as the engine of growth and prosperity. The policy focus then was on developing a vibrant private sector in the medium-term through the following measures:

- Facilitating private sector access to long term finance at affordable rates;

- Reducing institutional and legal bottlenecks to private sector development; and

- Promoting opportunities of modern entrepreneurship, especially among the youth, women and the vulnerable groups.

To improve access and increase volume of credit at affordable prices and to increase sources of long-term funding for micro, small and medium enterprises Government in 2003 facilitated private sector access to credit sourced from the African Development Foundation (ADF), an Italian Credit facility of 10,000,000 Euros and a $\$ 17$ million facility from the SOFITEL BANK of the USA.
}

The Ministry of Private Sector Development and PSI also established an Institutional and Legal Reform Division solely dedicated to reducing bottlenecks to private sector development as well as facilitating the collaboration between the public and private sector towards the drafting of a number of reform bills (including the Companies Code, the Insolvency Bill, Money Laundering Bill and Insurance Bill). A network infrastructure with appropriate software has been installed at the Registrar-General's Department to enable the registration and retrieval of business names to be conducted electronically.

These initiatives notwithstanding, a number of critical issues still remain that require some urgent attention. Primary among them are: complex and non-transparent existing regulations, lack of access to finance, especially for women; falling but still fairly high interest rates; weak capacity of the government establishment to formulate, implement, monitor and evaluate private sector development; lack of focus of policies that explicitly take into address the specific needs of enterprises, especially the interests of micro, small and medium scale enterprises; Weak commercial dispute resolution system; insecurity and vulnerability in the informal sector where the youth and women predominate; weak linkages between the informal sector and the formal sector activities; lack of social protection for men and women in the informal sector; and weak institutional and regulatory framework for small business administration.

Key policies identified to address these constraints (Box 3.1) are the following: improving Ghana's access to global and regional markets; enhancing the efficiency and accessibility of national markets; strengthening of firms' competency and capacity to operate effectively and efficiently; enhancing government capacity for private sector policy formulation, implementation, and monitoring and evaluation; facilitate private sector access to capital; facilitate the removal of institutional and legal bottlenecks; facilitate innovation and entrepreneurship; improve the provision of public services; and accelerate the development of strategic sectors. These priority interventions are mutually re-enforcing and some of the strategies for the various interventions are elaborated below. 


\subsubsection{Improve Ghana's access to global and regional markets}

To improve Ghana's access to global and regional markets, it is envisaged that the National Trade Policy which seeks to promote the integration of Ghana into global and regional markets will be fully implemented. Also the recommendations from the review of existing institutions responsible for providing quality standards and services to the private sector, such as Ghana Standards Board, Food and Drugs Board, and the Plant Protection and Regulatory Services will be implemented fully.

Given Ghana's limited access to the global market, the objective of government's export promotion drive will target the implementation of sector-specific measures to support strategic exports, focusing initially on the President's Special Initiatives (PSI), as well as supporting local companies to participate in foreign and domestic trade shows, fairs and exhibitions. With a relatively weak private sector and low technological development, foreign private capital will be critical to the economic transformation of Ghana. To attract foreign investment, will require taking bold actions aimed at ensuring good governance, improving infrastructural development, accelerating judicial reforms, expanding trade and investment promotion, etc.

\subsubsection{Enhance efficiency and accessibility to national markets}

To ensure efficient and accessible national markets that support widespread private sectorled growth, the focus of policy is to address constraints relating to the macroeconomic environment, financial sector, public sector, contract enforcement/debt recovery, and land acquisition and property rights.

\section{Macroeconomic Environment:}

In order to improve the macroeconomic environment for growth, the challenge is to encourage dialogue among stakeholders on key macroeconomic issues through constant dissemination of a pre-budget discussion paper highlighting key macroeconomic issues for private sector development, forming a budget working group with a broad range of private sector stakeholders, and periodic benchmarking of Ghana's macroeconomic policy environment.

\section{Financial Sector Reform:}

To ensure that the financial sector responds effectively to the needs of the private sector, financial sector reforms will be deepen. This will include the continuous implementation, monitoring and evaluation of the Financial Sector Strategic Plan (FINSSP), in addition to identifying and agreeing on a small number of key private sector development targets within the FINSSP. In particular efforts will be made to ensure that the urban and rural poor who form important components of the private sector are not squeezed out.

\section{Public Sector Reform:}

The policy priorities under public sector reforms will include: (i) ensuring private sector development is mainstreamed within the Public Sector Reform programme; (ii) development of pro-business tools within the Public Sector Reform Programme, including: service-focused training programmes for public servants; (iii) development of pro-business 'Customer Charters' and anti-corruption action plans for key private sector-related MDAs; 
(iv) conducting a fundamental review of tax policy and administration in relation to micro and small enterprises; and (v) development of a regulatory impact assessment methodology for all proposed new laws and regulations with significant private sector impact.

\section{Contract enforcement / debt recovery:}

To ensure that the country has an effective legal system that supports the rapid private sector growth envisaged in the framework, the following policy priorities will be given the much needed attention; (i) improve access to justice for businesses - especially micro and small businesses and enhance the mechanism for alternative dispute resolution within the context of the on-going Judicial Sector Reform Programme; and (ii) monitor and evaluate the level of access to justice for businesses in Ghana focusing on micro, small and medium size enterprises (MSMEs).

\subsection{IMPROVING THE BUSINESS AND INVESTMENT ENVIRONMENT FOR AGRICULTURE-LED GROWTH}

\subsubsection{Modernized Agriculture}

Achievement of the overall goal of GPRS II requires agriculture to continue to grow at the rate of $6 \%$ per annum over the next 4 years, with crops and livestock leading the growth at an average annual growth rate of about $6 \%$, followed by forestry and logging, and fisheries at the rates of $5.1 \%$ and $4.8 \%$ per annum respectively. The cocoa sub-sector is expected to remain robust in support of the other sub-sectors.

\footnotetext{
Box 3.2: Overview of the Agriculture sector (2003 - 2004)

Agriculture plays important roles in the socioeconomic development of Ghana. It contributes to insuring food security, provides raw materials for local industries, generates foreign exchange, and provides employment and incomes for most of the population (especially those living in the rural areas), thereby contributing to poverty reduction.
}

Since the implementation of GPRS I (2003-2005) some progress has been achieved in agriculture. Out of the twelve indicators monitored for the sector, seven recorded impressive progress over the period of implementation, with four of them exceeding their targets. Areas of noticeable progress were farmer access to mechanized tillage, access to processing equipment, area under fish farming, number of hatcheries constructed and reduction in post harvest losses. Farmer access to mechanized tillage increased from 5\% in 2002 to $12 \%$ in 2004 as against the target of $15 \%$, while access to processing equipment increased from $24 \%$ in 2003 to $42 \%$ in 2004 thereby exceeding the target of 30\%. Area under fish farming exceeded its target of 450 hectares, recording 112.3 hectares for functional fish ponds, and 2480.8 hectares for reservoirs during the same period. In the case of post harvest losses, cereal losses achieved its intended target of 15-20\% and perishables managed a moderate achievement of $33-35 \%$, falling short of the target of $15-20 \%$.

These notwithstanding, a number of important outstanding issues need to be resolved within the agriculture sector. The tractor to farmer ratio still remains low at 1:120,000, the extension officer farmer ratio was at 1:1,400 by the end of 2004 falling short of the 1: 1200 target, access to harvesters was at 2\% falling short of the 5\% target and quantity of fish produced per unit area of pond per cycle stood at 2.5 tons/ha/yr (not different from the 2002 and 2003 figures).

Further constraints to the sector's capacity include: low crop yield and output due to low soil fertility and overdependency on rainfall; unsustainable agricultural practices; low exploitation of ground water for irrigation purposes; lack of access to credit, especially of small-scale women farmers; low productivity and low resistance breeds of livestock; and high incidence of animal diseases and poor disease surveillance systems. Others are inappropriate husbandry practices and low level of dairy production; inadequate/poor aquaculture infrastructure and low level of fish production from water bodies; limited value addition and high post-harvest losses; and limited access to marketing centres due to poor road network 
There are a number of critical issues that must be addressed to achieve the ultimate aim of a competitive private sector that supports accelerated growth, particularly based on agriculture. The following broad areas have been earmarked for priority interventions:

- reform to land acquisition and property rights

- accelerating the provision of irrigation infrastructure

- enhancing access to credit and inputs for agriculture

- promoting selective crop development

- modernising livestock development

- improving access to mechanised agriculture

- increasing access to extension services

- provision of infrastructure for aquaculture

- restoration of degraded environment

The strategies for these various interventions are elaborated below:

\section{Reform to land acquisition and property rights:}

Existing variations in access and control over land in different communities will be reexamined to promote easy access and ensure equity to all, especially to usufructory holdings in addition to improving the system of land registration to protect the interests of small holders. Furthermore, the establishment of agri-business zones and land banks will be promoted. The Land Administration Project will be reviewed to recognise the importance of property rights to MSMEs and the Land Title Registration Law of 1985 will be enforced as a means of ensuring security of tenure of small land holders, especially women and the youth.

\section{Accelerating the provision of irrigation infrastructure:}

In the past, a lot more emphasis was placed on the development of large dams to the neglect of small scale interventions such as dug-outs, hand-pump systems, valley bottom schemes, etc, which have the potential to reach smallholder farmers and are best suited for certain geographical areas. The focus of policy under the GPRS II is to target the rehabilitation, expansion and promotion of the use of the existing irrigation facilities and infrastructure; along with interventions to promote the development of small-scale community based valley-bottom irrigation schemes; ground water development and exploitation for irrigation purposes; and the promotion of hand-fix pumps for irrigation purposes. It is expected that these interventions will bring more land under cultivation, generate quick supply responses and benefit the poor in the rural areas.

\section{Access to credit and inputs for agriculture:}

Recognising the reluctance of the formal sector to lend to risky sectors such as agriculture, special interventions will be initiated to improve access to affordable credit by farmers with special emphasis on increasing the proportion of women that can gain access to credit; and promote and support the establishment of farmer-based organizations to enhance access to group credit and other crucial inputs and services.

\section{Selective Crop Development:}

The focus will be on promoting and supporting the development of key selected crops with proven potential to contribute significantly to domestic food security, agro industry and export. This will be facilitated through updating existing technological packages and 
promoting environmentally sustainable cropping practices in agro-forestry, land and water management. Some of the key initiatives will include: developing and multiplying new and improved seeds, promoting soil fertility management systems and ensuring the integration of pest and disease management system.

\section{Livestock Development:}

The emphasis in livestock development will be to ensure the provision of improved breeds of animals, institute animal feed quality control system, improve animal husbandry practices and promote efficient veterinary public health system.

\section{Agriculture Mechanisation:}

Whilst promoting increased mechanisation in large scale agriculture, emphasis will also be given to the development and use of small-scale technologies that target smallholder farmers, especially women, in the areas of tillage, storage and processing such as bullock ploughs.

\section{Access to extension services:}

In seeking to expand the coverage and effectiveness of extension services in general, special attention will be given to commodities targeted to lead accelerated growth in the sector. This will increase the proportion of both men and women farmers that are reached particularly in the transition and savannah zones. In addition Extension Information Centres (EIC) will be established.

\section{Provision of infrastructure for aquaculture:}

To reduce overdependence on marine fisheries which has proven to be increasingly unsustainable, there is the need to scale up investments in inland fisheries, especially aquaculture. Some of the key interventions include: development of aquaculture infrastructure including fish hatcheries; promotion of private investment in aquaculture; utilization of irrigation systems and other impounded reservoirs for aquaculture. These will be supported by research and development aimed at promoting modern technological packages in support of aquaculture.

\section{Restoration of degraded environment:}

A major impediment to increased productivity and sustainability in agriculture is the environmental degradation associated with traditional farming practices. To minimize the impact of environmental degradation, and in line with MDG 7, the intended interventions are aimed at restoring the degraded natural resources especially water and land, ensuring sustainable use of natural resources for economic growth, and protecting and conserving unique habitats, natural treasures and bio-diversity. To achieve these objectives, the strategies will include the following:

Environment: (i) initiate measures to stem land degradation and towards regulating the impact of climate variability/change; (ii) promote an efficient and accessible industrial and domestic waste management system that deals with the plastic menace and promotes composting; (iii) promote integrated ecosystem management as well as human centred biodiversity conservation initiatives; and (iv) promote the use of environmentally friendly technologies and practices. Others include enacting relevant environmental laws to protect the environment at all times, as well as ensuring the enforcement of the existing 
environmental laws; and development of multi-agency approach to enhance resource management and the environment

Lands and forestry: (i) encourage reforestation of degraded forest and off-reserve areas; (ii) promote the development and use of alternative wood products, as well as plantation/woodlot development among communities; (iii) manage and enhance Ghana's land and permanent estate of forest and wildlife protected areas; (iv) ensure that socioeconomic activities are consistent with sound land administration practices; (v) develop a sustainable strategy for forest and wildlife to support eco-tourism and generate foreign exchange.

Fisheries: (i) ensure adequate scientific data for precautionary approach to fisheries management; (ii) establishment of co-management mechanisms for fisheries resources management; (iii) control of fishing effort; (iv) enhance fisheries resource of water bodies; (v) develop multi-agency approach to enhance resource management and the environment; and (vi) support effective monitoring, control and surveillance (MCS) system to ensure compliance with laws and regulations on fisheries.

\subsubsection{Promoting Trade and Industry}

In line with the long term vision of developing an agro-based industrial economy, the interventions in agriculture will be complemented with appropriate interventions in the Trade and Industry sector. Within the strategic growth framework, the broad industrial sector is expected to grow at the rate of $6 \%$ per annum over the next four years, with the construction sub-sector leading the growth with $7.1 \%$ average annual growth rate. The manufacturing sub-sector is expected to make a strong showing with the mining and quarrying sub-sectors growing at $6.6 \%$ and $4.4 \%$ average annual growth rates respectively, due to the coming into operation of the integrated aluminium project. The wholesale and retail sub-sector is expected to grow at an average rate of $6 \%$ over the same period. The broad policy objectives and strategies outlined to achieve these include:

Ensure proper integration of the nation's production sectors into the domestic market: identify and promote opportunities for economically beneficial linkages along production and supply chains in new and existing productive sectors; and promote credit catalysts and rural service centres where larger traders and associations can access credit and on-lend to small traders and small farmers.

Increased Agro-processing: promote and support the processing, preservation and utilization of crops, animal and fish products; develop and promote the use of standardized packaging materials and institutionalize the use of weights and measures; facilitate establishment of small-scale agro-processing industries for export; promote the establishment of fish storage facilities, including community level facilities; and facilitate the establishment of small-scale fish processing industries.

Agricultural Marketing: development of farmer based organizations (FBO) capable of securing fair prices for products; encourage the setting up of satellite markets in urban centres to provide outlets for rural farmers to dispose off their products; encourage the private sector to set-up produce buying companies; and promote and support product development and cold chain establishment.

Enhance access to export markets: provide concessionary export finance facilities to exporters; promote competition in airport cargo handling; encourage private sector 
investment in construction and operation of cold chain facilities from production point to the port; facilitate the provision by private sector of well organised container terminals with security, equipment, effective operators and computerised tracking; improve the multilateral trading environment by fully participating in negotiations and rule setting in multilateral trading fora to ensure that Ghana's national interests are secured; create a fair, transparent and equitable trade regime; and facilitate trade through Ghana's borders to reduce costs and improve ease of trade

Increase industrial output and improve the competitiveness of domestic industrial products: mobilize domestic and international resources for production of value-added products; enhance accessibility to productive infrastructure (i.e. road, water, telecommunication, electricity, etc); promote efficient management practices in production systems; promote the use of local products and services in government procurement; actively promote made in Ghana products within domestic and international markets; ensure the removal of technical barriers in the way of key current and potential export products; and assist exporters to comply with international standards required by selected export markets

Other policy interventions include: facilitate the development of commercially viable export and domestic market oriented enterprises in the rural areas; promote industrial subcontracting and partnership exchange through a mechanism for large companies to outsource their non-core activities to SMEs and identify areas of interface and linkages between large and small scale enterprises; and promote the development of the craft industry, targeting those with potential for export.

Ensure the health, safety and economic interest of consumers: ensure the enforcement of legislation that prevents the sale of unsafe and poor quality goods on the local market; strengthen the regulatory and enforcement framework for protection of economic rights of consumers; develop and implement national consumer awareness programmes; encourage formation of consumer association; and ensure representation of consumers on relevant national bodies

These set of policies provide clear guidelines for the implementation of the government's domestic and international trade policy, while ensuring a consistent and stable policy environment within which the private sector and consumers can operate effectively. It is expected that greater emphasis on these policy areas will bring about increased competitiveness of producers in local and international markets.

\subsection{SUPPORT SERVICES}

Strategic support sectors that would be developed to facilitate improved productivity in agriculture and agro-industry include:

\subsubsection{Transportation}

Road especially, rail and water transport are by far the principal forms of transport in Ghana. However exports of fruits and vegetables are mainly by air transport. Improving overall road maintenance, and rehabilitating farm-to-market roads, bridges and ferries would lower transportation costs and integrate rural economies with the urban economy. It would also lengthen vehicle life, reduce transportation costs and save foreign exchange in 
fuel and spare parts imports, and generate savings in travel time. The broad policy objectives therefore include: ensure the provision, expansion and maintenance of transport infrastructure of all kinds; and ensure provision of affordable and accessible transport system that recognises the needs of people with disabilities. A single Ministry of Transport will promote synergy and enhance planning and operations.

Some of the strategies proposed to achieve these stated objectives are: increase spatial access to markets through improvements in farm-to-markets roads; rehabilitate or accelerate the development of one major road linking rural and urban markets in every region; continue to develop and rehabilitate major highways in the country; provide adequate and modern railway terminals and platforms; promote the development of a well integrated and modern rail track system; maintain and provide efficient and modern ports and harbours infrastructure across the country; and construct three major highways to connect transECOWAS Highway.

Other strategies include promoting the adoption of Intermediate Means of Transport (IMT), encouraging general aviation and aviation support services such as the use of micro light aircraft in agriculture, passenger transport and health delivery, and the promoting subregional transport systems including air transport that ensures efficient movement of goods and persons across borders.

Achieving these objectives also requires an efficient institutional and regulatory framework. Subsequently the following strategies will be pursued: promote road, rail, air and river transport safety and traffic management scheme to reduce accidents; promote effective and sustainable maintenance of the road system (through the decentralization programme); promote private sector involvement in the financing, construction and maintenance of road, and rails, as well as provide entry point and terminal services; strengthen local capacity in both consulting and construction services and government capacity in the road, rail, air and marine sector; promote private participation in the investment and management of aviation infrastructure and equipment; promote high safety, security and environmental standards in the aviation industry; restructure the Ghana Civil Aviation to play its core role as an independent regulator of the aviation industry; strengthen and enforce the existing regulatory and institutional framework for efficient ports, rail, air and water transport system.

\subsubsection{Energy}

To support a growing agro-industrial and services sector, as well as the needs of households, the policy thrust for the sector is set within the context of ensuring a reliable supply of high quality energy services. The broad policy interventions outlined to achieve this overall goal include: ensure increased access to modern forms of energy to the poor and vulnerable; modernise and expand power infrastructure; improve the regulatory environment in the power sector, ensure full cost recovery for power supply and delivery while protecting the poor; and ensure productive and efficient use of energy and minimise the environmental impacts of energy supply and consumption through increased energy efficient technologies.

Other policy objectives include: promote and encourage private sector participation in the energy sector; diversify the national energy mix by implementing programmes to support renewable energy sources in Ghana (i.e. hydro, wind, solar PV etc.). 


\subsubsection{Science and Technology}

The major goal of National Science and Technology (S\&T) Policy is to establish an efficient research system which contributes to national development objectives. Promotion of a science and technology culture at all levels of the society and the mastery of known and mature technologies and their application in agriculture and industry will accelerate economic growth and social transformation. Science and technology policy objective will therefore be to: promote the adoption of appropriate technologies, both local and foreign, with the capacity to improve productivity and efficiency in the agricultural, industrial and services sectors especially for micro, small and medium rural enterprises; promote research and development in all sectors of the economy; build relevant linkages between research and production to ensure that research outputs are utilised; provide institutional and regulatory framework to promote the development of science and technology.

\subsection{DEVELOPING ADDITIONAL SECTORS TO SUPPORT GROWTH}

In addition to the focus on developing the agro-industrial and support sectors, there are other sectors which will be targeted for development particularly in view of their employment creation and income generation potentials. These include: mining (especially exploration and exploitation of the lesser developed minerals such as salt) and value addition to traditional minerals; Information and Communication Technology (ICT); tourism; music and film industry; as well as the development and production of commodities under the Special Initiatives for export including garments and textiles.

\subsubsection{Developing Information and Communication Technology (ICT)}

The implementation of an Information and Communication Technology (ICT) Strategy or "Connectivity Agenda", will be another priority in diversification of the economy. It will be a pivotal tool to improve governance, accountability and transparency, develop human resource potential, and strengthen national unity. ICT will facilitate e-transactions; increase public sector efficiency and transparency; and grant citizens access to public services by making them available online (e-government). Through outreach programmes, ICT will enable low-income individuals to gain access to the internet. It will also promote e-exports such as out-sourcing, and data processing (see Box 3.3), encourage economic diversification and create new jobs, particularly for women and the youth; and establish network connectivity to lower unit costs and increase benefits from network externalities.

To take advantage of the opportunities in this sector, Government will partner the private sector to increase coverage of telephones particularly in rural and peri-urban communities; improve the quality of telephone service; establish national network of internet backbone/broadband; implement National e-governance programme; implement National Electronic Security system; promote and support e-commerce to facilitate trade and commerce in the economy; implement National ICT strategy in Agriculture, Health and the Music industry; and source FDI and local investment to promote the development and marketing of hardware and suitable software.

Other interventions that will be implemented include: provide telephone coverage to all public schools and communities in Ghana; provide internet access to all districts with a model Senior Secondary School; ensure that ICT is made a core subject of all post-basic educational institutions including universities teacher training colleges; promote in-service ICT training for teachers; and encourage small companies to make use of services/assets 
made available by the national internet backbone.

\section{Box 3.3: Potentials of ICT as major source of income and employment generation}

When ACS/BPS introduced its data-entry operations in Ghana in May 2000, it brought more computers into one site than had existed anywhere else in Ghana. It also successfully introduced an entirely new kind of occupation, new methods of working, and a new system of piece-rate payment which had failed in other industries where it was introduced previously. In just a year of activity, the firm grew from 30 to 700 employees. The system works as follows: the headquarters of ACS/BPS, based in the United States, electronically sends scanned medical claim forms to Ghana, where over 700 clerks then input data by hand from the scanned images.

This has raised the salary and status of data entry clerks who now typically earn between $\$ 100$ and $\$ 200$ per month, in a country where the local average income is close to $\$ 32$ per month. Of significance is that 95 per cent of the staff is female. Other ripple effects include outsourcing of services, including transport, security, catering and training, as well as buying its computer hardware from local vendors. The firm plans to expand: to open another three sites and employ another 3,000 employees. One concern is its ability to find skilled labour, and to this end, it aims to tap into the student population of local universities and polytechnics. It has already developed an arrangement with Ghanaian secretarial colleges, teaching students to use its software.

\subsubsection{Mining}

In addition to the exploitation of the traditional minerals such as gold and diamonds, a policy to promote value addition to other mineral resources including bauxite and limestone, and also the exploitation of lesser known minerals such as salt will be promoted.

In the process, efforts will be made to control illicit activities and deleterious effects of mining; sustain the mining sector through continuous exploration, exploitation and management of mineral resources; improve the environmental and natural resources management for health and safety; promote collaborative management of mineral resources; and promote the use of international best practices to enhance the competitiveness of the mining sector as a whole.

\subsubsection{Developing the Tourism Sector for Revenue and Employment Generation}

Tourism is a young but expanding industry in Ghana. It currently accounts for almost 4 percent of GDP, and at the current annual growth rate of 12 per cent, tourism has the potential of becoming Ghana's main foreign exchange earner. Ghana's comparative advantage in this sector includes historical, cultural and archaeological sites that attract regional and international tourists (including African-Americans interested in Ghana's history with respect to slavery). Potential also exists for ecotourism. Recent indication that the new Ministry of Tourism will preserve important national sites reinforces this sector's potential for investment. However, there are major constraints to be overcome, including Ghana's lack of adequate infrastructure, marketing, and health and safety-related services and others that are important for tourists, such as tourist police and loss-recovery facilities. Tourism's infrastructure is weak, with few world-class hotels and almost no tourist-related services.

Within this context government will develop plans and strategies aimed at harnessing the potentials of the sector towards the provision of employment and incomes, while ensuring the preservation of the nation's culture and sustainable management of the environment. The broad policy thrust shall, therefore, be "to realise the potentials of the sector by making Ghana a competitive and quality tourism destination whilst preserving the country's cultural, historical and environmental heritage". Key policy interventions and strategies 
expected to be pursued over the period will include:

Promote tourism as a major source of domestic revenue: market Ghana as a competitive tourist destination; design programmes to reduce the credit constraint of operators in the tourism sector with particular focus on women entrepreneurs; enhance tourism services and standards through inspection, licensing and classification of formal and informal tourism establishments; and enhance human resource capacity of skilled and unskilled personnel in the hospitality industry.

Promote domestic tourism to foster national cohesion as well as redistribution of income: This will involve vigorous promotion of domestic tourism to encourage Ghanaians to appreciate and preserve their national heritage and create wealth in the communities.

Promote sustainable and responsible tourism in such a way to preserve historical, cultural and natural heritage: develop sustainable ecotourism, culture and historical sites; promote sustainable development and management of coastal lands; and enforce measures to reduce waste and antisocial behaviours and practices arising from tourist activities.

Promote crafts industry for tourist trade and export: provide opportunities and technical assistance for micro-enterprises of rural and urban crafts procurers and improve the quality and marketing of their products for the tourist industry and export.

\subsubsection{The Music and Film Industry for Growth and Job Creation}

The music and film industry is fast-growing with unlimited potential. As one of Ghana's most significant pioneer industries, the music and film industry is a powerful means of enhancing the country's identity and distinctiveness, while simultaneously creating employment, developing human skills and generating social capital and cohesion.

However, like any Ghanaian industry, it is infused with the perennial problems of lack of access to finance, limited application of modern technology, lack of effective laws and regulations to protect intellectual property rights, low level of awareness on intellectual property rights, lack of enforcement and supervision of laws and regulations, and inadequate export promotion services. One of the most devastating aspects of this legacy is that local music and films industry is not developing as fast as it should.

Towards this end the policy objectives proposed under the GPRS II to promote the industry to support tourism as well as make it a growth point for job and wealth creation include: provide the right legal and regulatory framework for promoting the music and films industry; promote the use of ICT and support of Multimedia Technology in the industry; support the development of both human and institutional capacity for the industry. The specific interventions to achieve these objectives have been outlined in the Policy matrix (Appendix IA).

\subsection{EMPLOYMENT GENERATION AND IMPROVEMENT AND EXPANSION OF SAFETY NETS}

GPRS II will pursue an employment-centred cross-sectoral development strategy for accelerated growth and poverty reduction. This is to ensure that employment expands along with production and that the benefits of growth are widely shared through better job 
opportunities and improved/enhanced incomes for poverty reduction. The broad employment sector objective will be to ensure an adequate, well regulated, stable labour market to support accelerated growth.

Pursuant to this strategic orientation, the National Employment Policy will address objectives for youth employment, labour market information, industry-based skills training, local economic development to support the large and growing informal economy, and also improvements in productivity ad incomes. A cross-sectoral approach to employment policy implementation will underpin the overall national strategy. The strategy also entails initiatives for social protection, social dialogue, and social inclusion, especially, of the disabled, women and aged.

The policy measures will enhance productivity and income/wage, with equal opportunities for men and women in all sectors of the economy, including the informal economy, ensure the effective implementation of a coherent employment policy on the youth, women, the vulnerable and excluded; and a comprehensive and integrated employment creation, monitoring and evaluation system.

Consistent with the Gender and Children's Policy, the Draft National Youth Policy, the Draft National Disability Policy, and Draft National Ageing Policy, a comprehensive Social Protection Framework will cover the vulnerable and excluded in society. It will promote conditional and unconditional cash transfer systems and other support to displaced workers, while they seek employment, pregnant and lactating women, and provide target subsidies to the elderly, pensioners, smallholder farmers and people with disabilities. The Social Protection Strategy will also expand the coverage of the school feeding programme, and facilitate access to micro-credit for small scale informal operators.

Government will facilitate the enhanced capacity of the relevant agencies, including the Ministry of Manpower Youth and Employment and its departments and agencies with a focus on the Department of Social Welfare to carry out their statutory functions effectively and responsibly. In addition, the social partners, relevant civil society and nongovernmental organizations will be encouraged to play a strategic role in complementing government's employment and social protection efforts. The Ministry of Manpower, Youth and Employment will establish an effective system to coordinate and monitor these efforts and activities to ensure efficiency within the economy, as well as equitable benefits to targeted beneficiaries. 


\section{CHAPTER FOUR}

\section{HUMAN RESOURCE DEVELOPMENT}

\subsection{INTRODUCTION}

The development of the human resources of the country is one of the three key pillars of the GPRS II. The main goal is to ensure the development of a knowledgeable, well-trained, disciplined and healthy population with the capacity to drive and sustain the private sectorled growth strategy. An essential component of the strategy is to ensure the right to basic social services such as health care, safe drinking water and sanitation and decent housing that improve the well being of all Ghanaians. An equally important aspect of the human resource development strategy is to ensure the protection of the rights of the vulnerable members of society, especially children, women, people with disabilities, the elderly and rural communities.

\subsection{REVIEW OF HUMAN RESOURCE DEVELOPMENT UNDER GPRS I}

Under GPRS I a number of measures were instituted in the medium-term to enhance the environment for sustainable human resource development. These included enhancing access to education; reducing gender disparities in education; and improving skills through training. In the health and other sectors priority measures focused on enhancing access to and delivery of quality health services; increasing access to safe drinking water and adequate environmental sanitation; population management; and controlling the HIV/AIDS epidemic. Key achievements are as summarized in box 4.1 below.

\section{Box 4.1: Situational analysis of Human Resource Development under GPRS I}

Considerable progress has been made towards the attainment of the objectives of Human Development under GPRS I. In education, enrolment rates have increased in primary, JSS and the post-basic sub-sectors. Gender Parity Index (GPI) and survival and completion rates have also all improved at the national level. Enrolment rates in the deprived districts and three northern regions have also shown marked improvements, generally above the national growth rate, albeit from low levels. In addition facilities at both secondary and tertiary levels have experienced rapid expansion.

In the health sector, most of the indicators show that considerable progress has been made in improving the health status of the Ghanaian. For instance life expectancy at birth has increased form 58\% in 1998 to $60 \%$ in 2003. On the other hand infant and childhood mortality have worsen, increasing from $57 \%$ to $64 \%$ over the same period.

Limited access to safe water remains a perennial problem in many Ghanaian communities. Currently about $63 \%$ of urban dwellers and $46.4 \%$ of rural dwellers have access to safe water. Many rural communities continue to rely on ponds and streams as their main source of water, resulting in undue exposure to guinea worm, bilharzia and other water-borne diseases. Although considerably better than rural water supply, urban water supply is generally less than satisfactory, especially in slums and other high population density areas where the capacity of water supply infrastructure has been overstretched.

The provision of adequate sewage and sanitation facilities is less than adequate. Households with access to adequate toilet facility (flush/ventilated improved pit), for example, is very low. Proper disposal of solid waste is also a major problem in peri-urban and urban communities as health hazards are created by urban drains, which are often, choked with refuse and stagnant water.

From the fore-going review, it is evident that there are still a number of policy issues that need to be addressed a comprehensive human resource development effort. Consequently the following broad policy areas have been identified as priorities for the development of the requisite human resources for accelerated economic growth: education, training and 
skills development; access to health care and adequate nutrition, malaria control and HIV/AIDS prevention and treatment; access to safe water and adequate sanitation; housing and slum upgrading; and population management.

The strategy will also include the promotion of vigorous health education campaign on the adoption of healthy environmental practices and lifestyles. In addition, outstanding issues relating to vulnerability and social exclusion will be mainstreamed into the human resource development strategy.

\subsection{EDUCATION, SKILLS, MANPOWER AND SPORTS DEVELOPMENT FOR ACCELERATED GROWTH}

In the broad education sector a holistic package of interventions have been identified as priorities for attaining a middle income country with a minimum per capita income of US $\$ 1000$ by 2015 . The strategy begins with early childhood development $(0-8$ years $)$ where the critical foundations are laid for psycho-social, emotional, and intellectual development. Initiatives that will give the best start in life for every Ghanaian child will be pursued. This will include measures that will strengthen the family, other caregivers and early childhood development programmes.

\subsubsection{Formal Education}

The basic education sub-sector is the next major building block for the development of human resources for accelerated growth. The policy issues/gaps in this sub-sector that need to be addressed include: inadequate progress in school enrolments; persistent geographical and gender disparities in access to education; less than satisfactory quality education; inadequate technical and vocational skills and ICT training.

\section{Box 4.2: Education Reform Policy}

The Education Reform Policy is aimed at addressing the weaknesses of the current educational system with a view to making it more responsive to current challenges. Specifically the policy addresses issues pertaining to the development and delivery of education, access to different levels of the education ladder, Information and Communication Technology (ICT), distance education, professional development and the management and financing of education. The essential elements of the reform include, among others, the following:

- re-structuring of the current Basic Education System to provide universal compulsory basic education comprising of 2 years of Kindergarten, 6 years of Primary, 3 years of Junior High and then 4 years of Senior High.

- emphasis on Technical, Agricultural and Vocational education as credible alternatives to general education for the majority of youth, especially for the 15 to 19 year bracket.

- formalization of community-based apprenticeship/skills training to offer opportunity for those who drop out of school to acquire proficiency in marketable skills

- improving Teacher Education, including teacher development at all levels of education

- $\quad$ improving institutions that provide education for children with special needs

The policy-related issues in the secondary education sub-sector are: equitable distribution of well-equipped secondary schools; well-trained and motivated teachers; and inability to absorb the majority of pupils who complete the compulsory basic education programme.

At the tertiary level the critical policy issues relate to: inadequate physical infrastructure to absorb the growing number of young adults who seek admission to tertiary institutions; and insufficient numbers of qualified and well motivated academic staff. The new Educational 
Sector Reform Programme introduced in 2004 aims at addressing these issues, particularly in the basic and secondary education sub-sectors.

Priority policy interventions in the education sector that will deepen and sustain the progress made in education under GPRS I and accelerate growth include the following: (i) increase access to and participation in education and training at all levels; (ii) bridge gender gaps in access to education in all districts; (iii) improve quality of teaching and learning; (iv) improve efficiency in the delivery of education services (v) promote science and technology education at all levels with particular attention to increased participation of girls.

\section{Increasing access to and participation in education and training:}

At the basic level, policy measures include: expand pre-school access in all basic schools to give every child a good start in learning; accelerate the rehabilitation/development of basic school infrastructure (with water and toilet facilities) particularly in most deprived districts; remove barriers to primary school entry and retention; shift the burden of payment for education services away from poorer families of children at the lower levels (especially the girl-child); facilitate the implementation of the capitation grant in all public primary schools; expand the ongoing school feeding programme to all poor districts; ensure that buildings and other physical infrastructure in schools are made accessible to the people with disabilities; adopt targeted programmes to improve access in underserved areas; improve the provision of JSS workshops in basic schools; enact laws that support implementation of FCUBE; and expand non-formal education in partnership with community groups, NGOs and private providers.

At the senior secondary school level, strategies will focus on: accelerate the implementation of the programme to upgrade one secondary school to "model secondary school" status in each district in order to address the issue of geographical disparities in access to quality secondary education; rehabilitate/develop physical infrastructure, provision of libraries and equipping science laboratories in other schools in the districts. In co-educational institutions, steps will be taken to ensure equitable access to facilities and opportunities for both boys and girls.

Strategies to improve and extend technical and vocational education and training include: establishment of a National Council for Technical and Vocational Education; ensure the relevance and coverage of vocational and technical training; (allowing for the diversification of vocational and technical curriculum e.g. to include agriculture and business studies); facilitate functional linkage between training institutions and industry; support private-public partnership in the management of vocational and technical schools; promote entrepreneurship among the youth.

At the tertiary level, on-going programmes for enhancing infrastructural development in the universities and polytechnics will be expanded to provide essential facilities like libraries, lecture halls, laboratories, workshops, equipment, and residential accommodation. A National Policy on Distance Education will be adopted and distance education centres established in all regions of the country.

\section{Bridging gender gap in access to education:}

Strategies towards attaining gender parity in access to education and meeting the objectives of MDG 3 will include provision of incentives/scholarship schemes to increase girls enrolment, retention and completion, particularly in the deprived areas; and sensitising parents and communities on the importance of girls' education. 


\section{Improving the quality of teaching and learning:}

To improve the quality of basic education, the strategy will focus on: introduce programme of national education quality assessment: expand teacher retention schemes; ensure teacher development (including upgrading and equipping Teacher Training Colleges to offer diploma courses), ensure deployment of teachers, particularly to more remote and rural areas; (iv) strengthen the supervision of teachers; provide incentive schemes for teachers especially female teachers who serve as role models, in deprived areas; ensure timely distribution of teaching and learning materials, including textbooks; improve the teaching of science, technology and mathematics in all basic schools; and develop and promote the use of ICT in schools and institutions of higher learning.

\section{Improving the quality and efficiency in the delivery of education services:}

The strategy to improve the quality and efficiency in the delivery of education services will include: strengthen and improve educational planning and management; promote and support private sector participation in education; strengthen monitoring and evaluation framework and reporting channels; strengthen institutional arrangement for enhancing the role of $\mathrm{CBO}, \mathrm{CSO}$ in advocacy, monitoring and evaluation.

\section{Promoting of science and technology education at all levels:}

Improvements in production techniques for more efficient production of larger quantities and high quality goods and services in the growth sectors require workers with modern scientific knowledge and ICT culture. Strategies to achieve this objective include providing incentive schemes to attract more teachers into the teaching of science and ICT; support science and research institutions; provide incentives to attract science students; increase funding for research and technology development including ICT; and support private sector initiatives in science and education.

\subsubsection{Training and Skills Development}

Outside the formal education system, many young people lack the requisite skills and entrepreneurial know-how to access jobs in the labour market, thus making them vulnerable in their livelihoods and subject to exploitation including the worst forms of child labour. Groups of young people requiring support most in this regard include: young persons 15 years and above who never went to school or who drop out of primary school and JSS; those who have completed JSS and SSS but are unemployed due to poor quality/relevance of education received; young people who have acquired some skills but need retraining especially in good management practices to enhance their access to the labour market; and young persons with disabilities.

Skills and entrepreneurial development will be guided by the following priorities: (i) provide skills and entrepreneurial training in a gender responsive and equitable manner; (ii) promote dialogue between industry and skills/professional training institutions to produce skilled labour required by industry; (iii) strengthen and support HR training institutions; (iv) promote apprenticeship training; (v) promote the adoption of the National Youth Policy and enactment of the Disability Bill.

\section{Provide skill and entrepreneurial training:}

In order to provide skill and entrepreneurial training the following strategies will be adopted: train unemployed in competency-based, demand-driven skills, including the STEP programme; promote and establish production units in all vocational training centres; set standards for vocational training and entrepreneurial development; intensify co-operative 
education and its practice in collaboration with stakeholders; revamp the Factories Inspectorate Division to intensify health and safety education at the workplace and training institutions; expand training infrastructure for skills upgrading; improve management skills and business efficiency; promote training of people with disability and; implement National apprenticeship programme.

Promote dialogue between industry and skills/professional training institutions to produce skilled labour required by industry:

The strategy is to promote dialogue between industry and skills/professional training institutions to produce demand driven skilled labour and establish effective collaboration between HR institutions and industry.

\section{Strengthen and support HR Training Institutions:}

The strategy to strengthen and support HR training institutions will include the following: assist HR institutions to develop new syllabi/curricula to meet requirements of industry and employees as well as persons preferring self-employment; conduct training needs assessment: provide logistical support.

\subsubsection{Sports Development}

Sports enhance one's personal abilities, general health, self-esteem while contributing to socio-economic development including improving public health and social cohesion. On the global level, sports foster friendship, cooperation and understanding between nations. In relation to the sport for excellence and sports for development and peace policies, priority interventions to support growth and poverty reduction will: build coalition and partnership in sports development; promote national integration and unity through sports; and promote international friendship, solidarity and cooperation.

\section{Building coalition and partnership in sports development:}

Strategies will include strengthening the capacities of the national sports institutions and organisations and enhancing the involvement of corporate bodies and individuals in sports promotion and development.

Promoting national integration and unity:

Adequate and appropriate sports and recreational facilities will be provided at local, district, regional and national levels, ensuring availability and affordability of sports equipment, promoting the production of local sports equipment, building the capacity of community sports clubs, amateur and professional clubs and fitness clubs and motivating and encouraging sports talents to achieve full potential.

\section{Promoting international friendship, solidarity and cooperation:}

Strengthening international friendship, solidarity and cooperation to achieve growth and poverty reduction will be promoted by establishing linkages and partnership with countries and international sport agencies committed to the development of sports, thereby enhancing its potential contribution to national development objectives. 


\subsection{IMPROVED ACCESS TO HEALTH CARE, MALARIA CONTROL AND PREVENTION OF HIV/AIDS}

\subsubsection{Improving Access to Health Care}

Generally the health status of Ghanaians has improved over the years. However there exist marked differences in some health indicators among the different geographical regions and socio-economic groupings. These variations in health status are in part due to differential access to quality health care. Despite the considerable investments in the provision of health care facilities, a significant proportion of the people lack access to quality health services. The main constraining factors affecting access to health care include geographical, financial barriers, service delivery and broad socio-cultural barriers including gender.

Factors contributing to poor geographical access include low capital investment in health facilities, poor feeder road systems in the country, poor location of facilities and lack of communication facilities. Service delivery barriers that have constrained access to quality health care include organizational and management constraints; weak support systems such as transportation and equipment for service delivery; human resource constraints. The exodus of critical health professionals in recent years is undermining efforts to improve access.

The 'Cash and Carry System' of paying for health care at the point of service is a key financial barrier to health care access for the poor. To remove the financial barrier to health services, the government initiated the National Health Insurance Scheme in 2001 aimed at abolishing this system and limiting out of pocket cash payment at the point of service delivery (see Box 4.3). The scheme makes provision for the poorest and most vulnerable people to be identified and exempted from making financial contributions to the system.

\footnotetext{
Box 4.3: National Health Insurance Scheme

The National Health Insurance was initiated to address the problem of financial barrier to health care posed by the 'Cash and Carry System' which requires out-of-pocket payment for health care at the point of service delivery.

The National Health Insurance Act (2004), Act 650, has been enacted and a Legislative instrument, LI 809, has also been passed to provide operational and administrative guidelines for its implementation. A Ministerial Oversight Committee has been formed. A National Health Insurance Council is in place.

District Mutual Health Insurance Schemes (DMHIS) serve as vehicles for delivering pro-poor policy to the underprivileged segment of society. All districts have been provided with an average of $\phi 250$ million each as start-up capital for the establishment of a DMHIS. So far 123 district schemes have been set up out of a total of the 138 districts and personnel to serve as District Scheme Managers have been recruited.

Currently a minimum benefit package covers about $95 \%$ of diseases in Ghana. Some of the diseases covered are malaria, diarrhoea, upper respiratory tract infections, skin diseases, tuberculosis, asthma and hypertension.

Challenges to the successful implementation of the NHIS are (a) how to increase enrolment of members into the district schemes and the NHIC plans to intensify education to improve this. (b) Costing of various types of services at the different health delivery points in order to fix tariffs / fees with health-care providers.

The Ministries of Health, Local Government \& Rural Development and Information as well as the NHIC need to intensify work in order to make this important national programme succeed.
}

The strategy for improved health care in Ghana under GPRS I, envisaged increasing total health expenditure as percentage of the total government expenditure from about $5 \%$ in 
2000 to about $7 \%$ in 2004 and $7.5 \%$ in 2005 . This increased expenditure, which was likely to guarantee a per capita health expenditure equivalent to $\$ 10$, is too low to bring Ghana anywhere near the internationally recommended levels of about $\$ 30-40$ per capita expenditure necessary to cover the costs of a basic minimum package of preventive and curative services. The Ghana, Macroeconomic and Health Initiative (GMHI) report recommends in the short term increasing government spending on health for the 2003 to 2007 financial years to the level that would raise the contacts for preventive and curative care from 0.34-0.44 OPD visits/ per-capita/year to 0.75 OPD visits/capita/year or raising the health expenditure per capita per year to around $\$ 20$ by 2007.

In order to accelerate access to quality health services, the health sector will continue to deepen efforts and focus on the three broad policy objectives: (i) bridge equity gap in access to quality health and nutrition services; (ii) ensure sustainable financing arrangements that protect the poor; (iii) enhance efficiency in service delivery.

\section{Bridging Equity Gap in Access to Quality Health and Nutrition Services:}

Strategies to be implemented under this policy objective include: develop "close to client' services to the poor; develop resource allocation criteria and a facility distribution plan to improve targeting of poor groups and geographical areas; redistribute health workers in favour of deprived areas; provide outreach services and clinics in deprived rural and periurban areas; improve Community-based Health Planning and Services (CHPS); develop and implement high impact yielding strategies for U5M \& MM and malnutrition; including scaling-up the successful Accelerated Child Survival and Development (ACSD) interventions; develop at least one fully functioning and well equipped hospital in each district; eradicate guinea worm and intensify implementation of DOTS strategy of the National Tuberculosis programme; improve access to reproductive health services by reducing unmet needs of family planning; improve essential obstetric care to reduce maternal mortality; and improve availability and access to essential and affordable drugs on sustainable basis.

\section{Ensuring Sustainable Financing Arrangements that Protect the Poor:}

Strategies under this objective include: accelerate the implementation of the National Health Insurance Scheme including the exemption policy through guided introduction of District mutual health insurance schemes, fix low acceptable levels of payment for the poor. The exemption policy will be strengthened to enhance access of poor and vulnerable groups to healthcare by improving the eligibility criteria, procedures, public awareness and responsiveness of the health service facilities.

\section{Strengthening Efficiency in Service Delivery:}

Strategies to strengthen efficiency in service delivery will include: expand pre-service health training institution facilities to increase intakes of trainees; providing incentive schemes to support the retention and redistribution of trained health personnel; decentralize human resource management to the regional level; strengthening systems for accountability in health service delivery; collaborate with informal health service providers, expand community-based health service delivery; improve the quality of traditional health service delivery system; accelerate the provision of staff accommodation at all levels; improve data collection in Epidemic Prevention and Care; strengthen M\&E of services; clarifying roles of MOH-GHS and District Assemblies in health service delivery (HSD); enhance linkages between public, private and NGOs, collaborating with other MDAs like Ghana Aids Commission, National Population Council, Ministry of Education, Ministry of Food and Agriculture and the Community Water and Sanitation Agency in service delivery. 


\subsubsection{Malaria Control}

Malaria in Ghana is the single most important cause of mortality especially among children under five years and pregnant women. In 2002, for instance, malaria was estimated to account for $44.5 \%$ of all outpatient illnesses, $36.9 \%$ of all admissions and $13.2 \%$ of all deaths in health facilities in Ghana. The disease is responsible for a substantial number of miscarriages and low birth weight babies among pregnant women. Among this group, malaria accounts for $13.8 \%$ of OPD attendance, $10.6 \%$ of admissions and $9.4 \%$ of deaths. Around 800,000 children under the age of five die from malaria in Africa every year, making this disease one of the major causes of infant and juvenile mortality.

Apart from the health consequences of malaria, it puts a heavy burden on economic development. It is estimated that a single bout of malaria costs a sum equivalent to over 10 working days in Africa. In Ghana malaria accounts for significant portion of the disease burden, causing about $10.6 \%$ of lost Disability Adjusted Life Years (DALY) and costing an equivalent of about $3 \%$ of GDP annually in economic burden. Hence the need to prioritize the control of malaria under the health sector interventions of GPRS II.

\footnotetext{
Box 4.4 : Government Effort at Controlling Malaria

Intensive government efforts at controlling malaria in Ghana dates back to 1957 when a malaria control unit within the MOH was established in the Volta Region in collaboration with WHO to train personnel in geographical reconnaissance, malariometric and entomological surveys, and to conduct trials of indoor residual insecticide application in the control of adult mosquito population. Ghana followed-up this in 1961 with the creation of a National Malaria Services when the country adopted the global Malaria Eradication Programme, which used residual spraying and larvicides to control malaria parasites. The programme had to be discontinued in 1967 due to technical and financial reasons. In 1992, the country launched a 5-year (1993-1997) National Malaria Control Action Plan with the focus on capacity building for improved disease management in health facilities. Drawing on past experiences and lessons, an accelerated malaria control programme piloted in 30 districts, was launched in 1997, again with a focus on case management.

Since 1998 Ghana has committed itself to the Roll Back Malaria (RBM) Initiative of WHO, which builds on the Global Malaria Strategy with a focus on Africa. The goal of the Roll Back Malaria Initiative is to halve the world's malaria burden by 2010. Consequently the country drew up a 'Medium Term Strategic Plan for Malaria Control in Ghana' (1998-2002), which sought to improve the coverage of malaria control activity by adopting an inter-sectoral approach involving other government sectors and partnership with the private sector and the community ${ }^{3}$. It has also committed itself to the Abuja Declaration on Roll Back Malaria in Africa, which similarly seeks to achieve specific targets on malaria prevention and control with time limits.
}

The Ministry of Health produced a Roll Back Malaria (RBM) Strategic Plan in 2000 with the overall goal of facilitating human resource development by reducing the malaria disease burden. The RBM is in line with the objectives of MDG 6. The following priority interventions in the RBM plan will be promoted and strengthened in GPRS II: improve malaria case management; multiple prevention; improved partnership; and focused research.

\section{Improving Malaria Case Management:}

Primary interventions include ensuring early case recognition, ensuring appropriate response and referral and improving access to services.

\section{Enhancing Multiple Prevention:}

Preventive strategies include: promote use of insecticide treated bednets, especially by

\footnotetext{
${ }^{3}$ Ministry of Health 1998. Strategic Plan (June 1998), Government of Ghana.
} 
children and pregnant women; encourage drainage, mosquito proofing and general sanitation; promote limited application of indoor and outdoor residual spraying; and promote chemoprophylaxis for pregnant women.

\section{Improving Partnership:}

The strategy to achieve this objective is to create and sustain partnerships for malaria control through close collaboration between departments and programmes in the health sector, partnerships between government sectors and partnerships with NGOs, private sector, informal sector, communities and traditional healers.

\section{Focused Research:}

The objective of this component of RBM is to ensure that efforts to roll back malaria are supported and well informed by well researched information to guide policy decisions and monitor progress and outcomes of key interventions. This will be achieved by increasing availability of funds for research; focused research agenda and improved dissemination and utilization of results; and capacity development for research.

\subsubsection{HIV/AIDS Prevention}

In addition to the malaria menace, HIV/AIDS pandemic at the prevalence rate of $3.4 \%$ has a negative impact on productivity. It results in loss of productive assets, high treatment costs and the break in the transfer of valuable livelihood knowledge from one generation to the next.

The following strategies will be adopted to prevent the spread of HIV/AIDS in order to keep the prevalence rate below 5\%: reduce new HIV/STI transmission; reduce the impact of HIV/AIDS related vulnerability, morbidity and mortality; and enhance the coordination and management of the national HIV/AIDS response.

\section{Reduce new HIV/STI transmission:}

The objective of reducing new infections will be achieved by intensifying behaviour change strategies, especially for high risk groups; preventing mother-to child transmissions; ensuring safe blood and blood products transfusion; improve HIV/AIDS/STI management; promoting safe sex practices; increase access to voluntary counselling and testing, condoms, and integrated youth friendly services; develop national behaviour change communication strategy, advocate for elimination of negative socio-cultural practices, address gender based vulnerability including violence, coercion and marginalization, strengthen links between HIV prevention programmes and reproductive health and information services.

\section{Reduce the impact of HIVIAIDS related vulnerability, morbidity and mortality:}

Policy measures with respect to this objective include: enhance service delivery; promote strategies to reduce stigma and discrimination, rapid scale-up of comprehensive care including antiretroviral therapy to all who need it; effectively standardize the utilization of useful traditional and alternative medicine for the provision of long-term care; ensure supportive environment for persons infected or affected by HIV/AIDS; ensure safety of orphans and vulnerable children; strengthen linkages between institutional care and community/home based care; increase assess to basic package of services for PLWHA.

\section{Enhance the management of the national HIV/AIDS response:}

Policy measures for achieving this objective will include: strengthen the capacity and core functions of the Ghana AIDS Commission; enhance the existing favourable, socio-political and 
policy environment; promote a multi-sectoral and multi-disciplinary approach in the formulation and implementation of HIV/AIDS/STDs policies and programmes at national, region and district levels, building capacity of weak frontline institutions; develop and implement clear strategies for research, monitoring and evaluation; mobilize resources to meet the increasing demand of new and diversified programmes

\subsection{POPULATION MANAGEMENT}

Population growth has strong linkages with economic growth and sustainable social development. Population growth increases the quantity of labour without necessarily improving its quality. Hence, population growth rates above 2 percent have been found to be counterproductive to growth. Even though the population growth rate in Ghana has reduced from its high level of about $3 \%$ in 1994 to $2.7 \%$ in 2000, it continues to outstrip the provision of social services and infrastructure. The high fertility rate has also resulted in a youthful population with a high dependency ratio. The immediate challenge for human resources development is to formulate appropriate strategies to manage the population to ensure that population growth rate is maintained at a level that will support economic growth and social development.

Population management will be based on the following priorities: promote access to and utilization of family planning services; educate the youth on sexual relationship, fertility regulation, adolescent health, marriage and child bearing; promote sexual health, delayed marriage and child bearing; promote compulsory education for children especially the girlchild up to secondary; promote compulsory and universal birth registration as a basic right and population management measure; integrate population variables into the GPRS at the national, regional and district levels and improve population database for the GPRS; promote the integration of HIV/AIDS into Sexual and Reproductive Health programmes; and strengthen the multi-sectoral, multi-disciplinary institutional co-ordination collaboration and networking for population management.

\section{Promote access to and utilization of family planning service:}

The strategies which will be implemented under this policy objective include: decentralize counselling services; strengthen the family planning component of maternal health delivery; and promote the sale of contraceptives through community agents, including maternity homes and field agents. Research will be undertaken on traditional practices and belief systems which inhibit contraceptive use followed by appropriate action.

\section{Educate the youth on sexual relationship, fertility regulation, adolescent health, marriage and child bearing:}

The strategies which will be implemented will include: promote family planning/RH education into formal and informal and out of school training programmes to prepare the youth for responsible parenthood; scale up effective implementation of the Adolescent Reproductive Health Policy.

\section{Promote the integration of HIVIAIDS into Sexual and Reproductive Health programmes, delayed marriage and child bearing:}

Strategies to promote sexual health, delay marriage and childbearing, include: ensure availability of and accessibility to family planning services to all who seek such services including youth-friendly services; educate and motivate the population at community levels on health, social and demographic values of family planning; promote formal education of girls as well as adult education and functional literacy with bias towards the maintenance of family values, reproductive health, population and development interrelation; conduct 
research into socio-cultural practices that promote early marriage, betrothal, early sexual behaviour and take appropriate social and legal action.

\section{Promote compulsory education for children especially the girl-child up to secondary level:}

The strategy will focus on programmes that encourage girls to stay in school up to at least the secondary level, improve school enrolment rate and reduce the high drop out rate.

\section{Promote compulsory and universal birth registration:}

The issue of birth registration was not addressed in the first GPRS. GPRS II recognises birth registration as in an important population management issue as well as the fundamental right of the child as a citizen. The implementation of the existing policy and programme will be accelerated to achieve universal coverage of $100 \%$ by 2009 from the current level of $50 \%$.

\section{Strengthening the multi-agency Co-ordination for Population Management:}

The policy interventions in this regard will include: build the capacity of the National Population Council and partner agencies for the integration of population concerns in the GPRS; provide technical leadership to co-ordinate population activities at all levels; and develop appropriate advocacy strategies for population management.

\subsection{SAFE WATER AND ENVIRONMENTAL SANITATION}

Improving access to potable water and sanitation is critical to achieving favourable health outcomes, which in turn facilitate economic growth and sustained poverty reduction. In particular improvement in access to safe water enhances school attendance, reduces women's workload and frees them to participate effectively in economic empowerment and governance activities. On the other hand, adequate sewerage and sanitation facilities are important for environmental cleanliness and prevention of many infectious diseases such as diarrhoea and dysentery.

There are several on-going investments in safe water provision through the rehabilitation and expansion of water systems for both rural and urban communities. There is the need to accelerate these interventions. The following priorities will guide the delivery of safe water and sanitation in the next four years: accelerate provision of safe water in rural and urban areas; accelerate the provision of adequate sanitation; and improve environmental sanitation in urban and rural areas.

\section{Accelerate the provision of safe water in rural and urban areas:}

Rural: Policy interventions to accelerate the provision of safe water in the rural areas will include: provide new investments in rural water, especially in guinea worm endemic areas; strengthen the management of on-going investments in deprived regions; ensure timely disbursement of recurrent budget to Community, Water and Sanitation Agency (CWSA); ensure timely disbursement of the District Assembly Common Fund; strengthen publicprivate and NGO partnerships in water provision; improve community owned and managed water supply systems; provide for in the building code an enactment requiring all building plans to include rain harvesting facilities, provide check-dams (dug out) to harvest rainwater for agricultural purposes, strengthen human resource capacity in water and to disseminate information on safe water. 
Urban: Strategies to accelerate the provision of safe water in the urban areas will include the following: establish regional offices of Public Utilities and Regulatory Commission; mobilize new investments for urban water systems; extend distribution networks especially to low income consumers; strengthen the management of Ghana Water Company to enhance service delivery; assess lifeline tariff for poor urban households; provide standpipes for the poor; provide, in the building code, an enactment requiring all building plans to include rain harvesting facilities; support the introduction of private sector into management and operation of the water supply systems under management and/or lease contract arrangement and to disseminate information on safe water .

\section{Accelerate the provision of adequate sanitation:}

Strategies to accelerate the provision of adequate sanitation consists of: promote the construction and use of domestic latrines; improve the treatment and disposal of waste in major towns and cities; enforce laws on the provision of sanitation facilities by landlords; promote widespread use of simplified sewerage systems in poor areas; improve the management of urban sewerage systems; improve household and institutional sanitation including schools; rationalize and update District Assembly bye-laws on safe management of liquid and solid waste at the household level; integrate hygiene education into water and sanitation delivery.

\section{Improve environmental sanitation:}

Interventions that will be implemented to improve environmental sanitation will involve: promote physical planning in both urban and rural areas, including the acquisition of land for the treatment and disposal of solid waste in major towns and cities; establish water and sanitation boards in small towns; support public-private partnership in solid waste management; and build the capacity of District Assemblies to better manage environmental sanitation.

\subsection{URBAN DEVELOPMENT, HOUSING AND SLUM UPGRADING/URBAN REGENERATION}

\subsubsection{Housing}

Access to adequate housing, safe water and sanitation facilities, is an important ingredient in efforts to improve the health outcomes and livelihood of Ghanaians. Current estimate of housing needs by the Ministry of Works and Housing indicate that the country needs at least seventy thousand $(70,000)$ housing units annually. Presently, the national supply is about $35 \%$ of this figure. Lack of sufficient housing units in the urban areas has contributed to overcrowding, development of illegal structures, children and young people living in the streets and undue pressure on the already limited water and sanitation facilities.

GPRS II treats housing provision as a strategic area for stimulating economic growth while at the same time improving the living conditions of Ghanaians. The very activity of providing housing contributes to economic growth through multiplier effect of housing construction on the economy. It is estimated that for every ten thousand dollars (US\$10,000) spent on housing construction more than seven (7) jobs are created in related industries and enterprises. Government is in the process of reviewing the National Shelter Policy, with the ultimate goal of providing adequate and affordable housing with requisite infrastructure and basic services to satisfy the needs of the people. 


\subsubsection{Slum Upgrading/Urban Regeneration}

The growing incidence of slum development in Ghana has been the result of rural-urban migration, limited supply of land, and regulatory frameworks that are, at best, indifferent and hostile to the needs of the poor. In 2001, the number of people living in slums in Ghanaian cities was estimated to be 4,993,000 and growing at a rate of $1.8 \%$ per annum. The slum areas are very pronounced in Accra, Kumasi, Sekondi-Takoradi, Tema and Tamale with growing incidence in the secondary cities of Cape Coast, Koforidua, Sunyani, Ho and Bolgatanga.

Priority strategies for housing and slum upgrading are as follows: strengthen the physical planning of urban settlements and ensure the enforcement of planning regulations and implementation of planning schemes; upgrade basic services in the urban areas; promote adequate supply of safe and affordable shelter; improve housing conditions in rural areas and low-income urban areas; facilitate adequate housing finance for all income groups; and) develop and promote the use of local building materials.

\section{Promote Urban Infrastructure development and provision of basic Services:}

The strategies to address urban infrastructure development and provision of basic services will include: provide and implement strategic/development plans for urban centres, enforce rules on land use plans; co-ordinate all aspects of town development; facilitate public/private partnerships in the development of urban infrastructure; provide basic urban services; foster the growth of settlements which can support rural transformation; improve infrastructure facilities in slum areas and restrict the formation of new slums; ensure efficient and effective management of flood control and drainage systems; and promote and facilitate private sector participation in flood control systems and coastal protection.

\section{Increase access to safe and affordable shelter:}

In order to increase access to safe and affordable shelter the following interventions will be pursued: streamline and improve land acquisition procedures; encourage mortgage financing by financial institutions to provide varied ending and savings services to house owners, would-be house owners and housing developers; facilitate private sector involvement in the provision of rental accommodation in urban centres; ensure that all houses have adequate facilities, which are friendly to persons living with disability and located in healthy environment, and promote the manufacturing and use of local building materials and appropriate technologies in housing.

\subsection{SOCIAL POLICY FRAMEWORK FOR MAINSTREAMING THE VULNERABLE AND EXCLUDED IN HUMAN RESOURCE DEVELOPMENT}

A significant proportion of Ghanaians including children, unemployed youth, women, persons with disabilities and the elderly either do not reach their full human potential or cannot contribute effectively to economic growth and sustainable social development due to vulnerability and exclusion. Their needs cut across many sectors and their human resource development requires a coherent and integrated Social Policy Framework and an overarching Social Protection Strategy. Several relevant social policies already exist including, the Early Childhood Care and Development (ECD) Policy, Gender and Children's Policy, Education Reform Policy, Health Reform Policy, Draft National Disability Policy, National Population Policy, Draft Youth Policy and Draft National Ageing Policy. A Draft Social Protection Strategy to cover the needs especially of the vulnerable and excluded has also been prepared. These would form the basis of the overall 
Social Development Policy Framework.

Issues of vulnerability and exclusion have been mainstreamed in the GPRS II. A comprehensive Social Policy Framework to update existing policies where necessary and provide guidelines for improved social development performance to bolster economic growth will be developed and adopted to strengthen the process of empowering the vulnerable and excluded to reduce their risks, protect their rights and enhance their contribution to national development

Critical policy issues to be addressed in GPRS II, besides education and health, include: integrated child development; strengthening of the family; HIV/AIDS; capacity development in social work and volunteerism; database on vulnerable and excluded groups; and institutional strengthening, linkages and coordination.

\subsubsection{Integrated Child Development}

As noted earlier, human capital formation starts from early childhood. Studies worldwide also show that investments in holistic early childhood care and development for children before birth to 8 years old covering care, infant stimulation, social and cognitive development, health, nutrition and early learning yield the highest rate of return of any child development activity at later stages in the life cycle. The returns are both in cost savings in fighting later poor health, malnutrition, poor cognitive and learning outcomes, school drop out etc and in positive human development, equality, poverty reduction and economic growth. Hence vigorous efforts will be made to implement the ECD policy to ensure that Ghanaian children receive the best possible care and start in life to guarantee their survival in a knowledge-based world. This will also ensure the reduction in the time burden of women and girls.

Priority attention will also be given to: child protection issues including intensified special programmes to eliminate the worst forms of child labour and child trafficking, child abuse, commercial sex exploitation of children and streetism; protect orphans and vulnerable children (OVC) and children in conflict with the law; enact the Disability, Human Trafficking and Domestic Violence Bills. The National Commission on Children and Development under MOWAC will be strengthened to harmonise and coordinate policies and activities of child development across sectors.

\subsubsection{Strengthening the Family}

Family values are under threat as cases of neglect and abuse of spouses and children increase and there is emerging dislocation of youth and parental authority and guidance. Trends in increasing single parent and female headed households indicate stresses on family members especially children. This is worsened by the fact that the family as an institution receives little or no attention from both public and private sector agencies. Departments and civil society organisations that traditionally address issues of family welfare have been quite weak and of limited effectiveness. Policy measures to alleviate the situation include: multifaceted support to build family capacity to provide for and care for its members according to their particular needs as girls, boys, women, men and the elderly taking into account peculiar social norms and practices; parenting and family life education through multimedia channels, civil society groups and trades associations; strengthen intersectoral collaboration among MMDAs and with NGOs. 


\subsubsection{HIV/AIDS and Vulnerability and Exclusion}

HIV/AIDS presents a rapidly emerging challenge to social security in Ghana. There should be an explicit strategy to harmonise efforts of public and private agencies in the campaign for behaviour change, as a means of reducing the potential impact of HIV/AIDS on vulnerability and exclusion. At the same time, the campaign against stigma and other forms of discrimination, as well as advocacy for treatment should be seen as parts of the effort to reduce vulnerability.

\subsubsection{Capacity Development in Social Work and Volunteerism}

There is a serious human capacity limitation in this area. Programmes to equip social services practitioners and new entrants with the necessary skills and at varying levels of expertise should be pursued. Existing training facilities at post secondary and tertiary levels need to be strengthened to support schools for PWDs, care programmes and skills training programmes. In addition, a more professional approach to the management of volunteerism should be introduced to encourage Ghanaians to give their time and resources towards the care and empowerment of vulnerable and excluded groups. Non-diploma short courses can be used to provide hands-on training in some cases. Community based support networks present an opportunity for such capacity building initiatives.

\subsubsection{Database on the Vulnerable and Excluded Groups}

A simple but efficient data management system will be put in place to draw social sector data into a common database that can be analysed by the Ghana Statistical Service (GSS) and presented as national statistics on the vulnerable and excluded. MMDAs should collaborate with the GSS, national research institutes, and NGOs on needed research and indepth studies ensuring that data collected are disaggregated by age, gender and geographical location. The database will facilitate and sharpen programme design, targeting, mainstreaming and monitoring and evaluation of vulnerability and exclusion in the country.

\subsubsection{Institutional Strengthening, Linkages and Coordination}

Major problems plaguing the design and implementation of social development programmes to address vulnerability are inadequate institutional framework, capacity and poor coordination. Four sector ministries have been identified as social sector ministries including MMYE, MOES, MOH and MOWAC. The Department of Community Development of the MLGRD provides assistance. Other agencies providing specialised but related support include CHRAJ, WAJU and the Legal Aid Board. Then there are numerous NGOs, CBOs and civil society organisations giving attention, care and support. The programmes of all these agencies and organisations often overlap leading to duplication and fragmentation of efforts. Compounding the problem is the absence of an overall Social Policy Framework to guide agency contributions and coordination

Policy measures to address this situation include: strengthen the technical capacity of key agencies such as the Department of Social Welfare, Department of Community Development, WAJU and CHRAJ; provide adequate human and financial resources to these and other agencies to effectively meet the needs of the vulnerable and excluded; promote 
greater linkages, complementarities and coordination among the agencies and organisations to maximize their ability to improve the lives and empower the vulnerable and excluded groups in the society. 


\section{CHAPTER FIVE}

\section{GOOD GOVERNANCE AND CIVIC RESPONSIBILITY}

\subsection{INTRODUCTION}

The broad objective of good governance and civic responsibility is to empower state and non-state entities to participate in the development process and to collaborate in promoting peace and stability in the body politic. Deepening the practice of good governance and promoting civic responsibility is one of the three areas of priority under GPRS II. The strategy to achieve this objective is to promote effective, responsible and accountable state machinery with improved capacity to engage the productive private sector and civil society in formulating policies and strategies for accelerated growth and poverty reduction and in the implementation monitoring and evaluation.

As part of the strategy for ensuring good governance, Ghana was one of the first countries to subscribe to the African Peer Review Mechanism (APRM) under the NEPAD initiative (See Box 5.1).

\footnotetext{
Box 5.1 African Peer Review Mechanism

The African Peer Review Mechanism (APRM), which is an initiative of the New Partnership of African Development (NEPAD), is a mutually agreed upon instrument which members of the African Union (AU) have voluntary acceded to as part of an African self-monitoring mechanism. The primary purpose of the APRM is to foster the adoption of policies, standards and practices that will lead to political stability, high economic growth, sustainable development and accelerated sub-regional and continental economic integration. This is expected to be achieved through the sharing of experiences and reinforcing successful and best practices, including identifying deficiencies and assessing the needs for capacity building.

In line with the initiative, Ghana completed its first country self-assessment process in February 2005. Subsequently, the assessment has been reviewed by the group of African eminent persons. Preparation of the final report on the independent country review is in progress.

Since the major objective of the APRM is to promote the use of a participatory monitoring and evaluation instrument for tracking deficiencies and weaknesses identified in the national self assessment report, the outcome of the report will influence the implementation of policies formulated under GPRS II.
}

\subsection{REVIEW OF GOVERNANCE UNDER GPRS I}

The priority areas for good governance under GPRS I included public sector reform, decentralisation, and security and rule of law. Some of the significant achievements are presented below.

\subsubsection{Public Sector Reform}

As part of the Public Sector Reform Programme, Government introduced programmes aimed at adjusting central government structures and organisations to make them more efficient, effective, and private sector-friendly. Public Financial Management Law, namely, the Financial Administration Act, 2003, (Act 654), The Internal Audit Agency Act, 2003 (Act 658) and the Public Procurement Act, 2003, (Act 663), have been enacted to regulate the utilization of public funds. In addition new approaches in the scope, timing and quality 
of reporting on budget management have been introduced.

Many other state and non-state institutions ${ }^{4}$ that have oversight responsibility for public resources are being strengthened. Fast track courts are being computerised and Parliament is being assisted with capacity building and other resources. Also key staff of the Judicial Service has acquired skills in Performance Management, Alternative Dispute Resolution, Court Automation, Case Management and Change Management.

Outside government, civil society groups such as the Ghana Anti-Corruption Coalition gained increased capacity to discharge its anti corruption advocacy.

The monitoring and evaluation of policy implementation in general has improved. The National Development Planning Commission has undertaken reviews of the implementation of GPRS and has issued three Annual Progress Reports (2002, 2003 and 2004). The dissemination of the APRs has improved public understanding of the GPRS and helped to secure public interest and ownership in monitoring the implementation of the strategy.

\subsubsection{Decentralisation}

In the area of decentralisation, greater fiscal, administrative and political empowerment at the sub-national levels has occurred through a number of policy initiatives. The District Assembly Common Fund (DACF), HIPC and other grant transfers are now regular sources of revenue for district development programmes.

To enhance the capacity of the District Assemblies to deliver on their mandate, a number of far-reaching policy initiatives have been introduced, among which are: the preparation of the National Decentralization Action Plan (NDAP); the establishment of Presidential Advisory Committee on Decentralization; the passage of the Local Government Service Bill into an Act; and the piloting of the cost-saving composite budgeting system in three districts.

In line with the goal of bringing democracy closer to the citizens and deepening good governance, 28 new District Assemblies have been created bringing the total to 138. There is growing collaboration between civil society groups and District Assemblies in managing district development programmes.

\subsubsection{Security and Rule of Law}

Considerable resources have been released for the empowerment of all law enforcement agencies and this has contributed in no small measure to the prevailing peace and security in Ghana.

Support to the security agencies including police service has enabled it to recruit additional officers, increase its equipment and logistical base, improve policing techniques, improve crime response rate and create neighbourhood watch committees as a complement to its work. Data shows a declining trend in the crime rate, which has further helped to maintain the current state of peace and security in the country. To promote safety and security of women and children, the Women and Juvenile Unit (WAJU) of the Police service is

\footnotetext{
${ }^{4}$ These include Parliament, the Judicial Service, the Controller and Accountant General Department, the Audit Service and the Ghana Anti-Corruption Coalition
} 
expanding its presence beyond the regional capitals.

At the broader level the objective of deepening the rule of law through a more robust administration of justice has led to the provision of increased support to the Ministry of Justice and Attorney General's Department, to enable it organise legal aid clinics, and expedite action on the handling of cases in court, especially for the poor and disadvantaged.

Additionally the work of the other key governance institutions including the National Commission on Civic Education and Parliament has registered positive growth. These institutions have mounted educational campaigns on civic responsibilities and on government policies. Through the repeal of prohibitive pieces of legislation, the role of the media in enhancing information dissemination has been greatly enhanced.

\subsection{CHALLENGES TO GOVERNANCE}

Despite these achievements the following areas still present challenges for good governance which need to be addressed under GPRS II:

- strengthening the process of democratisation

- improving existing institutional, legislative and policy environment

- evidence-based decision making

- ensuring gender equity

- fostering greater civic responsibility

- integrating traditional authorities into formal institutional structures for governance.

\subsubsection{Strengthening the process of democratization}

A major challenge to governance is the need to strengthen the process of democratisation. The focus is on creating space for increased citizen participation in local governance through an effective decentralisation programme, promoting the growth of strong governance institutions and integrating traditional authorities, the private sector and civil society into formal national governance structures and empowering them through information.

\subsubsection{Improving existing institutional, legal and policy environment}

The shift in emphasis of national policy towards accelerated economic growth presents another challenge to good governance, which involves the principles of transparency and accountability. For example there is the need for deliberate attempts at restoring public confidence in the banking system in order to raise the level of savings which is a prerequisite for increased local investments.

Of equal importance is the need to secure individual and corporate property rights. Appropriate policies and legislation that protect property rights, promote fidelity to contractual agreements and boost investor confidence need to be introduced or enforced where they already exist, as part of the broad governance strategy. These principles should be reflected at all levels in the management of fiscal policy, monetary policy and international trade, all of which have a strong bearing on the quest to achieve efficiency in public resource use, restrain inflationary pressures and increase the international competitiveness of the economy. 


\subsubsection{Evidence-based decision-making and public dialogue}

Although in recent years there has been some progress towards improving the quality and availability of statistics, there is still a long way to go to ensure that sufficient high-quality statistics and other information are produced and disseminated routinely and on a timely basis. Definite measures are needed to stem the loss of institutional capacity, in terms of both human resource and essential tools that have hampered the ability of the national statistical system to support government's development efforts. The capacity of the statistical system, encompassing all data generating MDAs and civil society should be enhanced to promote evidence-based governance in the public and private sectors and strengthen the government's ability to prescribe appropriate policies and assess policy effectiveness in critical areas, including macroeconomic policy, population management, gender equity, among others, in order to accelerate growth and poverty reduction.

\subsubsection{Ensuring gender equity}

The pursuit of gender equity is universally recognized as a basic prerequisite of good governance. Existing constitutional guarantees of fundamental rights and freedom provide legal backing for the protection of rights of all citizens, including women and children. However, Ghana is yet to attain the standards set by the international community as far as incorporating gender considerations into governance policies and programmes are concerned. A more daunting challenge in this regard is ensuring that these constitutional and legal provisions are practised.

\subsubsection{Fostering greater civic responsibility}

One of the main consequences of protracted periods of bad governance has been the eroding of public confidence in the institutions of state and a general lapse into apathetic, undisciplined and complacent attitudes on the part of many citizens. Personal interests and goals override public interests, often with negative outcomes in the use of time and financial resources of the state. This has undermined productivity and created hindrances to rapid economic growth. GPRS II proposes strategies to encourage active engagement of the citizenry in the process of national development within an environment that promotes responsible and disciplined civic behaviour. The strategies focus on education and dialogue, strengthening of law enforcement and exposure to systems that gradually lead to attitudinal change for the better.

\subsubsection{Involving Traditional Authorities in Development}

Provisions in the 1992 Constitution exclude chiefs from active involvement in partisan politics. Chiefs have also not been given any formal representation in the local government structure beyond discretionary participation in the district assemblies deliberation. These have not held back the role of chiefs as catalysts of development within and beyond their immediate communities. Reports of poor quality of service provision by local government administration and by external contractors within the jurisdiction of chiefs, have led to less efficient use of public resources. As part of the process of generating social accountability and achieving better development effectiveness, involving chiefs in formal development structures is becoming an unavoidable imperative. The challenge remains as to the nature of the integration and levels at which such integration should be done. An equally engaging 
challenge is whether to keep the institution outside the formal structures and channel some resources directly to chiefs to support their development efforts.

\subsection{GOVERNANCE STRATEGIES IN GPRS II}

The emphasis of GPRS II on accelerated economic growth calls for a corresponding realignment of the governance benchmarks. The appropriate policies and pieces of legislation that protect property rights, reduce the fear and aversion to savings, promote fidelity to contractual agreements and boost investor confidence, will be introduced or enforced where they already exist as part of the broad governance strategy. Additionally, the nature and processes of managing fiscal policy, monetary policy and international trade have strong bearing on the quest to achieve efficiency in public resource use, restrain inflationary pressures and increase international competitiveness of the economy.

In order to facilitate implementation in the medium term the main governance policy objectives under GPRS II are prioritised under four broad headings. These are political governance, economic governance, corporate governance and evidence-based decision making.

\subsection{POLITICAL GOVERNANCE}

Given the advances made in the practice of good governance and the challenges noted above, the need to consolidate and expand democratic practices has become a critical imperative. Key policy priorities in governance have been identified to include: strengthening parliament, enhancing decentralisation, protecting rights under rule of law, ensuring public safety and security, managing public policy, empowering women and vulnerable groups, enhancing development communication, ensuring good corporate governance, increasing access to information, and promoting civic responsibility. The policy priorities are discussed below.

\subsubsection{Strengthening Parliament}

The effectiveness of parliament has been constrained due to the fusion of functions of the arms of government leading to role conflicts for certain members of the legislature who concurrently hold ministerial responsibilities within the Executive. Resource disparity also appears to be undermining the roles of different arms of government, particularly Parliament.

To minimize the effect of conflict of roles and the risks associated with the fusion of functions of the arms of government, a review of constitutional power relations and the channeling of increased resources to parliament are proposed. A constitutional review commission will be established with a mandate to examine and make recommendations on among others, the issues of:

- maximum number of ministers that can be appointed and by the Executive

- maximum number of ministers that can be appointed from the membership of Parliament

- the perceived/apparent conflict of interest in the discharge of the dual roles of the Minister for Justice and Attorney General

- the nature and processes of Assets Declaration by public office holders 
- the age of retirement for public service office holders

- the maximum number of judges appointed to the Supreme Court

- entrenched provisions in the Constitution

- election of District Chief Executives

\subsubsection{Enhancing Decentralization}

A number of implementation difficulties have emerged since the introduction of the District Assembly concept as the core of the decentralization policy in 1988. The main constraints identified under the decentralization process include absence of a shared conceptual and political understanding across government and civil society regarding the overall pace and direction of decentralization and a general inconsistency between the legal framework for decentralization and the local government reform initiative.

The strategy to enhance decentralization includes improving administrative, political and fiscal decentralization.

With respect to administrative decentralization, a key policy objective is to strengthen the capacity of Metropolitan/Municipal/District Assemblies (MMDAs) for accountable, efficient, effective performance and service delivery. A complementary objective is to institutionalize district level planning and budgeting using a participatory approach. In this regard steps will be taken to accelerate the establishment of the Local Government Service.

Promoting citizen participation in local governance will necessarily involve accelerating the devolution of political power to the districts and sub-district structures. In the area of development planning and monitoring, GPRS II recognizes that implementation and monitoring of policies and strategies is a shared responsibility between sub-national level institutions and agencies, and those at the national level. Existing practices have been highly centralised and supply driven. Programmes will be introduced to strengthen the ownership and involvement of regional and district authorities in the GPRS II process. In addition, social accountability will be strengthened to improve the environment for citizen involvement in the development process. Regional and District Development Monitoring Groups will be adequately empowered to participate effectively in monitoring the implementation of the GPRS.

Progress towards the implementation of fiscal decentralization remains slow as MDAs still retain large fiscal decision-making powers at the expense of the MMDAs. This is largely due to the absence of the appropriate legal framework to support fiscal decentralization. Equally worrying is the issue of the low revenue generating capacity of most MMDAs. The programme to implement the recently reviewed Financial Memoranda for MMDAs offers a good opportunity to improve revenue mobilization and utilization by MMDAs. Appropriate strategies are proposed in the Policy Matrix in the Appendix I.

\subsubsection{Protecting Rights under the Rule of Law}

There is the need to promote and protect economic, social, cultural, civil and political rights as enshrined in the constitution and all international human rights instruments to which Ghana is signatory. The quality of the administration of justice is central to securing these rights. The major difficulties associated with the administration of justice in Ghana can be categorised into two, namely judicial and attitudinal. Those that can be traced to the judiciary include delays and costs in administration of justice resulting in lack of confidence 
in the judiciary, and inaccessibility of justice and legal institutions. Key attitudinal issues relate to poor compliance with rules, regulations and procedures and weak enforcement of existing rules, regulations and procedures.

The strategies for addressing these constraints are detailed in the Policy Matrix in Appendix IA.

\subsubsection{Ensuring Public Safety \& Security}

A secure and safe country enables individuals to pursue their economic activities without fear. The disruptive effects of civil strife and external aggression threaten the practice of good governance. Cases of states that are becoming gradually dysfunctional and on the brink of total collapse are evident in Africa. Forestalling such disruptions is critical for growth and poverty reduction. These considerations are instrumental in identifying public safety and security as an important policy priority. This policy priority addresses issues related to ensuring citizen safety, internal security and territorial integrity and covers immigration, control of narcotics and small arms.

Increasing national capacity to assure safety of life and property including as well as strategic national installations from man-made and natural disasters is an imperative. This is to be achieved through institutionalization of early warning systems and promoting disaster management consciousness at all levels, including effective sharing of information among public safety and security institutions.

\subsubsection{Public Policy Management and Public Sector Reform}

Addressing the challenge of public policy management requires a multifaceted approach. The strategy proposed will among others seek to promote the participation of people of all political persuasions, state and non-state actors including traditional authorities in the design and implementation of national development agenda. Traditional rulers for example would be encouraged to make inputs at the district, regional and national levels. This is aimed at promoting ownership and achieving national consensus, thereby assuring policy sustainability without disruption occasioned by changes in political administration.

Additionally, the strategy seeks to reduce overlapping functions in MDAs and promote adequate and formalized public - civic society interface through the on-going Public Sector Reform programmes. These include interventions in the area of: (i) reform of pay policy implementation and the evolution of efficient performance management and evaluation system in the public and civil service; (ii) institution of systems of reward for efficient performance and penalties for inefficiencies; and (iii) institutionalization of ethics training at all levels of the public service to promote transparency and accountability and reduce corruption. These will be augmented by institutionalization and internalization of policy formulation, planning and programming, compilation of relevant data, and a well coordinated Monitoring and Evaluation System at all levels.

An ultimate aim of improving public policy management is to achieve sustainable development, which is in line with MDG 7 i.e. mainstreaming of sustainable development principles into national policies and programmes. The evidence in Ghana suggests inconsistencies in the consideration of the environment in the public policy process. The strategy is to ensure that sustainable development principles are institutionalized and mainstreamed by subjecting the public policy formulation process to Strategic 
Public policy is effective if it is evidence-driven. The GPRS II will promote evidence-based decision-making through strengthening of institutions that have the responsibility to generate the appropriate data and information on policy implementation in a timely and a more proactive manner.

\subsubsection{Fighting Corruption and Economic Crimes}

The government policy on corruption, over the past years has been focused on eliminating malfeasance in public administration, especially those that relate to fraudulent payments and wages. The CHRAJ, SFO, the Audit Service and the Controller and Accountant-General's Department were all supported to perform their statutory duties. Other complementary measures that were taken included; the introduction and stern application of criminal law, promotion of civic education, promotion of the National Integrity Initiative (as a local chapter of Transparency International), and the creation of the Ghana Anti-Corruption Coalition. The Office of Accountability was created in 2003 as an internal corrective body under the Presidency, with the responsibility for identifying and dealing with issues relating to corruption within the Executive.

The incidence of corruption and economic crimes still remains a challenge to good governance. To address this problem, GPRS II proposes a three-pronged approach; (i) reducing opportunities for rent-seeking, (ii) strengthening the capacity of the anti-corruption institutions and the law enforcement agencies; and (iii) encouraging civil society organizations, including the media to play their role effectively. Specific strategies to achieve these objectives are outlined in the attached matrix.

\subsubsection{Empowering Women}

Disparities among women and men are being reduced as a result of specific interventions at all levels of the economic, political, social and cultural structures. Despite progress made to broaden the space for women in politics and decision-making, a lot more needs to be done. Among the interventions to address the imbalance is the reform of outmoded customs that violate women's rights. The active participation of traditional authorities in this respect cannot be over-emphasized. There is also the need for mainstreaming gender into policy formulation and budgeting processes, supported with proper documentation and analysis of the patterns and magnitude of sex-differentials in key indicators.

Existing gaps in the legal framework that limit the opportunities of women to participate in public decision-making on an equitable basis will be closed. The systematic compilation, analysis and dissemination of gender disaggregated statistics on all aspects of life - social, economic and political, is essential for effective targeting of programme interventions.

\subsubsection{Enhancing Development Communication}

The lack of a coherent communications strategy has been identified as one of the major limitations of GPRS I.

The main challenges therefore are the management of information both quantitative and qualitative - inter/intra institutional frameworks and the lack of adequate database for 
planning. The key strategy is to ensure implementation of existing communication strategies at all levels while promoting the development of modern information management system including e-governance and the application of ICT in the information flow. Strategies to strengthen the critical role of the media in enhancing development communication will be promoted.

\subsubsection{Promoting Civic Responsibility}

Civic responsibility involves understanding what it takes to be a good citizen, as well as acceptable attitudes and behaviour within the society and at workplaces that promote sustainable national development. The increasing over-dependence on government by communities for the provision of all basic necessities of life undermines ownership, maintenance and the sense of civic responsibility for sustaining development initiatives. Over the years, state and non-state institutions have played various advocacy roles in integrating civic responsibility in the body politic; however a lot remains to be done with respect to indiscipline and disregard for laws, poor work ethics and attitudes, irresponsible conduct of adults and lack of a sense of patriotism. To address these issues a number of strategies both at the formal and the informal level will be pursued.

In the public domain, rules and regulations will be enforced systematically in all spheres, including school, workplaces, on the streets, in religious institutions, etc. Also measures will be instituted to reward responsible behaviour. Institutions including National Commission for Civic Education will be strengthened to pursue advocacy roles in this regard.

The return of society to traditional values of neighbourly conduct, respect for authority, honesty and integrity, will be pursued through the full implementation of Ghana Cultural policy. In addition the formal and informal institutions of socialization and learning will be supported to perform their roles as channels of change. At the community level, traditional authorities would be empowered to actively participate in ensuring responsible civic behaviour. Additionally, civic education materials taught in basic schools will be expanded to include civic responsibilities. Partnership with the public media will be strengthened to promote civic responsible behaviour.

\subsection{ECONOMIC GOVERNANCE}

Lessons learnt from the implementation of GPRS I point to the attainment of generally positive targeted economic indicators. However there is the need to sustain these gains, while introducing new initiatives where necessary to support accelerated growth and poverty reduction.

The priorities for enhancing Economic Governance under GPRS II will focus on Fiscal Policy Management, Monetary Policy Management and International Trade Management.

\subsubsection{Fiscal Policy Management}

Ongoing initiatives elaborated in GPRS I will be enhanced. The strategies will focus on improving public expenditure management, promoting effective debt management, and improving fiscal resource mobilization. 


\section{Improving Public Expenditure Management:}

Efforts will be intensified to further improve public expenditure management started under the GPRS I such as the adoption of computerised accounting and financial management systems. The MTEF and PUFMARP initiatives will be reviewed and refinanced with a view to further strengthening its implementation. The BPEMS will also be fully implemented.

Other strategies will include developing a more effective mechanism for data collection, commitment control and procurement, transparency in the use of special statutory funds, enforcing budget controls on the State Owned Enterprises (SOEs) and strengthening payroll management.

\section{Promoting Effective Debt Management:}

Considerable success has been achieved in restructuring and reducing the domestic debt stock. The domestic debt management efforts will be continued to further reduce and stabilise the domestic debt to stem the increase in interest payments and achieve the desired decline in real interest rates.

This requires more effective mechanisms to monitor the debt stock, restructure the domestic debt to ensure a greater balance between short and long-term debt instruments re-direct more resources to reduce the size of the domestic debt and limit domestic borrowing.

\subsubsection{Improving Fiscal Resource Mobilization}

Achieving higher levels of growth and poverty reduction requires increasing revenue generating capacities to finance and sustain the growth and poverty reduction efforts.

The strategies include: minimize revenue leakages in all revenue collection agencies; review and revise existing taxes, fees and user charges; strengthen the capacities of revenue collecting agencies; and strengthening the District Assemblies for improved tax collection.

\subsubsection{Monetary Policy Management}

Monetary policy management will continue to focus on price and exchange rate stability. This is to further reduce inflation, minimise exchange rate fluctuations and promote the efficient operation of the banking and credit systems. The Bank of Ghana will work to remove the inefficiencies in the management of the financial sector in order to allow for a well functioning sector which impacts positively on growth and poverty reduction.

Government in pursuit of monetary policy will continue to use open market operations and adjustments in the prime rate to achieve its objectives. The thrust of monetary policy will be on market-oriented policy measures that will allow for smooth functioning of the financial system, in addition to creating a more diversified financial sector and improved access to financial services. The effective functioning of the Monetary Policy Committee (MPC) will be ensured to: achieve price and exchange rate stability; improve liquidity management; establish an efficient inter-bank foreign exchange market; and improve the institutional, legal and regulatory framework for monetary management. In addition the establishment of a central securities depository for government securities, enactment of long-term savings law for private pension and housing schemes, and improvement in the administrative framework for micro finance will be central to monetary policy. 
Given the growing importance of foreign remittances in the Ghanaian economy, policies aimed at reducing the cost of remittances (both implicit and explicit) as well as those aimed at channelling remittances through the formal sector will be pursued.

\subsubsection{International Trade Management}

The main governance issues underlying international trade management within the framework of trade liberalization are related to international treaties, agreements, market access, trade barriers, dumping, among others. A comprehensive Trade Policy has been developed for Ghana that provides guidelines for the implementation of government's domestic and international trade agenda. The policy is set within the context of Ghana's long-term strategic vision of achieving middle-income status by 2015 and also becoming a leading agro-industrial country. The fundamental principle underlying the Trade Policy is the recognition of the private sector as the engine of growth with government providing a trade-enabling environment to actively stimulate private sector initiatives.

GPRS II will promote the elimination of constraints to international trade including: reduce the administrative bottlenecks associated with the export and import processes; minimize the incidence of "dumping"; diversify and increase the export base; promote new areas of competitive advantage; continue to take full advantage of preferential access to markets (AGOA, EU-ACP); engage fully in multi-lateral trade negotiations; and set up information system to track and measure progress in these areas.

\subsection{GOOD CORPORATE GOVERNANCE}

The quality of corporate governance practices has a direct impact on accelerated growth and poverty reduction. The recent events leading to business failures around the world and the misapplication of public funds in Ghana have reinforced the need for effective corporate governance. The strategic direction in this regard will be to: promote an enabling environment and effective regulatory framework for corporate management; ensure that corporations act as good corporate citizens with regard to human rights, social responsibility and environmental sustainability; promote the adoption of codes of good business ethics in achieving the objectives of the organization; ensure that corporations treat all their stakeholders in a fair and just manner, and; provide for accountability of corporations and directors.

\subsection{PROMOTING EVIDENCE-BASED DECISION MAKING}

Availability of relevant and timely statistics is critical to enabling conditions for policy development and assessment that allow for measuring inputs, outcomes, and impacts. Relevant, reliable statistics convey the clearest message with regards to policy intention, evidence-based outcome, effectiveness, and accountability of the government. They are also the most effective means to empower and facilitate the public's participation in the national development process, and ensure transparency and accountability, including policy dialogue, policy formulation, monitoring of implementation, and evaluation of the outcomes.

A major challenge to strengthening the data base for policy formulation and decisionmaking is how to shift from the existing practise of using a fragmented set of uncoordinated 
statistical programmes to a national statistical system with coherent and integrated activities, and harmonized methodologies. This will ensure that consistent definitions are used and comparable statistics are produced and disseminated.

Strategies to address this issue will include strengthening of the national statistical system to generate good-quality and consistent data on the key areas of the GPRS II, including in particular, the development of economic indicators.

Among the activities to upgrade the performance of the national statistical system and ensure transparency and accountability are: rationalizing the production of data within the statistical system, defining the roles and mandates of the various data producing institutions, adopting common definitions, methods and classifications; a review of the Statistical Law and adoption of a statistical master plan; and application of international standards and good practices system-wide, including the United Nations Principles for Official Statistics and the IMF's General Data Dissemination Standards. 


\section{CHAPTER SIX}

\section{MONITORING AND EVALUATION}

\subsection{INTRODUCTION}

Monitoring and Evaluation (M\&E) has served as an essential management tool in the GPRS I, and will provide an additional impetus both in the pursuit of policy, programme and project effectiveness and to ensure accountability, responsiveness and transparency in the allocation of resources in GPRS II.

\subsection{REVIEW OF M\&E SYSTEM UNDER GPRS I}

A comprehensive GPRS Monitoring and Evaluation Plan was formulated to support the implementation of GPRS I. Key policy initiatives under the plan included the following;

- development of institutional framework for coordinating the system, including analysis and mode of reporting on the progress on GPRS implementation to different stakeholders, including Government, civil society and development partners

- establishment of monitoring indicators against GPRS baselines and core targets

- establishment of special indicators to facilitate the tracking of the HIPC, Millennium Development Goals (MDGs), and the Medium terms priorities.

- studies to enhance the knowledge and data base for the conduct of objective impact analysis of GPRS (i.e. PSIAs).

- plans for dissemination and a communication strategy were adopted, based on sound understanding of the key stakeholders, the information they required from the monitoring and evaluation system, how best to communicate with them, and what range and style of outputs should be produced.

- wider stakeholder participation (government, parliament, NGOs, CSOs, private sector) in monitoring progress of the GPRS was agreed in the Monitoring and Evaluation Plan

\subsubsection{Key Achievements}

M\&E Institutional Arrangements: The following groups were established to support the implementation of the GPRS I Monitoring and Evaluation Plan: (i) The National IntraAgency Poverty Monitoring Groups (NIPMG) chaired by representatives of MDAs (ii) GPRS Dissemination Committee; and (iii) The PSIA Technical and Advisory Committees.

Five NIPMG based on the GPRS I thematic areas have been established at the national level. These groups are inter-sectoral and include both governmental and non-governmental representatives selected for their expertise in a specific thematic area. To deepen the M\&E institutional arrangements, Regional poverty monitoring groups have been established as well.

M\&E Communication Strategy: A comprehensive communication strategy was developed at the end of the third quarter of 2003, to inform and educate all stakeholders about the GPRS and the APRs findings. In addition, the interaction with civil society organisations (CSOs) has been improved to enhance the mechanism of effective representation in the $\mathrm{M} \& \mathrm{E}$ process. 
Monitoring the GPRS Indicators: The Annual Progress Report (APR) has provided the key platform for the monitoring and evaluation of progress towards the achievement of GPRS targets as well as the outcomes and impacts of government policies. Three successions of APRs (2002, 2003 and 2004) have been prepared and widely disseminated. The recommendations from these reports have influenced the respective annual national budgets and the formulation of GPRS II.

As part of the process of determining the impact of the socio-economic policies on the poor, poverty and social impact analysis (PSIAs) studies were also undertaken. The National Development Planning Commission (NDPC) with the support of development partners has commissioned five PSIAs to ascertain the impacts of selected policy reforms implemented under the GPRS.

\subsubsection{The Challenges}

Among the lessons drawn from the implementation of the current M\&E system are the severe institutional and technical capacity constraints and the fragmented set of uncoordinated information, both at the national and sub-national levels that confront the development of an effective and efficient M\&E system. The two key institutions, the National Development Planning Commission (NDPC) and the Ghana Statistical Service (GSS), continue to depend on the existing systems of MDAs, who are the primary sources, of information. These systems which have been in place over different time spans reflect a variety of approaches to sector specific monitoring and varying degrees of success. Another level of contribution lies with the regional and district level institutions, embodied in the District Assemblies.

\subsection{STRENGTHENING THE M\&E SYSTEM UNDER GPRS II}

In spite of the achievements in M\&E for the GPRS I, more is needed to ensure that the system is firmly established, recognized and accepted by all, with full participation and contribution of all stakeholders. The key institutions need to be strengthened and empowered to lead the process and sustain the system with continuous flow of timely, reliable, accurate and relevant information that will be used to track progress. A common, centrally located database will be established for the storage and retrieval of basic data for the country as a whole, and also by regions and districts, providing easy assess to all stakeholders, of which a national database in the form of (GhanaInfo) ${ }^{5}$ is the core.

The primary goal of the M\&E System under GPRS II is to facilitate the tracking of progress and effectiveness, as well as to identify bottlenecks associated with the implementation of the Strategy. The proposed system, which forms an integral part of the GPRS II, would have the following specific objectives:

- $\quad$ reinforcing institutional arrangements with adequate capacity to support and sustain effective monitoring and evaluation

- $\quad$ strengthening and effectively coordinating existing mechanisms for monitoring and evaluating the effectiveness of public sector service delivery

- $\quad$ evolving an efficient system for generating relevant, reliable and timely quantitative and qualitative information

\footnotetext{
${ }^{5}$ GhanaInfo is a comprehensive and up to date national socio-economic database system that was launched in Ghana in July 2005. It is expected, among others, to increase availability of up-to-date indicators for monitoring the implementation of GPRS II.
} 
- managing an effective feedback mechanism that make statistical information available in useable form to government and civil society

- $\quad$ ensuring a holistic approach to M\&E that would include monitoring of inputs (notably resource allocation and use), as well as processes and outputs, in addition to evaluating the outcomes of programmes/ projects.

- fostering participatory M\&E

- $\quad$ improving coordination between CMAs and MDAs to strengthen demand for M\&E.

\subsubsection{Reinforcing institutional arrangements}

The key institutions involved in the participatory M\&E system includes: Office of the President, Parliament, NDPC, Ministry of Finance and Economic Planning, Ghana Statistical Service, PPMEDs of MDAs, National Inter-Agency Monitoring Groups, Regional Monitoring Groups, District Monitoring Groups and Civil Society Organisations. The technical responsibility for coordinating the system rests with NDPC in active collaboration with GSS.

In conformity with the decentralization policy, it is important that all district assemblies have staff on their team representing these two institutional components of the $M \& E$ system.

To ensure improved implementation of the M\&E plan the institutional arrangements currently in place will be reviewed to identify ways of strengthening roles and institutional capacities.

\subsubsection{Strengthening and effective coordination of existing mechanisms}

Greater coordination is needed between the key government agencies including the Office of President, NDPC, MOFEP, GSS, MLGRD and the other MDAs. This includes better information flow and incentives for monitoring and evaluation at all levels. There is therefore the need to build the capacities and develop the expertise in these key institutions for effective coordination and sustainability of the M\&E system.

\subsubsection{Evolving an efficient system for evidence-based monitoring and evaluation:}

Adopting an evidence-based M\&E systems will mean ensuring a holistic approach to M\&E that would include monitoring of inputs (notably resource allocation and use), as well as processes and outputs, in addition to evaluating the outcomes of programmes/ projects. Essential to the M\&E plan is the selection of core indicators to be used in tracking the performance of the GPRS II implementation. Indicators will be disaggregated to a level appropriate for proper tracking of differential impact of poverty with respect to districts, gender, and ecological zones. Data collected during the implementation of GPRS I and other existing reports and surveys will form the basis for developing indicators, where appropriate, for GPRS II.

The Ghana Statistical Service (GSS) will oversee data collection and compilation activities across government institutions. The GSS will therefore continue to take the lead role in all 
major surveys and in the systematic compilation of statistics and indicators from all major sources of data, i.e., censuses, sample surveys, and administrative records.

A crucial component of evidence-based $M \& E$ is the management of effective feedback mechanisms which is in turn contingent upon a good data dissemination system founded on a comprehensive database. At present, though the Ghana Statistical Service does not produce enough statistics to meet the wide range of needs, the limited data available through censuses and surveys are underutilized, and are generally not made available to users who could add value to the statistics through their research and policy analysis. Moreover, most MDAs collect administrative information that can be processed to generate valuable statistics. More concerted effort would need to be made to harness the potentials of these rich sources of data.

The GhanaInfo will be the software for the compilation and dissemination of indicators required for monitoring GPRS II at the district, regional and national levels. A National Expenditure Tracking System (NETS) has been developed by the Ministry of Finance and Economic Planning and the Accountant General's Department to capture all sources of public sector funds and expenditure. This system is being rolled out to MDAs. The NETS will serve as a useful link for the monitoring (at least on expenditure or inputs) of the implementation of the GPRS when harmonization of GPRS format with the MTEF budget format is completed.

\subsubsection{Ensuring participatory monitoring and evaluation}

Under GPRS II a participatory M\&E mechanism will be implemented by deploying the knowledge resources of a wide of stakeholders including central and local governments, NGOs, civil society organisations, the private sector, the academic community and, especially, poor people themselves in the monitoring and evaluation processes. This will be achieved through consultative mechanisms including Citizen's Report Cards and independent results elicited from the African Peer Review Mechanism (APRM) which periodically assesses the performance of Government interventions and their impact on growth and poverty reduction.

Dissemination of information on growth and poverty reduction will continue to be a key component of the monitoring and evaluation plan. Efforts will be made to ensure that timely information is available in the right form to meet the needs of stakeholders, including development partners.

Regular Bulletins will be prepared and disseminated by PPMEDs and MMDAs to inform stakeholders on the status of M\&E activities. Annual Progress Reports (APRs) will continue to be produced in the first quarter of each year by the National Development Planning Commission. The report will summarise the movements of significant indicators during the year, including the Millennium Development Goals, the District Assemblies' Common Fund, and the disbursement and utilization of HIPC funds.

A central repository of relevant documentation on the GPRS will be established at the NDPC. 


\section{CHAPTER SEVEN}

\section{FINANCING THE GPRS II}

\subsection{The Resource Envelope}

The resource envelope comprises both domestic and external sources of financing. In each of the four years within the GPRS II period, budgetary resources will constitute an average of 35 percent of annual GDP. Domestic revenue sources make up some 23 percent of GDP, while grants from bilateral and multilateral sources constitute about 5.5 percent of GDP. The remaining 6.5 percent is expected to come from divestiture receipts, programme loans and exceptional financing arrangements.

It is envisage that Ghana would gradually wean itself off excessive reliance on donor budgetary support. This will entail intensified domestic revenue mobilization that will not damage Ghana's competitiveness within a tax framework ascertained as fair by taxpayers, especially by corporate enterprises. Although the potential for additional domestic resource mobilization appears to be circumscribed, efforts will be directed at increased tax revenue mobilization at the margin through three main areas, viz:

- broadening the tax base to raise the tax - GDP ratio with minimal additional tax increases after critical impact analyses

- elimination of exemptions and loopholes in the tax system, and

- strengthening of tax administration, especially in areas where efficiency gains have not been fully explored exhausted, such as customs and the informal sector.

With regard to external inflows, it is expected that HIPC savings and other debt relief as well as resources from the Millennium Challenge Account will be channelled to augment domestic resources. Proceeds from the MCA Compact, in particular, will largely enhance the financing of transport and irrigation facilities required to promote integrated agricultural development. With the current improved sovereign ratings and the deepening and sustenance of political and economic governance, Ghana can take advantage of resources on the international capital market by issuing sovereign bonds.

Additionally, the financial environment is expected to improve significantly with the implementation of the Financial Sector Strategic Plan. This initiative will impact positively on the mobilization of domestic savings for the strengthening of the private sector. Two key policy instruments, namely, the long term savings schemes, and the Venture Capital funds will be instituted to strengthen the financial environment for the implementation of the GPRS II. 
Table 7.1: Medium Term Expenditure Framework - 2005-2009

(a) Total Payments (in billion cedis)

\begin{tabular}{|c|c|c|c|c|c|}
\hline & $\begin{array}{c}2005 \\
\begin{array}{c}\text { Proj. Outturn } \\
\text { (Q1-Q4) }\end{array}\end{array}$ & $\begin{array}{c}2006 \\
\text { Budget } \\
\text { Estimate } \\
\end{array}$ & $\begin{array}{c}2007 \\
\text { Projected } \\
\text { Estimates } \\
\end{array}$ & $\begin{array}{c}2008 \\
\text { Projected } \\
\text { Estimates } \\
\end{array}$ & $\begin{array}{c}2009 \\
\text { Projected } \\
\text { Estimates } \\
\end{array}$ \\
\hline Total Payments & $35,672.2$ & $38,972.9$ & $44,767.4$ & $49,828.7$ & $55,135.9$ \\
\hline Statutory Payments & $12,217.6$ & $13,993.2$ & $13,035.1$ & $13,637.4$ & $14,775.1$ \\
\hline External Debt Service & $3,610.0$ & $4,537.4$ & $3,404.5$ & $3,417.5$ & $3,898.6$ \\
\hline Principal 1/ & $2,608.0$ & $3,473.1$ & $2,452.9$ & $2,447.1$ & $2,778.4$ \\
\hline Interest & $1,002.0$ & $1,064.3$ & 951.6 & 970.3 & $1,120.1$ \\
\hline Domestic Interest & $2,470.6$ & $2,426.8$ & $1,607.9$ & $1,187.4$ & 848.5 \\
\hline District Assemblies Common Fund & $1,069.9$ & $1,204.3$ & $1,443.7$ & $1,607.8$ & $1,780.4$ \\
\hline Transfers to Households & $2,927.8$ & $3,340.6$ & $3,789.4$ & $4,280.8$ & $4,759.7$ \\
\hline Pensions & 613.8 & 705.9 & 804.5 & 911.0 & $1,012.9$ \\
\hline Gratuities & 356.0 & 409.4 & 466.6 & 528.4 & 587.5 \\
\hline Social Security & 618.8 & 711.6 & 793.2 & 887.9 & 987.2 \\
\hline National Health Fund (NHF) & $1,339.2$ & $1,513.7$ & $1,725.1$ & $1,953.5$ & $2,172.1$ \\
\hline Education Trust Fund & $1,175.6$ & $1,386.3$ & $1,538.4$ & $1,727.1$ & $1,912.7$ \\
\hline Road Fund & 883.3 & $1,068.9$ & $1,251.2$ & $1,416.8$ & $1, \mathbf{5 7 5 . 3}$ \\
\hline Petroleum-related Fund & 80.3 & 28.9 & 0.0 & $\mathbf{0 . 0}$ & $\mathbf{0 . 0}$ \\
\hline Discretionary Payments & $23,454.6$ & $24,979.7$ & $31,732.4$ & $36,191.4$ & $40,360.9$ \\
\hline Personal Emoluments (MDAs- Item 1) & $8,683.1$ & $9,990.0$ & $11,129.7$ & $12,458.2$ & $13,851.9$ \\
\hline Administration (MDAs- Item 2) & $1,613.0$ & $2,186.8$ & $2,507.0$ & $2,853.0$ & $3,184.0$ \\
\hline $\begin{array}{l}\text { Service (MDAs- Item 3) } \\
\text { Domestic Investment (Item 4) (Excl. }\end{array}$ & 969.6 & 808.8 & 927.3 & $1,055.2$ & $1,177.6$ \\
\hline Statutory Funds) & $1,427.9$ & $1,684.8$ & $3,200.3$ & $4,783.7$ & $8,484.4$ \\
\hline Net Lending & 98.0 & 39.5 & 0.0 & $\mathbf{0 . 0}$ & $\mathbf{0 . 0}$ \\
\hline New Loans & 98.0 & 39.5 & 0.0 & 0.0 & 0.0 \\
\hline Loan Recoveries & 0.0 & 0.0 & 0.0 & 0.0 & 0.0 \\
\hline Foreign-financed Investment (Item 4) & $5,790.0$ & $6,251.8$ & $8,279.3$ & $9,646.9$ & $10,791.0$ \\
\hline Strategic Oil Stocks & 145.0 & 145.0 & 145.0 & 145.0 & 145.0 \\
\hline VAT refunds & 72.0 & 100.0 & 111.0 & 124.6 & 138.0 \\
\hline Outstanding Commitments & $1,117.7$ & 347.0 & 97.0 & 0.0 & $\mathbf{0 . 0}$ \\
\hline Roads & 100.0 & 100.0 & 0.0 & 0.0 & 0.0 \\
\hline Non-roads & $1,017.7$ & 247.0 & 97.0 & 0.0 & 0.0 \\
\hline Utility Price Subsidies & 412.0 & $\mathbf{0 . 0}$ & 0.0 & 0.0 & $\mathbf{0 . 0}$ \\
\hline o/w TOR's Under- recovery & 412.0 & & & & \\
\hline Other Transfers & 350.0 & 350.0 & 398.9 & 451.8 & 502.2 \\
\hline Safety net for petroleum deregulation & 250.0 & 250.0 & 284.9 & 322.7 & 358.7 \\
\hline Lifeline consumers of electricity & 100.0 & 100.0 & 114.0 & 129.1 & 143.5 \\
\hline HIPC-financed Expenditure & $1,614.8$ & $1,822.1$ & $2,193.8$ & $2,114.3$ & $2,086.8$ \\
\hline Divestiture Liabilities & 0.0 & 0.0 & $\mathbf{0 . 0}$ & $\mathbf{0 . 0}$ & 0.0 \\
\hline $\begin{array}{l}\text { Repayment of Domestic Debt } \\
\text { Redemption of Deferred Interest }\end{array}$ & 996.2 & $1,167.7$ & $2,740.0$ & $2,558.7$ & $\mathbf{0 . 0}$ \\
\hline Payments on inflation-indexed Bonds & 165.3 & 86.2 & 3.1 & $\mathbf{0 . 0}$ & $\mathbf{0 . 0}$ \\
\hline Discrepancy & 0.0 & 0.0 & 0.0 & 0.0 & 0.0 \\
\hline
\end{tabular}


(b) Total Receipts (in billion cedis)

\begin{tabular}{|c|c|c|c|c|c|}
\hline & $\begin{array}{c}2005 \\
\text { Proj. Outturn } \\
\text { (Q1-Q4) }\end{array}$ & $\begin{array}{c}2006 \\
\text { Budget } \\
\text { Estimates }\end{array}$ & $\begin{array}{c}2007 \\
\text { Projected } \\
\text { Estimates }\end{array}$ & $\begin{array}{c}2008 \\
\text { Projected } \\
\text { Estimates }\end{array}$ & $\begin{array}{c}2009 \\
\text { Projected } \\
\text { Estimates }\end{array}$ \\
\hline $\begin{array}{l}\text { Total receipts } \\
\text { Total Revenue (domestic tax }\end{array}$ & $35,672.5$ & $38,972.9$ & $44,767.4$ & $49,828.7$ & $55,135.9$ \\
\hline and non-tax) & $24,116.2$ & $26,411.3$ & $29,902.3$ & $33,303.9$ & $36,872.0$ \\
\hline Grants & $5,354.8$ & $5,099.3$ & $7,400.3$ & $8,467.6$ & $9,104.3$ \\
\hline Project & $2,840.0$ & $2,505.9$ & $4,028.1$ & $4,866.6$ & $5,443.7$ \\
\hline Programme & $1,354.0$ & $1,388.0$ & $2,091.5$ & $2,351.8$ & $2,630.7$ \\
\hline HIPC Assistance & $1,160.8$ & $1,205.4$ & $1,280.7$ & $1,249.2$ & $1,029.9$ \\
\hline Loans & $4,437.0$ & $5,383.4$ & $6,018.6$ & $6,767.7$ & $7,570.3$ \\
\hline Project Loans & $2,950.0$ & $3,746.0$ & $4,251.2$ & $4,780.4$ & $5,347.3$ \\
\hline Programme Loans & $1,487.0$ & $1,637.5$ & $1,767.3$ & $1,987.3$ & $2,223.0$ \\
\hline Divestiture Receipts & 150.0 & 335.0 & 0.0 & 0.0 & $\mathbf{0 . 0}$ \\
\hline $\begin{array}{l}\text { Domestic Financing (Borrowing) } \\
\text { Deferred Interest Payments on }\end{array}$ & 0.0 & 0.0 & $\mathbf{0 . 0}$ & 0.0 & 93.1 \\
\hline $\begin{array}{l}\text { Inflation-indexed Bonds } \\
\text { Exceptional Financing (HIPC Debt }\end{array}$ & 66.7 & 14.8 & 0.0 & 0.0 & $\mathbf{0 . 0}$ \\
\hline Relief) & $1,547.8$ & $1,729.1$ & $1,446.2$ & $1,289.6$ & $1,496.3$ \\
\hline $\begin{array}{l}\text { Memo items } \\
\text { Overall Cash Balance (including }\end{array}$ & & & & & \\
\hline Divestiture) & $-2,281.7$ & $-2,400.4$ & $-2,268.8$ & $-3,051.4$ & $-6,381.2$ \\
\hline percent of GDP & -2.4 & -2.1 & -1.8 & -2.1 & -4.0 \\
\hline Domestic Revenue & $24,116.2$ & $26,411.3$ & $29,902.3$ & $33,303.9$ & $36,872.0$ \\
\hline percent of GDP & 24.9 & 23.5 & 23.4 & 23.0 & 22.9 \\
\hline Domestic Primary Expenditure & $21,522.4$ & $24,156.1$ & $28,635.7$ & $33,018.2$ & $39,597.9$ \\
\hline percent of GDP & 22.2 & 21.5 & 22.4 & 22.8 & 24.6 \\
\hline Domestic Primary Balance & $2,593.8$ & $2,255.3$ & $1,266.7$ & 285.7 & $-2,726.0$ \\
\hline percent of GDP & 2.7 & 2.0 & 1.0 & 0.2 & -1.7 \\
\hline Nominal GDP (billion cedis) & 97,018.0 & $112,320.3$ & $128,012.8$ & $144,960.7$ & $161,177.3$ \\
\hline
\end{tabular}

\subsection{The Resource Gap}

The estimated total resources required to finance the GPRS II is US\$ 8.06 billion (20062009). These costs consist primarily of investment and service costs and exclude wages, salaries and administrative expenses associated with project and programme implementation. The budgeted expenditures for investments and services over the same period amount to US\$6.27 billion, indicating an overall funding gap of $\$ 1.79$ billion, which is expected to be filled by external inflows and resources from the capital market.

The external inflows expected to be harnessed from HIPC savings, debt cancellation and Millennium Challenge Account will complement domestic resources. Given Ghana's favourable sovereign ratings, augmented by good governance, additional resources could be sourced from the international capital market. 


\section{APPENDICES}

\section{APPENDIX 1: Ranking of Poverty Incidence by Region and by Districts}

\begin{tabular}{|c|c|c|c|c|}
\hline REGION & DISTRICT & OVERALL & RURAL & URBAN \\
\hline GREATER ACCRA & AMA & 8 & 0 & 8 \\
\hline GREATER ACCRA & TMA & 19 & 35 & 17 \\
\hline GREATER ACCRA & $\mathrm{Ga}$ & 26 & 54 & 16 \\
\hline GREATER ACCRA & Dangbe West & 51 & 58 & 29 \\
\hline GREATER ACCRA & Dangbe East & 54 & 61 & 23 \\
\hline WESTERN & Wassa West & 16 & 18 & 11 \\
\hline WESTERN & SAEMA & 17 & 0 & 17 \\
\hline WESTERN & Juabeso-Bia & 22 & 22 & 29 \\
\hline WESTERN & Bibiani/Anhwiaso/Bekwai & 23 & 25 & 19 \\
\hline WESTERN & Wassa Amenfi & 25 & 26 & 22 \\
\hline WESTERN & Sefwi-Wiawso & 28 & 28 & 30 \\
\hline WESTERN & Mpohor/Wassa East & 29 & 29 & 30 \\
\hline WESTERN & Aowin/Suaman & 29 & 28 & 32 \\
\hline WESTERN & Jomoro & 42 & 51 & 20 \\
\hline WESTERN & Ahanta West & 44 & 51 & 15 \\
\hline WESTERN & Nzema East & 45 & 55 & 18 \\
\hline ASHANTI & KMA & 10 & 0 & 10 \\
\hline ASHANTI & Adansi West & 25 & 47 & 10 \\
\hline ASHANTI & Afigya/Kwabere & 36 & 43 & 25 \\
\hline ASHANTI & Ashanti Akim North & 37 & 52 & 25 \\
\hline ASHANTI & Ejusu/Juaben & 40 & 46 & 22 \\
\hline ASHANTI & Afigya Sekyere & 43 & 53 & 24 \\
\hline ASHANTI & Sekyere West & 44 & 58 & 23 \\
\hline ASHANTI & Atwima & 45 & 51 & 25 \\
\hline ASHANTI & Ashanti Akim South & 45 & 49 & 29 \\
\hline ASHANTI & Offinso & 47 & 53 & 33 \\
\hline ASHANTI & Amansie East & 50 & 54 & 19 \\
\hline ASHANTI & Bosomtwe/Atwima/Kwawoma & 50 & 51 & 46 \\
\hline ASHANTI & Amansie West & 52 & 52 & 0 \\
\hline ASHANTI & Ejura/Sekyeredumase & 52 & 65 & 38 \\
\hline ASHANTI & Sekyere East & 53 & 65 & 30 \\
\hline ASHANTI & Ahafo-Ano North & 55 & 62 & 23 \\
\hline ASHANTI & Adansi East & 57 & 60 & 21 \\
\hline ASHANTI & Ahafo-Ano South & 64 & 65 & 50 \\
\hline BRONG AHAFO & Sunyani & 34 & 58 & 25 \\
\hline BRONG AHAFO & Berekum & 37 & 54 & 23 \\
\hline BRONG AHAFO & Techiman & 41 & 63 & 24 \\
\hline BRONG AHAFO & Tanoso & 48 & 61 & 31 \\
\hline BRONG AHAFO & Dormaa & 51 & 62 & 28 \\
\hline BRONG AHAFO & Asunafo & 56 & 64 & 35 \\
\hline BRONG AHAFO & Asutifi & 60 & 64 & 37 \\
\hline BRONG AHAFO & Jaman & 69 & 80 & 41 \\
\hline BRONG AHAFO & Atebubu & 69 & 85 & 35 \\
\hline BRONG AHAFO & Wenchi & 71 & 83 & 44 \\
\hline BRONG AHAFO & Nkoranza & 71 & 83 & 35 \\
\hline BRONG AHAFO & Kintampo & 73 & 86 & 32 \\
\hline BRONG AHAFO & Sene & 83 & 89 & 24 \\
\hline VOLTA & Kadjebi & 33 & 35 & 23 \\
\hline VOLTA & Nkwanta & 43 & 45 & 24 \\
\hline VOLTA & Kpando & 44 & 51 & 21 \\
\hline VOLTA & Ho & 45 & 58 & 20 \\
\hline VOLTA & Keta & 46 & 54 & 40 \\
\hline VOLTA & Hohoe & 49 & 54 & 27 \\
\hline VOLTA & Ketu & 52 & 60 & 37 \\
\hline VOLTA & Jasikan & 52 & 55 & 38 \\
\hline VOLTA & Krachi & 53 & 53 & 49 \\
\hline VOLTA & South Tongu & 58 & 61 & 36 \\
\hline
\end{tabular}




\begin{tabular}{|c|c|c|c|c|}
\hline REGION & DISTRICT & OVERALL & RURAL & URBAN \\
\hline VOLTA & Akatsi & 60 & 67 & 34 \\
\hline VOLTA & North Tongu & 64 & 67 & 48 \\
\hline EASTERN & New-Juaben Municipal & 20 & 38 & 17 \\
\hline EASTERN & Akuapim North & 31 & 31 & 32 \\
\hline EASTERN & Yilo Krobo & 31 & 31 & 33 \\
\hline EASTERN & Akuapim South & 32 & 35 & 29 \\
\hline EASTERN & Kwahu South & 35 & 40 & 26 \\
\hline EASTERN & East Akim & 38 & 39 & 35 \\
\hline EASTERN & Birim South & 43 & 47 & 40 \\
\hline EASTERN & Kwaebibirem & 44 & 46 & 41 \\
\hline EASTERN & Suhum/Kroboa/Coaltar & 44 & 49 & 28 \\
\hline EASTERN & Fanteakwah & 45 & 48 & 30 \\
\hline EASTERN & Birim North & 47 & 45 & 60 \\
\hline EASTERN & West Akim & 47 & 52 & 36 \\
\hline EASTERN & Manya Krobo & 58 & 85 & 17 \\
\hline EASTERN & Asuogyaman & 62 & 78 & 17 \\
\hline EASTERN & Afram Plains & 84 & 87 & 22 \\
\hline CENTRAL & Cape Coast Municipal & 36 & 54 & 27 \\
\hline CENTRAL & Awutu/Effutu/Senya & 49 & 65 & 41 \\
\hline CENTRAL & Mfantsiman & 50 & 58 & 41 \\
\hline CENTRAL & Assin & 52 & 48 & 77 \\
\hline CENTRAL & Upper Denkyira & 54 & 49 & 71 \\
\hline CENTRAL & Twifu/Heman/Lower Denkyira & 55 & 50 & 84 \\
\hline CENTRAL & Komenda/Edina/Eguafo/Abirem & 56 & 64 & 37 \\
\hline CENTRAL & Gomoa & 58 & 62 & 49 \\
\hline CENTRAL & Ajumako/Enyam/Essiem & 61 & 64 & 46 \\
\hline CENTRAL & Asikuma/Odoben/Brakwa & 62 & 74 & 35 \\
\hline CENTRAL & Abura/Asebu/Kwamankese & 63 & 68 & 49 \\
\hline CENTRAL & Agona & 68 & 51 & 77 \\
\hline NORTHERN & Tamale & 59 & 87 & 43 \\
\hline NORTHERN & Savelugu-Nanton & 77 & 91 & 51 \\
\hline NORTHERN & East Dagomba & 84 & 92 & 63 \\
\hline NORTHERN & East Gonja & 85 & 92 & 41 \\
\hline NORTHERN & Bole & 87 & 92 & 50 \\
\hline NORTHERN & West Mamprusi & 87 & 92 & 52 \\
\hline NORTHERN & Nanumba & 88 & 88 & 90 \\
\hline NORTHERN & Chereponi-Saboba & 88 & 90 & 69 \\
\hline NORTHERN & East Mamprusi & 88 & 89 & 80 \\
\hline NORTHERN & West Gonja & 89 & 94 & 43 \\
\hline NORTHERN & Zabzugu-Tatale & 89 & 89 & 94 \\
\hline NORTHERN & Tolon & 90 & 90 & 98 \\
\hline NORTHERN & Gushiegu-Karaga & 92 & 92 & 95 \\
\hline UPPER WEST & $\mathrm{Wa}$ & 79 & 98 & 33 \\
\hline UPPER WEST & Lawra & 88 & 96 & 38 \\
\hline UPPER WEST & Jirapa-Lambussie & 89 & 98 & 37 \\
\hline UPPER WEST & Sissala & 91 & 98 & 30 \\
\hline UPPER WEST & Nadowli & 96 & 96 & 0 \\
\hline UPPER EAST & Bolgatanga & 88 & 99 & 51 \\
\hline UPPER EAST & Kassena-Nankani & 91 & 99 & 48 \\
\hline UPPER EAST & Bawku West & 92 & 98 & 62 \\
\hline UPPER EAST & Builsa & 98 & 98 & 0 \\
\hline UPPER EAST & Bongo & 99 & 99 & 0 \\
\hline UPPER EAST & Bawku East & 99 & 99 & 0 \\
\hline
\end{tabular}




\section{APPENDIX II: POLICY MATRIX}

\section{APPENDIX I1A: PRIORITIES FOR PRIVATE SECTOR COMPETITIVENESS}

\begin{tabular}{|c|c|c|c|c|c|}
\hline KEY AREA OF FOCUS & ISSUES & POLICY & STRATEGIES & $\begin{array}{l}\text { IMPLEMENTING AND } \\
\text { COLLABORATIVE AGENCY }\end{array}$ & $\begin{array}{l}\text { GLOBAL / } \\
\text { REGIONAL } \\
\text { LINKAGES }\end{array}$ \\
\hline \multirow[t]{2}{*}{$\begin{array}{l}\text { I. PRIVATE SECTOR } \\
\text { DEVELOPMENT }\end{array}$} & $\begin{array}{l}\text { Poor terms of trade } \\
\text { - Lack of export } \\
\text { promotion support } \\
\text { - Limited identification of } \\
\text { key markets } \\
\text { - Lack of Information }\end{array}$ & $\begin{array}{l}\text { 1. Improve Ghana's } \\
\text { position in global } \\
\text { and regional } \\
\text { markets }\end{array}$ & $\begin{array}{l}\text { 1. 1 Implement a fully-fledged National } \\
\text { Trade Policy to promote the } \\
\text { integration of Ghana into global } \\
\text { and regional markets } \\
\text { 1.2 Implement the key } \\
\text { recommendations from the review } \\
\text { of existing institutions tasked with } \\
\text { providing quality standards } \\
\text { services to the private sector. } \\
\text { 1.3 Attract investment through } \\
\text { measures at the national level to } \\
\text { improve the investment climate } \\
\text { 1.4 Implement sector-specific } \\
\text { measures for strategic exports - } \\
\text { focusing initially on the } \\
\text { President's Special Initiatives } \\
\text { (PSI) }\end{array}$ & $\begin{array}{l}\text { MPSD, MOTI, GIPC, GEPC, EDIF, } \\
\text { MOJ }\end{array}$ & \multirow[t]{2}{*}{$\begin{array}{l}\text { MDG 8, APRM, } \\
\text { Obj.1/2 under } \\
\text { Economic } \\
\text { Governance; Obj.1 } \\
\text { under Corporate } \\
\text { Governance }\end{array}$} \\
\hline & $\begin{array}{l}\text { - Inefficient and costly } \\
\text { bureaucracy } \\
\text { - High taxes, levies and } \\
\text { fees which are poorly } \\
\text { administered } \\
\text { - Weak exchange rates } \\
\text { - Complexity and non- } \\
\text { transparency of } \\
\text { regulations }\end{array}$ & $\begin{array}{l}\text { 2. Enhance efficiency } \\
\text { and accessibility of } \\
\text { national markets }\end{array}$ & $\begin{array}{l}\text { Macroeconomic Environment } \\
2.1 \begin{array}{l}\text { Issue and widely disseminate a } \\
\text { pre-budget discussion paper }\end{array} \\
\text { highlighting key macro economic } \\
\text { issues for private sector } \\
\text { development. } \\
\text { 2.2 } \begin{array}{l}\text { Form a budget working group with } \\
\text { broad range of private sector } \\
\text { stakeholders }\end{array}\end{array}$ & MPSD, MOFEP, BOG, PEF & \\
\hline
\end{tabular}




\begin{tabular}{|c|c|c|c|c|c|}
\hline KEY AREA OF FOCUS & ISSUES & POLICY & STRATEGIES & $\begin{array}{l}\text { IMPLEMENTING AND } \\
\text { COLLABORATIVE AGENCY }\end{array}$ & $\begin{array}{l}\text { GLOBAL / } \\
\text { REGIONAL } \\
\text { LINKAGES }\end{array}$ \\
\hline & $\begin{array}{l}\text { - Slow and costly } \\
\text { business registration and } \\
\text { approvals } \\
\text { - Unpredictability and } \\
\text { uncertainty of laws and } \\
\text { policies, and their } \\
\text { application. } \\
\text { - Limited application of } \\
\text { scientific technology to } \\
\text { the country's natural } \\
\text { resource base } \\
\text { - Unfriendly labour laws } \\
\text { - High interest rates } \\
\text { - Crime and security } \\
\text { - Inadequate export } \\
\text { promotion services } \\
\text { - Poor electricity } \\
\text { supply/utility } \\
\text { connections and services } \\
\text { - Delays in customs } \\
\text { clearance } \\
\text { - Non availability of } \\
\text { good health and } \\
\text { environmental standards } \\
\text { - Ineffective incentive } \\
\text { systems } \\
\text { - Difficulties in acquiring } \\
\text { land } \\
\text { - A weak commercial } \\
\text { dispute resolution } \\
\text { system }\end{array}$ & & 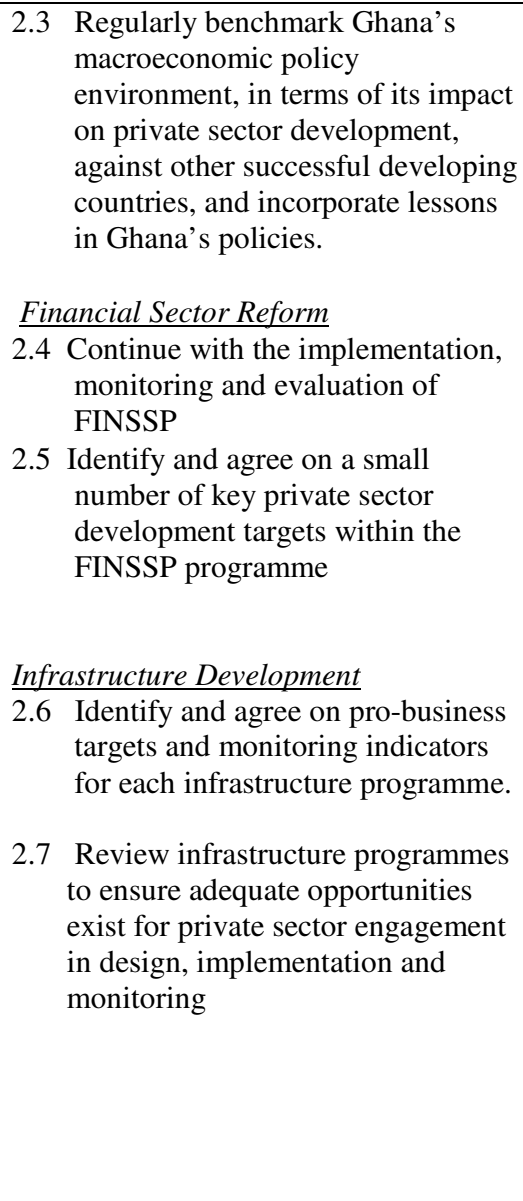 & $\begin{array}{l}\text { MPSD, MOFEP, BOG, PEF, MRT, } \\
\text { MOE, }\end{array}$ & $\begin{array}{l}\text { MDG 8, APRM, } \\
\text { obj1/.2/3 under } \\
\text { Economic } \\
\text { Governance; Obj.1 } \\
\text { under Corporate } \\
\text { Governance }\end{array}$ \\
\hline
\end{tabular}




\begin{tabular}{|c|c|c|c|c|c|}
\hline KEY AREA OF FOCUS & ISSUES & POLICY & STRATEGIES & $\begin{array}{l}\text { IMPLEMENTING AND } \\
\text { COLLABORATIVE AGENCY }\end{array}$ & $\begin{array}{l}\text { GLOBAL / } \\
\text { REGIONAL } \\
\text { LINKAGES }\end{array}$ \\
\hline & & & 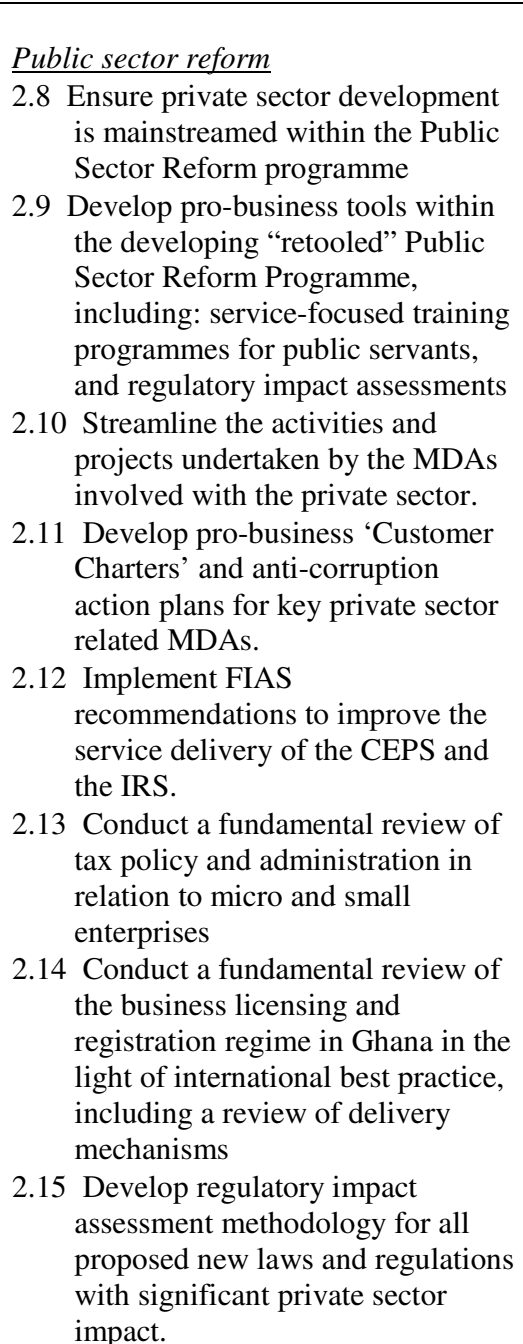 & MPSD, MOFEP, BOG, PEF & $\begin{array}{l}\text { MDG 8, APRM, } \\
\text { Obj.5 under Policy } \\
\text { Governance; } \\
\text { Obj.2 under } \\
\text { Economic } \\
\text { Governance; Obj.1 } \\
\text { under Corporate } \\
\text { Governance }\end{array}$ \\
\hline
\end{tabular}




\begin{tabular}{|c|c|c|c|c|c|}
\hline KEY AREA OF FOCUS & ISSUES & POLICY & STRATEGIES & $\begin{array}{l}\text { IMPLEMENTING AND } \\
\text { COLLABORATIVE AGENCY }\end{array}$ & $\begin{array}{l}\text { GLOBAL / } \\
\text { REGIONAL } \\
\text { LINKAGES }\end{array}$ \\
\hline & & & $\begin{array}{l}\text { Contract enforcement / debt recovery } \\
2.16 \text { Carry out a fundamental review of } \\
\text { the on-going commercial law } \\
\text { reform effort and develop } \\
\text { proposals for focusing and } \\
\text { prioritising efforts. } \\
2.17 \text { Improve access to justice for } \\
\text { businesses - especially micro and } \\
\text { small businesses, and consider the } \\
\text { scope for enhancing alternative } \\
\text { dispute resolution within the } \\
\text { context of the developing Justice } \\
\text { Sector Reform Programme. } \\
2.18 \text { Conduct a study on the level of } \\
\text { access to justice for businesses in } \\
\text { Ghana focusing on MSMEs and } \\
\text { developing cost effective solutions } \\
\text { to enhance access to justice. }\end{array}$ & \multirow[t]{2}{*}{ MPSD, MOFEP, BOG, PEF } & \multirow[t]{2}{*}{$\begin{array}{l}\text { MDG 8, APRM, } \\
\text { Obj.2 under } \\
\text { Economic } \\
\text { Governance; Obj.1 } \\
\text { under Corporate } \\
\text { Governance; Obj.2 } \\
\text { under Socio- } \\
\text { economic } \\
\text { development }\end{array}$} \\
\hline & $\begin{array}{l}\text { - Lack of access to finance } \\
\text { - Informal nature of } \\
\text { businesses } \\
\text { - Limited managerial } \\
\text { skills } \\
\text { - Limited training }\end{array}$ & $\begin{array}{l}\text { 3. Strengthen Firms } \\
\text { Competency and } \\
\text { capacity to operate } \\
\text { effectively and } \\
\text { efficiently }\end{array}$ & $\begin{array}{l}\text { 3.1 Develop and implement a plan to } \\
\text { phase-out Government provision } \\
\text { of subsidised finance to firms. } \\
\text { 3.2 Develop a "best practice } \\
\text { framework" with best practise } \\
\text { criteria against which firm level } \\
\text { initiatives will be judged. } \\
\text { 3.3 Develop league tables for existing } \\
\text { and new firm level initiatives, } \\
\text { using the above best practice } \\
\text { criteria. } \\
\text { 3.4 Develop and implement a strategy } \\
\text { to ensure effective monitoring and } \\
\text { evaluation of, and dissemination of } \\
\text { information about firm level } \\
\text { interventions } \\
\text { 3.5 Improve linkages of informal sector } \\
\text { with formal sector }\end{array}$ & & \\
\hline
\end{tabular}




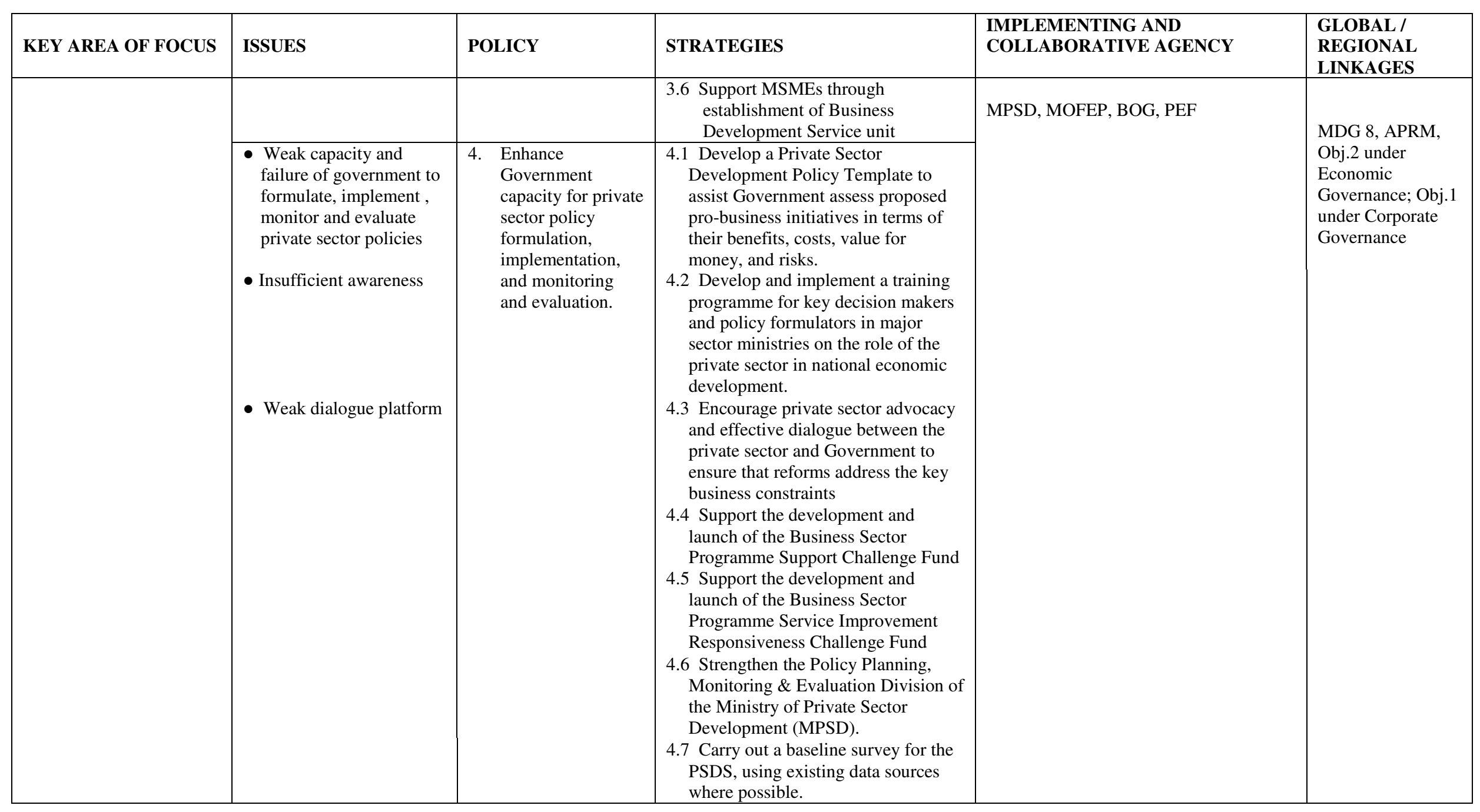




\begin{tabular}{|c|c|c|c|c|c|}
\hline KEY AREA OF FOCUS & ISSUES & POLICY & STRATEGIES & $\begin{array}{l}\text { IMPLEMENTING AND } \\
\text { COLLABORATIVE AGENCY }\end{array}$ & $\begin{array}{l}\text { GLOBAL / } \\
\text { REGIONAL } \\
\text { LINKAGES }\end{array}$ \\
\hline & & & $\begin{array}{l}\text { 4.8 Identify and support 'private sector } \\
\text { champions' to monitor } \\
\text { implementation of the Strategy, and } \\
\text { hold Government accountable for } \\
\text { delivering results }\end{array}$ & & \multirow{7}{*}{$\begin{array}{l}\text { MDG 8, APRM, } \\
\text { Obj.2 under } \\
\text { Economic } \\
\text { Governance; obj.1 } \\
\text { under Corporate } \\
\text { Governance, Obj.2 } \\
\text { under Socio- } \\
\text { economic } \\
\text { development. }\end{array}$} \\
\hline & & $\begin{array}{l}\text { 5. Facilitate private } \\
\text { sector access to } \\
\text { capital }\end{array}$ & $\begin{array}{l}\text { 5.1 Improve access and increase } \\
\text { volume of credit at affordable prices } \\
5.2 \text { Reduce bottlenecks to private } \\
\text { sector development }\end{array}$ & MPSD, MOFEP, BOG & \\
\hline & & $\begin{array}{l}\text { 6. Facilitate the } \\
\text { removal of } \\
\text { institutional and } \\
\text { legal bottlenecks }\end{array}$ & $\begin{array}{l}\text { 6.1 Promote entrepreneurship through } \\
\text { business development services. } \\
\text { Provide skills and entrepreneurial } \\
\text { development for the youth }\end{array}$ & MPSD, MOFEP, BOG & \\
\hline & & $\begin{array}{l}\text { 7. Facilitate Innovation } \\
\text { and entrepreneurship }\end{array}$ & $\begin{array}{l}\text { 7.1 Promote innovation and } \\
\text { entrepreneurship training as part of } \\
\text { school curriculum }\end{array}$ & \multirow[t]{2}{*}{$\begin{array}{l}\text { PSR, OHSC, MOJ, PEF, NBSSI, } \\
\text { EMPRETEC, GRATIS }\end{array}$} & \\
\hline & & $\begin{array}{l}\text { 8. Ensure that private } \\
\text { sector development } \\
\text { programmes are } \\
\text { complimentary and } \\
\text { also cover a broad } \\
\text { range of needs }\end{array}$ & $\begin{array}{l}\text { 8.1 Rationalize the role of the state } \\
\text { 8.2 Encourage and facilitate the } \\
\text { provision of public services by the } \\
\text { private sector }\end{array}$ & & \\
\hline & & $\begin{array}{l}\text { 10. Supportive and } \\
\text { mindset change of } \\
\text { the population } \\
\text { towards the private } \\
\text { sector }\end{array}$ & $\begin{array}{l}\text { 10.1 Create a supportive mindset of the } \\
\text { population towards the private } \\
\text { sector }\end{array}$ & MPSD, MOTI, MOES, MOI, The Media & \\
\hline & & $\begin{array}{l}\text { 11.Accelerated } \\
\text { development of } \\
\text { strategic sectors }\end{array}$ & $\begin{array}{l}\text { 11.1 Develop new pillars of growth by } \\
\text { accelerating the development of } \\
\text { selected products into lead export } \\
\text { earners, particularly in the rural } \\
\text { areas }\end{array}$ & MOFA, MOE, MOFEP, MRT, MLGRD & \\
\hline
\end{tabular}




\begin{tabular}{|c|c|c|c|c|c|}
\hline KEY AREA OF FOCUS & ISSUES & POLICY & STRATEGIES & $\begin{array}{l}\text { IMPLEMENTING AND } \\
\text { COLLABORATIVE AGENCY }\end{array}$ & $\begin{array}{l}\text { GLOBAL / } \\
\text { REGIONAL } \\
\text { LINKAGES }\end{array}$ \\
\hline \multicolumn{6}{|c|}{ II. AGRICULTURE LED-GROWTH } \\
\hline $\begin{array}{l}\text { (a) Modernized } \\
\text { Agriculture }\end{array}$ & $\begin{array}{l}\text { - Low agricultural } \\
\text { productivity and output } \\
\text { due to over-dependency } \\
\text { on rainfall } \\
\text { - Generally low access of } \\
\text { women to land } \\
\text { including irrigated land } \\
\text { - Inadequate access to } \\
\text { agricultural land } \\
\text { - Re-zoning of agricultural } \\
\text { lands for residential } \\
\text { purposes }\end{array}$ & $\begin{array}{l}\text { 1. Ensure sustainable } \\
\text { increase in } \\
\text { agricultural } \\
\text { productivity and } \\
\text { output to support } \\
\text { industry and provide } \\
\text { stable income for } \\
\text { farmers }\end{array}$ & $\begin{array}{l}\text { Irrigation development } \\
\text { 1.1 Promote the use of existing } \\
\text { irrigation facilities especially in } \\
\text { drought prone areas } \\
\text { 1.2 Rehabilitate of viable irrigation } \\
\text { infrastructure } \\
\text { 1.3 Expand irrigation infrastructure - } \\
\text { valley bottoms, dams and dug-outs, } \\
\text { bore holes tube wells, etc } \\
\text { especially in the three northern } \\
\text { regions } \\
\text { 1.4 Promote land reforms that ensures } \\
\text { equal access to irrigated land for } \\
\text { men, women and Persons with } \\
\text { Disability } \\
\text { Land system and property right } \\
\text { 1.5 Ensure the development of a land } \\
\text { use master plan that demarcates all } \\
\text { lands in dispute } \\
\text { 1.6 Reform land administration by } \\
\text { reviewing the Land Administration } \\
\text { Project in the light of the } \\
\text { importance of property rights to } \\
\text { MSMEs } \\
\text { 1.7 Take forward recommendations by } \\
\text { FIAS to improve the site } \\
\text { development and land } \\
\text { administration system } \\
\text { 1.8 Promote the establishment of agri- } \\
\text { business zones and land banks with } \\
\text { special consideration for needs of } \\
\text { women }\end{array}$ & $\begin{array}{l}\text { MOFA, WRC, FBOs } \\
\text { MOFA, WRC, FBOs } \\
\text { MOFA, WRC, FBOs }\end{array}$ & $\begin{array}{c}\text { MDG 1, } \\
\text { ECOWAS, APRM } \\
\text { Obj.2 under Socio- } \\
\text { economic } \\
\text { development }\end{array}$ \\
\hline
\end{tabular}




\begin{tabular}{|c|c|c|c|c|c|}
\hline KEY AREA OF FOCUS & ISSUES & POLICY & STRATEGIES & $\begin{array}{l}\text { IMPLEMENTING AND } \\
\text { COLLABORATIVE AGENCY }\end{array}$ & $\begin{array}{l}\text { GLOBAL / } \\
\text { REGIONAL } \\
\text { LINKAGES }\end{array}$ \\
\hline & $\begin{array}{l}\text { - Low soil fertility } \\
\text { - High incidence of pest } \\
\text { and diseases } \\
\text { - Low agricultural } \\
\text { productivity } \\
\text { - Over reliance on } \\
\text { traditional agricultural } \\
\text { commodities } \\
\text { - Unsustainable } \\
\text { agriculture management } \\
\text { practices } \\
\\
\text { - Low productivity and } \\
\text { low resistance breeds of } \\
\text { livestock } \\
\text {-Inappropriate husbandry } \\
\text { practices } \\
\text { - Low level of dairy } \\
\text { production } \\
\text { - High incidence of animal } \\
\text { and zoonotic diseases } \\
\text { Poor disease } \\
\text { surveillance and disease } \\
\text { surveillance system }\end{array}$ & & $\begin{array}{l}\text { Selected Crop development } \\
\text { 1.9 } \begin{array}{l}\text { Develop and multiply new and } \\
\text { improved seeds and planting } \\
\text { materials of selected crops. }\end{array} \\
\text { 1.10 Promote soil fertility management } \\
\text { systems } \\
\text { 1.11 Promote an integrated pest and } \\
\text { disease management system } \\
\text { 1.12 Promote and expand bio- } \\
\text { technology - promote pineapple, } \\
\text { cashew, oil palm } \\
\text { 1.13 Promote the development of } \\
\text { horticulture in the country } \\
\text { 1.14 Update existing technological } \\
\text { packages and promote } \\
\text { environmentally sustainable } \\
\text { cropping practices in agro-forestry, } \\
\text { land and water management in } \\
\text { farming communities } \\
\text { Livestock development } \\
1.15 \text { Provide improved breeds-small } \\
\text { ruminant, guinea fowl } \\
\text { 1.16 Animal feed quality control } \\
1.17 \text { Improve animal husbandry } \\
\text { practices } \\
\text { 1.18 Intensify the work of Veterinary } \\
\text { Public Health Services } \\
1.19 \text { Promote dairy production } \\
\text { 1.20 Intensify disease control and } \\
\text { surveillance, especially for } \\
\text { zoonotic and scheduled diseases }\end{array}$ & $\begin{array}{l}\text { MOFA, CSIR, Private Sector, NGOs } \\
\text { MOFA, CSIR, Private Sector, NGOs } \\
\text { MOFA, CSIR, Private Sector, NGOs, } \\
\text { EPA } \\
\text { MOFA, GAEC, Private Sector, CSIR } \\
\text { MOFA, GAEC, Private Sector } \\
\text { MOFA, CSIR, Private Sector, MLFM, } \\
\text { EPA, NGOs }\end{array}$ & $\begin{array}{l}\text { MDG 1/8, } \\
\text { ECOWAS, APRM } \\
\text { Obj..2 under } \\
\text { Socio-economic } \\
\text { development }\end{array}$ \\
\hline
\end{tabular}




\begin{tabular}{|c|c|c|c|c|c|}
\hline KEY AREA OF FOCUS & ISSUES & POLICY & STRATEGIES & $\begin{array}{l}\text { IMPLEMENTING AND } \\
\text { COLLABORATIVE AGENCY }\end{array}$ & $\begin{array}{l}\text { GLOBAL / } \\
\text { REGIONAL } \\
\text { LINKAGES }\end{array}$ \\
\hline & $\begin{array}{l}\text { - Cattle rustling } \\
\text { - Poor system of cattle } \\
\text { identification } \\
\text { - High incidence of tsetse } \\
\text { disease } \\
\text { - Limited access to tractor } \\
\text { services and other farm } \\
\text { machinery/equipment } \\
\text { and technology } \\
\text { especially in the case of } \\
\text { women } \\
\text { - Low exploitation of } \\
\text { ground water for } \\
\text { irrigation purposes } \\
\text { - High rate of drudgery in } \\
\text { farming activities } \\
\text { - Lack of access to credit } \\
\text { especially of small-scale } \\
\text { women farmers }\end{array}$ & & 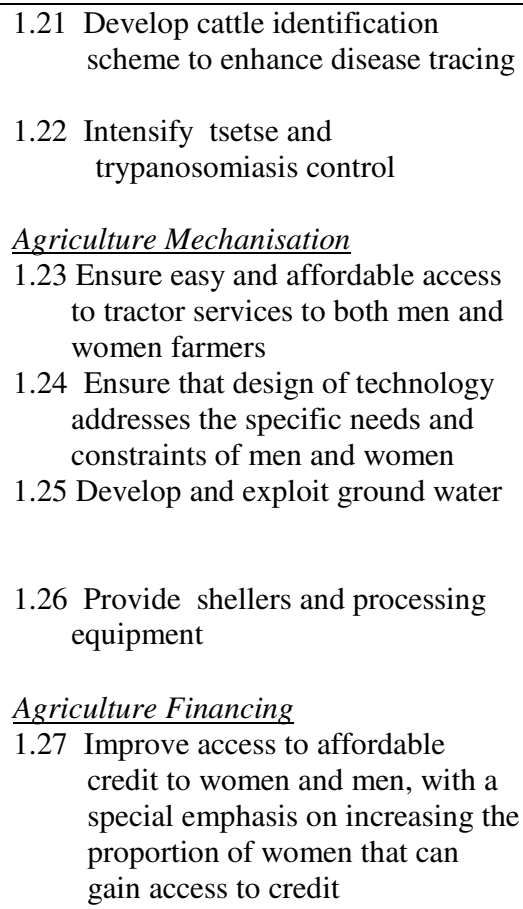 & $\begin{array}{l}\text { MOFA, Private Sector, District } \\
\text { Assemblies, CSIR } \\
\text { MOFA, Private Sector, CSIR } \\
\text { MOFA, Private Sector, } \\
\text { MOFA, Private Sector, } \\
\text { MOFA, Private Sector, } \\
\text { MOFA, ADB, RURAL BANKS, NGOs, } \\
\text { PRIVATE SECTOR }\end{array}$ & $\begin{array}{l}\text { MDG 1/8 } \\
\text { NEPAD } \\
\text { APRM, obj.1 } \\
\text { under Corporate } \\
\text { Governance; } \\
\text { Obj.4 under Socio- } \\
\text { economic } \\
\text { deveopment }\end{array}$ \\
\hline & $\begin{array}{l}\text { - Limited value addition } \\
\text { and high post-harvest } \\
\text { losses } \\
\text { - Improper packaging of } \\
\text { agricultural produce and } \\
\text { products } \\
\text { - Lack of quality standards }\end{array}$ & $\begin{array}{l}\text { 2. Ensure food security } \\
\text { for all and increase } \\
\text { the access of the } \\
\text { poor to adequate } \\
\text { food and nutrition }\end{array}$ & 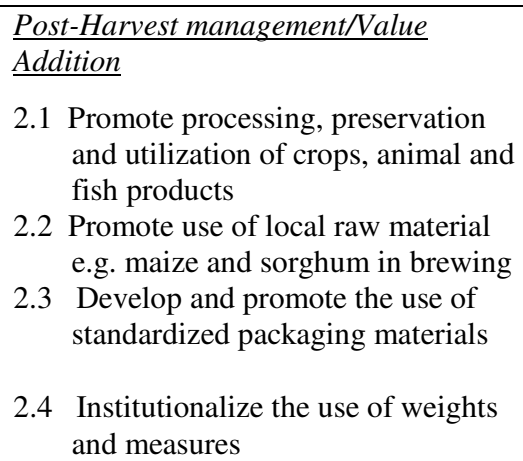 & $\begin{array}{l}\text { MOFA, MOFI, Private Sector, CSIR, } \\
\text { GAEC } \\
\text { MOFA, MOFI, Private Sector, CSIR, } \\
\text { GAEC }\end{array}$ & $\begin{array}{l}\text { MDG } 1 \text { and } \\
\text { NEPAD }\end{array}$ \\
\hline
\end{tabular}




\begin{tabular}{|c|c|c|c|c|c|}
\hline KEY AREA OF FOCUS & ISSUES & POLICY & STRATEGIES & $\begin{array}{l}\text { IMPLEMENTING AND } \\
\text { COLLABORATIVE AGENCY }\end{array}$ & $\begin{array}{l}\text { GLOBAL / } \\
\text { REGIONAL } \\
\text { LINKAGES }\end{array}$ \\
\hline & $\begin{array}{l}\text { - Low level of exports of } \\
\text { value added agricultural } \\
\text { products } \\
\text { - Lack of storage facilities, } \\
\text { especially at the } \\
\text { community level } \\
\text { - Some food processing } \\
\text { technologies are a health } \\
\text { hazard and } \\
\text { environmentally } \\
\text { unfriendly }\end{array}$ & & $\begin{array}{l}\text { 2.5 Facilitate establishment of small } \\
\text { scale agro-processing industries for } \\
\text { exports } \\
\text { 2.6 Promote the establishment of } \\
\text { storage facilities, including } \\
\text { community level facilities } \\
2.7 \begin{array}{l}\text { Develop and promote user and } \\
\text { environmentally friendly } \\
\text { technology for food processing }\end{array}\end{array}$ & 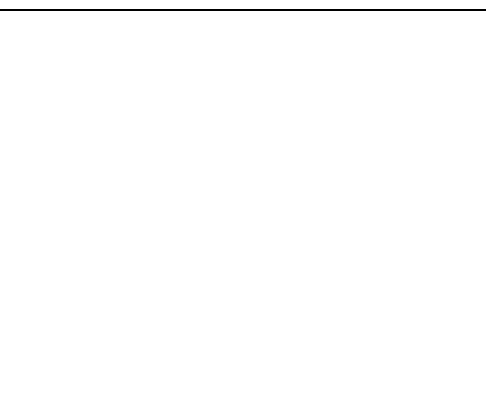 & MDG 7 \\
\hline & $\begin{array}{l}\text { - Inability of farmers to } \\
\text { obtain premium prices } \\
\text { due to weak and } \\
\text { ineffective Farmer } \\
\text { Based Organizations } \\
\text { - Output fluctuations due } \\
\text { to instability in prices }\end{array}$ & & $\begin{array}{l}\text { Agriculture Marketing } \\
2.8 \begin{array}{l}\text { Develop farmer based } \\
\text { organizations (FBO) capable of } \\
\text { securing fair prices for products }\end{array} \\
2.9 \begin{array}{l}\text { Encourage the setting up of satellite } \\
\text { markets in urban centers to provide } \\
\text { outlets for rural farmers to dispose } \\
\text { off their products, whiles } \\
\text { overcoming the exploitation from } \\
\text { urban traders }\end{array} \\
\begin{array}{l}\text { 2.10 Promote price and income } \\
\text { stability measures }\end{array} \\
\text { 2.11 Encourage the private sector to set } \\
\text { up produce buying companies }\end{array}$ & $\begin{array}{l}\text { MOFA, MOFI, MOTI, DOC, Private } \\
\text { Sector, DISTRICT ASSEMBLIES, } \\
\text { MPSD\&PSI }\end{array}$ & $\begin{array}{l}\text { APRM Obj.4 } \\
\text { under Socio- } \\
\text { economic Devt }\end{array}$ \\
\hline & $\begin{array}{l}\text { Low extension coverage } \\
\text { especially amongst poor } \\
\text { farmers in the transition } \\
\text { and savannah zones. } \\
\text { Women farmers } \\
\text { amongst this group have } \\
\text { less contact with } \\
\text { extension officers } \\
\text { compared to men. }\end{array}$ & $\begin{array}{l}\text { 3. Ensure the } \\
\text { development and } \\
\text { strengthening of } \\
\text { the requisite } \\
\text { institutional } \\
\text { capacity to support } \\
\text { agriculture } \\
\text { productivity }\end{array}$ & $\begin{array}{l}\text { Access to Extension Services } \\
\text { 3.1 Promote alternative extension } \\
\text { approaches that will increase the } \\
\text { proportion of both men and women } \\
\text { farmers that are reached } \\
\text { particularly in the transition and } \\
\text { savannah zones. } \\
\text { 3.2 Establishment of extension } \\
\text { information centers (EIC) }\end{array}$ & MOFA, Private Sector, NGOs & MDG 1 \\
\hline
\end{tabular}




\begin{tabular}{|c|c|c|c|c|c|}
\hline KEY AREA OF FOCUS & ISSUES & POLICY & STRATEGIES & $\begin{array}{l}\text { IMPLEMENTING AND } \\
\text { COLLABORATIVE AGENCY }\end{array}$ & $\begin{array}{l}\text { GLOBAL / } \\
\text { REGIONAL } \\
\text { LINKAGES }\end{array}$ \\
\hline & $\begin{array}{l}\text {-Ad-hoc approaches to } \\
\text { agricultural promotion } \\
\text { and development }\end{array}$ & & $\begin{array}{l}\text { 3.3 Adopt common agricultural. } \\
\text { policies in research, training, } \\
\text { production, preservation, } \\
\text { processing and marketing of crops } \\
\text { livestock and fisheries. }\end{array}$ & MOFA, CSIR, GAEC MOTI & \\
\hline \multirow[t]{2}{*}{$\begin{array}{l}\text { (b) Modernized Fishing } \\
\text { methods and aquaculture } \\
\text { development }\end{array}$} & $\begin{array}{l}\text {-Inadequate/poor } \\
\text { aquaculture } \\
\text { infrastructure } \\
\text { - Limited private } \\
\text { investment in } \\
\text { aquaculture } \\
\text { - Low level of fish } \\
\text { production from water } \\
\text { bodies } \\
\text { - Over-dependence on the } \\
\text { known fisheries species } \\
\text { - Low productivity of fish } \\
\text { farms }\end{array}$ & $\begin{array}{l}\text { Ensure the } \\
\text { development of } \\
\text { aquaculture to } \\
\text { meet shortfall in } \\
\text { fish production }\end{array}$ & $\begin{array}{l}\text { 1.1 Develop of aquaculture } \\
\text { infrastructure including fish } \\
\text { hatcheries } \\
\text { 1.2 } \begin{array}{l}\text { Promote private investment in } \\
\text { aquaculture }\end{array} \\
\text { 1.3 Utilize of irrigation systems and } \\
\text { other impounded reservoirs for } \\
\text { aquaculture }\end{array}$ & $\begin{array}{l}\text { MOFI, Private Sector, CSIR Universities } \\
\text { Institutions, MOFA, MOH }\end{array}$ & MDG 1 \\
\hline & & $\begin{array}{ll}\text { 2. } & \text { Ensure value } \\
\text { addition of } \\
\text { fisheries products } \\
\text { to improve } \\
\text { fisheries } \\
\text { contribution to } \\
\text { Ghana's GDP }\end{array}$ & $\begin{array}{l}\text { 2.1 Promote processing/ preservation } \\
\text { and utilization of fish products } \\
\text { 2.2 Promote the establishment of fish } \\
\text { storage facilities } \\
\text { 2.3 Establish and promote of standards } \\
\text { for fish safety } \\
\text { 2.4 } \begin{array}{l}\text { Develop and promote the use of } \\
\text { standardized packaging material }\end{array} \\
\text { 2.5 Facilitate the establishment of } \\
\text { small-scale fish processing } \\
\text { industries for export. } \\
\text { 2.6 } \begin{array}{l}\text { Promote an efficient fish trade and } \\
\text { marketing in tandem with } \\
\text { international standards }\end{array}\end{array}$ & $\begin{array}{l}\text { MOFI, MOFA, Private Sector, CSIR, } \\
\text { MPSD\&PSI, GSB, MOTI }\end{array}$ & MDG 1 \\
\hline
\end{tabular}




\begin{tabular}{|c|c|c|c|c|c|}
\hline KEY AREA OF FOCUS & ISSUES & POLICY & STRATEGIES & $\begin{array}{l}\text { IMPLEMENTING AND } \\
\text { COLLABORATIVE AGENCY }\end{array}$ & $\begin{array}{l}\text { GLOBAL / } \\
\text { REGIONAL } \\
\text { LINKAGES }\end{array}$ \\
\hline \multirow[t]{2}{*}{$\begin{array}{l}\text { (c) Restoration of } \\
\text { degraded } \\
\text { environment and } \\
\text { Natural Resource } \\
\text { Management }\end{array}$} & $\begin{array}{l}\text { - Degradation of the } \\
\text { nation's forest } \\
\text { - Over reliance on major } \\
\text { species like mahogany, } \\
\text { odom, sapale, etc } \\
\text { - Fast depletion of the } \\
\text { nation's biomass without } \\
\text { replacement. } \\
\text { - Inefficient use and } \\
\text { management of natural } \\
\text { resources } \\
\text { - Advancing/creeping } \\
\text { desertification through } \\
\text { bush fires, poor farming } \\
\text { practices, energy use, } \\
\text { etc. } \\
\text { - Lack of awareness on } \\
\text { climate change and its } \\
\text { impact }\end{array}$ & $\begin{array}{l}\text { 1. Ensure the } \\
\text { restoration of } \\
\text { degraded natural } \\
\text { resources }\end{array}$ & 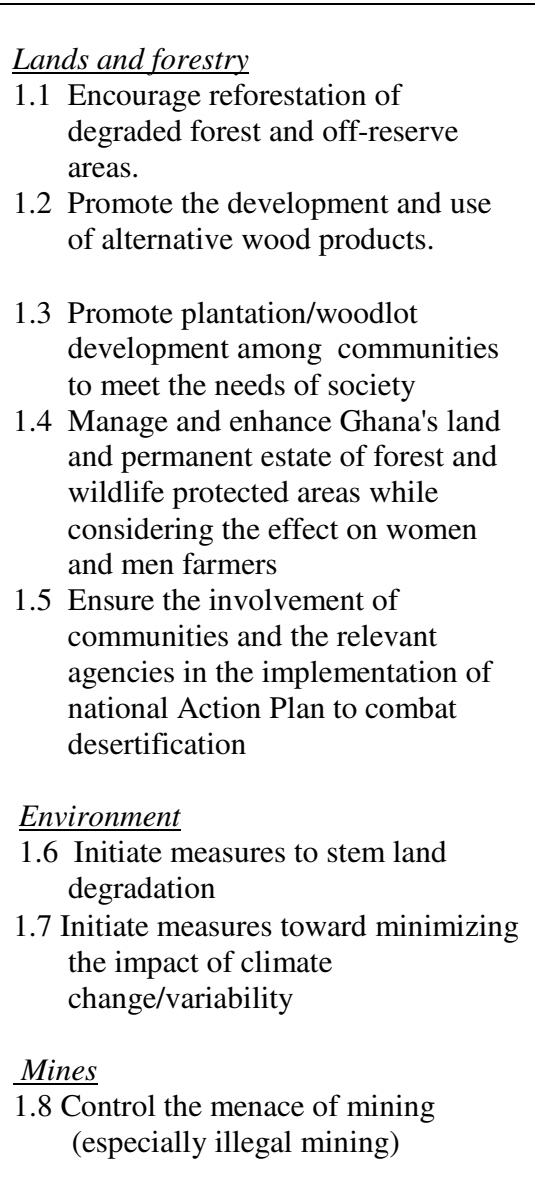 & $\begin{array}{l}\text { MLFM, MES, MLGRD, District } \\
\text { Assemblies, Environmental Protection } \\
\text { Agency (EPA), CSIR, Forestry } \\
\text { Commission and Environmental NGO's, } \\
\text { NADMO, FIRE SERVICE, DISTRICT } \\
\text { ASSEMBLIES, GMA }\end{array}$ & $\begin{array}{l}\text { ECOWAS, } \\
\text { NEPAD, MDG 7, } \\
\text { APRM Obj.1 } \\
\text { under Corporate } \\
\text { Governance }\end{array}$ \\
\hline & $\begin{array}{l}\text { - Inefficient industrial } \\
\text { waste management }\end{array}$ & $\begin{array}{ll}2 . & \text { Promote } \\
\text { sustainable natural } \\
\text { resource } \\
\text { management }\end{array}$ & $\begin{array}{l}\text { Environment } \\
\text { 2.1 Promote an efficient and accessible } \\
\text { industrial and domestic waste } \\
\text { management system including the } \\
\text { menace of plastic waste }\end{array}$ & $\begin{array}{l}\text { MLFM, EPA, MES MLGRD, District } \\
\text { Assemblies, CSIR, Wild Life Society and } \\
\text { the relevant agencies, MOT/MCC }\end{array}$ & \\
\hline
\end{tabular}




\begin{tabular}{|c|c|c|c|c|c|}
\hline KEY AREA OF FOCUS & ISSUES & POLICY & STRATEGIES & $\begin{array}{l}\text { IMPLEMENTING AND } \\
\text { COLLABORATIVE AGENCY }\end{array}$ & $\begin{array}{l}\text { GLOBAL / } \\
\text { REGIONAL } \\
\text { LINKAGES }\end{array}$ \\
\hline & $\begin{array}{l}\text { - Negative impact of some } \\
\text { farm practices and } \\
\text { mining technologies } \\
\text { - Depletion of some } \\
\text { endangered species } \\
\text { - Lack of efficient } \\
\text { ecosystem management } \\
\\
\text { - Inadequate scientific } \\
\text { data for fisheries } \\
\text { management (inland and } \\
\text { marine) } \\
\text { - Insufficient monitoring } \\
\text { and control to ensure } \\
\text { compliance with laws } \\
\text { and regulations on } \\
\text { fisheries. } \\
\text { - Weak or inexistent } \\
\text { collaboration with } \\
\text { communities towards the } \\
\text { management of fisheries } \\
\text { resources } \\
\text { - Over-exploitation of } \\
\text { fisheries resources } \\
\text { - Unsafe and unhygienic } \\
\text { working conditions at } \\
\text { landing beaches } \\
\text { Over-dependence on } \\
\text { fisheries as a means of } \\
\text { livelihood due to lack of } \\
\text { alternative employment } \\
\text { for women and men }\end{array}$ & & $\begin{array}{l}\text { 2.2 Promote the use of environmentally } \\
\text { friendly technologies and practices. } \\
\text { 2.3 Promote human centred } \\
\text { biodiversity conservation initiatives } \\
\text { 2.4 Promote integrated ecosystem } \\
\text { management which is friendly } \\
\text { towards men and women equally. } \\
\text { Fisheries } \\
\text { 2.5 Promote the gathering of adequate } \\
\text { scientific data for fisheries } \\
\text { management } \\
\text { 2.6 Establish effective monitoring, } \\
\text { control and surveillance systems to } \\
\text { ensure compliance with laws and } \\
\text { regulations on fishery resource } \\
\text { 2.7 Establish co-management } \\
\text { mechanism for fisheries resource } \\
\text { management } \\
\text { 2.8 Control of fishing effort } \\
\text { 2.9 Enhancement of fisheries resource } \\
\text { of water bodies } \\
\text { 2.10 Improve fish landing site } \\
\text { 2.11 Develop credit lines for } \\
\text { improvement of fisheries } \\
\text { livelihoods } \\
\text { for men and women in the post } \\
\text { harvest fisheries sector }\end{array}$ & $\begin{array}{l}\text { MOFI, MOFEP, MOWAC, MPSD\$PSI, } \\
\text { Private Sector, CSIR, Universities } \\
\text { Institutions }\end{array}$ & $\begin{array}{l}\text { ECOWAS, } \\
\text { NEPAD, MDG 7, } \\
\text { APRM Obj.1 } \\
\text { under Corporate } \\
\text { Governance }\end{array}$ \\
\hline
\end{tabular}




\begin{tabular}{|c|c|c|c|c|c|}
\hline KEY AREA OF FOCUS & ISSUES & POLICY & STRATEGIES & $\begin{array}{l}\text { IMPLEMENTING AND } \\
\text { COLLABORATIVE AGENCY }\end{array}$ & $\begin{array}{l}\text { GLOBAL / } \\
\text { REGIONAL } \\
\text { LINKAGES }\end{array}$ \\
\hline & $\begin{array}{l}\text { - Inadequate gender } \\
\text { consideration in land } \\
\text { administration projects } \\
\text { - Duplication of functions } \\
\text { within the land sector } \\
\text { agencies } \\
\text { - Inequality in sharing of } \\
\text { benefit from natural } \\
\text { resources } \\
\text { - Lack of compensation to } \\
\text { land owners } \\
\text { - Inadequate involvement } \\
\text { of communities, } \\
\text { particularly women in } \\
\text { resource management } \\
\text { - Lack of viable and } \\
\text { efficient industries } \\
\text { which utilize primary } \\
\text { products } \\
\text { - Inadequate exploration } \\
\text { of mineral resources } \\
\text { within the country } \\
\text { - Over-dependence on the } \\
\text { few precious minerals } \\
\text { - Degradation of land, } \\
\text { pollution of water and } \\
\text { air and high incidence of } \\
\text { mining accidents } \\
\text { - Minimal stakeholders } \\
\text { involvement in the } \\
\text { management of mineral } \\
\text { resources }\end{array}$ & & $\begin{array}{l}\text { Lands and forestry } \\
2.13 \text { Ensure that the current land } \\
\text { administration project is } \\
\text { engendered } \\
\text { 2.14 Ensure socio-economic activities } \\
\text { are consistent with sound land } \\
\text { administration practices } \\
\text { 2.15 Promote equitable benefit sharing } \\
\text { from land, forest and wildlife } \\
\text { resources } \\
\text { 2.16 Ensure prompt, fair and adequate } \\
\text { compensation for government } \\
\text { acquired lands } \\
\text { 2.17 Maximise community } \\
\text { involvement, especially women, in } \\
\text { sustainable land, forest and wildlife } \\
\text { resources } \\
\text { 2.18 Promote the development of viable } \\
\text { and efficient forest and wildlife- } \\
\text { based industries, particularly in } \\
\text { secondary and tertiary processing } \\
\text { Mines } \\
\text { 2.19 Sustain mining sector through } \\
\text { exploration, exploitation and } \\
\text { management of mineral resources. } \\
\text { 2.20 Diversify the mineral base of the } \\
\text { nation to reduce over-dependence } \\
\text { on the few precious mineral } \\
\text { 2.21 Improve the environmental and } \\
\text { natural resources management for } \\
\text { health and safety, and increased } \\
\text { sustainable production } \\
\text { 2.22 Promote collaborative } \\
\text { management of the nation's mineral } \\
\text { resources }\end{array}$ & $\begin{array}{l}\text { MLFM, EPA, MES, MLGRD, District } \\
\text { Assemblies, Wild Life Society and other } \\
\text { relevant agencies }\end{array}$ & $\begin{array}{l}\text { ECOWAS, } \\
\text { NEPAD, MDG } 3 \\
\text { MDG 7, APRM } \\
\text { Obj.1 under } \\
\text { Corporate } \\
\text { Governance }\end{array}$ \\
\hline
\end{tabular}




\begin{tabular}{|c|c|c|c|c|c|}
\hline KEY AREA OF FOCUS & ISSUES & POLICY & STRATEGIES & $\begin{array}{l}\text { IMPLEMENTING AND } \\
\text { COLLABORATIVE AGENCY }\end{array}$ & $\begin{array}{l}\text { GLOBAL / } \\
\text { REGIONAL } \\
\text { LINKAGES }\end{array}$ \\
\hline & $\begin{array}{l}\text { - Outmoded mining } \\
\text { regulations which do not } \\
\text { attract investors }\end{array}$ & & $\begin{array}{l}\text { 2.23 Review the existing regulations to } \\
\text { enhance the competitiveness of the } \\
\text { mining sector }\end{array}$ & & $\begin{array}{l}\text { NEPAD, } \\
\text { ECOWAS }\end{array}$ \\
\hline & $\begin{array}{l}\text { - Weak institutional } \\
\text { capacities for } \\
\text { environmental } \\
\text { management at all levels } \\
\text { - Low enforcement of } \\
\text { environmental laws } \\
\\
\text { - Weak collaboration } \\
\text { among relevant agencies } \\
\text { on natural resource } \\
\text { management }\end{array}$ & $\begin{array}{l}\text { 3. Build the requisite } \\
\text { institutions and } \\
\text { strengthen the } \\
\text { regulatory } \\
\text { framework to ensure } \\
\text { sustainable natural } \\
\text { resource } \\
\text { management }\end{array}$ & $\begin{array}{l}\text { 3.1 Enact relevant environmental laws } \\
\text { to protect the environment at all } \\
\text { times } \\
\text { 3.2 Enforce existing environmental laws } \\
\text { 3.3 Enforce the legality assurance } \\
\text { scheme under the Validation of } \\
\text { Legal Timber Program (VLTP) } \\
\text { 3.4 Develop multi-agency approach to } \\
\text { enhance resource management and } \\
\text { the environment } \\
\text { 3.5 Assist mining companies to carry } \\
\text { out their business to generate } \\
\text { employment, create wealth and } \\
\text { improve living standards of local } \\
\text { communities } \\
\text { 3.6 Harmonize the relationship between } \\
\text { the mining companies and mining } \\
\text { communities } \\
\text { 3. Explore avenues and opportunities } \\
\text { under the EU Forest Law } \\
\text { Enforcement, Governance and } \\
\text { Trade (FLEGT) } \\
\text { 3.8 Promulgate and implement the new } \\
\text { minerals bill covering the small } \\
\text { scale operations. }\end{array}$ & $\begin{array}{l}\text { MLFM, GHANA CHAMBER OF } \\
\text { MINES, MES, MLGRD, District } \\
\text { Assemblies, MOTI, NBSSI, ASSI, Wild } \\
\text { Life Society and other relevant agencies, } \\
\text { NADMO, EPA, FIRE SERVICE, LAW } \\
\text { ENFORCEMENT AGENCIES }\end{array}$ & $\begin{array}{l}\text { NEPAD, MDG } 7 \\
\text { MDG } 8\end{array}$ \\
\hline & $\begin{array}{l}\text { - Lack of collaboration } \\
\text { among member states of } \\
\text { ECOWAS on natural }\end{array}$ & $\begin{array}{l}\text { 4. Build regional and } \\
\text { global linkages } \\
\text { toward the }\end{array}$ & $\begin{array}{l}\text { 4.1 Co-ordinate and harmonize policies } \\
\text { and programmes with other } \\
\text { member states of ECOWAS }\end{array}$ & $\begin{array}{l}\text { MLFM, MES, MLGRD, District } \\
\text { Assemblies, MOTI, NBSSI, ASSI, Wild } \\
\text { Life Society and the relevant agencies, }\end{array}$ & $\begin{array}{l}\text { NEPAD, } \\
\text { ECOWAS } \\
\text { MDG 7, MDG } 8\end{array}$ \\
\hline
\end{tabular}




\begin{tabular}{|c|c|c|c|c|c|}
\hline \multirow[t]{2}{*}{ KEY AREA OF FOCUS } & ISSUES & POLICY & STRATEGIES & $\begin{array}{l}\text { IMPLEMENTING AND } \\
\text { COLLABORATIVE AGENCY }\end{array}$ & $\begin{array}{l}\text { GLOBAL / } \\
\text { REGIONAL } \\
\text { LINKAGES }\end{array}$ \\
\hline & resource management & $\begin{array}{l}\text { management of } \\
\text { natural resources }\end{array}$ & $\begin{array}{l}\text { 4.2 Exchange information on the } \\
\text { prospection, mapping, production } \\
\text { and processing of mineral } \\
\text { resources and exploration, and } \\
\text { distribution of water resources } \\
\text { among member countries } \\
4.3 \text { Develop a system of transfer of } \\
\text { expertise and exchange of } \\
\text { scientific, technical and economic } \\
\text { remote sensing data among } \\
\text { member states of Ecowas }\end{array}$ & FIRE SERVICE & $\begin{array}{l}\text { NEPAD, } \\
\text { ECOWAS MDG } 7 \\
\text { MDG } 8 \\
\\
\text { NEPAD, } \\
\text { ECOWAS } \\
\text { MDG7/8 }\end{array}$ \\
\hline \multirow[t]{2}{*}{$\begin{array}{l}\text { (d) Promoting Trade } \\
\text { and Industrial } \\
\text { Development }\end{array}$} & $\begin{array}{l}\text { - Limited economically } \\
\text { beneficial linkages } \\
\text { along the production } \\
\text { and supply chains. } \\
\\
\text { - Lack of information on } \\
\text { availability of credit } \\
\text { especially for women } \\
\text { - Lack of credit to support } \\
\text { trade and peasant } \\
\text { farmers, especially } \\
\text { women. } \\
\end{array}$ & $\begin{array}{l}\text { 1. Ensure proper } \\
\text { integration of the } \\
\text { nation's production } \\
\text { sector into the } \\
\text { domestic market } \\
\text { with equal } \\
\text { opportunities for } \\
\text { women and men. }\end{array}$ & $\begin{array}{l}\text { 1.1 Identify and promote opportunities } \\
\text { for economically beneficial } \\
\text { linkages along production and } \\
\text { supply chains in new and existing } \\
\text { productive sectors } \\
1.2 \text { Promote credit catalysts and rural } \\
\text { service centers where larger traders } \\
\text { and associations can access credit } \\
\text { and on-lend to small traders and } \\
\text { peasant farmers }\end{array}$ & $\begin{array}{l}\text { MOFEP, MOFA, MPSD\&PSI, MRT, } \\
\text { GEPC, MOTI NBSSI, Registrar General } \\
\text { Department, ASSI, SBA, AGI, GHANA } \\
\text { CHAMBER OF COMMERCE }\end{array}$ & $\begin{array}{l}\text { MDG 1; NEPAD, } \\
\text { APRM, Obj.4 } \\
\text { under Socio- } \\
\text { economic } \\
\text { development }\end{array}$ \\
\hline & $\begin{array}{l}\text { - Limited, ineffective and } \\
\text { inefficient trade support } \\
\text { services denying } \\
\text { exporters access to the } \\
\text { open EU and America } \\
\text { markets }\end{array}$ & $\begin{array}{l}\text { 2. Enhance access to } \\
\text { export markets for } \\
\text { both women and } \\
\text { men }\end{array}$ & $\begin{array}{l}\text { 2.1 Provide concessionary export } \\
\text { finance facilities to exporters } \\
\text { 2.2 Promote competition in airport } \\
\text { ground handling } \\
\text { 2.3 Encourage private sector } \\
\text { investment in construction, and } \\
\text { operating cold chain facilities from } \\
\text { production point to the port } \\
\text { 2.4 Facilitate the provision by private } \\
\text { sector well organised container } \\
\text { terminals with security, equipment, } \\
\text { effective operators and } \\
\text { computerised tracking. }\end{array}$ & $\begin{array}{l}\text { CEPS, MRT, OFFICE OF THE } \\
\text { PRESIDENT, GEPC, MOTI GPHA, } \\
\text { MOFEP, NBSSI, Private sector, ASSI, } \\
\text { MPSD \& PSI , MOFA, MOFI, GHANA } \\
\text { CHAMBER OF COMMERCE, Ministry } \\
\text { of Regional Integration \& NEPAD }\end{array}$ & $\begin{array}{l}\text { MDG 8; APRM, } \\
\text { obj.4 under Socio- } \\
\text { economic } \\
\text { development }\end{array}$ \\
\hline
\end{tabular}




\begin{tabular}{|c|c|c|c|c|c|}
\hline KEY AREA OF FOCUS & ISSUES & POLICY & STRATEGIES & $\begin{array}{l}\text { IMPLEMENTING AND } \\
\text { COLLABORATIVE AGENCY }\end{array}$ & $\begin{array}{l}\text { GLOBAL / } \\
\text { REGIONAL } \\
\text { LINKAGES }\end{array}$ \\
\hline & $\begin{array}{l}\text { - Inability to derived the } \\
\text { maximum benefit from } \\
\text { multilateral trading } \\
\text { negotiations } \\
\text { - Lack of fairness and } \\
\text { transparency in the } \\
\text { nation's import-export } \\
\text { regime } \\
\text { - Bottlenecks in moving } \\
\text { goods through the } \\
\text { nation's borders }\end{array}$ & & $\begin{array}{l}\text { 2.5 Improve the multi-lateral trading } \\
\text { environment by fully participating } \\
\text { in negotiations and rule setting in } \\
\text { multi-lateral trading fora } \\
\text { 2.6 Create a fair, transparent and } \\
\text { equitable trade regime } \\
\text { 2.7 Facilitate trade through Ghana's } \\
\text { border to reduce costs and improve } \\
\text { ease of trade }\end{array}$ & & $\begin{array}{l}\text { NEPAD, } \\
\text { ECOWAS } \\
\text { NEPAD, } \\
\text { ECOWAS, } \\
\text { MDG } 8\end{array}$ \\
\hline & $\begin{array}{l}\text { - Low investment in the } \\
\text { services and } \\
\text { manufacturing sectors. } \\
\text { - Lack of well-developed } \\
\text { and efficient national } \\
\text { infrastructure to support } \\
\text { industrial productions. } \\
\text { - Lack of professionalism } \\
\text { in the management of } \\
\text { production systems. } \\
\text { - Limited use of local } \\
\text { products and services in } \\
\text { government projects } \\
\text { - Low patronage for made } \\
\text { in Ghana products in the } \\
\text { domestic and } \\
\text { international markets }\end{array}$ & $\begin{array}{l}\text { 3. Increase industrial } \\
\text { output and } \\
\text { improve the } \\
\text { competitiveness of } \\
\text { domestic industrial } \\
\text { products }\end{array}$ & $\begin{array}{l}\text { 3.1 } \begin{array}{l}\text { Mobilize domestic and } \\
\text { international resources for } \\
\text { production of value-added products }\end{array} \\
\text { 3.2 Enhance accessibility to } \\
\text { competitive productive } \\
\text { infrastructures (i.e. road, water, } \\
\text { telecommunication, electricity, etc) } \\
\text { 3.3 Promote efficient management } \\
\text { practices in production systems. } \\
\text { 3.4 Promote the use of local products } \\
\text { and services in government } \\
\text { procurement } \\
\text { 3.5 Actively promote made in Ghana } \\
\text { products within domestic and } \\
\text { international markets } \\
\text { 3.6 Promote industrial sub-contracting } \\
\text { and partnership exchange } \\
\text { 3.7 Facilitating the development of } \\
\text { commercially viable export } \\
\text { oriented and domestic market } \\
\text { oriented enterprises in rural } \\
\text { communities }\end{array}$ & $\begin{array}{l}\text { GEPC, MOTI , MOFA, MOFI, NBSSI, } \\
\text { GIPC, Registrar General Department, } \\
\text { ASSI, AGI, MPSD \& PSI, Private Sector, } \\
\text { Financial Sector, Bank of Ghana, } \\
\text { MLGRD, MRT, MOC, MPHR, MOE, } \\
\text { MWH, MES, GHANA CHAMBER OF } \\
\text { COMMERCE, PEF, Education } \\
\text { Institutions, EMPRETEC MOFEP, GSB, } \\
\text { GRATIS, GHANA NATIONAL } \\
\text { PROCUREMENT AGENCY, TFOC, } \\
\text { ITC, ATAG, }\end{array}$ & $\begin{array}{l}\text { NEPAD, } \\
\text { ECOWAS } \\
\text { MDG } 8 \\
\\
\\
\text { NEPAD } \\
\text { MDG 1 } \\
\text { ECOWAS, } \\
\text { NEPAD } \\
\text { MDG 1 }\end{array}$ \\
\hline
\end{tabular}




\begin{tabular}{|c|c|c|c|c|c|}
\hline KEY AREA OF FOCUS & ISSUES & POLICY & STRATEGIES & $\begin{array}{l}\text { IMPLEMENTING AND } \\
\text { COLLABORATIVE AGENCY }\end{array}$ & $\begin{array}{l}\text { GLOBAL / } \\
\text { REGIONAL } \\
\text { LINKAGES }\end{array}$ \\
\hline & $\begin{array}{l}\text { - Poor quality of domestic } \\
\text { products which do not } \\
\text { meet international } \\
\text { standards }\end{array}$ & & $\begin{array}{l}\text { 3.8 Promote the development of the } \\
\text { craft industry for mass production } \\
\text { and export } \\
\text { 3.9 Ensure that designed standard } \\
\text { organisations participate in } \\
\text { international standard setting } \\
\text { 3.10 Ensure the removal of technical } \\
\text { barriers in the way of key current } \\
\text { and potential export products } \\
\text { 3.11 Assist exporters to comply with } \\
\text { international standards required } \\
\text { by selected export markets. }\end{array}$ & $\begin{array}{l}\text { MOTI, MOFA, MOFI, GEPC, GSB, } \\
\text { FDB, AGI, ASSI, GIPC, MPSD \& PSI, } \\
\text { EPA, Private sector } \\
\text { MOTI, MOFA, MOFI, GEPC, AGI, } \\
\text { ASSI, GIPC, MPSD \& PSI, Private } \\
\text { sector, CSIR } \\
\text { MOTI, MOFA, MOFI, GEPC, AGI, } \\
\text { ASSI, GIPC, MPSD \& PSI, Private } \\
\text { sector, CSIR }\end{array}$ & \\
\hline & $\begin{array}{l}\text { - Exploitation of } \\
\text { consumer due to } \\
\text { monopoly situation } \\
\text { - Frustration in the } \\
\text { registration and } \\
\text { licensing of new } \\
\text { businesses } \\
\text { - Slow integration of the } \\
\text { countries in the } \\
\text { ECOWAS sub-region. } \\
\text { - Lack of effective laws } \\
\text { and regulations to } \\
\text { protect intellectual } \\
\text { property rights } \\
\\
\text { - Low awareness on } \\
\text { intellectual property } \\
\text { rights. }\end{array}$ & $\begin{array}{l}\text { 4. Strengthen the legal, } \\
\text { regulatory and } \\
\text { institutional } \\
\text { framework to } \\
\text { support industrial } \\
\text { production and trade }\end{array}$ & $\begin{array}{l}\text { 4.1 Improve on the rules of competition } \\
\text { and ensure effective enforcement } \\
\text { 4.2 Improve the speed and efficiency of } \\
\text { business registration and licensing } \\
\text { 4.3 Fully support measures aimed at } \\
\text { removing obstacles to full } \\
\text { ECOWAS integration } \\
\text { 4.4 Provide effective rules to protect } \\
\text { intellectual property rights and } \\
\text { coordination mechanism to ensure } \\
\text { effective administration of } \\
\text { copyright and industrial property } \\
\text { rights } \\
\text { 4.5 Design and implement a programme } \\
\text { of awareness and education on } \\
\text { intellectual property rights targets } \\
\text { women and men }\end{array}$ & $\begin{array}{l}\text { MOTI, MOFA, MOFI, NBSSI, GIPC, } \\
\text { ASSI, AGI, MPSD \& PSI, Private Sector, } \\
\text { EMPRETEC, Educational Institutions } \\
\text { CEPS, MRT, GEPC, MOTI, MOFA, } \\
\text { MOFI, GPHA, NBSSI, Registrar } \\
\text { General Department, ASSI, } \\
\text { GEPC, MOTI, NBSSI, GIPC, MPSD \& } \\
\text { PSI, MOFA, MOFI,, Ministry of } \\
\text { Regional Integration and NEPAD } \\
\text { MOJ \&Attorney-General, MOTI, } \\
\text { MOFA, MOFI, GEPC, NBSSI, MPSD \& } \\
\text { PSI, Ministry of Regional Integration and } \\
\text { NEPAD } \\
\text { MOJ \&Attorney-General, MOTI, } \\
\text { MOFA, MOFI, GEPC, NBSSI, MPSD \& } \\
\text { PSI, Ministry of Regional Integration and } \\
\text { NEPAD }\end{array}$ & $\begin{array}{l}\text { ECOWAS, } \\
\text { NEPAD } \\
\text { MDG } 8\end{array}$ \\
\hline
\end{tabular}




\begin{tabular}{|c|c|c|c|c|c|}
\hline KEY AREA OF FOCUS & ISSUES & POLICY & STRATEGIES & $\begin{array}{l}\text { IMPLEMENTING AND } \\
\text { COLLABORATIVE AGENCY }\end{array}$ & $\begin{array}{l}\text { GLOBAL / } \\
\text { REGIONAL } \\
\text { LINKAGES }\end{array}$ \\
\hline & $\begin{array}{l}\text { - Lack of balance } \\
\text { between economic } \\
\text { interest, consumption } \\
\text { patterns and } \\
\text { environmental } \\
\text { protection }\end{array}$ & & $\begin{array}{l}\text { 4.6 Promote environmentally friendly } \\
\text { consumption }\end{array}$ & $\begin{array}{l}\text { MOTI, F MOFA, MOFI, DB, GSB, } \\
\text { DISTRICT ASSEMBLIES, MOE, } \\
\text { MPSD\&PSI, EPA, LAW } \\
\text { ENFORCEMENT AGENCIES, } \\
\text { ADVOCACY GROUPS, MEDIA, } \\
\text { NCCE. }\end{array}$ & MDG 7 \\
\hline & $\begin{array}{l}\text { - Poor quality, dangerous } \\
\text { content, and poor } \\
\text { handling of products } \\
\text { endanger the health of } \\
\text { consumers, especially } \\
\text { low income earners. } \\
\text { - Unfair pricing, and } \\
\text { arbitrary application of } \\
\text { weights and measures in } \\
\text { selling of goods } \\
\text { - Complete absence of, or } \\
\text { limited consumer } \\
\text { representation on issues } \\
\text { affecting them }\end{array}$ & $\begin{array}{l}\text { 5. Ensure the health, } \\
\text { safety and economic } \\
\text { interest of consumers }\end{array}$ & $\begin{array}{l}\text { 5.1 Ensure the enforcement of } \\
\text { legislation that prevents the sale of } \\
\text { unsafe and poor quality goods on } \\
\text { the local market. } \\
\text { 5.2 } \begin{array}{l}\text { Strengthen the regulatory and } \\
\text { enforcement framework for } \\
\text { protection of economic rights of }\end{array} \\
\text { consumers } \\
\text { 5.3 } \begin{array}{l}\text { Develop and implement national } \\
\text { consumer awareness programs }\end{array} \\
\text { 5.4 Encourage formation of consumer } \\
\text { association } \\
\text { 5.5 Ensure representation of consumers } \\
\text { on relevant national bodies }\end{array}$ & $\begin{array}{l}\text { MOTI, MOFA, MOFI, MOH, FDB, } \\
\text { GSB, DISTRICT ASSEMBLIES, MOE, } \\
\text { MPSD\&PSI, EPA, LAW } \\
\text { ENFORCEMENT AGENCIES, } \\
\text { ADVOCACY GROUPS, MEDIA, } \\
\text { NCCE. } \\
\text { MOTI, FDB, GSB, DISTRICT } \\
\text { ASSEMBLIES, MOE, MOFA, MOFI, } \\
\text { MPSD\&PSI, EPA, MOH, MLGRD, } \\
\text { LAW ENFORCEMENT AGENCIES, } \\
\text { ADVOCACY GROUPS, MEDIA, } \\
\text { NCCE. }\end{array}$ & \\
\hline \multicolumn{6}{|c|}{ III .SUPPORT SERVICES } \\
\hline $\begin{array}{l}\text { (a) Transport } \\
\text { Infrastructure: Road, } \\
\text { Rail, Water and Air } \\
\text { Tran sport }\end{array}$ & $\begin{array}{l}\text { - Poor road infrastructure } \\
\text { - Traffic congestion in } \\
\text { urban centers and } \\
\text { outline areas }\end{array}$ & $\begin{array}{l}\text { 1. Ensure the } \\
\text { provision, expansion } \\
\text { and maintenance of } \\
\text { transport } \\
\text { infrastructure of all } \\
\text { kinds }\end{array}$ & $\begin{array}{l}\text { 1.1 Increase spatial access to market } \\
\text { through improvement in farm roads } \\
\text { to markets } \\
\text { 1.2 Maintain and expand feeder roads } \\
\text { 1.3 Construct and rehabilitate more } \\
\text { access roads in the urban centers. } \\
\text { 1.4 Rehabilitate or develop one major } \\
\text { road linking rural and urban } \\
\text { markets in every region. } \\
\text { 1.5 Develop and rehabilitate major } \\
\text { highways in the country }\end{array}$ & $\begin{array}{l}\text { MRT, DFR, MOFA, DUR, District } \\
\text { Assemblies/Metropolitan Authorities } \\
\text { MRT, GHA, DFR, DUR, District } \\
\text { Assemblies/Metropolitan Authorities }\end{array}$ & $\begin{array}{l}\text { MDG } 1 \\
\text { MDG } 1\end{array}$ \\
\hline
\end{tabular}




\begin{tabular}{|c|c|c|c|c|c|}
\hline KEY AREA OF FOCUS & ISSUES & POLICY & STRATEGIES & $\begin{array}{l}\text { IMPLEMENTING AND } \\
\text { COLLABORATIVE AGENCY }\end{array}$ & $\begin{array}{l}\text { GLOBAL / } \\
\text { REGIONAL } \\
\text { LINKAGES }\end{array}$ \\
\hline & \multirow{3}{*}{$\begin{array}{l}\text { - Insufficient and } \\
\text { dilapidated rail terminals } \\
\text { and platforms } \\
\text { - Dilapidated rail tracks } \\
\text { and lack of appropriate } \\
\text { linkages of tracks for } \\
\text { economically beneficial } \\
\text { purpose }\end{array}$} & & $\begin{array}{l}\text { 1.6 Enhance regional co-operation and } \\
\text { trade through cross-border road } \\
\text { infrastructure development } \\
\text { 1.7 Develop and maintain all access } \\
\text { routes leading to the Volta Lake } \\
\text { 1.8 Provide adequate and modern } \\
\text { railway terminals and platforms } \\
\text { 1.9 Promote the development of a well } \\
\text { integrated and modernized rail } \\
\text { track system }\end{array}$ & $\begin{array}{l}\text { MPHR, MRT, GHA, DFR, VLTC, GRC, } \\
\text { District Assemblies/ Metropolitan } \\
\text { Authorities, Private Sector }\end{array}$ & $\begin{array}{l}\text { NEPAD, } \\
\text { ECOWAS } \\
\text { MDG } 8\end{array}$ \\
\hline & & & $\begin{array}{l}\text { 1.10 Link the northern part of the } \\
\text { country to the south, through an } \\
\text { efficient rail network. } \\
\text { 1.11 Maintain and provide efficient and } \\
\text { modernized ports and Harbors } \\
\text { infrastructure across the country. } \\
\text { 1.12 Promote the development of } \\
\text { regional rail network and ports } \\
\text { facilities. } \\
\text { 1.13 Encourage general aviation and } \\
\text { aviation support services such as } \\
\text { the use of micro light aircraft in } \\
\text { agriculture, passenger transport and } \\
\text { health delivery services }\end{array}$ & \multirow[t]{2}{*}{$\begin{array}{l}\text { GCAA, Office of the President, MRT, } \\
\text { Private sector, MOH }\end{array}$} & ECOWAS \\
\hline & & & $\begin{array}{l}\text { 1.14 Development of air strips in } \\
\text { remote areas }\end{array}$ & & \\
\hline & $\begin{array}{l}\text { - Inaccessible } \\
\text { transportation network } \\
\text { to the urban centers. } \\
\text { - Sparsely distributed } \\
\text { settlements in certain } \\
\text { regions }\end{array}$ & $\begin{array}{l}\text { 2. Ensure the } \\
\text { provision of } \\
\text { affordable and an } \\
\text { accessible } \\
\text { transport system }\end{array}$ & $\begin{array}{l}\text { 2.1 Sustain the development of mass } \\
\text { transportation system for road } \\
\text { 2.2 Promote the development of } \\
\text { disability friendly public transport } \\
\text { system for all modes of } \\
\text { transportation } \\
\text { 2.4 Promote the development and use of } \\
\text { Intermediate Modes of transport } \\
\text { (IMT) }\end{array}$ & $\begin{array}{l}\text { MRT GCAA MMC, MMDAs, GPRTU } \\
\text { MRT, MPHR, Office of the President } \\
\text { GCAA MMC, MMDAs } \\
\text { MRT, MMDAs, CSIR, }\end{array}$ & MDG 1 \\
\hline
\end{tabular}




\begin{tabular}{|c|c|c|c|c|c|}
\hline KEY AREA OF FOCUS & ISSUES & POLICY & STRATEGIES & $\begin{array}{l}\text { IMPLEMENTING AND } \\
\text { COLLABORATIVE AGENCY }\end{array}$ & $\begin{array}{l}\text { GLOBAL / } \\
\text { REGIONAL } \\
\text { LINKAGES }\end{array}$ \\
\hline & $\begin{array}{l}\text { - Lack of safety of/on } \\
\text { water transport } \\
\text { - Inadequate water } \\
\text { transportation }\end{array}$ & & $\begin{array}{l}\text { 2.5 Provide a smooth affordable and } \\
\text { safe water transport system for the } \\
\text { country } \\
\text { 2.6 Sustain the development of mass } \\
\text { transport for rail and water modes } \\
\text { of transport } \\
\text { 2.7 Provide efficient and reliable port } \\
\text { services } \\
\text { 2.8 Promote the integration of all modes } \\
\text { of transport } \\
\text { 2.9 Promote sub- regional rail and ports } \\
\text { management system that ensures } \\
\text { efficient movement of goods and } \\
\text { humans across borders. }\end{array}$ & $\begin{array}{l}\text { MPHR, MMDAs, VLTC } \\
\text { MPHR, MMDAs, VLTC, GRC } \\
\text { MPHR, MMDAs, VLTC, GRC, } \\
\text { GHAPOHA, CEPS } \\
\text { MRT, MPHR, VLTC, GRC, GHA, DFR, } \\
\text { DUR } \\
\text { MPHR, MMDAs, VLTC, GRC, } \\
\text { GHAPOHA, CEPS }\end{array}$ & $\begin{array}{l}\text { ECOWAS } \\
\text { NEPAD, MDG } 8\end{array}$ \\
\hline & & & $\begin{array}{l}\text { 2.10 Promote high safety, security and } \\
\text { environmental standards for the } \\
\text { aviation industry } \\
\text { 2.11 Promote the development of } \\
\text { human resource and the use of ICT } \\
\text { in the aviation industry }\end{array}$ & $\begin{array}{l}\text { GCAA, Office of the President, MRT, } \\
\text { Private sector, MOH, CEPS, Immigration } \\
\text { Service, Ghana Police Service, Ghana } \\
\text { Fire service, MCT }\end{array}$ & MDG 8 \\
\hline & $\begin{array}{l}\text { - Lack of/insufficient legal } \\
\text { and regulatory } \\
\text { framework to regulate } \\
\text { water, air, marine and } \\
\text { road transport }\end{array}$ & $\begin{array}{l}\text { 3. Develop and } \\
\text { strengthen the } \\
\text { appropriate legal, } \\
\text { institutional and } \\
\text { regulatory } \\
\text { framework to } \\
\text { regulate all modes } \\
\text { of transportation to } \\
\text { ensure an efficient } \\
\text { transport system }\end{array}$ & $\begin{array}{l}\text { 3.1 Streamline transport regulation and } \\
\text { enforcement } \\
\text { 3.2 Promote road safety and traffic } \\
\text { management scheme to reduce road } \\
\text { traffic accidents } \\
\text { 3.3 Promote private sector involvement } \\
\text { in the road sector financing, } \\
\text { construction and maintenance } \\
\text { 3.4 Strengthen local capacity in both } \\
\text { consulting and construction } \\
\text { services and Government } \\
\text { institutional capacity in the road } \\
\text { sector }\end{array}$ & $\begin{array}{l}\text { MRT, MMDAs, GPRTU, MTTU, } \\
\text { DVLA, National Road Safety } \\
\text { Commission, MOJ, Judiciary, Law } \\
\text { enforcement agencies, Office of the } \\
\text { President } \\
\text { MRT, District / Metropolitan Assemblies, } \\
\text { GPRTU, MTTU, DVLA, National Road } \\
\text { Safety Commission } \\
\text { MRT, Private sector, Financial } \\
\text { Institutions, BRRI } \\
\text { MRT, Private sector, Local consultants, } \\
\text { BRRI }\end{array}$ & \\
\hline
\end{tabular}




\begin{tabular}{|c|c|c|c|c|c|}
\hline KEY AREA OF FOCUS & ISSUES & POLICY & STRATEGIES & $\begin{array}{l}\text { IMPLEMENTING AND } \\
\text { COLLABORATIVE AGENCY }\end{array}$ & $\begin{array}{l}\text { GLOBAL / } \\
\text { REGIONAL } \\
\text { LINKAGES }\end{array}$ \\
\hline & $\begin{array}{l}\text { - Poor road maintenance } \\
\text { culture }\end{array}$ & & $\begin{array}{l}\text { 3.5 Support small scale contractors } \\
\text { through the classification and } \\
\text { registration process } \\
\text { 3.6 Promote effective and sustainable } \\
\text { maintenance of the road system } \\
\text { (through government } \\
\text { decentralization programme). } \\
\text { 3.7 Promote rail and water safety } \\
\text { management scheme to reduce boat } \\
\text { disasters and derailment } \\
\text { 3.8 Promote private sector involvement } \\
\text { in port services and in the } \\
\text { financing, construction and } \\
\text { maintenance of rail services. } \\
\text { 3.9 Strengthen local capacity in both } \\
\text { consulting and construction } \\
\text { services and government capacity } \\
\text { in the road, rail and marine sector } \\
\text { 3.10 Develop appropriate legal and } \\
\text { institution framework to ensure } \\
\text { security at the rail and other } \\
\text { terminal facilities. } \\
\text { 3.11 Strengthen existing regulatory and } \\
\text { institutional framework for efficient } \\
\text { ports, rail, water and air transport } \\
\text { system } \\
\text { 3.12 Restructure Ghana Civil Aviation } \\
\text { Authority to play it is role as an } \\
\text { independent regulator. } \\
\text { 3.13 Promote private sector } \\
\text { involvement in the investment and } \\
\text { management of aviation } \\
\text { infrastructure and equipment. } \\
\text { 3.14 Adequately develop the road fund } \\
\text { to fully cater for the annual road } \\
\text { maintenance }\end{array}$ & $\begin{array}{l}\text { MRT, MPSD\&PSI, Private Sector GHA, } \\
\text { DFR, DUR, MOFEP } \\
\text { MRT, GHA, DFR, DUR, MMDAs } \\
\text { MPHR, MMDAs VLTC, GRC } \\
\text { MPHR, VLTC, GRC, GHAPOHA, } \\
\text { Private sector, Financial Institutions } \\
\text { MPHR, VLTC, GRC, GHAPOHA, } \\
\text { Private sector (Local consultants), CEPS, } \\
\text { Maritime Academy, MRT } \\
\text { MPHR, VLTC, GRC, GHAPOHA, } \\
\text { Maritime Academy, MOJ, Parliament, } \\
\text { MRT } \\
\text { MPHR, VLTC, GRC, GHAPOHA, } \\
\text { Maritime Academy, MOJ, Parliament, } \\
\text { Office of the President, MRT, GCAA } \\
\text { GCAA, Office of the President, MRT, } \\
\text { Private sector, MPSD, GIPC }\end{array}$ & \\
\hline
\end{tabular}




\begin{tabular}{|c|c|c|c|c|c|}
\hline KEY AREA OF FOCUS & ISSUES & POLICY & STRATEGIES & $\begin{array}{l}\text { IMPLEMENTING AND } \\
\text { COLLABORATIVE AGENCY }\end{array}$ & $\begin{array}{l}\text { GLOBAL / } \\
\text { REGIONAL } \\
\text { LINKAGES }\end{array}$ \\
\hline \multirow[t]{5}{*}{$\begin{array}{ll}\text { (b) Energy Supply to } \\
\text { Support Industry and } \\
\text { Households }\end{array}$} & $\begin{array}{l}\text { Deforestation and } \\
\text { environmental } \\
\text { degradation due to } \\
\text { indiscriminate felling of } \\
\text { trees }\end{array}$ & $\begin{array}{l}\text { 1. Increase access to } \\
\text { the modern forms } \\
\text { of energy to the } \\
\text { poor and } \\
\text { vulnerable }\end{array}$ & $\begin{array}{l}\text { 1.1 Implement the Self-Help } \\
\text { Electrification Programme (SHEP) } \\
\text { in the rural and peri-urban areas } \\
\text { 1.2 Implement rural energy programme } \\
\text { involving renewable energy (solar } \\
\text { PV, small hydro, wind, biogas etc.) } \\
\text { in areas where it is economically } \\
\text { feasible. } \\
\text { 1.3 Encourage and support the use of } \\
\text { safe, affordable liquefied petroleum } \\
\text { gas (LPG) especially in the rural } \\
\text { areas }\end{array}$ & $\begin{array}{l}\text { MOE, VRA, ECG, Energy Commission, } \\
\text { private sector, DPs, KITE, Energy } \\
\text { Foundation }\end{array}$ & $\begin{array}{l}\text { MDG 1/ 7, } \\
\text { NEPAD, } \\
\text { ECOWAS; } \\
\text { APRM obj.4 } \\
\text { under Socio- } \\
\text { economic } \\
\text { development }\end{array}$ \\
\hline & $\begin{array}{l}\text {-Inadequate power } \\
\text { infrastructure to } \\
\text { support the delivery of } \\
\text { modern energy services }\end{array}$ & $\begin{array}{l}\text { 2. Provide support to } \\
\text { modernize and } \\
\text { expand power } \\
\text { infrastructure }\end{array}$ & $\begin{array}{l}\text { 2.1 Implement ECG Distribution } \\
\text { System Upgrade project. } \\
\text { 2.2 Implement NED Distribution } \\
\text { system Upgrade Project } \\
\text { 2.3 Implement transmission and power } \\
\text { generation projects to assure } \\
\text { reliable power supply }\end{array}$ & MOE, ECG, DPs & $\begin{array}{l}\text { NEPAD, APRM } \\
\text { Obj.4 under Socio- } \\
\text { economic Devt }\end{array}$ \\
\hline & $\begin{array}{l}\text { - Need to diversify } \\
\text { national energy mix and } \\
\text { assure energy security. }\end{array}$ & $\begin{array}{l}\text { 3. Diversify the } \\
\text { national energy mix } \\
\text { including the use of } \\
\text { indigenous }\end{array}$ & $\begin{array}{l}\text { 3.1 Implement programmes to support } \\
\text { renewable energy sources in Ghana } \\
\text { ( Hydro, wind, solar PV etc.) }\end{array}$ & $\begin{array}{l}\text { MOE, VRA, Energy Commission, } \\
\text { Donors }\end{array}$ & \multirow[t]{2}{*}{$\begin{array}{l}\text { MDG 7, APRM } \\
\text { Obj.4 under Socio- } \\
\text { economic Devt }\end{array}$} \\
\hline & $\begin{array}{l}\text { - Need for long- term } \\
\text { sustainable operation of } \\
\text { the power sector }\end{array}$ & $\begin{array}{l}\text { 4. Improve } \\
\text { management and } \\
\text { accountability in } \\
\text { power utilities } \\
\text { 5. Improve the } \\
\text { regulatory } \\
\text { environment in the } \\
\text { power sector } \\
\text { 6. Ensure full cost } \\
\text { recovery for power } \\
\text { supply and delivery } \\
\end{array}$ & $\begin{array}{l}\text { 4.1 Implement Power Sector Reform } \\
\text { Programme } \\
\text { 5.1 Support human resource and } \\
\text { capacity building in the PURC and } \\
\text { Energy Commission } \\
\text { 6.1 Implement a policy of full cost } \\
\text { recovery for electricity while } \\
\text { protecting the poor. }\end{array}$ & 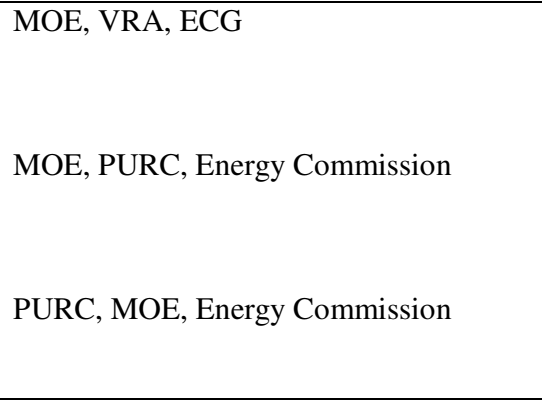 & \\
\hline & $\begin{array}{l}\text { - Need for secure long } \\
\text { term source of fuel for }\end{array}$ & $\begin{array}{l}\text { 7. Develop long term } \\
\text { source of fuel for the }\end{array}$ & $\begin{array}{l}\text { 7.1 Assume a lead role in the West } \\
\text { African Gas Pipeline Project }\end{array}$ & $\begin{array}{l}\text { MOE, WAGPP, VRA, PURC, Energy } \\
\text { Commission, MOFEP, FIRE SERVICE }\end{array}$ & \\
\hline
\end{tabular}




\begin{tabular}{|c|c|c|c|c|c|}
\hline KEY AREA OF FOCUS & \multirow{2}{*}{$\begin{array}{l}\text { ISSUES } \\
\text { the power system }\end{array}$} & \multirow{2}{*}{$\begin{array}{l}\text { POLICY } \\
\text { thermal plants }\end{array}$} & \multirow{2}{*}{$\begin{array}{l}\text { STRATEGIES } \\
\text { 7.2 Develop secondary market for gas } \\
\text { under the West Africa Gas Pipe } \\
\text { Line Project. }\end{array}$} & \multirow[t]{2}{*}{$\begin{array}{l}\text { IMPLEMENTING AND } \\
\text { COLLABORATIVE AGENCY }\end{array}$} & \multirow[t]{2}{*}{$\begin{array}{l}\text { GLOBAL / } \\
\text { REGIONAL } \\
\text { LINKAGES } \\
\end{array}$} \\
\hline & & & & & \\
\hline & $\begin{array}{l}\text { - Health problems } \\
\text { experienced by women } \\
\text { due to inefficient wood } \\
\text { fuel technologies }\end{array}$ & $\begin{array}{l}\text { 8. Minimize } \\
\text { environmental } \\
\text { impacts of energy } \\
\text { supply and } \\
\text { consumption through } \\
\text { increased renewable } \\
\text { energy / energy } \\
\text { efficiency } \\
\text { technologies }\end{array}$ & $\begin{array}{l}\text { 8.1 Promote energy efficient } \\
\text { technologies that safeguard the } \\
\text { health of domestic users especially } \\
\text { women and children }\end{array}$ & $\begin{array}{l}\text { MOE, Energy Foundation, Energy } \\
\text { Commission, ECG, MOWAC, MOFA, } \\
\text { MOFI }\end{array}$ & $\begin{array}{l}\text { MDG 3; APRM } \\
\text { Obj.4 under Socio- } \\
\text { economic Devt }\end{array}$ \\
\hline & $\begin{array}{l}\text { Low adoption of } \\
\text { energy efficiency } \\
\text { technologies among } \\
\text { domestic users. }\end{array}$ & $\begin{array}{l}\text { 9. Ensure productive } \\
\text { and efficient use of } \\
\text { energy(both rural } \\
\text { and urban) }\end{array}$ & $\begin{array}{l}\text { 9.1 Implement programmes on energy } \\
\text { efficiency and conservation. } \\
9.2 \text { Implement a productive uses of } \\
\text { energy programme in the rural } \\
\text { areas to stimulate growth and } \\
\text { development }\end{array}$ & $\begin{array}{l}\text { MOE, Energy Foundation, Energy } \\
\text { Commission, VRA, ECG } \\
\text { MOE, Energy Foundation, Energy } \\
\text { Comm., VRA, ECG }\end{array}$ & $\begin{array}{l}\text { MDG 1; APRM } \\
\text { Obj.4 under Socio- } \\
\text { economic } \\
\text { development }\end{array}$ \\
\hline & $\begin{array}{l}\text { - Need for improvement } \\
\text { in the operation of the } \\
\text { power supply chain }\end{array}$ & $\begin{array}{l}\text { 10. Improve the } \\
\text { overall management } \\
\text { and operation of the } \\
\text { power sector }\end{array}$ & $\begin{array}{l}\text { 10.1 Implement the Power Sector } \\
\text { Reform Programme }\end{array}$ & MOE, Energy Commission & \multirow{2}{*}{$\begin{array}{l}\text { NEPAD, } \\
\text { ECOWAS; APRM } \\
\text { obj.4 under Socio- } \\
\text { economic } \\
\text { development }\end{array}$} \\
\hline & $\begin{array}{l}\text { - Low involvement of } \\
\text { private capital in the } \\
\text { energy sector }\end{array}$ & $\begin{array}{l}\text { 11. Promote and } \\
\text { encourage the } \\
\text { participation of the } \\
\text { private sector in the } \\
\text { energy sector }\end{array}$ & $\begin{array}{l}\text { 11.1 Implement full cost recovery in } \\
\text { the power sector } \\
\text { 11.2 Deregulate the petroleum sector }\end{array}$ & $\begin{array}{l}\text { MOE, VRA, ECG, PURC } \\
\text { MOE, NPA }\end{array}$ & \\
\hline 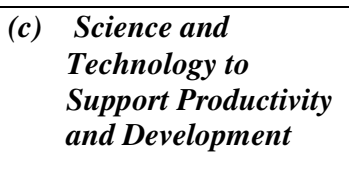 & $\begin{array}{l}\text { - Lack of science and } \\
\text { technology culture in all } \\
\text { aspect of the society }\end{array}$ & $\begin{array}{l}\text { 1. Promote research } \\
\text { and development at } \\
\text { all sectors of the } \\
\text { economy }\end{array}$ & $\begin{array}{l}\text { 1.1 Promote science and development at } \\
\text { all levels of production }\end{array}$ & $\begin{array}{l}\text { MES, CSIR, Private Sector, MOTI, } \\
\text { MOES, NBSSI, ITTU, GAEC, } \\
\text { University institutions, MOFA, MOFI }\end{array}$ & $\begin{array}{l}\text { MDG } 8, \text { NEPAD, } \\
\text { APRM obj.4 } \\
\text { under Socio- } \\
\text { economic } \\
\text { development }\end{array}$ \\
\hline
\end{tabular}




\begin{tabular}{|c|c|c|c|c|c|}
\hline KEY AREA OF FOCUS & ISSUES & POLICY & STRATEGIES & $\begin{array}{l}\text { IMPLEMENTING AND } \\
\text { COLLABORATIVE AGENCY }\end{array}$ & $\begin{array}{l}\text { GLOBAL / } \\
\text { REGIONAL } \\
\text { LINKAGES }\end{array}$ \\
\hline & $\begin{array}{l}\text { Lack of national policy } \\
\text { to promote the } \\
\text { development of } \\
\text { appropriate technology } \\
\text { to support agriculture } \\
\text { and small to medium } \\
\text { scale enterprises }\end{array}$ & & $\begin{array}{l}\text { 1.2 Promote the development of } \\
\text { appropriate technology to support } \\
\text { agriculture and rural small and } \\
\text { medium scale enterprises }\end{array}$ & & \multirow{3}{*}{$\begin{array}{l}\text { MDG 8, NEPAD, } \\
\text { APRM obj.4 under } \\
\text { Socio-economic } \\
\text { MRT, MPHR, } \\
\text { Office of the } \\
\text { President GCAA } \\
\text { MMC, MMDAs }\end{array}$} \\
\hline & $\begin{array}{l}\text { - Lack of national policy } \\
\text { on commercialization of } \\
\text { scientific research }\end{array}$ & $\begin{array}{l}\text { 2. Build appropriate } \\
\text { linkages between } \\
\text { research and } \\
\text { production to ensure } \\
\text { that research output } \\
\text { are utilized }\end{array}$ & $\begin{array}{l}\text { 2.1 Actively encourage the diffusion } \\
\text { and transfer of technology } \\
\text { development }\end{array}$ & \multirow[t]{2}{*}{$\begin{array}{l}\text { MES, CSIR, Private Sector, MOTI, } \\
\text { MOES, NBSSI, ITTU, GAEC, } \\
\text { University institutions, MOFA, MOFI, } \\
\text { MPSD\$PSI, MOFEP }\end{array}$} & \\
\hline & & $\begin{array}{l}\text { 3. Strengthen the } \\
\text { appropriate } \\
\text { institutions and } \\
\text { regulatory } \\
\text { framework to } \\
\text { promote the } \\
\text { development of } \\
\text { science and } \\
\text { technology research } \\
\end{array}$ & $\begin{array}{l}\text { 3.1 Provide support for business to } \\
\text { adopt Research and Development } \\
\text { as critical component of production } \\
\text { 3.2 Resource the existing science and } \\
\text { technology institutions to undertake } \\
\text { scientific research }\end{array}$ & & \\
\hline \multicolumn{6}{|c|}{ IV. DEVELOPING NEW SECTORS TO SUPPORT GROWTH } \\
\hline $\begin{array}{l}\text { (a) Developing } \\
\text { information and } \\
\text { communication } \\
\text { technology }(\text { ICT })\end{array}$ & $\begin{array}{l}\text { - Low accessibility to } \\
\text { telephone facilities, } \\
\text { especially in rural areas } \\
\text { - Poor quality of } \\
\text { telephone services } \\
\text { - Poor and/or inadequate } \\
\text { internet infrastructure } \\
\text { - ICT not affordable to } \\
\text { majority of potential } \\
\text { users }\end{array}$ & $\begin{array}{l}\text { 1. Enhance the } \\
\text { development of } \\
\text { ICT Infrastructure }\end{array}$ & $\begin{array}{l}\text { 1.1 Increase coverage of telephones } \\
\text { particularly in rural and peri-urban } \\
\text { communities } \\
\text { 1.2 Improve the quality of telephone } \\
\text { service } \\
\text { 1.3 Establish national network of } \\
\text { Internet backbone/ broadband } \\
\text { 1.4 } \begin{array}{l}\text { Source FDI and national } \\
\text { investment to promote the } \\
\text { development and marketing of } \\
\text { hardware and suitable software }\end{array} \\
\text { 1.5 Facilitate the development of } \\
\text { community information centres } \\
\text { (CICs) nationwide }\end{array}$ & $\begin{array}{l}\text { MOC, NCA, MOES, } \\
\text { MOI, MPSD, Service Providers }\end{array}$ & $\begin{array}{l}\text { MDG 8, NEPAD, } \\
\text { APRM obj.4 under } \\
\text { Socio-economic } \\
\text { development }\end{array}$ \\
\hline
\end{tabular}




\begin{tabular}{|c|c|c|c|c|c|}
\hline KEY AREA OF FOCUS & ISSUES & POLICY & STRATEGIES & $\begin{array}{l}\text { IMPLEMENTING AND } \\
\text { COLLABORATIVE AGENCY }\end{array}$ & $\begin{array}{l}\text { GLOBAL / } \\
\text { REGIONAL } \\
\text { LINKAGES }\end{array}$ \\
\hline & $\begin{array}{l}\text { - Unsecured data } \\
\text { management system } \\
\text { - Low level of } \\
\text { deployment of ICT } \\
\text { culture }\end{array}$ & $\begin{array}{l}\text { 2. Promote } \\
\text { development of E- } \\
\text { strategies in key } \\
\text { sectors of the } \\
\text { economy }\end{array}$ & $\begin{array}{l}\text { 2.1 Implement National E-Governance } \\
\text { programme. } \\
\text { 2.2 Implement National Electronic } \\
\text { Security system. } \\
\text { 2.3 Promote and Support E-commerce } \\
\text { system }\end{array}$ & \multirow[t]{3}{*}{$\begin{array}{l}\text { MOC, MDAs, Office of the President, } \\
\text { State Enterprise } \\
\text { Commission }\end{array}$} & \multirow{3}{*}{ 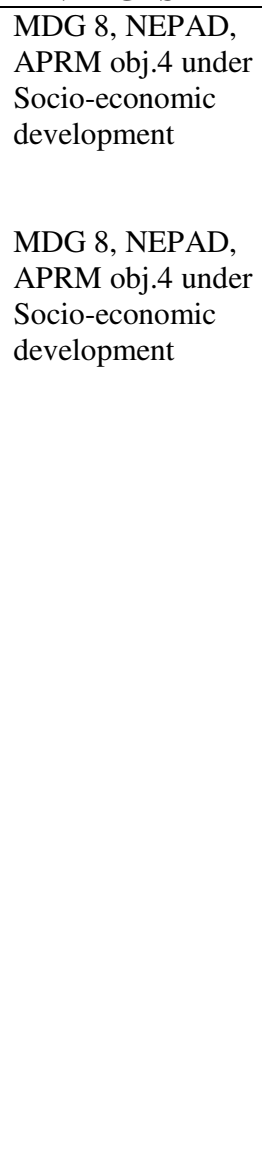 } \\
\hline & & & $\begin{array}{l}\text { 2.4 Implement National ICT strategy in } \\
\text { Health } \\
\text { 2.5 Implement ICT in Agriculture and } \\
\text { the Music industry } \\
\text { 2.6 Implement National strategy on } \\
\text { ICT and gender. } \\
\text { 2.7 Create ICT awareness through } \\
\text { documentaries and publications }\end{array}$ & & \\
\hline & $\begin{array}{l}\text { - Limited development of } \\
\text { IT programmes in } \\
\text { schools }\end{array}$ & $\begin{array}{l}\text { 3. Promote the use of } \\
\text { ICT in Education }\end{array}$ & $\begin{array}{l}\text { 3.1 Provide telephone coverage to all } \\
\text { public schools and communities in } \\
\text { Ghana } \\
\text { 3.2 Provide internet access to all } \\
\text { districts with a model Senior } \\
\text { Secondary School } \\
\text { 3.3 Ensure that ICT is made a core } \\
\text { subject of all post-basic educational } \\
\text { institutions including university } \\
\text { 3.4 Ensure that ICT is made a core } \\
\text { subject of teacher training } \\
\text { education } \\
\text { 3.5 Promote in-service ICT training } \\
\text { for teachers, targeting both women } \\
\text { and men } \\
\text { 3.6 } \begin{array}{l}\text { Design a tracking system for ICT } \\
\text { graduates }\end{array}\end{array}$ & & \\
\hline & $\begin{array}{l}\text { - Limited use of ICT as a } \\
\text { tool to enhance the } \\
\text { management and } \\
\text { efficiency of businesses }\end{array}$ & $\begin{array}{l}\text { 4. Promote the use of } \\
\text { ICT in productive } \\
\text { activities }\end{array}$ & $\begin{array}{l}\text { 4.1 Encourage small companies to } \\
\text { make use of services/assets made } \\
\text { available by national internet } \\
\text { backbone. }\end{array}$ & $\begin{array}{l}\text { MOC, MES, MOFEP, MOFA, MOFI, } \\
\text { MOI, MLGRD, SEC, District Assembly }\end{array}$ & \\
\hline
\end{tabular}




\begin{tabular}{|c|c|c|c|c|c|}
\hline KEY AREA OF FOCUS & ISSUES & POLICY & STRATEGIES & $\begin{array}{l}\text { IMPLEMENTING AND } \\
\text { COLLABORATIVE AGENCY }\end{array}$ & $\begin{array}{l}\text { GLOBAL / } \\
\text { REGIONAL } \\
\text { LINKAGES }\end{array}$ \\
\hline & $\begin{array}{l}\text { - Lack of ICT skilled } \\
\text { human resource }\end{array}$ & & $\begin{array}{l}\text { 4.2 Ensure the existence of better } \\
\text { educated workforce with well } \\
\text { developed skills that meet the hi- } \\
\text { tech employment opportunities of } \\
\text { the country. }\end{array}$ & & \multirow[t]{4}{*}{$\begin{array}{l}\text { MDG } 8, \text { NEPAD, } \\
\text { APRM obj.4 under } \\
\text { Socio-economic } \\
\text { development }\end{array}$} \\
\hline & & \multirow{2}{*}{$\begin{array}{l}\text { 5. Build the } \\
\text { necessary capacity } \\
\text { and strengthen the } \\
\text { legal and } \\
\text { institutional } \\
\text { framework to } \\
\text { support ICT }\end{array}$} & $\begin{array}{l}\text { 5.1 Review existing regulatory body in } \\
\text { order to improve functionality }\end{array}$ & $\begin{array}{l}\text { MOC, NCA, MOES, MOI, MPSD, } \\
\text { SEC, Service providers }\end{array}$ & \\
\hline & $\begin{array}{l}\text { - Lack of adequate } \\
\text { institutional and } \\
\text { regulatory framework to } \\
\text { support ICT } \\
\text { development }\end{array}$ & & $\begin{array}{l}\text { 5.2 Create an environment conducive } \\
\text { for ICT } \\
\text { 5.3 Facilitate the partnership between } \\
\text { Government and small and large } \\
\text { business in the private sector } \\
\text { owned by women and men in the } \\
\text { areas of technology development. } \\
\text { 5.4 Support and provide services and } \\
\text { technology to tenant companies } \\
\text { 5.5 Provide R\&D and innovation } \\
\text { facilities to the Private Sector. } \\
\text { 5.6 Lay the foundations for a national } \\
\text { ICT export base } \\
\text { 5.7 Establish a digitize content } \\
\text { development bureau }\end{array}$ & MOC, MES, MOFEP, MOI & \\
\hline & $\begin{array}{l}\text { Poor dissemination of } \\
\text { meteorological data and } \\
\text { forecast to support } \\
\text { economic development }\end{array}$ & $\begin{array}{l}\text { 6. Facilitate the } \\
\text { provision of quality } \\
\text { meteorological data } \\
\text { and forecast in } \\
\text { support of weather } \\
\text { sensitive sectors of } \\
\text { the economy }\end{array}$ & $\begin{array}{l}\text { 6.1 Restructure the existing } \\
\text { institutional framework for an } \\
\text { effective meteorological service } \\
\text { delivery and forecasting } \\
\text { 6.2 Enhance the institutional capacity of } \\
\text { the meteorological agency to meet } \\
\text { the minimum global requirement } \\
\text { for monitoring the climate and the } \\
\text { environment } \\
\text { 6.3 Enhance human resource } \\
\text { capacity through staff training } \\
\text { in modem equipment and } \\
\text { practices }\end{array}$ & $\begin{array}{l}\text { MOC (GMA), MOFA, WRC, FAO, } \\
\text { GCCA }\end{array}$ & \\
\hline
\end{tabular}




\begin{tabular}{|c|c|c|c|c|c|}
\hline KEY AREA OF FOCUS & ISSUES & POLICY & STRATEGIES & $\begin{array}{l}\text { IMPLEMENTING AND } \\
\text { COLLABORATIVE AGENCY }\end{array}$ & $\begin{array}{l}\text { GLOBAL / } \\
\text { REGIONAL } \\
\text { LINKAGES }\end{array}$ \\
\hline & & & $\begin{array}{l}\text { 6.4 Promote global collaboration for } \\
\text { an effective data collection and } \\
\text { management, and forecasting }\end{array}$ & & \\
\hline \multirow[t]{2}{*}{$\begin{array}{l}\text { (b) Developing the } \\
\text { Tourism Sector for } \\
\text { Revenue and } \\
\text { Employment } \\
\text { Generation }\end{array}$} & $\begin{array}{l}\text { - Low revenue generation } \\
\text { capacity from tourism in } \\
\text { the country. } \\
\text { - Over-dependence on } \\
\text { traditional sources of } \\
\text { revenue for the country. } \\
\text { - Lack of appreciation of } \\
\text { the contribution of } \\
\text { tourism to the national } \\
\text { account } \\
\text { - Low resource } \\
\text { mobilization for the } \\
\text { development of tourism } \\
\text { among communities. } \\
\text { - Limited capacity and } \\
\text { access to credit } \\
\text { especially women } \\
\text { entrepreneurs such as } \\
\text { caterers and local fast } \\
\text { food vendors. } \\
\text { - Poor tourism services } \\
\text { and low quality } \\
\text { standards in the industry } \\
\text { - Lack of professionalism } \\
\text { to enhance the } \\
\text { productivity of the } \\
\text { industry }\end{array}$ & $\begin{array}{l}\text { 1. Promote tourism as } \\
\text { a major source of } \\
\text { national revenue }\end{array}$ & $\begin{array}{l}\text { 1.2 Develop tourism satellite account to } \\
\text { determine tourism contribution to } \\
\text { GDP. } \\
\text { 1.3 Revise tourism investment policy to } \\
\text { promote SMEs in the communities. } \\
\text { 1.4 Design programmes to reduce the } \\
\text { credit constraint of operators in the } \\
\text { tourism sector with a particular } \\
\text { focus on women entrepreneurs. } \\
\text { 1.5 Enhance tourism services and } \\
\text { standards through inspection, } \\
\text { licensing and classification of } \\
\text { formal and informal tourism } \\
\text { establishments } \\
\text { 1.6 Enhance human resource capacity } \\
\text { of skilled and unskilled personnel } \\
\text { in the hospitality industry }\end{array}$ & $\begin{array}{l}\text { MOT/MCC, GTB, GIS, GSS, BOG, } \\
\text { MOFEP, SNV } \\
\text { MOT/MCC, GTB, GIPC, MOFEP, } \\
\text { GHATOF } \\
\text { MOT/MCC, GTB, GIPC, MOFEP, } \\
\text { GHATOF, FIRE SERVICE } \\
\text { MOT/MCC, GTB, GHATOF, } \\
\text { DISTRICT ASSEMBLIES, FIRE } \\
\text { SERVICE } \\
\text { MOT/MCC, HOTCATT, MOES, } \\
\text { GHATOF, MMYE }\end{array}$ & $\begin{array}{l}\text { ECOWAS, } \\
\text { NEPAD }\end{array}$ \\
\hline & $\begin{array}{l}\text { Inadequate modern } \\
\text { infrastructure in the } \\
\text { capital city and other } \\
\text { tourism sites to support } \\
\text { tourism } \\
\end{array}$ & $\begin{array}{l}\text { 2. Modernize the } \\
\text { capital city to } \\
\text { attract investment } \\
\text { and tourism }\end{array}$ & $\begin{array}{l}\text { 2.1 Develop modern infrastructure in } \\
\text { the capital city }\end{array}$ & MOT/MCC, AMA, T\&CP, & \\
\hline
\end{tabular}




\begin{tabular}{|c|c|c|c|c|c|}
\hline KEY AREA OF FOCUS & \multirow{2}{*}{$\begin{array}{l}\text { ISSUES } \\
\text { High incidence of } \\
\text { commercial sex, that } \\
\text { also involves children } \\
\end{array}$} & \multirow[t]{2}{*}{ POLICY } & \multirow[t]{2}{*}{ STRATEGIES } & \multirow[t]{2}{*}{$\begin{array}{l}\text { IMPLEMENTING AND } \\
\text { COLLABORATIVE AGENCY }\end{array}$} & \multirow[t]{2}{*}{$\begin{array}{l}\text { GLOBAL / } \\
\text { REGIONAL } \\
\text { LINKAGES } \\
\end{array}$} \\
\hline & & & & & \\
\hline & $\begin{array}{l}\text { - Inadequate promotion of } \\
\text { domestic tourism }\end{array}$ & $\begin{array}{l}\text { 3. Promote domestic } \\
\text { tourism to foster } \\
\text { national cohesion } \\
\text { as well as } \\
\text { redistribution of } \\
\text { income } \\
\end{array}$ & $\begin{array}{l}\text { 3.1 Vigorously promote domestic } \\
\text { tourism to encourage Ghanaians to } \\
\text { appreciate and preserve their } \\
\text { national heritage and create wealth } \\
\text { in the communities. }\end{array}$ & $\begin{array}{l}\text { MOT/MCC, GTB, MOES, GHATOF, } \\
\text { MDA'S, District Assembly }\end{array}$ & \\
\hline & $\begin{array}{l}\text {-Increasing adulteration of } \\
\text { our culture and } \\
\text { degradation of the } \\
\text { environment. } \\
\text { - Poor waste management }\end{array}$ & $\begin{array}{l}\text { 4. Promote sustainable } \\
\text { and responsible } \\
\text { tourism in such a } \\
\text { way to preserve } \\
\text { historical, cultural } \\
\text { and natural } \\
\text { heritage. }\end{array}$ & $\begin{array}{l}\text { 4.1 Develop sustainable ecotourism, } \\
\text { culture and historical sites. } \\
\text { 4.2 Enforce measures to reduce waste } \\
\text { arising from tourist activities }\end{array}$ & $\begin{array}{l}\text { MOT/MCC, MLF, NCC, DA’S, } \\
\text { GHATOF, NCRC, GTB. } \\
\text { MES, MOT/MCC, MWH, MDA’S, } \\
\text { GHATOF, GTB }\end{array}$ & \multirow[t]{4}{*}{ NEPAD, MDG 7} \\
\hline & & & $\begin{array}{l}\text { 4.3 Ensure the reduction of sex abuse } \\
\text { and spread of sexually transmitted } \\
\text { diseases and HIV/Aids associated } \\
\text { with tourism }\end{array}$ & $\begin{array}{l}\text { MOT/MCC, GTB, MOES, GHATOF, } \\
\text { MOH, GSMF, PPAG, GAC, MOWAC, } \\
\text { GHANA AIDS COMMISSION }\end{array}$ & \\
\hline & $\begin{array}{l}\text { - Lack of relevant capacity } \\
\text { at the institutional and } \\
\text { community level to } \\
\text { enhance service } \\
\text { delivery. }\end{array}$ & $\begin{array}{l}\text { Enhance capacity } \\
\text { and strengthen the } \\
\text { legal and } \\
\text { institutional } \\
\text { framework to } \\
\text { support tourism } \\
\text { industry } \\
\end{array}$ & $\begin{array}{l}\text { 5.1 Build capacities at institutional and } \\
\text { communities levels. }\end{array}$ & $\begin{array}{l}\text { MOT/MCC, MDA'S, District } \\
\text { Assemblies, GHATOF, TRADITONAL } \\
\text { AUTHORITIES, HOTCATT, GTB, } \\
\text { MOI, ISD }\end{array}$ & \\
\hline $\begin{array}{l}\text { (c) The Music Industry } \\
\text { for Growth and Job } \\
\text { Creation }\end{array}$ & & $\begin{array}{l}\text { Provide the right } \\
\text { legal and } \\
\text { regulatory } \\
\text { framework for } \\
\text { promoting the } \\
\text { music and film } \\
\end{array}$ & $\begin{array}{l}\text { 1.1 Redefine music and films as an } \\
\text { industry within the broad context of } \\
\text { tourism development, private, small } \\
\text { and medium enterprise } \\
\text { development, export and } \\
\text { investment promotion }\end{array}$ & $\begin{array}{l}\text { MOTMCC, NMC, IMD, MUSIGA, } \\
\text { Ministry Justice and Attorney General, } \\
\text { MPSD \& PSI, MOTI, GIPC, Copy Right, } \\
\text { PROMAG, Mark Pank Institute for } \\
\text { research, World Bank and other } \\
\text { Development partners, MOI, ISD. }\end{array}$ & \\
\hline
\end{tabular}




\begin{tabular}{|c|c|c|c|c|c|}
\hline KEY AREA OF FOCUS & ISSUES & POLICY & STRATEGIES & $\begin{array}{l}\text { IMPLEMENTING AND } \\
\text { COLLABORATIVE AGENCY }\end{array}$ & $\begin{array}{l}\text { GLOBAL / } \\
\text { REGIONAL } \\
\text { LINKAGES }\end{array}$ \\
\hline & & industry & $\begin{array}{l}\text { 1.2 Revise the Cultural Policy to } \\
\text { promote and protect Ghanaian } \\
\text { creative industry and cultural } \\
\text { diversity issues, especially when } \\
\text { international commitments are } \\
\text { being made in the areas of trade } \\
\text { policy, bilateral and multilateral } \\
\text { trade agreements world. } \\
\text { 1.3 Review industry-related laws } \\
\text { following the five column models } \\
\text { which are copyright law, copyright } \\
\text { contract, neighboring rights, } \\
\text { collecting societies and } \\
\text { enforcement, to conform to global } \\
\text { standards and enhance the vibrancy } \\
\text { of the Ghana music and films } \\
\text { industry } \\
\text { Create policies in support of } \\
\text { financing the music and films } \\
\text { industry production chain } \\
\text { 1.5 Establish Policies to promote local } \\
\text { content on all relevant electronic } \\
\text { networks such as cable networks }\end{array}$ & $\begin{array}{l}\text { MOTMCC, NMC, IMD, MUSIGA, } \\
\text { Ministry Justice and Attorney General, } \\
\text { MPSD \& PSI, MOTI, All Banks, Copy } \\
\text { Right, PROMAG, NBSSI, ASSI, Mark } \\
\text { Pank Institute for research, World Bank } \\
\text { and other Development partners, MOI, } \\
\text { ISD }\end{array}$ & \\
\hline & & $\begin{array}{l}\text { 2. Human and } \\
\text { institutional } \\
\text { resource capacity } \\
\text { building for the } \\
\text { Music and films } \\
\text { Industry }\end{array}$ & $\begin{array}{l}\text { 2.1 Ensure the training of specialists for } \\
\text { different professional needs of the } \\
\text { industry to ensure high quality } \\
\text { domestic products } \\
\text { 2.2 Provide industry related awareness } \\
\text { for the Judiciary and encourage the } \\
\text { training and education in } \\
\text { entertainment law } \\
\text { 2.3 Promote the establishment of public } \\
\text { and private professional centers for } \\
\text { identifying and training talented } \\
\text { young musicians and other } \\
\text { performing artists }\end{array}$ & $\begin{array}{l}\text { MOTMCC, PROMAG, GIMPA, IMD, } \\
\text { NMC, MUSIGA, EMPRETEC, } \\
\text { WORLD BANK, SME's, Ghana Law } \\
\text { School, University of Ghana, GEA } \\
\text { MOTMCC, MCT, PROMAG, GIMPA, } \\
\text { IMD, NMC, MUSIGA, EMPRETEC, } \\
\text { WORLD BANK, SME's, Ghana Law } \\
\text { School, University of Ghana }\end{array}$ & \\
\hline
\end{tabular}




\begin{tabular}{|c|c|c|c|c|c|}
\hline KEY AREA OF FOCUS & ISSUES & POLICY & STRATEGIES & $\begin{array}{l}\text { IMPLEMENTING AND } \\
\text { COLLABORATIVE AGENCY }\end{array}$ & $\begin{array}{l}\text { GLOBAL / } \\
\text { REGIONAL } \\
\text { LINKAGES }\end{array}$ \\
\hline & & & $\begin{array}{l}\text { 2.4 Expand opportunities for } \\
\text { stakeholders in the music and films } \\
\text { industry to acquire industry-related } \\
\text { knowledge and resources } \\
\text { 2.5 Link the industry with the academia } \\
\text { 2.6 Strengthen the administrative } \\
\text { structure of the music and films } \\
\text { industry making it more } \\
\text { accountable, transparent and } \\
\text { democratic } \\
\text { 2.7 Create a National Music Council } \\
\text { Board and Structure }\end{array}$ & $\begin{array}{l}\text { NMC, UNESCO, MOTMCC, GES, } \\
\text { MOES } \\
\text { MOTMCC, NMC, IMD, MUSIGA, } \\
\text { Ministry Justice and Attorney General, } \\
\text { MPSD \& PSI, MOTI, All Banks, Copy } \\
\text { Right, PROMAG, NBSSI, ASSI, Mark } \\
\text { Pank Institute for research, World Bank } \\
\text { and other Development partners }\end{array}$ & \\
\hline & & $\begin{array}{ll}\text { 3. } & \text { Support the } \\
\text { industry with ICT } \\
\text { and Multimedia } \\
\text { Technology }\end{array}$ & $\begin{array}{l}\text { 3.1 Create information centre for } \\
\text { members online and in print } \\
\text { 3.2 Create networks worldwide } \\
\text { 3.3 Create avenues to promote and } \\
\text { enhance local and indigenous } \\
\text { music and films }\end{array}$ & $\begin{array}{l}\text { MOTMCC, MCT, MUSIGA, NMC, } \\
\text { IMD, World Bank and other } \\
\text { Development partners }\end{array}$ & \\
\hline \multirow[t]{2}{*}{$\begin{array}{l}\text { V. EMPLOYMENT } \\
\text { GENERATION } \\
\text { AND } \\
\text { IMPROVEMENT } \\
\text { AND EXPANSION } \\
\text { OF SAFETY NETS }\end{array}$} & $\begin{array}{l}\text { - Inadequate institutional } \\
\text { capacity for } \\
\text { Employment Policy } \\
\text { Implementation } \\
\text { - Weak employment } \\
\text { monitoring system. }\end{array}$ & $\begin{array}{l}\text { Develop } \\
\text { instiutional } \\
\text { capacity of the } \\
\text { MMYE for } \\
\text { Employment } \\
\text { Policy } \\
\text { Management }\end{array}$ & $\begin{array}{l}\text { 1.1 Restructure and develop } \\
\text { Institutional Capacity of MMYE } \\
\text { and its departments and agencies } \\
\text { for effective and efficient } \\
\text { employment policy management } \\
\text { 1.2 Develop and implement systems } \\
\text { and processes for efficient policy } \\
\text { development, monitoring and } \\
\text { coordination }\end{array}$ & MMYE, Depts. \&Agencies & MDG 1 \\
\hline & $\begin{array}{l}\text { - Inadequate Sectoral } \\
\text { Capacity for formulating } \\
\text { and Implementing } \\
\text { Employment Policy that } \\
\text { is sensitive to the needs } \\
\end{array}$ & $\begin{array}{l}\text { 2. Develop and } \\
\text { implement a } \\
\text { national } \\
\text { employment policy }\end{array}$ & $\begin{array}{l}\text { 2.1 Develop and implement a } \\
\text { comprehensive national } \\
\text { employment policy that addresses } \\
\text { the needs of the youth, women and } \\
\text { people living with disability. }\end{array}$ & $\begin{array}{l}\text { MMYE, Depts. \&Agencies } \\
\text { Organized Labour, GEA, MDAs and } \\
\text { Other stakeholders }\end{array}$ & $\begin{array}{l}\text { MDG 1/3, APRM } \\
\text { Obj.1 under Socio- } \\
\text { economic } \\
\text { development }\end{array}$ \\
\hline
\end{tabular}




\begin{tabular}{|c|c|c|c|c|c|}
\hline KEY AREA OF FOCUS & ISSUES & POLICY & STRATEGIES & $\begin{array}{l}\text { IMPLEMENTING AND } \\
\text { COLLABORATIVE AGENCY }\end{array}$ & $\begin{array}{l}\text { GLOBAL / } \\
\text { REGIONAL } \\
\text { LINKAGES }\end{array}$ \\
\hline & $\begin{array}{l}\text { of women, youth and } \\
\text { people living with } \\
\text { disability. }\end{array}$ & & \begin{tabular}{|l} 
2.2 Promote the establishment of \\
country-wide network of Public and \\
Private Youth Employment Centres \\
2.3 Promote alternative livelihood \\
programmes. \\
2.4 Adopt a labour based technology \\
in infrastructure development and \\
other works, including Youth in \\
Agriculture programmes \\
2.5 Facilitate initiatives for local \\
economic development and \\
decentralized employment \\
generation \\
2.6 Promote employable skills beyond \\
traditional ones for women and \\
people living with disabilities \\
2.7 $\begin{array}{l}\text { Support microfinance } \\
\text { intermediation for the informal }\end{array}$ \\
economy \\
2.8 Develop implement and coordinate \\
employment audit system
\end{tabular} & $\begin{array}{l}\text { MMYE, Depts. \&Agencies } \\
\text { Organized Labour, GEA, MDAs and } \\
\text { Other stakeholders }\end{array}$ & \\
\hline & $\begin{array}{l}\text { - Inadequate capacity and } \\
\text { systems for social } \\
\text { dialogue and } \\
\text { protection for improved } \\
\text { labour and industrial } \\
\text { relations }\end{array}$ & $\begin{array}{l}\text { 3. Develop and } \\
\text { implement policy } \\
\text { and strategies to } \\
\text { strengthen tripartism } \\
\text { and social protection }\end{array}$ & $\begin{array}{l}\text { 3.1 } \begin{array}{l}\text { Strengthen the institutional } \\
\text { structures for providing social } \\
\text { dialogue and social protection }\end{array} \\
\text { 3.2 Establish a functioning tripartite } \\
\text { secretariat } \\
\text { 3.3 Build capacity of the tripartite } \\
\text { partners } \\
\text { 3.4 Ensure enforcement of the Labour } \\
\text { Laws which protect the security, } \\
\text { health and welfare of workers }\end{array}$ & $\begin{array}{l}\text { MMYE, GEA, Organised Labour, } \\
\text { MDAs, Other Stakeholders }\end{array}$ & $\begin{array}{l}\text { MDG } 1 \text {, APRM, } \\
\text { Obj .4 under } \\
\text { Corporate } \\
\text { Governance }\end{array}$ \\
\hline
\end{tabular}




\begin{tabular}{|c|c|c|c|c|c|}
\hline KEY AREA OF FOCUS & ISSUES & POLICY & STRATEGIES & $\begin{array}{l}\text { IMPLEMENTING AND } \\
\text { COLLABORATIVE AGENCY }\end{array}$ & $\begin{array}{l}\text { GLOBAL / } \\
\text { REGIONAL } \\
\text { LINKAGES }\end{array}$ \\
\hline & & & $\begin{array}{l}\text { 3.5 Strengthen the capacity of public } \\
\text { and private sector agencies, } \\
\text { including the Factories } \\
\text { Inspectorate Department of the } \\
\text { MMYE to facilitate workplace } \\
\text { occupational safety and health } \\
\text { standards }\end{array}$ & & \\
\hline & $\begin{array}{l}\text { Inadequate labour } \\
\text { market information } \\
\text { system for a coherent } \\
\text { and improve labour and } \\
\text { employment } \\
\text { management }\end{array}$ & $\begin{array}{l}\text { 4. Develop and } \\
\text { implement a fully } \\
\text { functioning } \\
\text { system that } \\
\text { provides labour } \\
\text { market } \\
\text { information and } \\
\text { statistics to } \\
\text { support relevant } \\
\text { decision making. }\end{array}$ & $\begin{array}{l}\text { 4.1 Design and implement a labour } \\
\text { market information system } \\
\text { 4.2 } \begin{array}{l}\text { Support organisation and } \\
\text { dissemination of labour market } \\
\text { information for informed decision } \\
\text { making }\end{array} \\
4.3 \begin{array}{l}\text { Strengthen research and gender } \\
\text { analysis capacity of the Ministry of } \\
\text { Manpower Development, Youth } \\
\text { and Employment }\end{array} \\
\text { 4.4 Promote collaboration among users } \\
\text { of labour market information. }\end{array}$ & $\begin{array}{l}\text { MMYE, GEA, Organised Labour, } \\
\text { MDAs, Other Stakeholders }\end{array}$ & \multirow[t]{2}{*}{$\begin{array}{l}\text { MDG 1, APRM } \\
\text { Obj.1 under Socio- } \\
\text { economic } \\
\text { development. }\end{array}$} \\
\hline & $\begin{array}{l}\text { - Improper pricing of } \\
\text { labour leading to low } \\
\text { labour productivity and } \\
\text { income } \\
\text { - Inadequate labour } \\
\text { productivity } \\
\text { management system }\end{array}$ & $\begin{array}{l}\text { 5. Adopt a national } \\
\text { policy for enhancing } \\
\text { productivity and } \\
\text { income in both } \\
\text { formal and informal } \\
\text { sectors }\end{array}$ & $\begin{array}{l}\text { 5.1 Develop and implement } \\
\text { productivity measurement and } \\
\text { enhancement programmes for the } \\
\text { formal and informal sectors of the } \\
\text { economy } \\
\text { 5.2 Support the development and } \\
\text { implementation of capacity } \\
\text { enhancement programmes that } \\
\text { take into consideration the } \\
\text { specific needs of men and women, } \\
\text { in both the formal and the } \\
\text { informal sectors of the economy } \\
\text { 5.3 Support establishment of } \\
\text { participatory and cooperative } \\
\text { mechanisms to enhance income } \\
\text { and job security in the informal } \\
\text { economy }\end{array}$ & $\begin{array}{l}\text { MMYE, GEA, Organised Labour, } \\
\text { MDAs, Other Stakeholders, SEC }\end{array}$ & \\
\hline
\end{tabular}




\begin{tabular}{|c|c|c|c|c|c|}
\hline KEY AREA OF FOCUS & ISSUES & POLICY & STRATEGIES & $\begin{array}{l}\text { IMPLEMENTING AND } \\
\text { COLLABORATIVE AGENCY }\end{array}$ & $\begin{array}{l}\text { GLOBAL / } \\
\text { REGIONAL } \\
\text { LINKAGES }\end{array}$ \\
\hline & 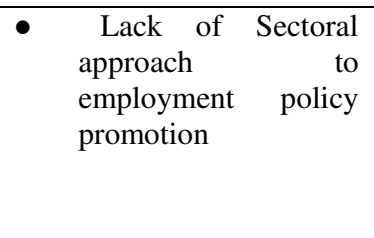 & $\begin{array}{l}\text { 6. Integrate } \\
\text { employment } \\
\text { strategies in } \\
\text { Sectoral policies }\end{array}$ & $\begin{array}{l}\text { 6.1 Develop employment enhancement } \\
\text { strategies for sectors } \\
\text { 6.2 Set employment targets for Sectoral } \\
\text { projects and programmes } \\
\text { 6.3 Establish employment monitoring } \\
\text { system for sectors }\end{array}$ & $\begin{array}{l}\text { MMYE, MOFA, MOTI, MOT/MCC, } \\
\text { MRT, MWH, MOE, MLFM, MOFI, } \\
\text { MPSD\&PSI, MES, MPHR, MLGRD, } \\
\text { and other sector ministries }\end{array}$ & \\
\hline \multirow[t]{2}{*}{$\begin{array}{l}\text { VI. EMPLOYMENT } \\
\text { Related } \\
\text { Vulnerability and } \\
\text { Exclusion }\end{array}$} & $\begin{array}{l}\text { Young adults } \\
\text { - Apprenticeships: Lack } \\
\text { of opportunities to gain } \\
\text { and retain skills, } \\
\text { through innovative } \\
\text { means as wells as } \\
\text { apprenticeships and } \\
\text { employment } \\
\text { - Workplace insecurity: } \\
\text { lack of protection } \\
\text { against accidents and } \\
\text { illness at work, } \\
\text { through safety and } \\
\text { health regulations, } \\
\text { limits on working time } \\
\text { Increasing } \\
\text { casualisation of labour } \\
\text { among private sector } \\
\text { enterprise } \\
\text { - Low prospects for } \\
\text { career advancement, } \\
\text { training or skills } \\
\text { enhancement }\end{array}$ & $\begin{array}{l}\text { 1. Adequate protection } \\
\text { on occupational } \\
\text { safety }\end{array}$ & $\begin{array}{l}\text { 1.1 Provide protected work for young } \\
\text { adult through the provision of after } \\
\text { school vocational training for } \\
\text { children aged 15-18years } \\
\text { 1.2 Develop and enforce policy on the } \\
\text { payment of stipend for } \\
\text { apprentices } \\
\text { 1.3 Institute a framework for reforming } \\
\text { and regulating apprenticeships in } \\
\text { both the formal and informal } \\
\text { sectors }\end{array}$ & $\begin{array}{l}\text { DSW, MOWAC, MMYE, The National } \\
\text { Labour Commission, Organised Labour, } \\
\text { GEA, MOFA, MOFI }\end{array}$ & \multirow[t]{2}{*}{$\begin{array}{l}\text { APRM, Obj.10 } \\
\text { under Political } \\
\text { Governance; obj.4 } \\
\text { under Corporate } \\
\text { Governance } \\
\\
\text { MDG1, APRM, } \\
\text { Obj.10 under } \\
\text { Political } \\
\text { Governance, Obj.1 } \\
\text { under Socio- } \\
\text { economic Devt. }\end{array}$} \\
\hline & $\begin{array}{l}\text { The Unemployed men and } \\
\text { women } \\
\text { - } 15-24 \text { years are the most } \\
\text { vulnerable }\end{array}$ & $\begin{array}{l}\text { 2. Facilitate skills } \\
\text { acquisition and job } \\
\text { creation to absorb } \\
\text { unemployed and } \\
\text { under employed } \\
\text { youth }\end{array}$ & $\begin{array}{l}\text { 2.1 Adopt measures to integrate formal } \\
\text { and informal sectors }\end{array}$ & $\begin{array}{l}\text { MMYE, Labour Dept., Public Services } \\
\text { Commission, Head of Civil Service } \\
\text { Employers Association, Organised } \\
\text { Labour }\end{array}$ & \\
\hline
\end{tabular}




\begin{tabular}{|c|c|c|c|c|c|}
\hline KEY AREA OF FOCUS & ISSUES & POLICY & STRATEGIES & $\begin{array}{l}\text { IMPLEMENTING AND } \\
\text { COLLABORATIVE AGENCY }\end{array}$ & $\begin{array}{l}\text { GLOBAL / } \\
\text { REGIONAL } \\
\text { LINKAGES }\end{array}$ \\
\hline & $\begin{array}{l}\text { Inadequate of targeting } \\
\text { for skills training and } \\
\text { other supports for } 15-24 \\
\text { old men and women }\end{array}$ & & $\begin{array}{l}\text { 2.2 Develop policies to address } \\
\text { seasonal unemployment and } \\
\text { migration for young women and men }\end{array}$ & & \\
\hline & $\begin{array}{l}\text { - Weak enforcement of the } \\
\text { New Labour Act }\end{array}$ & $\begin{array}{l}\text { 3. Foster the } \\
\text { enforcement of the } \\
\text { New Labour Act } \\
\text { Policy } \\
\text { recommendations }\end{array}$ & $\begin{array}{l}\text { 3.1 Build capacity of redeployed labour } \\
\text { through retraining, education on } \\
\text { cooperatives and introduction to new } \\
\text { technologies } \\
\text { 3.2 Enforce the new Labour Act }\end{array}$ & & \\
\hline & $\begin{array}{ll} & \text { Dwindling } \\
\text { employment } \\
\text { opportunities }\end{array}$ & $\begin{array}{l}\text { 4. Create opportunities } \\
\text { for unemployed } \\
\text { graduates to } \\
\text { acquire } \\
\text { entrepreneurial } \\
\text { skills }\end{array}$ & $\begin{array}{l}\text { Establish entrepreneurial skills } \\
\text { development programmes to aid } \\
\text { products of tertiary educational } \\
\text { institutions to access funds from } \\
\text { participating banks to set-up own } \\
\text { enterprises }\end{array}$ & $\begin{array}{l}\text { MMYE, in collaboration with the private } \\
\text { sector (i.e. EMPRETEC, NBSSI) }\end{array}$ & \\
\hline \multirow[t]{2}{*}{$\begin{array}{l}\text { VII. LIFE CYCLE } \\
\text { RELATED } \\
\text { VULNERABILITY } \\
\text { AND EXCLUSION }\end{array}$} & $\begin{array}{l}\text { - } \quad \text { Children in Difficult } \\
\text { Circumstances } \\
\text { - } \quad \text { Child Poverty } \\
\text { - Lack of parental } \\
\text { support } \\
\text { - High exposure to risks }\end{array}$ & $\begin{array}{l}\text { 1. Promote and protect } \\
\text { the welfare of } \\
\text { children in difficult } \\
\text { circumstances }\end{array}$ & $\begin{array}{l}\text { 1.1 Protect children from direct and } \\
\text { indirect physical and emotional harm } \\
\text { and promote their welfare } \\
\text { 1.2 Increase budget allocation to and } \\
\text { strengthen the capacity of the } \\
\text { MMYE, DSW and GNCC }\end{array}$ & $\begin{array}{l}\text { MMYE, MOWAC, GNCC, DSW } \\
\text { NGOs }\end{array}$ & \multirow{2}{*}{$\begin{array}{l} \\
\\
\text { APRM, Obj.10 } \\
\text { under Political } \\
\text { Governance; obj.1 } \\
\text { under Socio- } \\
\text { economic } \\
\text { development }\end{array}$} \\
\hline & $\begin{array}{l}\text { Child Labour } \\
\text { - The need to Strengthen } \\
\text { measures to eliminate the } \\
\text { worst forms of child } \\
\text { labour (WFCL) in the } \\
\text { shortest possible time } \\
\text { - Strengthen institutional } \\
\text { and socio-economic } \\
\text { bases for tackling all } \\
\text { child labour }\end{array}$ & $\begin{array}{l}\text { 2. Protect children } \\
\text { from direct and } \\
\text { indirect physical } \\
\text { and emotional harm }\end{array}$ & $\begin{array}{l}\text { 2.1 Ensure that the state and non-state } \\
\text { agencies provide adequate support for } \\
\text { the well being of children } \\
\text { 2.2 Provide shelter for street children } \\
\text { during skills training and support } \\
\text { their integration process with start up } \\
\text { capitals programmes } \\
\text { 2.3 Develop programmes for out of } \\
\text { school children to equip them with } \\
\text { employable skills } \\
\text { 2.4 Equip government, MDAs and } \\
\text { workers' and employers' } \\
\text { organization with the mandate and } \\
\text { the capacity to undertake effective } \\
\text { action against WFCL }\end{array}$ & $\begin{array}{l}\text { MMYE, MOWAC, GNCC, DSW } \\
\text { NGOs }\end{array}$ & \\
\hline
\end{tabular}




\begin{tabular}{|c|c|c|c|c|c|}
\hline KEY AREA OF FOCUS & ISSUES & POLICY & STRATEGIES & $\begin{array}{l}\text { IMPLEMENTING AND } \\
\text { COLLABORATIVE AGENCY }\end{array}$ & $\begin{array}{l}\text { GLOBAL / } \\
\text { REGIONAL } \\
\text { LINKAGES }\end{array}$ \\
\hline & & & $\begin{array}{l}\text { 2.5 Strengthen the legal framework and } \\
\text { enforcement of laws that prohibit } \\
\text { child labour } \\
\text { 2.6 Mobilize society to support the fight } \\
\text { against child labour } \\
\text { 2.7 Strengthen and expand } \\
\text { apprenticeship and skills training } \\
\text { systems contribute to the } \\
\text { elimination of WFCL } \\
\text { 2.8 Improve the knowledge base for } \\
\text { planning, designing, implementing } \\
\text { and evaluating child labour } \\
\text { interventions } \\
\text { 2.9 Develop standards, protocols for } \\
\text { withdrawal, prevention and } \\
\text { rehabilitation of children in WFCL } \\
\text { 2.10 Funding sources such as the Social } \\
\text { Investment Fund, Rural Banks and } \\
\text { other potential partners are } \\
\text { involved in targeting credit and } \\
\text { entrepreneurship development } \\
\text { schemes for families of children at } \\
\text { risk of WFCL } \\
\text { 2.11 Conduct needs assessment for } \\
\text { social protection among poor } \\
\text { single mothers and female heads }\end{array}$ & $\begin{array}{l}\text { MMYE, MOWAC, GNCC, DSW } \\
\text { NGOs }\end{array}$ & \\
\hline & $\begin{array}{l}\text { Single mothers and Female } \\
\text { heads of households } \\
\text { - The African Charter on } \\
\text { Human Rights and } \\
\text { Optional Protocol on } \\
\text { Women's Rights have } \\
\text { not been ratified } \\
\text { - Women in Difficult } \\
\text { circumstances }\end{array}$ & $\begin{array}{l}3 \text { Provide livelihood } \\
\text { support to poor } \\
\text { single parents }\end{array}$ & $\begin{array}{l}\text { 3. } 1 \text { Make special provisions for poor } \\
\text { single mothers and female heads in } \\
\text { social protection policies e.g. tax } \\
\text { breaks and exemptions, } \\
\text { 3.2 Introduce special support } \\
\text { programme for the poor single } \\
\text { parents such as agricultural input } \\
\text { support, skills training and access to } \\
\text { other productive assets to boost their } \\
\text { livelihoods }\end{array}$ & $\begin{array}{l}\text { DSW, MOWAC, WAJU, FIDA, MOJ, } \\
\text { MOFEP, IRS }\end{array}$ & $\begin{array}{l}\text { MDG1, APRM, } \\
\text { Obj.10 under } \\
\text { Political } \\
\text { Governance; obj.1 } \\
\text { under Socio- } \\
\text { economic } \\
\text { development. }\end{array}$ \\
\hline
\end{tabular}




\begin{tabular}{|c|c|c|c|c|c|}
\hline KEY AREA OF FOCUS & ISSUES & POLICY & STRATEGIES & $\begin{array}{l}\text { IMPLEMENTING AND } \\
\text { COLLABORATIVE AGENCY }\end{array}$ & $\begin{array}{l}\text { GLOBAL / } \\
\text { REGIONAL } \\
\text { LINKAGES }\end{array}$ \\
\hline & & $\begin{array}{l}4 \text { Support poor single } \\
\text { mothers and female } \\
\text { household heads to } \\
\text { gain access to skills } \\
\text { and productive } \\
\text { assets to boost their } \\
\text { livelihoods }\end{array}$ & $\begin{array}{l}\text { 4.1 Conduct needs assessment for social } \\
\text { protection among poor single mothers } \\
\text { and female heads }\end{array}$ & $\begin{array}{l}\text { DSW, MOWAC, WAJU, FIDA, MOJ, } \\
\text { MOFEP, IRS }\end{array}$ & \\
\hline & & $\begin{array}{l}\text { 5. Improve well-being } \\
\text { of women through } \\
\text { better access to } \\
\text { information, } \\
\text { decision making and } \\
\text { material resources } \\
\text { for their livelihoods } \\
\text { activities } \\
\end{array}$ & $\begin{array}{l}\text { Increase percentage of budgetary } \\
\text { allocation to women empowerment }\end{array}$ & $\begin{array}{l}\text { MOWAC, DSW, Banks, NBSSI } \\
\text { MMDAs, NGOs }\end{array}$ & \\
\hline & \multirow{2}{*}{$\begin{array}{l}\text { Economically marginalized } \\
\text { women } \\
\text { - Low access to credit } \\
\text { - Low purchasing power } \\
\text { - Low budgetary } \\
\text { allocation } \\
\text { - Non existent policies } \\
\text { - No social protection } \\
\text { - Informal sector is not } \\
\text { part of national } \\
\text { accounting }\end{array}$} & $\begin{array}{l}\text { 6. Strengthen the Dept. } \\
\text { of Social Welfare } \\
\text { and other relevant } \\
\text { institutions to } \\
\text { deliver on their } \\
\text { mandate }\end{array}$ & $\begin{array}{l}\text { 6.1 Commit resources to DSW, WAJU } \\
\text { and Local Authorities }\end{array}$ & & \multirow[t]{2}{*}{$\begin{array}{l}\text { MDG3, APRM, } \\
\text { Obj.10 under } \\
\text { Political } \\
\text { Governance }\end{array}$} \\
\hline & & $\begin{array}{l}\text { 7. Develop policies for } \\
\text { equitable } \\
\text { distribution of } \\
\text { financial and non- } \\
\text { financial resources }\end{array}$ & $\begin{array}{l}\text { 7.1 Include informal sector into } \\
\text { national accounting } \\
\text { 7.2 Encourage banks and alternative } \\
\text { micro finance institutions to develop } \\
\text { flexible packages to meet women's } \\
\text { needs and constraints }\end{array}$ & & \\
\hline & $\begin{array}{l}\text { The Elderly } \\
\text { - Women } \\
\text { - Lack of definition on the } \\
\text { elderly } \\
\text { - The Aged vulnerable } \\
\text { due low pension } \\
\text { stipends }\end{array}$ & $\begin{array}{l}\text { 8. Enhance the safety } \\
\text { nets and social } \\
\text { insurance of the } \\
\text { elderly }\end{array}$ & $\begin{array}{l}\text { 8.1 Streamline and facilitate } \\
\text { disbursement of pension stipends } \\
\text { to the aged }\end{array}$ & $\begin{array}{l}\text { MMYE, DSW, Help Age Ghana, } \\
\text { SSNIT, CBOs, NGOs, MMDAs, } \\
\text { Insurance Companies }\end{array}$ & $\begin{array}{l}\text { MDG3, APRM, } \\
\text { Obj.10 under } \\
\text { Political } \\
\text { Governance }\end{array}$ \\
\hline
\end{tabular}




\begin{tabular}{|c|c|c|c|c|c|}
\hline KEY AREA OF FOCUS & ISSUES & POLICY & STRATEGIES & $\begin{array}{l}\text { IMPLEMENTING AND } \\
\text { COLLABORATIVE AGENCY }\end{array}$ & $\begin{array}{l}\text { GLOBAL / } \\
\text { REGIONAL } \\
\text { LINKAGES } \\
\end{array}$ \\
\hline \multirow[t]{3}{*}{$\begin{array}{l}\text { VIII. ENVIRONMENT } \\
\text { RELATED } \\
\text { FACTORS IN } \\
\text { VULNERABILI } \\
\text { TY AND } \\
\text { EXCLUSION }\end{array}$} & $\begin{array}{l}\text { - Floods: Loss of lives and } \\
\text { property }\end{array}$ & $\begin{array}{l}\text { 1. Deal with the effect } \\
\text { of climate change } \\
\text { especially drought } \\
\text { and desertification }\end{array}$ & $\begin{array}{l}\text { 1.1 Promote the development of small } \\
\text { scale irrigation dams and dug-outs } \\
\text { as well as rain water harvesting } \\
\text { 1.2 Review, disseminate and enforce } \\
\text { reforestation policy } \\
\text { 1.3 Develop policy on alternative } \\
\text { livelihood opportunities } \\
\text { 1.4 Promote the development and use of } \\
\text { alternative sources of energy } \\
\text { (biogas) } \\
\text { 1.5 Adopt policy framework on climate } \\
\text { change and mainstream of the } \\
\text { national action programme to } \\
\text { combat drought and desertification } \\
\text { 1.6 Intensify public education on floods } \\
\text { in flood prone areas } \\
\text { 1.7 Develop strategies to protect life } \\
\text { property and identify flood prone } \\
\text { areas } \\
\text { 1.8 Provision of drainage facilities in } \\
\text { flood prone areas } \\
\text { 1.9 Enforce existing laws on building } \\
\text { and sanitation }\end{array}$ & $\begin{array}{l}\text { MOFA, MOFI, IDA, ICOUR, MLFM, } \\
\text { MES, EPA, GMA, CSIR, MMYE, MOE, } \\
\text { ENERGY COMMISSION, KITE, } \\
\text { ENERGY FOUNDATION }\end{array}$ & $\begin{array}{l}\text { MDG 7; APRM, } \\
\text { obj.10 under } \\
\text { Political } \\
\text { Governance }\end{array}$ \\
\hline & $\begin{array}{l}\text { Bush Fires } \\
\text { - Destruction of farms, } \\
\text { forest cover and } \\
\text { property }\end{array}$ & $\begin{array}{l}\text { 2. Reduction in bush } \\
\text { fires }\end{array}$ & $\begin{array}{l}2.1 \text { Intensify public education on the } \\
\text { effects and laws on bush fires }\end{array}$ & $\begin{array}{l}\text { Ghana Fire Service, NADMO } \\
\text { Fire Volunteers, MMDAs }\end{array}$ & \multirow[t]{2}{*}{$\begin{array}{l}\text { MDG 7, APRM, } \\
\text { Obj.10 under } \\
\text { Political } \\
\text { Governance }\end{array}$} \\
\hline & $\begin{array}{l}\text { - Lack of awareness and } \\
\text { enforcement of } \\
\text { environmental } \\
\text { regulations and policies }\end{array}$ & $\begin{array}{l}\text { 3. Facilitate multi } \\
\text { stakeholder } \\
\text { commitment to } \\
\text { natural resource } \\
\text { management }\end{array}$ & $\begin{array}{l}\text { 3. } 1 \text { Develop policy on research, } \\
\text { surveillance, training, early warning } \\
\text { system and traditional knowledge } \\
\text { 3.2 Build capacity and create } \\
\text { awareness on the prevention and } \\
\text { management of all forms of } \\
\text { disasters }\end{array}$ & $\begin{array}{l}\text { NADMO, Town and Country Planning, } \\
\text { EPA, Traditional authorities } \\
\text { Metro and District Assemblies } \\
\text { Fire Service, MOFA, MLFM }\end{array}$ & \\
\hline
\end{tabular}




\begin{tabular}{|c|c|c|c|c|c|}
\hline KEY AREA OF FOCUS & ISSUES & POLICY & STRATEGIES & $\begin{array}{l}\text { IMPLEMENTING AND } \\
\text { COLLABORATIVE AGENCY }\end{array}$ & $\begin{array}{l}\text { GLOBAL / } \\
\text { REGIONAL } \\
\text { LINKAGES }\end{array}$ \\
\hline & $\begin{array}{l}\text { - Duplication of functions } \\
\text { by land sector agencies } \\
\text { Man-made Disasters } \\
\text { - Weak policy } \\
\text { environment and } \\
\text { enforcement of } \\
\text { regulations } \\
\text { - Weak housing } \\
\text { structures, inadequate } \\
\text { infrastructure and low } \\
\text { threshold for coping } \\
\text { with disaster } \\
\text { - Ineffective monitoring } \\
\text { and management of } \\
\text { illegal mining/small } \\
\text { scale mining } \\
\text { - Persistent land disputes }\end{array}$ & $\begin{array}{l}\text { Improve } \\
\text { environmental and } \\
\text { natural resources } \\
\text { management for } \\
\text { health, safety and } \\
\text { increased } \\
\text { sustainable } \\
\text { production }\end{array}$ & $\begin{array}{l}\text { 4.1 Adopt or enforce collaboration } \\
\text { between EPA and MMDAs to } \\
\text { better manage natural resources, } \\
\text { environmental health and illegal } \\
\text { mining }\end{array}$ & $\begin{array}{l}\text { MLFM, MES, MLGRD, MOTI, NBSSI, } \\
\text { ASSI, Wild Life Society and relevant } \\
\text { agencies, Town \& Country Planning } \\
\text { EPA, NADMO, Metropolitan, Municipal } \\
\text { and District Assembly (MMDA) } \\
\text { Chamber of Mines, Architectural and } \\
\text { Engineering Services Limited }\end{array}$ & MDG 7 \\
\hline & & $\begin{array}{l}\text { 5. Develop policy and } \\
\text { awareness in early } \\
\text { warning systems } \\
\text { with particular } \\
\text { effect on women } \\
\text { and children }\end{array}$ & $\begin{array}{l}\text { 5.1 Review and engender laws and } \\
\text { policies relating to land floods bush } \\
\text { fires air, water, vehicular, and soil } \\
\text { pollution } \\
\text { 5.2 Develop incentives to encourage } \\
\text { recycling to foster alternative } \\
\text { income sources especially for } \\
\text { women }\end{array}$ & $\begin{array}{l}\text { Ghana Institution of Engineers, Institute } \\
\text { of Architects, Institute of Planners, } \\
\text { Institute of Surveyors }\end{array}$ & MDG 3, MDG 7 \\
\hline
\end{tabular}


APPENDIX I1B: HUMAN DEVELOPMENT AND BASIC SERVICES

\begin{tabular}{|c|c|c|c|c|c|}
\hline $\begin{array}{l}\text { KEY AREA OF } \\
\text { FOCUS }\end{array}$ & ISSUE & POLICIES & STRATEGIES & $\begin{array}{c}\text { IMPLEMENTING AND } \\
\text { COLLABORATING } \\
\text { AGENCY }\end{array}$ & $\begin{array}{l}\text { GLOBAL / } \\
\text { REGIONAL } \\
\text { LINKAGES }\end{array}$ \\
\hline I. EDUCATION & $\begin{array}{l}\text { Slow progress in } \\
\text { achieving universal } \\
\text { basic education and } \\
\text { adult literacy }\end{array}$ & $\begin{array}{l}\text { 1. Increase access to and } \\
\text { participation in education } \\
\text { and training at all levels }\end{array}$ & $\begin{array}{l}\text { 1.1 Expand preschool access in all basic schools } \\
\text { to ensure smooth transition from home to } \\
\text { school. } \\
\text { 1.2 Increase School enrolment } \\
\text { 1.3 Accelerate the rehabilitation /development of } \\
\text { basic school infrastructure (with water and } \\
\text { toilet facilities) } \\
\text { 1.4 Remove barriers to primary school entry and } \\
\text { retention } \\
\text { 1.5 Shift burden of payments for education } \\
\text { services away from poorer students at lower } \\
\text { levels (especially the girl-child) } \\
\text { 1.6 Ensure that buildings and other physical } \\
\text { infrastructure in schools and training } \\
\text { institutions are made accessible to the } \\
\text { physical disabled } \\
\text { 1.7 Adopt targeted programmes to improve } \\
\text { access in underserved areas } \\
\text { 1.8 Expand Non Formal Education in } \\
\text { partnership with community groups, NGOs } \\
\text { and private providers } \\
\text { 1.9 Facilitate the implementation of capitation } \\
\text { grant in all public primary schools } \\
\text { 1.10 Enact laws that support implementation of } \\
\text { FCUBE } \\
\text { 1.11 Ensure relevance and coverage of } \\
\text { vocational and technical training } \\
\text { 1.12 Diversify vocational and technical training } \\
\text { to link with industry }\end{array}$ & $\begin{array}{l}\text { MOES, Ghana Education } \\
\text { Service, MOFEP, MMDAs, } \\
\text { CHASS, The Private } \\
\text { Sector, GNAT, } \\
\text { NABPTEX, NGOs, DSW, } \\
\text { TCPD }\end{array}$ & $\begin{array}{l}\text { MDG 2, APRM } \\
\text { obj.1/2/3 under } \\
\text { Socio-economic } \\
\text { development }\end{array}$ \\
\hline
\end{tabular}




\begin{tabular}{|c|c|c|c|c|c|}
\hline $\begin{array}{l}\text { KEY AREA OF } \\
\text { FOCUS }\end{array}$ & ISSUE & POLICIES & STRATEGIES & $\begin{array}{c}\text { IMPLEMENTING AND } \\
\text { COLLABORATING } \\
\text { AGENCY }\end{array}$ & $\begin{array}{l}\text { GLOBAL / } \\
\text { REGIONAL } \\
\text { LINKAGES }\end{array}$ \\
\hline & & & 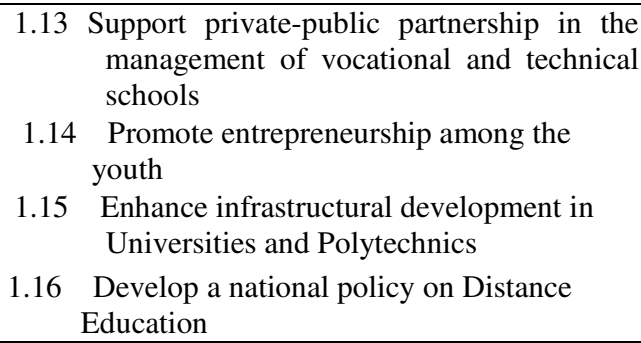 & \multirow[t]{4}{*}{$\begin{array}{l}\text { MOES, Ghana Education } \\
\text { Service, MOFEP, MMDAs, } \\
\text { CHASS, The Private } \\
\text { Sector, GNAT, } \\
\text { NABPTEX, NGOs, } \\
\text { Tertiary Education Council, } \\
\text { WAEC, CSIR, CBOs, } \\
\text { CSOs }\end{array}$} & \multirow[t]{4}{*}{$\begin{array}{l}\text { MDG 2, APRM } \\
\text { Obj.1/2/3 under } \\
\text { Socio-economic } \\
\text { Development }\end{array}$} \\
\hline & $\begin{array}{l}\text { Persistent gender } \\
\text { disparities in school } \\
\text { enrolment and } \\
\text { Geographical disparity } \\
\text { in access to quality } \\
\text { secondary education } \\
\end{array}$ & $\begin{array}{l}\text { 2. Bridge gender gap in } \\
\text { access to education }\end{array}$ & $\begin{array}{l}\text { 2.1 Provide incentive schemes to increase girls } \\
\text { enrolment, retention and completion } \\
\text { particularly in deprived areas } \\
\text { 2.2 Sensitise parents and communities about the } \\
\text { importance of girl's education }\end{array}$ & & \\
\hline & $\begin{array}{l}\text { Concern about poor } \\
\text { quality of education }\end{array}$ & $\begin{array}{l}\text { 3. Improve quality of } \\
\text { teaching and learning }\end{array}$ & $\begin{array}{l}\text { 3.1 Introduce programme of national education } \\
\text { quality assessment } \\
\text { 3.2 Expand teacher retention schemes } \\
\text { 3.3 Ensure teacher development, deployment and } \\
\text { supervision } \\
\text { 3.4 Provide incentives to teachers in deprived } \\
\text { areas } \\
\text { 3.5 Improve the teaching of Science, technology } \\
\text { and mathematics in all basic schools } \\
\text { 3.6 Develop and promote the use of ICT in all } \\
\text { schools and institutions of higher learning. }\end{array}$ & & \\
\hline & $\begin{array}{l}\text { Inefficient delivery of } \\
\text { education services }\end{array}$ & $\begin{array}{l}\text { 4. Improve quality and } \\
\text { efficiency in delivery of } \\
\text { education services }\end{array}$ & $\begin{array}{l}\text { 4.1 Strengthen and improve educational planning } \\
\text { and management } \\
\text { 4.2 Stress and support private sector participation } \\
\text { in education } \\
\text { 4.3 Strengthen institutional arrangement for the } \\
\text { role of CBO, CSO in advocacy, monitoring } \\
\text { and evaluation } \\
\text { 4.4 Strengthen monitoring and evaluation } \\
\text { framework and reporting channels as a key } \\
\text { priority }\end{array}$ & & \\
\hline
\end{tabular}




\begin{tabular}{|c|c|c|c|c|c|}
\hline $\begin{array}{l}\text { KEY AREA OF } \\
\text { FOCUS }\end{array}$ & ISSUE & POLICIES & STRATEGIES & $\begin{array}{l}\text { IMPLEMENTING AND } \\
\text { COLLABORATING } \\
\text { AGENCY }\end{array}$ & $\begin{array}{l}\text { GLOBAL / } \\
\text { REGIONAL } \\
\text { LINKAGES }\end{array}$ \\
\hline & $\begin{array}{l}\text { - Inadequate access to } \\
\text { science and technical } \\
\text { education }\end{array}$ & $\begin{array}{l}\text { 5. Promote science and } \\
\text { technical education at all } \\
\text { levels }\end{array}$ & $\begin{array}{l}\text { 5.1 Provide incentive schemes to attract more } \\
\text { teachers into the teaching of science and } \\
\text { technical education. } \\
\text { 5.2 Support science and research institutions. } \\
\text { 5.3 Provide incentives to attract science students } \\
\text { 5.4 Increase funding for research and technology } \\
\text { development } \\
\text { 5.5 Support private sector initiatives in } \\
\text { science education }\end{array}$ & \multirow[t]{2}{*}{$\begin{array}{l}\text { MOES, Ghana Education } \\
\text { Service, MOFEP, MMDAs, } \\
\text { CHASS, The Private } \\
\text { Sector, GNAT, } \\
\text { NABPTEX, NGOs, } \\
\text { National AIDs, MES, } \\
\text { MOC, MOH, PPAG, } \\
\text { NCCE, GNFS, Road Safety } \\
\text { Commission, EPA, } \\
\text { MLGRD, MOWAC }\end{array}$} & $\begin{array}{l}\text { MDG 2, APRM } \\
\text { Obj.1/2/3 under } \\
\text { Socio-economic } \\
\text { development }\end{array}$ \\
\hline & $\begin{array}{l}\text { - Inadequate attitudinal } \\
\text { change relating to } \\
\text { population, gender, } \\
\text { health, HIV/AIDS/STI, } \\
\text { fire safety, civic }\end{array}$ & $\begin{array}{l}\text { 6. Mainstream issues of } \\
\text { population, Family life } \\
\text { education, gender, health, } \\
\text { HIV/AIDS/STI, fire } \\
\text { safety, road safety, Civic } \\
\text { responsibility and } \\
\text { environment in the school } \\
\text { curriculum }\end{array}$ & $\begin{array}{l}\text { 6.1 Promote the study of and integrate in the } \\
\text { curricula of schools and institutions of } \\
\text { higher learning attitudinal change regarding } \\
\text { population, family life education, good } \\
\text { health, gender, fire safety, road safety, civic } \\
\text { responsibility and environment concerns } \\
6.2 \text { Identify and promote programmes that will } \\
\text { assist in the prevention and management of } \\
\text { HIV/AIDS/STI } \\
6.3 \text { Promote vigorous health education } \\
\text { campaign on the adoption of healthy } \\
\text { environmental practices and lifestyle }\end{array}$ & & $\begin{array}{l}\text { MDG 6, APRM } \\
\text { Obj.5 under } \\
\text { Socio-economic } \\
\text { development }\end{array}$ \\
\hline & $\begin{array}{l}\text { PWDs } \\
\text { - Weak capacity and low } \\
\text { priority given to the } \\
\text { agencies responsible } \\
\text { for PWDs } \\
\text { - Limited number of } \\
\text { rehabilitation } \\
\text { professionals and } \\
\text { financial resources }\end{array}$ & $\begin{array}{l}\text { 7. Create an enabling } \\
\text { environment to ensure } \\
\text { the active involvement of } \\
\text { PWDs in mainstream } \\
\text { society }\end{array}$ & $\begin{array}{l}\text { 7.1 Strengthen the capacity of institutions } \\
\text { responsible for PWDs e.g. specialist } \\
\text { teachers, Resource Assessment Centres, \& } \\
\text { Rehabilitation Centres } \\
\text { 7.2 Train more rehabilitation professionals } \\
\text { 7.3 Design action plan to implement the } \\
\text { disability bill }\end{array}$ & $\begin{array}{l}\text { DSW, MMYE, NGOs } \\
\text { Ghana Federation of the } \\
\text { Disabled, AESL, Town and } \\
\text { Country Planning, GNFS, } \\
\text { MOES, GES }\end{array}$ & $\begin{array}{l}\text { APRM, Obj.10 } \\
\text { under Political } \\
\text { Governance }\end{array}$ \\
\hline & $\begin{array}{l}\text { Conflict management } \\
\text { - Ghana surrounded by } \\
\text { countries with conflict. } \\
\text { Pockets of conflict } \\
\text { internally. } \\
\end{array}$ & $\begin{array}{l}\text { 8. Promote peace and } \\
\text { stability through civic } \\
\text { education }\end{array}$ & $\begin{array}{l}\text { 8.1 Introduce civic education and conflict } \\
\text { prevention in basic schools (HRD) }\end{array}$ & $\begin{array}{l}\text { MOES, GES, NCCE, } \\
\text { Ministry of Interior } \\
\text { CSOs, NGOs, DSW } \\
\text { MOWAC } \\
\text { NADMO, MOT/MCC } \\
\end{array}$ & \\
\hline
\end{tabular}




\begin{tabular}{|c|c|c|c|c|c|}
\hline \multirow[t]{2}{*}{$\begin{array}{l}\text { KEY AREA OF } \\
\text { FOCUS }\end{array}$} & ISSUE & POLICIES & STRATEGIES & $\begin{array}{c}\text { IMPLEMENTING AND } \\
\text { COLLABORATING } \\
\text { AGENCY }\end{array}$ & $\begin{array}{l}\text { GLOBAL / } \\
\text { REGIONAL } \\
\text { LINKAGES }\end{array}$ \\
\hline & - Human trafficking & 9. Curb Human trafficking & $\begin{array}{l}\text { 9.1 Encourage the setting up of anti-trafficking } \\
\text { clubs in schools in sending areas (hrd0 } \\
\text { 9.2 Undertake public education about the dangers } \\
\text { of human trafficking and avenues of safe } \\
\text { migration with special focus on sending and } \\
\text { receiving districts }\end{array}$ & $\begin{array}{l}\text { MOES, NCCE, MOI, CSO, } \\
\text { NGOs, CDOs, DSW, } \\
\text { MOWAC }\end{array}$ & \\
\hline \multirow[t]{3}{*}{$\begin{array}{ll}\text { II. } & \text { SKILLS AND } \\
\text { MANPOWER } \\
\text { DEVELOPME } \\
\text { NT }\end{array}$} & $\begin{array}{l}\text { - Lack of coherent } \\
\text { National Human } \\
\text { Resource Development } \\
\text { Policy }\end{array}$ & $\begin{array}{l}\text { 1. Provide a Framework for } \\
\text { National Human Resource } \\
\text { Development }\end{array}$ & $\begin{array}{l}\text { 1.1 Develop a comprehensive manpower } \\
\text { development policy framework that takes } \\
\text { into account the specific needs of men and } \\
\text { women, Persons living with Disability, } \\
\text { HIV/AIDS, the public and private sector at } \\
\text { all levels. }\end{array}$ & \multirow{3}{*}{$\begin{array}{l}\text { MOES, Ghana Education } \\
\text { Service, MOFEP, MMDAs, } \\
\text { CHASS, The Private } \\
\text { Sector, GNAT, } \\
\text { NABPTEX, NGOs, } \\
\text { MMYE, NVTI, PEF, } \\
\text { NAFTI, MDAs, NALVET }\end{array}$} & MDG 1 \\
\hline & & $\begin{array}{l}\text { 2. Develop and retain } \\
\text { Human Resource capacity } \\
\text { at National, Regional and } \\
\text { District levels }\end{array}$ & $\begin{array}{l}\text { 2.1 } \begin{array}{l}\text { Develop a Manpower Development Plan at } \\
\text { all levels. }\end{array} \\
\text { 2.2 } \begin{array}{l}\text { Provide adequate incentive to retain skilled } \\
\text { labour }\end{array} \\
2.3 \begin{array}{l}\text { Provide adequate resources for human } \\
\text { resource capacity development }\end{array} \\
2.4 \text { Undertake Human Resource capacity survey } \\
2.5 \text { Improve labour market and engendered } \\
\text { manpower statistics including the care } \\
\text { economy }\end{array}$ & & MDG 1 \\
\hline & $\begin{array}{l}\text { - Inadequate skills and } \\
\text { entrepreneurial } \\
\text { development }\end{array}$ & $\begin{array}{l}\text { 3. Provide skills and } \\
\text { entrepreneurial training }\end{array}$ & $\begin{array}{l}\text { 3.1 Train unemployed youth in competency } \\
\text { based demand driven skills, including the } \\
\text { STEP programme } \\
\text { 3.2 Promote and establish production units in all } \\
\text { Vocational Training Centres } \\
\text { 3.3 Set standards for vocational training and } \\
\text { entrepreneurial development } \\
\text { 3.4 Intensify Co-operative education and its } \\
\text { practice in collaboration with stakeholders } \\
\text { 3.5 Expand Training infrastructure for skills } \\
\text { upgrading } \\
\text { 3.6 Promote the training of people with } \\
\text { disability } \\
\text { 3.7 Implement National Apprenticeship } \\
\text { Programme }\end{array}$ & & \\
\hline
\end{tabular}




\begin{tabular}{|c|c|c|c|c|c|}
\hline $\begin{array}{l}\text { KEY AREA OF } \\
\text { FOCUS }\end{array}$ & ISSUE & POLICIES & STRATEGIES & $\begin{array}{c}\text { IMPLEMENTING AND } \\
\text { COLLABORATING } \\
\text { AGENCY }\end{array}$ & $\begin{array}{l}\text { GLOBAL / } \\
\text { REGIONAL } \\
\text { LINKAGES }\end{array}$ \\
\hline & & $\begin{array}{l}\text { 4. Promote dialogue } \\
\text { between industry and } \\
\text { skills /professional } \\
\text { training institutions to } \\
\text { produce skilled labour } \\
\text { required for industry }\end{array}$ & $\begin{array}{l}\text { 4.1 Establish collaboration between human } \\
\text { resource capacity development institutions } \\
\text { and industry }\end{array}$ & \multirow{2}{*}{$\begin{array}{l}\text { MOES, Ghana Education } \\
\text { Service, MOFEP, MMDAs, } \\
\text { CHASS, The Private } \\
\text { Sector, GNAT, } \\
\text { NABPTEX, NGOs, } \\
\text { MMYE, NVTI, PEF, } \\
\text { NAFTI }\end{array}$} & \\
\hline & & $\begin{array}{l}\text { 5. Strengthen and support } \\
\text { hr training }\end{array}$ & $\begin{array}{ll}5.1 \text { Assist HR institutions to develop new } \\
\text { syllabi/curriculum to meet requirement of } \\
\text { industry } \\
5.2 \text { Conduct an HR needs assessment }\end{array}$ & & \\
\hline & $\begin{array}{l}\text { Street Children } \\
\text { - Lack of funds } \\
\text { - Poor accessibility to } \\
\text { parents } \\
\text { - Lack of start up capital } \\
\text { for beneficiaries of } \\
\text { these programmes } \\
\text { - Inadequate child } \\
\text { maintenance and } \\
\text { parental care }\end{array}$ & $\begin{array}{l}\text { 6. Reduce the incidence of } \\
\text { streetism }\end{array}$ & $\begin{array}{l}\text { 6.1 Provide shelter for street children during } \\
\text { skills training and support their integration } \\
\text { process with start up capitals programmes } \\
\text { 6.2 Develop programmes for out of school } \\
\text { children to equip them with employable skills } \\
\text { and mainstream children into formal } \\
\text { education system } \\
\text { 6.3 Design and implement programmes that keep } \\
\text { street children of the street } \\
\text { 6.4 Ensure full implementation of FCUBE }\end{array}$ & $\begin{array}{l}\text { MMYE, } \quad \text { GES, } \\
\text { DSW, } \\
\text { Parliament }\end{array}$ & $\begin{array}{l}\text { APRM, Obj.9/10 } \\
\text { under Political } \\
\text { Governance }\end{array}$ \\
\hline \multirow[t]{2}{*}{$\begin{array}{l}\text { III. SPORTS } \\
\text { DEVELOPMENT }\end{array}$} & & $\begin{array}{l}\text { 1. Build coalition and } \\
\text { partnership in sports } \\
\text { development }\end{array}$ & $\begin{array}{l}\text { 1.1 Strengthen the capacities of the National } \\
\text { Sports Council, National Olympic } \\
\text { Committee, National Sports Associations, } \\
\text { National Sports institutions and colleges } \\
\text { and sports oriented NGOs } \\
\text { 1.2 Enhance the involvement of corporate bodies } \\
\text { and individuals in sports promotion and } \\
\text { development }\end{array}$ & \multirow[t]{2}{*}{$\begin{array}{l}\text { MOES, Ghana Education } \\
\text { Service, MOFEP, MMDAs, } \\
\text { CHASS, The Private } \\
\text { Sector, NGOs, MMYE, } \\
\text { NSC, GFA, GAAA }\end{array}$} & \\
\hline & & $\begin{array}{l}\text { 2. Promote national } \\
\text { integration and unity }\end{array}$ & $\begin{array}{l}\text { 2.1 Provide adequate and appropriate sports and } \\
\text { recreational facilities at local, district, } \\
\text { regional and national levels } \\
\text { 2.2 Ensure availability and affordability of sports } \\
\text { equipment }\end{array}$ & & \\
\hline
\end{tabular}




\begin{tabular}{|c|c|c|c|c|c|}
\hline $\begin{array}{l}\text { KEY AREA OF } \\
\text { FOCUS }\end{array}$ & ISSUE & POLICIES & STRATEGIES & $\begin{array}{c}\text { IMPLEMENTING AND } \\
\text { COLLABORATING } \\
\text { AGENCY } \\
\end{array}$ & $\begin{array}{l}\text { GLOBAL / } \\
\text { REGIONAL } \\
\text { LINKAGES }\end{array}$ \\
\hline & & & $\begin{array}{l}\text { 2.3 Promote the production of local sports } \\
\text { equipment } \\
\text { 2.4 Build the capacity of community sports, } \\
\text { amateur, professional and fitness club }\end{array}$ & \multirow{2}{*}{$\begin{array}{l}\text { MOES, Ghana Education } \\
\text { Service, MOFEP, MMDAs, } \\
\text { CHASS, The Private } \\
\text { Sector, NGOs, MMYE, } \\
\text { NSC, GFA, GAAA }\end{array}$} & \\
\hline & & $\begin{array}{l}\text { 3. Promote international } \\
\text { friendship, solidarity and } \\
\text { cooperation }\end{array}$ & $\begin{array}{l}\text { 3.1 Establish linkages and partnership with } \\
\text { countries and international sports agencies }\end{array}$ & & \\
\hline \multirow[t]{3}{*}{ IV. HEALTH } & $\begin{array}{l}\text { - Pressure on health care } \\
\text { services and other } \\
\text { scarce resources }\end{array}$ & $\begin{array}{l}\text { 1. Bridge equity gaps in } \\
\text { access to health care and } \\
\text { nutrition services }\end{array}$ & 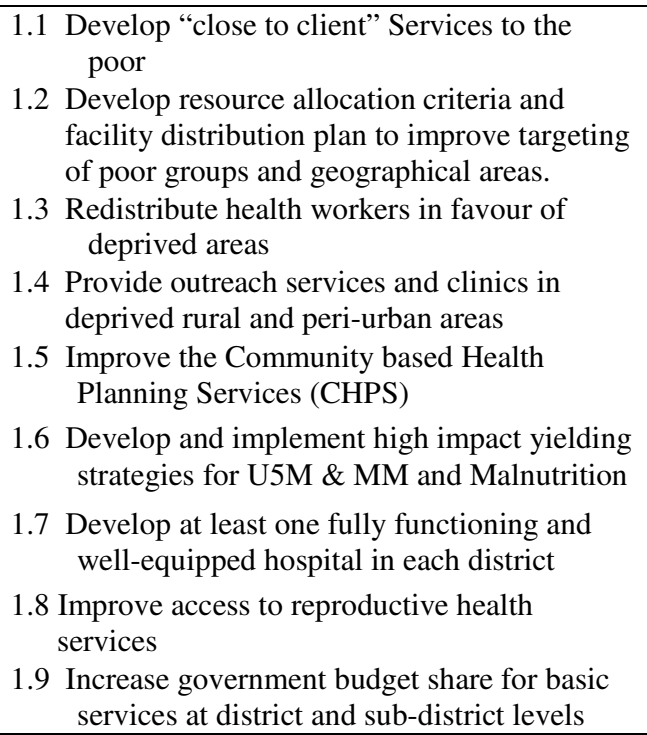 & \multirow[t]{3}{*}{$\begin{array}{l}\text { MOH, GHS, NHIS, } \\
\text { MMDAs, MLGRD, Nurses } \\
\text { and Midwife Council, } \\
\text { GMA, PPAG, MOE, GES }\end{array}$} & $\begin{array}{l}\text { MDG } 4 / 5 \text {, APRM } \\
\text { obj. } 1 / 2 / 3 \text { under } \\
\text { Socio-economic } \\
\text { development }\end{array}$ \\
\hline & $\begin{array}{l}\text { - Low level of overall } \\
\text { health expenditure and } \\
\text { inadequate social } \\
\text { protection }\end{array}$ & $\begin{array}{l}\text { 2. Ensure } \\
\text { sustainable } \\
\text { financing } \\
\text { arrangements that } \\
\text { protect the poor }\end{array}$ & $\begin{array}{l}\text { 2.1 Accelerate the Implementation of the health } \\
\text { insurance scheme } \\
\text { 2.2 Fix low acceptable rate of payment for } \\
\text { deprived districts }\end{array}$ & & \multirow[t]{2}{*}{$\begin{array}{l}\text { MDG 2, APRM } \\
\text { obj.1/2/3 under } \\
\text { Socio-economic } \\
\text { development }\end{array}$} \\
\hline & $\begin{array}{l}\text { Inefficient and over } \\
\text { centralised health care } \\
\text { system and services }\end{array}$ & $\begin{array}{l}\text { 3. Strengthen efficiency in } \\
\text { service delivery }\end{array}$ & $\begin{array}{l}\text { 3.1 Expand pre service health training } \\
\text { institutions facilities to increase intake of } \\
\text { trainees }\end{array}$ & & \\
\hline
\end{tabular}




\begin{tabular}{|c|c|c|c|c|c|}
\hline $\begin{array}{l}\text { KEY AREA OF } \\
\text { FOCUS }\end{array}$ & ISSUE & POLICIES & STRATEGIES & $\begin{array}{c}\text { IMPLEMENTING AND } \\
\text { COLLABORATING } \\
\text { AGENCY }\end{array}$ & $\begin{array}{l}\text { GLOBAL / } \\
\text { REGIONAL } \\
\text { LINKAGES }\end{array}$ \\
\hline & & & $\begin{array}{l}\text { 3.2 Provide incentive schemes to support the } \\
\text { retention and redistribution of trained health } \\
\text { personnel } \\
\text { 3.3 Decentralise HR management to regional } \\
\text { level } \\
\text { 3.4 Collaborate with informal service providers } \\
\text { 3.5 Expand community-based health service } \\
\text { delivery } \\
\text { 3.6 Improve the quality of traditional health } \\
\text { service delivery system } \\
\text { 3.7 Improve Data Collection in Epidemic } \\
\text { Prevention and Care } \\
\text { 3.8 Clarify roles of MOH-GHS and MMDAs in } \\
\text { health service delivery (HSD) } \\
\text { 3.9 Strengthen M\&E System } \\
\text { 3.10 Enhance linkage between public, private } \\
\text { and NGO collaboration with the Ghana } \\
\text { Aids Commission, The National Population } \\
\text { Council and related MMDAs in service } \\
\text { delivery }\end{array}$ & $\begin{array}{l}\text { MOH, GHS, NHIS, } \\
\text { MMDAs, MLGRD, Nurses } \\
\text { and Midwife Council, } \\
\text { GMA, PPAG, NGOs }\end{array}$ & \\
\hline $\begin{array}{l}\text { V. HEALTH } \\
\text { RELATED } \\
\text { VULNERABILIT } \\
\text { Y AND } \\
\text { EXCLUSION }\end{array}$ & $\begin{array}{l}\text { Health and occupational } \\
\text { safety: } \\
\text { - Inadequate enforcement } \\
\text { of occupational health } \\
\text { regulations } \\
\text { - Poor knowledge of } \\
\text { labour law }\end{array}$ & $\begin{array}{l}\text { 1. Promote a healthy work } \\
\text { environment that protects } \\
\text { workers from physical } \\
\text { and emotional risks }\end{array}$ & $\begin{array}{l}\text { 1.1 Promote Education on ILO Convention } 161 \\
\text { 1.2 Subsidize personal protective equipment } \\
\text { 1.3 Public education on occupational safety for } \\
\text { all especially PWDs, women and children on } \\
\text { the consequences of occupational hazards } \\
\text { and their rights (e.g. smoke inhalation, open } \\
\text { fires } \\
\text { 1.4 Promote and produce equipment which pose } \\
\text { less hazardous e.g. with low noise level } \\
\text { 1.5 Resource Factories Inspectorate Division of } \\
\text { MMYE to promote health and safety } \\
\text { especially in the informal sector } \\
\text { 1.6 Integrate occupational safety \& health in } \\
\text { school curriculum for basic and vocational } \\
\text { education }\end{array}$ & $\begin{array}{l}\text { Factories Inspectorate } \\
\text { Division, ITTU, MMYE, } \\
\text { MOH, NCCE, Min. of } \\
\text { Information, MOWAC, } \\
\text { GHS, MOE, GES, Tertiary } \\
\text { Education Council }\end{array}$ & $\begin{array}{l}\text { APRM, Obj.10 } \\
\text { under Political } \\
\text { Governance }\end{array}$ \\
\hline
\end{tabular}




\begin{tabular}{|c|c|c|c|c|c|}
\hline $\begin{array}{l}\text { KEY AREA OF } \\
\text { FOCUS }\end{array}$ & ISSUE & POLICIES & STRATEGIES & $\begin{array}{c}\text { IMPLEMENTING AND } \\
\text { COLLABORATING } \\
\text { AGENCY }\end{array}$ & $\begin{array}{l}\text { GLOBAL / } \\
\text { REGIONAL } \\
\text { LINKAGES }\end{array}$ \\
\hline & $\begin{array}{l}\text { - Outbreak of diseases } \\
\text { and pest infestations }\end{array}$ & & $\begin{array}{l}\text { 1.7 Provide immunization programmes for } \\
\text { livestock } \\
\text { 1.8 Train and equip extension officers }\end{array}$ & MOFA, MOH, GHS & \\
\hline & $\begin{array}{l}\text { Nutrition: } \\
\text { - Increasing malnutrition } \\
\text { rates among children } \\
\text { particularly in rural } \\
\text { areas and northern } \\
\text { Ghana } \\
\text { - Underweight among } \\
\text { Women in their Fertility } \\
\text { Ages (WIFA }\end{array}$ & $\begin{array}{l}\text { 2. Reduce malnutrition } \\
\text { related disorders and } \\
\text { deaths among young } \\
\text { children and Women in } \\
\text { their Fertility Ages } \\
\text { (WIFA) }\end{array}$ & $\begin{array}{l}\text { 2.1Target areas at the greatest risks of } \\
\text { malnutrition and replicate best practices and } \\
\text { expand coverage }\end{array}$ & \multirow[t]{5}{*}{$\begin{array}{l}\text { MOH, GES, MOES, } \\
\text { MMDAs, GHS, NGOs } \\
\text { MOFA, WIAD }\end{array}$} & \multirow[t]{5}{*}{$\begin{array}{l}\text { APRM, Obj.9/10 } \\
\text { under Political } \\
\text { Governance }\end{array}$} \\
\hline & $\begin{array}{l}\text { - U-5: } 35.8 \% \\
\text { malnourished, } 30 \% \\
\text { stunted \& } 22 \% \\
\text { wasted }\end{array}$ & $\begin{array}{l}\text { 3. Promote the consumption } \\
\text { of affordable balance } \\
\text { meals including the } \\
\text { consumption of } \\
\text { micronutrients among } \\
\text { children and Women in } \\
\text { their Fertility } \\
\text { Ages (WIFA) }\end{array}$ & $\begin{array}{l}\text { 3.1 Ensure effective management of the } \\
\text { implementation of the school feeding } \\
\text { programme } \\
\text { 3.2 Develop programmes to promote } \\
\text { consumption of adequate and affordable } \\
\text { meals including consumption of } \\
\text { micronutrients among children and Women in } \\
\text { their Fertility } \\
\text { Ages (WIFA) }\end{array}$ & & \\
\hline & $\begin{array}{l}\text { - Limited geographical } \\
\text { coverage of nutrition } \\
\text { programmes }\end{array}$ & $\begin{array}{l}\text { 4. Increase coverage of } \\
\text { nutritional programmes }\end{array}$ & $\begin{array}{l}\text { 4.1 Document findings on state of malnutrition } \\
\text { around the country with special reference to } \\
\text { possible solution to the problem }\end{array}$ & & \\
\hline & $\begin{array}{l}\text { Limited facilities and } \\
\text { services }\end{array}$ & $\begin{array}{l}\text { 5. Increase resource } \\
\text { allocation for nutrition } \\
\text { programmes particularly } \\
\text { among young children } \\
\text { and Women in their } \\
\text { Fertility Ages (WIFA) }\end{array}$ & $\begin{array}{l}\text { 5.1 Ensure food security such as food } \\
\text { supplementation } \\
\text { 5.2 Advocate for support for nutrition programme }\end{array}$ & & \\
\hline & $\begin{array}{l}\text { - Lack of national } \\
\text { nutrition and food } \\
\text { security policy }\end{array}$ & $\begin{array}{l}\text { 6. Develop a national } \\
\text { nutrition and food } \\
\text { security policy }\end{array}$ & $\begin{array}{l}\text { 6.1 Set up an intersectoral task force to develop a } \\
\text { national nutrition and food security policy }\end{array}$ & & \\
\hline
\end{tabular}




\begin{tabular}{|c|c|c|c|c|c|}
\hline $\begin{array}{l}\text { KEY AREA OF } \\
\text { FOCUS }\end{array}$ & ISSUE & POLICIES & STRATEGIES & $\begin{array}{l}\text { IMPLEMENTING AND } \\
\text { COLLABORATING } \\
\text { AGENCY }\end{array}$ & $\begin{array}{l}\text { GLOBAL / } \\
\text { REGIONAL } \\
\text { LINKAGES }\end{array}$ \\
\hline & $\begin{array}{l}\text { - Lack of support for } \\
\text { nutritional activities }\end{array}$ & & $\begin{array}{l}\text { 6.2 Ensure integration of nutrition programmes } \\
\text { into existing national and routine } \\
\text { programmes of GHS }\end{array}$ & & \multirow[t]{2}{*}{$\begin{array}{l}\text { APRM, Obj.10 } \\
\text { under Political } \\
\text { Governance }\end{array}$} \\
\hline & $\begin{array}{l}\text { The Elderly } \\
\text { - Lack of universal } \\
\text { implementation of } \\
\text { Health exemptions } \\
\text { (fees a/charges) and } \\
\text { inappropriateness of } \\
\text { health care service } \\
\text { (Geriatric care) }\end{array}$ & $\begin{array}{l}\text { 7. Ensure that healthcare is } \\
\text { made more affordable } \\
\text { and accessible to older } \\
\text { persons, as well as } \\
\text { making geriatrics a } \\
\text { specialized area of health } \\
\text { care system }\end{array}$ & $\begin{array}{l}\text { 7.1 Intensify public education on exemptions } \\
\text { especially fore the aged } \\
\text { 7.2 Review curriculum of health training } \\
\text { institutions to include Geriatrics } \\
\text { 7.3 Include geriatric care in health care } \\
\text { systems } \\
\text { 7.4 Implement health (cost) exemption for } \\
\text { relevant/appropriate healthcare services }\end{array}$ & $\begin{array}{l}\text { DSW, Help Age Ghana, } \\
\text { NGOs, CBOs, MMYE } \\
\text { MOH, GHS }\end{array}$ & \\
\hline \multirow[t]{4}{*}{$\begin{array}{l}\text { VI. MALARIA } \\
\text { CONTROL }\end{array}$} & & $\begin{array}{l}\text { 1. Improve malaria case } \\
\text { management }\end{array}$ & $\begin{array}{l}\text { 1.1 Ensure early case recognition } \\
\text { 1.2 Ensure appropriate response and referral } \\
\text { 1.3 Improve access to services }\end{array}$ & \multirow{4}{*}{$\begin{array}{l}\text { MOH, GES, MOES, } \\
\text { Malaria Control Programme } \\
\text { MMDAs, GHS, NGOs, } \\
\text { MLGRD, NCCE, Min. of } \\
\text { Information }\end{array}$} & \multirow[t]{4}{*}{$\begin{array}{l}\text { MDG 6, MDG } 8 \\
\text { (Target 17) }\end{array}$} \\
\hline & & $\begin{array}{l}\text { 2. Enhance multiple } \\
\text { prevention }\end{array}$ & $\begin{array}{l}\text { 2.1 Promote use of insecticide treated bed nets } \\
\text { 2.2 Encourage drainage, mosquito proofing and } \\
\text { general sanitation } \\
\text { 2.3 Promote limited application of indoor and } \\
\text { outdoor residual spraying } \\
\text { 2.4 Promote chemoprophylaxis for pregnant } \\
\text { women }\end{array}$ & & \\
\hline & & $\begin{array}{l}\text { 3. Improve collaboration } \\
\text { and Partnership }\end{array}$ & $\begin{array}{l}\text { 3.1 Improve collaborate between departments } \\
\text { and programmes in health sector } \\
\text { 3.2 Promote partners between government } \\
\text { sector, private sector, informal sector, } \\
\text { communities and Traditional Healers }\end{array}$ & & \\
\hline & & $\begin{array}{l}\text { 4. Enhance Focused } \\
\text { Research }\end{array}$ & $\begin{array}{l}\text { 4.1 Increase availability of funds for research } \\
\text { 4.2 Focus research agenda } \\
\text { 4.3 Improve dissemination and utilisation of } \\
\text { results } \\
\text { 4.4 Develop capacity for research }\end{array}$ & & \\
\hline
\end{tabular}




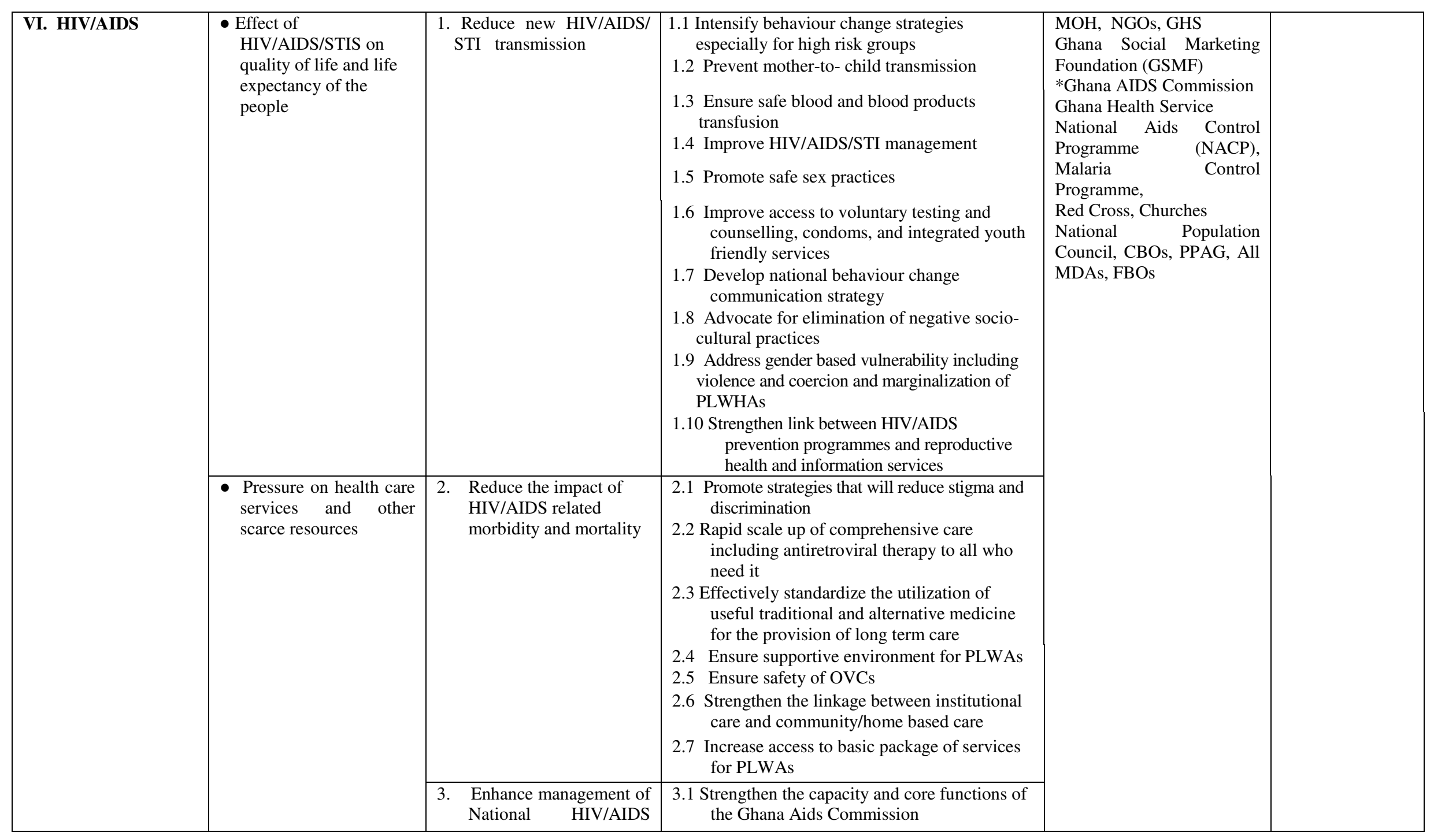




\begin{tabular}{|c|c|c|c|c|c|}
\hline & & response & $\begin{array}{l}\text { 3.2 Enhance the existing favourable socio- } \\
\text { political and policy environment } \\
\text { 3.3 Promote a multi-sectoral and multi- } \\
\text { disciplinary approach in the formulation and } \\
\text { implementation of HIV/AIDS/STIs policies } \\
\text { and programmes at national, regional and } \\
\text { district levels } \\
\text { 3.4 Develop and implement clear strategies for } \\
\text { research. } \\
\text { 3.5 Monitoring and evaluation } \\
\text { 3.6 Mobilize resources to meet the increasing } \\
\text { demand of new and diversified programmes }\end{array}$ & 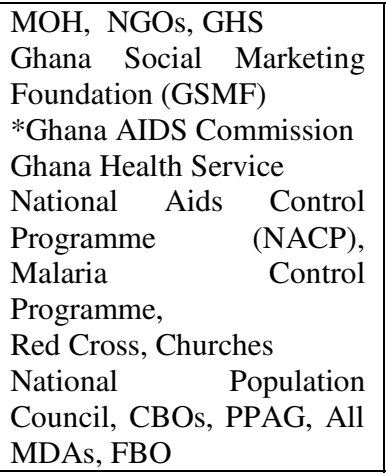 & \\
\hline & $\begin{array}{l}\text { HIV/AIDS } \\
\text { - People living with } \\
\text { AIDS: - Prevention, } \\
\text { Treatment and support, } \\
\text { Stigmatization } \\
\text { - Weak policy } \\
\text { framework }\end{array}$ & $\begin{array}{l}\text { 4. Combat the vulnerability } \\
\text { exclusion of families with } \\
\text { PLWHAs }\end{array}$ & $\begin{array}{l}\text { 4.1 Provide expanded and coordinated } \\
\text { programmes for care and support for people } \\
\text { with HIV/AIDS } \\
\text { 4.2 Promote campaign leaders to widen the } \\
\text { network of HIV/AIDS educators around the } \\
\text { country } \\
\text { 4.3 Target high risks areas and groups for health } \\
\text { and HIV/AIDS awareness education } \\
\text { 4.4 Increase percentage of budget allocation to } \\
\text { HIV/AIDS support } \\
\text { 4.5 Provide support for care givers of PLWHAs } \\
\text { 4.6 Provide families with adequate information } \\
\text { and other support to care for and promote the } \\
\text { development and well being of OVCs, } \\
\text { PLWHA }\end{array}$ & $\begin{array}{l}\text { MOH, NGOs, GHS } \\
\text { Ghana Social Marketing } \\
\text { Foundation (GSMF) } \\
\text { *Ghana AIDS Commission } \\
\text { Ghana Health Service } \\
\text { National Aids Control } \\
\text { Programme (NACP) } \\
\text { Red Cross, Churches } \\
\text { National Population } \\
\text { Council, CBOs, FBOs }\end{array}$ & \multirow[t]{2}{*}{$\begin{array}{l}\text { APRM, Obj.9/10 } \\
\text { under Political } \\
\text { Governance }\end{array}$} \\
\hline & $\begin{array}{l}\text { - Orphans and } \\
\text { Vulnerable Children } \\
\text { - Child Care Homes and } \\
\text { Child Maintenance } \\
\text { - Ignorance of Children's } \\
\text { Act } \\
\text { - Poor data management }\end{array}$ & $\begin{array}{l}\text { 5. Ensure the safety and } \\
\text { well-being of orphans and } \\
\text { vulnerable children,. }\end{array}$ & $\begin{array}{l}\text { 5.1 Institute measures that protect AIDS orphans } \\
\text { from stigmatization and discrimination } \\
\text { 5.2 Provide adequate resource care homes in } \\
\text { support of orphaned children } \\
\text { 5.3 Provide adequate counselling services and } \\
\text { safety nets for children affected and infected } \\
\text { with HIV/AIDS } \\
\text { 5.3 Train more professional counsellors and } \\
\text { provide incentives for them to go to rural } \\
\text { areas } \\
\text { 5.4 Ensure the implementation of the legal } \\
\text { framework that protects the rights of OVCs }\end{array}$ & $\begin{array}{l}\text { GAC, DSW, NGOs, } \\
\text { MMDAs, CBOs e.g. Queen } \\
\text { Mothers Association, FBOs }\end{array}$ & \\
\hline
\end{tabular}




\begin{tabular}{|c|c|c|c|c|c|}
\hline & & & $\begin{array}{l}\text { 5.5 Ensure that the state and non-state agencies } \\
\text { provide adequate support for the well being } \\
\text { of children }\end{array}$ & & \\
\hline \multirow[t]{5}{*}{$\begin{array}{l}\text { VII. POPULATION } \\
\text { MANAGEMENT }\end{array}$} & $\begin{array}{l}\text { - Inadequate population } \\
\text { data for planning }\end{array}$ & $\begin{array}{l}\text { 1. Promote access to and } \\
\text { utilization of family } \\
\text { planning services }\end{array}$ & $\begin{array}{l}\text { 1.1 Decentralize counselling services } \\
\text { 1.2 Strengthen the family planning component of } \\
\text { maternal health delivery. } \\
\text { 1.3 Promote the sale of contraceptives through } \\
\text { community agents including Maternity } \\
\text { Homes and Field Agents }\end{array}$ & \multirow{5}{*}{$\begin{array}{l}\text { NDPC, NPC, NDPC, } \\
\text { MLGRD, MMDAs, NYC, } \\
\text { PPAG, MOH/GHS, } \\
\text { GRMA, MDAs, Population } \\
\text { Association of Ghana, GSS, } \\
\text { BDR, NCCE, Min. of } \\
\text { Information, }\end{array}$} & \multirow{5}{*}{ MDG $1 / 3 / 5$} \\
\hline & & $\begin{array}{l}\text { 2. Educate the youth on } \\
\text { sexual relationship, } \\
\text { fertility regulation, } \\
\text { adolescent health } \\
\text { marriage and child } \\
\text { bearing }\end{array}$ & $\begin{array}{l}\text { 2.1 Promote family planning/RH education into } \\
\text { formal and informal and out of school } \\
\text { training programmes to prepare the youth } \\
\text { for responsible parenthood. }\end{array}$ & & \\
\hline & & $\begin{array}{l}\text { 3. Promote sexual health, } \\
\text { delay marriage and child } \\
\text { bearing. }\end{array}$ & $\begin{array}{l}\text { 3.1 Ensure availability of and accessibility to FP } \\
\text { services to all who seek such services } \\
\text { including the youth. } \\
\text { 3.2 Educate and motivate the population at } \\
\text { community levels on health, social and } \\
\text { demographic values of family planning. } \\
\text { 3.3 Promote adult education and functional } \\
\text { literacy with bias towards the maintenance } \\
\text { of family values, reproductive health, } \\
\text { population and development interrelation. }\end{array}$ & & \\
\hline & & $\begin{array}{l}\text { 4. Promote compulsory } \\
\text { education for children } \\
\text { especially the girl-child up to } \\
\text { secondary level. }\end{array}$ & $\begin{array}{l}\text { 4.1 Promote policies and programmes that } \\
\text { encourage girls to continue schooling up to } \\
\text { at least secondary school. } \\
\text { 4.2 Promote programmes to improve school } \\
\text { enrolment rate } \\
\text { 4.3 Reduce high dropout rate }\end{array}$ & & \\
\hline & & $\begin{array}{l}\text { 5. Improve Birth and Death } \\
\text { Registration coverage }\end{array}$ & $\begin{array}{l}\text { 5.1 Promote intersectoral collaboration on birth } \\
\text { and death registration coverage } \\
\text { 5.2 Educate the public on birth and death issues } \\
\text { 5.3 Enhance birth and death service delivery }\end{array}$ & & \\
\hline
\end{tabular}




\begin{tabular}{|c|c|c|c|c|}
\hline & $\begin{array}{l}\text { 6. Improve population } \\
\text { database }\end{array}$ & $\begin{array}{l}\text { 6.1 Accelerate the development and maintenance } \\
\text { of effective and efficient population } \\
\text { database }\end{array}$ & $\begin{array}{l}\text { NDPC, NPC, NDPC, } \\
\text { MLGRD, MMDAs, NYC, } \\
\text { PPAG, MOH/GHS, } \\
\text { GRMA, MDAs, Population } \\
\text { Association of Ghana, GSS, }\end{array}$ & \\
\hline $\begin{array}{l}\text { VIII. WATER AND } \\
\text { ENVIRONMEN } \\
\text { TAL } \\
\text { SANITATION }\end{array}$ & $\begin{array}{l}\text { 1. Accelerate the provision } \\
\text { of safe water }\end{array}$ & $\begin{array}{l}\text { Rural Areas } \\
\text { 1.1 Provide new investments in rural water, } \\
\text { especially in guinea worm endemic areas } \\
\text { 1.2 Strengthen the management of on-going } \\
\text { investments in deprived regions } \\
\text { 1.3 Ensure timely disbursement of recurrent } \\
\text { budget to CWSA } \\
\text { 1.4 Ensure timely disbursement of the District } \\
\text { Assembly Common Fund } \\
\text { 1.5 Strengthen public-private and NGO } \\
\text { partnerships in water provision } \\
\text { 1.6 Improve community owned and managed } \\
\text { water supply systems } \\
\text { 1.7 The building code must enforce the use of } \\
\text { rain harvesting facilities in building plans } \\
\text { 1.8 Provide check-dams (dug out) o harvest } \\
\text { rainwater for agriculture purposes } \\
\text { 1.9 Strengthen the human resource capacity in } \\
\text { water management } \\
\text { 1.10 Disseminate information on safe water } \\
\text { Urban Areas } \\
\text { 1.11 Establish regional offices of PURC } \\
\text { 1.12 Mobilize new investments for urban water } \\
\text { systems } \\
\text { 1.13 Extend distribution networks especially to } \\
\text { low income consumers } \\
\text { 1.14 Strengthen the management of Ghana Water } \\
\text { Company to enhance service delivery }\end{array}$ & 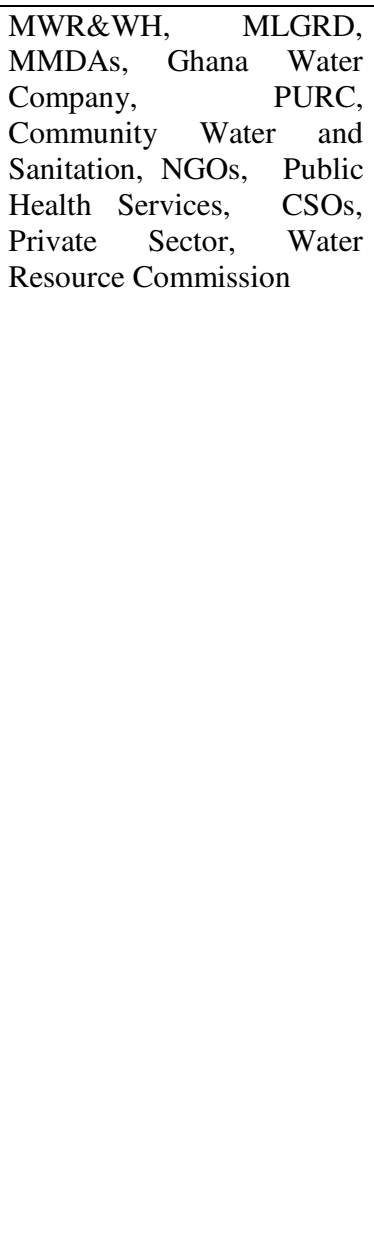 & $\begin{array}{lr}\text { MDG } & 7 ; \text { APRM } \\
\text { Obj.4 } & \text { under } \\
\text { Socio-economic } \\
\text { development }\end{array}$ \\
\hline
\end{tabular}




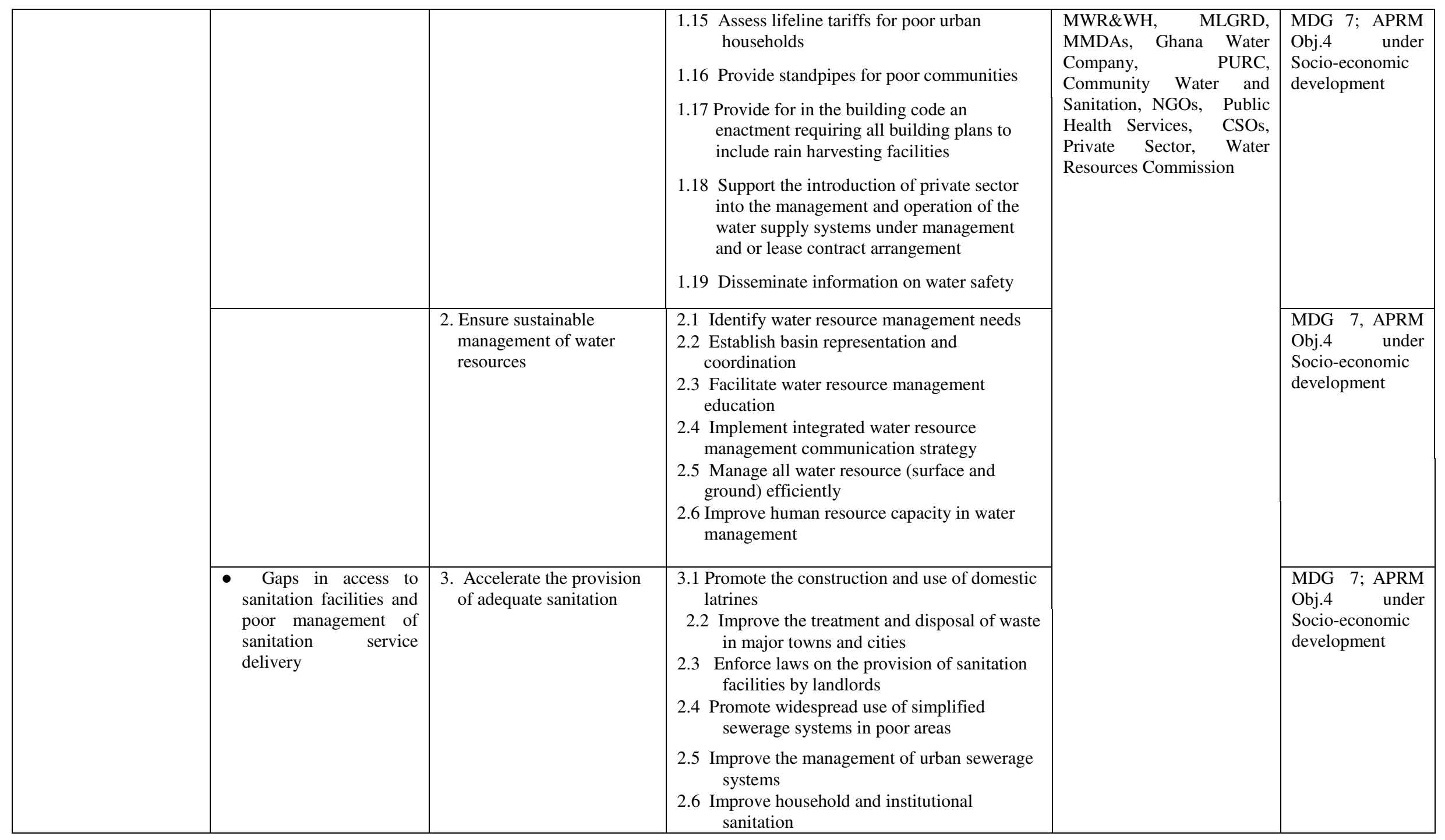




\begin{tabular}{|c|c|c|c|c|}
\hline & & $\begin{array}{l}\text { 2.7 Rationalize and update District Assembly } \\
\text { bye-laws on safe management of liquid and } \\
\text { solid waste at the household level } \\
\text { 2.8 Integrate hygiene education into water and } \\
\text { sanitation delivery }\end{array}$ & \multirow{2}{*}{$\begin{array}{l}\text { MWR\&WH, MLGRD, } \\
\text { MMDAs, Ghana Water } \\
\text { Company, PURC, } \\
\text { Community Water and } \\
\text { Sanitation, NGOs, Public } \\
\text { Health Services, CSOs, } \\
\text { Private Sector }\end{array}$} & \multirow[t]{2}{*}{$\begin{array}{l}\text { MDG 7; } \text { APRM } \\
\text { obj.4 under } \\
\text { Socio-economic } \\
\text { development }\end{array}$} \\
\hline & $\begin{array}{l}\text { 4. Improve environmental } \\
\text { sanitation }\end{array}$ & $\begin{array}{l}\text { 3.1 Acquire land for the treatment and disposal } \\
\text { of solid waste in major towns and cities } \\
\text { 3.2 Establish water and sanitation boards in } \\
\text { small towns } \\
\text { 3.3 Support public-private partnership in solid } \\
\text { waste management } \\
\text { 3.4 Build the capacity of District Assemblies to } \\
\text { better manage environmental sanitation }\end{array}$ & & \\
\hline \multirow[t]{2}{*}{$\begin{array}{l}\text { IX. URBAN } \\
\text { DEVELOPMENT, } \\
\text { HOUSING AND } \\
\text { SLUM } \\
\text { UPGRADING }\end{array}$} & $\begin{array}{l}\text { Promote urban } \\
\text { infrastructure } \\
\text { development and } \\
\text { provision of basic } \\
\text { services }\end{array}$ & 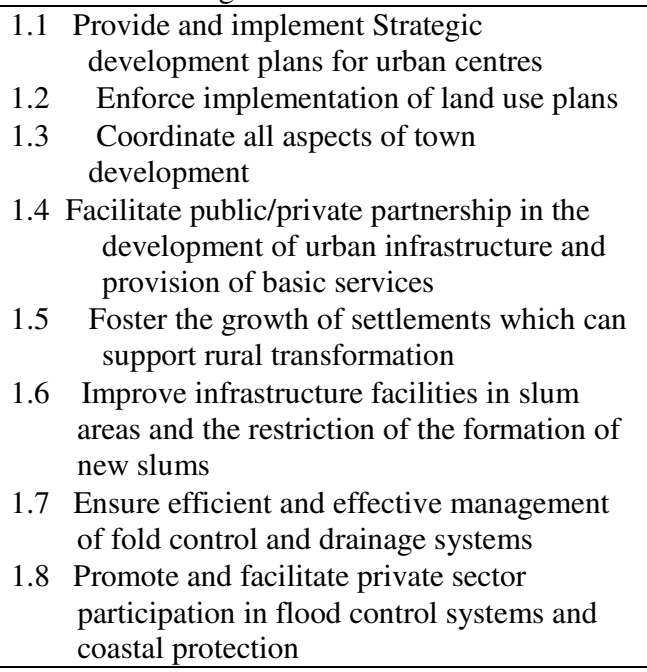 & \multirow[t]{2}{*}{$\begin{array}{lr}\text { MWR\&WH, } & \text { MLGRD, } \\
\text { MMDAS, Town and } \\
\text { Country } & \text { Planning, } \\
\text { MOT/MCC, Private Sector, } \\
\text { NGOs }\end{array}$} & \multirow[t]{2}{*}{$\begin{array}{l}\text { MDG 7(Target } \\
\text { 11); APRM obj.4 } \\
\text { under Socio- } \\
\text { economic } \\
\text { development }\end{array}$} \\
\hline & $\begin{array}{l}\text { 2. Increase access to safe } \\
\text { and affordable shelter }\end{array}$ & $\begin{array}{l}\text { 2.1 Streamline and improve land acquisition } \\
\text { procedures } \\
\text { 2.2 Establish mortgage finance institutions to } \\
\text { provide varied ending and savings services } \\
\text { to house owners, would-be house owners } \\
\text { and estate developers }\end{array}$ & & \\
\hline
\end{tabular}




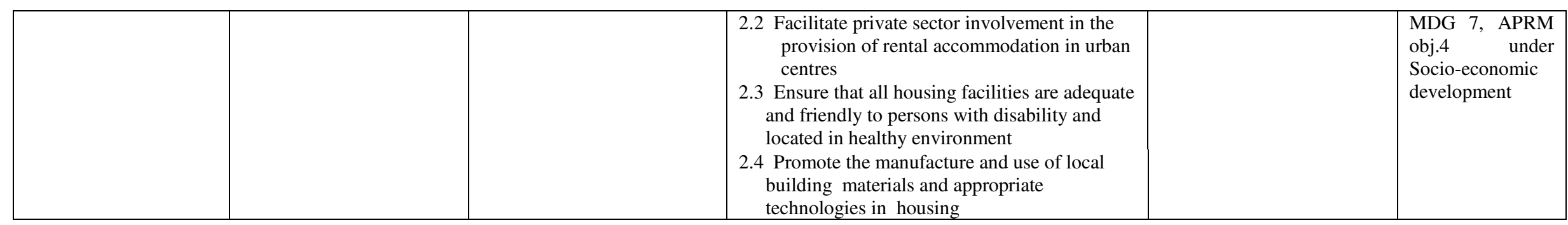


APPENDIX 1IC: GOOD GOVERNANCE AND CIVIC RESPONSIBILITY

\begin{tabular}{|c|c|c|c|c|c|}
\hline KEY AREA OF FOCUS & ISSUES & POLICY & STRATEGIES & $\begin{array}{c}\text { IMPLEMENTING AND } \\
\text { COLLABORATIVE } \\
\text { AGENCY } \\
\end{array}$ & $\begin{array}{l}\text { GLOBAL / REGIONAL } \\
\text { LINKAGES }\end{array}$ \\
\hline \multicolumn{6}{|c|}{ POLITICAL GOVERNANCE } \\
\hline \multirow[t]{6}{*}{$\begin{array}{l}\text { I. STRENGTHENING } \\
\text { PRACTICE OF } \\
\text { DEMOCRACY }\end{array}$} & $\begin{array}{l}\text { Fusion of functions of } \\
\text { the arms of } \\
\text { government leading to } \\
\text { conflict of roles. } \\
\text { - Resource disparity } \\
\text { undermining the role } \\
\text { of different arms of } \\
\text { government }\end{array}$ & 1. Strengthen Parliament & $\begin{array}{l}\text { 1.1 Review constitutional power } \\
\text { relations and establish relative resource } \\
\text { parity } \\
\text { 1.2 Establish relative resource parity } \\
\text { 1.3 Build capacity of Parliament to draft laws }\end{array}$ & \multirow[t]{6}{*}{$\begin{array}{l}\text { Parliament, MOJ, Office of } \\
\text { the President, MOFEP, Min. } \\
\text { of Parliamentary Affairs, } \\
\text { Parliamentary Service, CDD, } \\
\text { IDEG, IEA, NGOs and CBO, } \\
\text { NDPC, CHRAJ, SFO, The } \\
\text { Governance Programme }\end{array}$} & \multirow[t]{2}{*}{$\begin{array}{l}\text { MDG 8, APRM, Obj.2\&4 } \\
\text { under Political Governance }\end{array}$} \\
\hline & \begin{tabular}{|l|} 
- Weak impact of \\
development process \\
Lack of public \\
ownership \& \\
harmonization \\
of the development \\
process
\end{tabular} & $\begin{array}{l}\text { 2. Promote coordination, } \\
\text { harmonization and } \\
\text { ownership of } \\
\text { development processes }\end{array}$ & $\begin{array}{l}\text { 2.1 Institutionalize mutually } \\
\text { agreed framework for development dialogue }\end{array}$ & & \\
\hline & $\begin{array}{l}\text { Lack of a level } \\
\text { playing field }\end{array}$ & $\begin{array}{l}\text { 3. Fight corruption in the } \\
\text { political process }\end{array}$ & $\begin{array}{l}\text { 3.1 Enforce legal, operational and financial } \\
\text { standards for party organization }\end{array}$ & & \multirow[t]{4}{*}{ MDG 8} \\
\hline & $\begin{array}{l}\text { - Integrity of and access } \\
\text { to the electoral process }\end{array}$ & $\begin{array}{l}\text { 4. Ensure free and credible } \\
\text { elections }\end{array}$ & $\begin{array}{l}\text { 4.1 Establish election fund with clear } \\
\text { transparency and accountability requirement }\end{array}$ & & \\
\hline & \begin{tabular}{|l} 
- Limited Public \\
awareness and \\
advocacy
\end{tabular} & $\begin{array}{l}\text { 5. Foster Civic Advocacy to } \\
\text { nurture the culture } \\
\text { of democracy }\end{array}$ & $\begin{array}{l}5.1 \text { Support institutions and schemes } \\
\text { aimed at empowering civic participation }\end{array}$ & & \\
\hline & & $\begin{array}{l}\text { 6. Enhance transparency } \\
\text { and accountability in state } \\
\text { and non-state institutions }\end{array}$ & 6.1 Free access to public information & & \\
\hline
\end{tabular}




\begin{tabular}{|c|c|c|c|c|c|}
\hline KEY AREA OF FOCUS & ISSUES & POLICY & STRATEGIES & $\begin{array}{l}\text { IMPLEMENTING AND } \\
\text { COLLABORATIVE } \\
\text { AGENCY }\end{array}$ & $\begin{array}{l}\text { GLOBAL / REGIONAL } \\
\text { LINKAGES }\end{array}$ \\
\hline \multirow{9}{*}{\begin{tabular}{|l|} 
II. ENHANCING \\
DECENTRALIZATIO \\
$\mathbf{N}$
\end{tabular}} & \multicolumn{5}{|l|}{ (a) Administrative } \\
\hline & & $\begin{array}{l}\text { 1. Strengthen the capacity of } \\
\text { MMDAs for accountable, } \\
\text { effective performance } \\
\text { and service delivery }\end{array}$ & $\begin{array}{l}\text { 1.1 Implement PA 3, National Decentralization } \\
\text { Action Plan }\end{array}$ & \multirow[t]{8}{*}{$\begin{array}{l}\text { MLGRD, Local Govt } \\
\text { Service/Institute, MMDAS, } \\
\text { MOFED, Parliament, MOJ }\end{array}$} & \multirow[t]{7}{*}{$\begin{array}{l}\text { MDG 8, APRM, Obj } 2 \\
\text { under Political Governance }\end{array}$} \\
\hline & \begin{tabular}{|l|} 
Limited \\
implementation of \\
composite budgeting
\end{tabular} & $\begin{array}{l}\text { 2. Institutionalize District } \\
\text { level planning and } \\
\text { budgeting involving all } \\
\text { stakeholders through } \\
\text { participatory democracy } \\
\text { at the national and } \\
\text { district level }\end{array}$ & $\begin{array}{l}\text { 2.1 Effectively operationalize district planning } \\
\text { guidelines }\end{array}$ & & \\
\hline & \begin{tabular}{|l|} 
Lack of functional \\
clarity and \\
administrative \\
coordination at \\
district level and sub- \\
district levels
\end{tabular} & $\begin{array}{l}\text { 3. Ensure Political } \\
\text { commitment to the } \\
\text { implementation of the } \\
\text { Local Government } \\
\text { Service Act }\end{array}$ & $\begin{array}{l}\text { 3.1 Operationalize Local Government Service } \\
\text { 3.2 Prepare Schemes and Conditions of Local } \\
\text { Government Service }\end{array}$ & & \\
\hline & & $\begin{array}{l}\text { 4. Modernise Public } \\
\text { expenditure management } \\
\text { framework }\end{array}$ & 4.1 Incorporate ICT in accounting procedures & & \\
\hline & \multicolumn{3}{|l|}{ (b) Political } & & \\
\hline & \begin{tabular}{|l|} 
- Limited political buy- \\
in across MDAs \\
\end{tabular} & $\begin{array}{l}\text { 1. Accelerate the devolution } \\
\text { of political power to the } \\
\text { districts and Sub-district } \\
\text { structures }\end{array}$ & $\begin{array}{l}\text { 1.1 Mainstream decentralization in } \\
\text { Public Sector Reforms }\end{array}$ & & \\
\hline & \multicolumn{3}{|l|}{ (c)Fiscal } & & \\
\hline & \begin{tabular}{|l|} 
Absence of appropriate \\
inter-governmental \\
revenue sharing \\
arrangement
\end{tabular} & $\begin{array}{l}\text { 1. Provide the appropriate } \\
\text { legal framework to } \\
\text { support fiscal } \\
\text { decentralization }\end{array}$ & $\begin{array}{l}\text { 1.1 Review constitutional provisions and } \\
\text { statutes with direct and indirect impact. } \\
1.2 \begin{array}{l}\text { Restructuring of resource allocation } \\
\text { formula }\end{array}\end{array}$ & & \begin{tabular}{|l|} 
MDG 8, APRM, Obj.1/3 \\
under Economic Governance
\end{tabular} \\
\hline
\end{tabular}




\begin{tabular}{|c|c|c|c|c|c|}
\hline KEY AREA OF FOCUS & ISSUES & POLICY & STRATEGIES & $\begin{array}{c}\text { IMPLEMENTING AND } \\
\text { COLLABORATIVE } \\
\text { AGENCY } \\
\end{array}$ & $\begin{array}{c}\text { GLOBAL / REGIONAL } \\
\text { LINKAGES }\end{array}$ \\
\hline & $\begin{array}{l}\text { - Weak internal revenue } \\
\text { mobilization } \\
\text { - Over dependence on } \\
\text { the DACF and other } \\
\text { External Grants }\end{array}$ & $\begin{array}{l}\text { 2. Promote internal revenue } \\
\text { generation }\end{array}$ & $\begin{array}{l}\text { 2.1 DSDA II and other best practice database } \\
\text { initiatives replicated in all districts } \\
\text { 2.2 Develop the capacity of the MMDAs } \\
\text { towards effective revenue mobilization }\end{array}$ & & \\
\hline & $\begin{array}{l}\text { - Weak financial } \\
\text { management practices }\end{array}$ & $\begin{array}{l}\text { 3. Ensure transparency in } \\
\text { fiscal decentralization }\end{array}$ & $\begin{array}{l}\text { 3.1 Strengthen collection and dissemination of } \\
\text { records and progressively mechanize } \\
\text { records }\end{array}$ & & \\
\hline \multirow[t]{3}{*}{$\begin{array}{l}\text { III. PROTECTING } \\
\text { RIGHTS UNDER } \\
\text { RULE OF LAW }\end{array}$} & & $\begin{array}{l}\text { 1. Increase the capacity of } \\
\text { the legal sector, enhance } \\
\text { speedy and affordable } \\
\text { access to justice }\end{array}$ & $\begin{array}{l}\text { 1.1 Improve case management systems of the } \\
\text { courts including scaling up mechanization, } \\
\text { Enhance Human Resource Levels, Revise } \\
\text { and implement rule of procedures and } \\
\text { expansion of infrastructure. } \\
\text { 1.2 Effectively mainstream Alternative Dispute } \\
\text { Resolution mechanism } \\
\text { 1.3 Promote the provision of legal aid for the } \\
\text { poor }\end{array}$ & \multirow{3}{*}{$\begin{array}{l}\text { MOJ, Judiciary Service, } \\
\text { CHRAJ; NCCE, EC, Legal } \\
\text { Aid, MOWAC, WAJU, } \\
\text { DSW, CBOs, MMYE, } \\
\text { MMDAs. } \\
\\
\end{array}$} & \multirow[t]{3}{*}{$\begin{array}{l}\text { APRM, Obj 2/4/10 under } \\
\text { Political Governance }\end{array}$} \\
\hline & $\begin{array}{l}\text { - Poor compliance with } \\
\text { rules, regulations and } \\
\text { procedures } \\
\text { - Weak enforcement of } \\
\text { rules, regulations and } \\
\text { procedures }\end{array}$ & $\begin{array}{l}\text { 2. Strengthen the capacity } \\
\text { of state institutions to } \\
\text { promote compliance and } \\
\text { enforcement of laws }\end{array}$ & $\begin{array}{l}\text { 3.1 Streamline legal \& Institutional framework } \\
\text { for enforcement } \\
\text { 3.2 Scaling up operational \& Human Resource } \\
\text { levels within state institutions responsible } \\
\text { for enforcement }\end{array}$ & & \\
\hline & $\begin{array}{l}\text { - Weak appreciation of } \\
\text { and demand for basic } \\
\text { social services }\end{array}$ & $\begin{array}{l}\text { 3. Promote and protect } \\
\text { economic, social } \\
\text { cultural, civil and } \\
\text { political rights as } \\
\text { enshrined in our } \\
\text { constitution and all } \\
\text { African and international } \\
\text { human rights } \\
\text { instruments to which } \\
\text { Ghana is a signatory }\end{array}$ & $\begin{array}{l}\text { 4.1 Promote the development of Citizen } \\
\text { Charters } \\
\text { 4.2 Promote Public education on the economic, } \\
\text { social, cultural, civil and political rights of } \\
\text { citizenry } \\
\text { 4.3 Scaling up demand for basic right } \\
\text { 4.4 Develop NGO policies } \\
\text { 4.5 Reducing International instruments into } \\
\text { municipal laws }\end{array}$ & & \\
\hline
\end{tabular}




\begin{tabular}{|c|c|c|c|c|c|}
\hline KEY AREA OF FOCUS & ISSUES & POLICY & STRATEGIES & $\begin{array}{c}\text { IMPLEMENTING AND } \\
\text { COLLABORATIVE } \\
\text { AGENCY }\end{array}$ & $\begin{array}{l}\text { GLOBAL / REGIONAL } \\
\text { LINKAGES }\end{array}$ \\
\hline $\begin{array}{l}\text { IV. IMPROVED ACCESS } \\
\text { TO RIGHTS AND } \\
\text { ENTILTEMENTS }\end{array}$ & 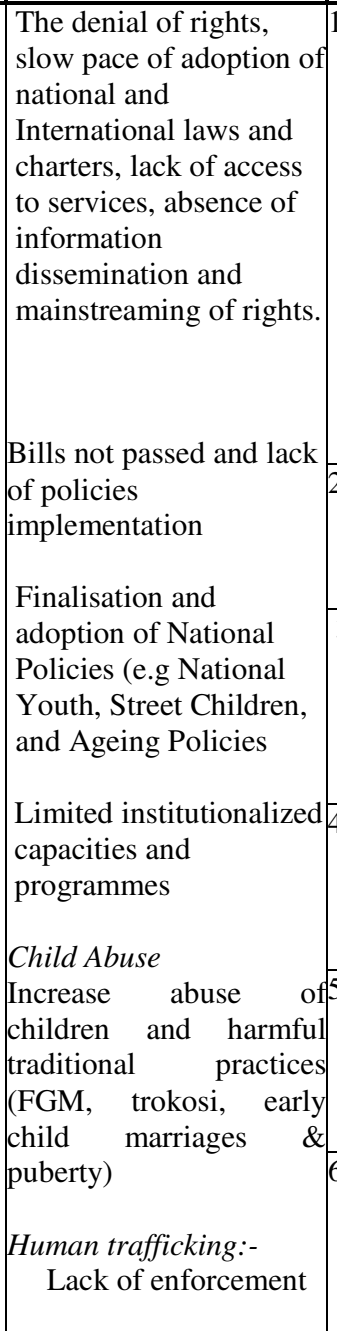 & \begin{tabular}{|l|}
$\begin{array}{l}\text { 5. Protect children from } \\
\text { direct and indirect } \\
\text { physical and emotional } \\
\text { harm }\end{array}$ \\
$\begin{array}{l}\text { 6. Eliminate child trafficking } \\
\text { and apply the standards } \\
\text { and codes to children } \\
\text { rights to ensure that the } \\
\text { legal framework for }\end{array}$ \\
\end{tabular} & 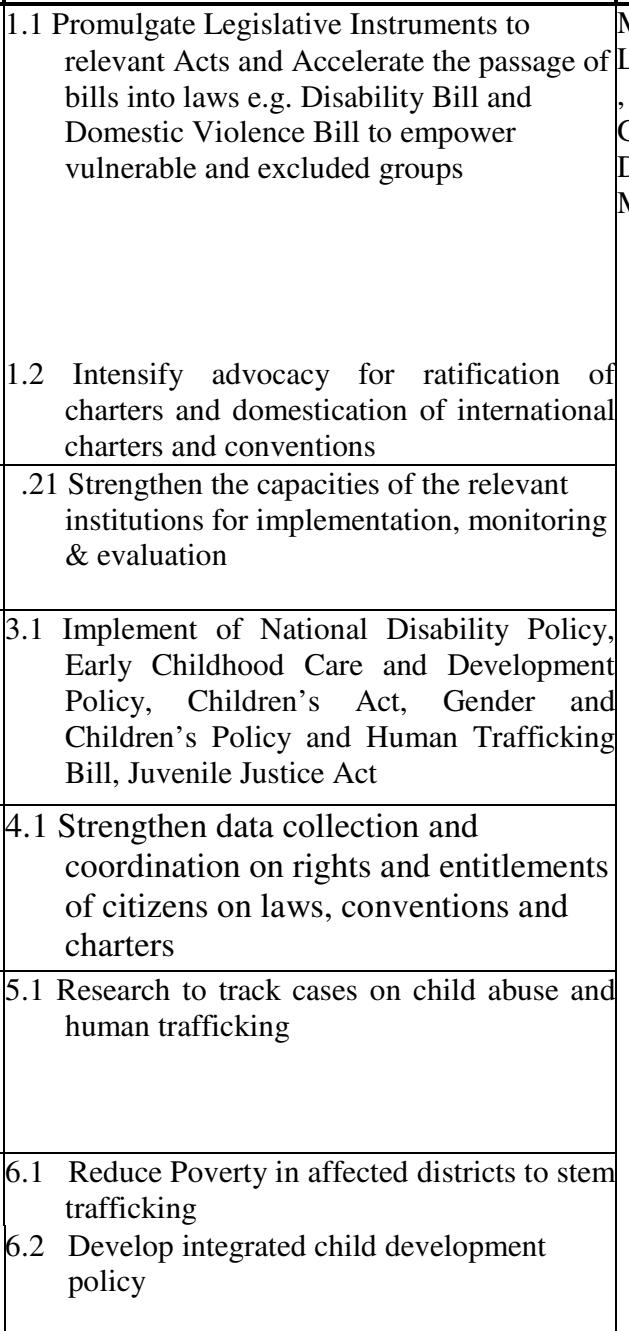 & \multicolumn{2}{|c|}{$\begin{array}{l}\text { MOJ, CHRAJ; NCCE, EC, MDG 1/3, APRM, obj.3 } \\
\text { Legal Aid, MOWAC, WAJU/9/10 under Political } \\
\text { DSW, CBOs, MMYE, Governance, Obj. } 5 \text { under } \\
\text { Ghana Federation of the Socio-economic } \\
\text { Disabled Households, GIS, development } \\
\text { MMDAs, } \\
\\
\\
\end{array}$} \\
\hline
\end{tabular}




\begin{tabular}{|c|c|c|c|c|c|}
\hline \multirow[t]{5}{*}{ KEY AREA OF FOCUS } & ISSUES & POLICY & STRATEGIES & $\begin{array}{l}\text { IMPLEMENTING AND } \\
\text { COLLABORATIVE } \\
\text { AGENCY }\end{array}$ & $\begin{array}{l}\text { GLOBAL / REGIONAL } \\
\text { LINKAGES }\end{array}$ \\
\hline & $\begin{array}{l}\text { of policies, Human } \\
\text { Trafficking Bill, } \\
\text { Domestic Violence } \\
\text { Bill and Children's } \\
\text { Act } 1998 . \\
\text { Laws not passed }\end{array}$ & $\begin{array}{l}\text { sanctions against child } \\
\text { trafficking is in place }\end{array}$ & $\begin{array}{l}\text { 6.3 Launch public education about the dangers } \\
\text { of child trafficking, child abuse and } \\
\text { children's rights and human rights with } \\
\text { special focus on sending districts and } \\
\text { receiving districts }\end{array}$ & & Governance \\
\hline & $\begin{array}{l}\text { - Limited capacity for } \\
\text { effective education } \\
\text { and enforcement }\end{array}$ & $\begin{array}{l}\text { 7. Effective public } \\
\text { awareness creation on } \\
\text { laws for the protection of } \\
\text { V\&E }\end{array}$ & $\begin{array}{l}\text { 7.1 Build capacity for public education and } \\
\text { dissemination of information on rights }\end{array}$ & & \multirow[t]{4}{*}{$\begin{array}{l}\text { MDG 1/3, APRM, Obj.3 } \\
\text { /9/10 under Political } \\
\text { Governance }\end{array}$} \\
\hline & $\begin{array}{l}\text { Children in conflict of } \\
\text { the law }\end{array}$ & $\begin{array}{l}\text { 8. Provide counselling and } \\
\text { support services to } \\
\text { families to help to reduce } \\
\text { the incidence of children } \\
\text { in conflict with the law }\end{array}$ & $\begin{array}{l}\text { 8.1 Provide counselling and support services to } \\
\text { families to help to reduce the incidence of } \\
\text { children in conflict with the law } \\
\text { 8.2 Ensure the implementation of Child rights } \\
\text { in relation to their handling by law } \\
\text { enforcement agencies }\end{array}$ & \multirow{2}{*}{\begin{tabular}{|l} 
Ghana Police Service, \\
DSW, NGOs, \\
Prisons Service \\
\\
\end{tabular}} & \\
\hline & & $\begin{array}{l}\text { 9. Ensure the } \\
\text { implementation of Child } \\
\text { rights in relation to their } \\
\text { handling by law } \\
\text { enforcement agencies }\end{array}$ & \begin{tabular}{|ll}
9.1 & $\begin{array}{l}\text { Increase budgetary allocation to agencies } \\
\text { responsible for children in conflict with the } \\
\text { law }\end{array}$ \\
9.2 & $\begin{array}{l}\text { Strengthen the capacities of institutions to } \\
\text { monitor and track juvenile offenders }\end{array}$ \\
9.3 & Intensify education on Juvenile Justice Act
\end{tabular} & & \\
\hline & $\begin{array}{l}P W D s \\
\text { - Weak capacity and } \\
\text { low priority given to } \\
\text { the agencies } \\
\text { responsible for }\end{array}$ & $\begin{array}{l}\text { 10. Create an enabling } \\
\text { environment to ensure } \\
\text { the active involvement of } \\
\text { PWDs in mainstream } \\
\text { society }\end{array}$ & $\begin{array}{l}\text { 10.1 Introduce explicit affirmative action } \\
\text { initiatives for persons' with disability with } \\
\text { due consideration to gender }\end{array}$ & $\begin{array}{l}\text { DSW, MMEY, NGOs, Ghana } \\
\text { Federation of the Disabled } \\
\text { AESL, Town and Country } \\
\text { Planning, GNFS, MOES } \\
\text { GES }\end{array}$ & \\
\hline
\end{tabular}




\begin{tabular}{|c|c|c|c|c|c|}
\hline \multirow[t]{2}{*}{ KEY AREA OF FOCUS } & ISSUES & POLICY & STRATEGIES & $\begin{array}{c}\text { IMPLEMENTING AND } \\
\text { COLLABORATIVE } \\
\text { AGENCY } \\
\end{array}$ & $\begin{array}{l}\text { GLOBAL / REGIONAL } \\
\text { LINKAGES }\end{array}$ \\
\hline & $\begin{array}{l}\text { PWDs } \\
\text { Disability Bill not } \\
\text { passed } \\
\text { - Limited awareness, } \\
\text { dissemination and } \\
\text { implementation on } \\
\text { National Disability } \\
\text { Policy }\end{array}$ & $\begin{array}{l}\text { 11. Design action plan to } \\
\text { implement the disability } \\
\text { bill }\end{array}$ & $\begin{array}{l}\text { 11.1 Intensify consultation on National } \\
\text { Disability Bill and take measure to pass the } \\
\text { bill }\end{array}$ & $\begin{array}{l}\text { DSW, MMEY, NGOs, Ghana } \\
\text { Federation of the Disabled } \\
\text { AESL, Town and Country } \\
\text { Planning, GNFS, MOES } \\
\text { GES }\end{array}$ & \\
\hline \multirow[t]{3}{*}{ 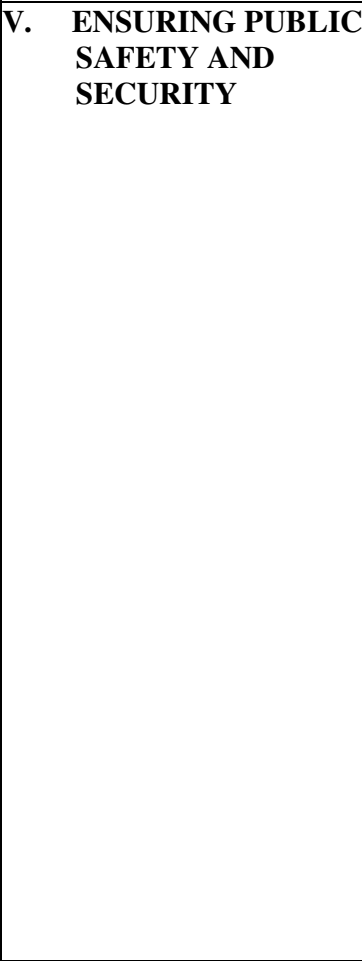 } & \begin{tabular}{|l|} 
- High level of violent \\
crimes \\
- Proliferation of Small \\
Arms \\
- Proliferation of Private \\
Security Organizations \\
- High rate of recidivism \\
- High rate of drug \\
abuse and incidence of \\
trafficking of narcotic \\
drugs \\
- Influx of refugees \\
- Poor monitoring of \\
activities of foreigners
\end{tabular} & 1. Improve internal security & $\begin{array}{l}\text { 1.1 Improve institutional capacity of the Police, } \\
\text { Immigration Service, Prisons and Narcotic } \\
\text { Control Boardstrengthen \& institutionalise } \\
\text { early warning systems } \\
\text { 1.2 Sensitize public on dangers of small arms } \\
\text { 1.3 Regulate Private sector involvement in the } \\
\text { provision of security } \\
\text { 1.4 Comprehensive monitoring of activities of } \\
\text { foreigners } \\
\begin{array}{l}\text { 1.5 Step up programs to rehabilitate and reform } \\
\text { prisoners }\end{array}\end{array}$ & \multirow[t]{3}{*}{\begin{tabular}{|l|} 
MOI, MOD, GAF, Ghana \\
Police Service, National \\
Security, Ghana Immigration \\
Service, Min. of Foreign \\
Affairs, Min. of Regional \\
Cooperation \& NEPAD, \\
MOWAC, WAJU, DSW, \\
NGOs, NCCE, Private \\
Sector, Ghana Air Force, \\
Ghana Navy, National House \\
of Chief
\end{tabular}} & \multirow[t]{3}{*}{$\begin{array}{l}\text { MDG 8/APRM, Obj. } 1 \\
\text { under Political Governance }\end{array}$} \\
\hline & $\begin{array}{l}\text { - Fire and safety risks to } \\
\text { national property \& } \\
\text { installations }\end{array}$ & $\begin{array}{l}\text { 2. Increase national capacity } \\
\text { to ensure safety of life and } \\
\text { property }\end{array}$ & 2.1 Increase safety awareness of citizens & & \\
\hline & \begin{tabular}{|l|} 
Instability in the sub- \\
region \\
- Need to deter potential \\
incidents of external \\
aggression \\
- Means of enhancing \\
logistics of the armed \\
forces
\end{tabular} & $\begin{array}{l}\text { 3. Forestall external } \\
\text { aggression, safeguard } \\
\text { territorial integrity and } \\
\text { contribute to } \\
\text { international peace } \\
\text { keeping efforts } \\
\end{array}$ & $\begin{array}{l}\text { 3.1 Build operational, human resource and } \\
\text { logistics capacity of the Ministry of } \\
\text { Defence } \\
\text { 3.2 Encourage participation of Ghana in } \\
\text { external peacekeeping missions }\end{array}$ & & \\
\hline
\end{tabular}




\begin{tabular}{|c|c|c|c|c|c|}
\hline KEY AREA OF FOCUS & ISSUES & POLICY & STRATEGIES & $\begin{array}{c}\text { IMPLEMENTING AND } \\
\text { COLLABORATIVE } \\
\text { AGENCY }\end{array}$ & $\begin{array}{l}\text { GLOBAL / REGIONAL } \\
\text { LINKAGES }\end{array}$ \\
\hline & $\begin{array}{l}\text { Divert attention of the } \\
\text { troops from engaging } \\
\text { in subversive } \\
\text { activities. }\end{array}$ & & & & \\
\hline & $\begin{array}{l}\text { - High incidence of } \\
\text { economic crimes and } \\
\text { fraud }\end{array}$ & $\begin{array}{l}\text { 4. Enhance the ability of } \\
\text { state institutions to } \\
\text { combat economic crimes }\end{array}$ & $\begin{array}{l}\text { 4.1 Improve institutional capacity of } \\
\text { security agencies } \\
4.2 \text { Increase public awareness of economic } \\
\text { crime and fraud }\end{array}$ & $\begin{array}{l}\text { MOI, MOD, GAF, Ghana } \\
\text { Police Service, National } \\
\text { Security, Ghana Immigration } \\
\text { Service, Min. of Foreign } \\
\text { Affairs, Min. of Regional } \\
\text { Cooperation \& NEPAD, } \\
\text { MOWAC, WAJU, DSW, } \\
\text { NGOs, NCCE, Private } \\
\text { Sector, Ghana Air Force, } \\
\text { Ghana Navy }\end{array}$ & \\
\hline & $\begin{array}{l}\text { Conflict management: } \\
\text { - Ghana surrounded by } \\
\text { countries with } \\
\text { conflict. } \\
\text { - Pockets of conflict } \\
\text { internally }\end{array}$ & $\begin{array}{l}\text { 5. Promote peace and } \\
\text { stability by adoption of } \\
\text { concrete conflict } \\
\text { resolution measures }\end{array}$ & $\begin{array}{l}\text { 5.1 Conflict management and alternative dispute } \\
\text { resolution mechanisms introduced for all } \\
\text { especially women, traditional authority and } \\
\text { FBOs } \\
\text { 5.2 Develop programmes cultural exchange } \\
\text { among students especially within the } \\
\text { country and among ECOWAS } \\
\text { 5.3 Develop rapid response mechanisms for all }\end{array}$ & $\begin{array}{l}\text { Ministry of Interior } \\
\text { NCCE, CSOs, NGOs, } \\
\text { MOWAC, WAJU, DSW } \\
\text { NADMO, MOT\&MCC } \\
\end{array}$ & \\
\hline \multirow[t]{2}{*}{$\begin{array}{l}\text { VI. PUBLIC POLICY } \\
\text { MANAGEMENT AND } \\
\text { PUBLIC SECTOR } \\
\text { REFORMS }\end{array}$} & $\begin{array}{l}\text { - Lack of systematic } \\
\text { training } \\
\text { for Civil and Public } \\
\text { Servants. } \\
\text { Poor conditions of } \\
\text { service Ineffective } \\
\text { Supervision. }\end{array}$ & $\begin{array}{l}\text { 1. Increase the capacity of } \\
\text { the public and civil } \\
\text { service for accountable, } \\
\text { efficient, timely, } \\
\text { effective performance } \\
\text { and service delivery }\end{array}$ & $\begin{array}{l}3.1 \text { Accelerate the on-going public } \\
\text { sector reform programs }\end{array}$ & \multirow{2}{*}{$\begin{array}{l}\text { Min. of Public Sector } \\
\text { Reforms, Office of the } \\
\text { President, The Senior, Civil } \\
\text { Servant Association, PEF, } \\
\text { AGI, GEA, MPSD Minister's } \\
\text { Office, Public Services } \\
\text { Commission, Parliament, All } \\
\text { Political Parties, National } \\
\text { House of Chief, The } \\
\text { Governance Programme }\end{array}$} & $\begin{array}{l}\text { MDG 8, APRM, obj.5 } \\
\text { under Political Governance }\end{array}$ \\
\hline & $\begin{array}{l}\text { National consensus } \\
\text { and ownership on } \\
\text { key issues devoid of } \\
\text { politicization }\end{array}$ & $\begin{array}{l}\text { 2. Deepen pluralistic } \\
\text { involvement in support } \\
\text { of poverty reduction and } \\
\text { growth }\end{array}$ & $\begin{array}{l}\text { 1.1 Involve the role of Parliament in policy } \\
\text { formulation process } \\
1.2 \text { Create avenues for inter-party participation } \\
\text { in policy formulation }\end{array}$ & & $\begin{array}{l}\text { MDG 1/8, APRM, obj.1 } \\
\text { under Political Governance; } \\
\text { obj.5/6 under Socio- } \\
\text { economic development }\end{array}$ \\
\hline
\end{tabular}




\begin{tabular}{|c|c|c|c|c|c|}
\hline KEY AREA OF FOCUS & ISSUES & POLICY & STRATEGIES & $\begin{array}{c}\text { IMPLEMENTING AND } \\
\text { COLLABORATIVE } \\
\text { AGENCY } \\
\end{array}$ & $\begin{array}{l}\text { GLOBAL / REGIONAL } \\
\text { LINKAGES }\end{array}$ \\
\hline & & & $\begin{array}{l}\text { 1.3 Increase the representation of women in } \\
\text { public life } \\
\text { 1.4 Involve traditional authorities in formal } \\
\text { decision making structures } \\
\text { 1.5 Create opportunities for civil society } \\
\text { participation in managing public policy } \\
\text { 1.6 Involve key public institutions in decision } \\
\text { making processes for effective } \\
\text { implementation }\end{array}$ & \multirow[t]{4}{*}{\begin{tabular}{|l|} 
Min. of Public Sector \\
Reforms, Office of the \\
President, The Senior, Civil \\
Servant Association, PEF, \\
AGI, GEA, MPSD Minister's \\
Office, Public Services \\
Commission, Parliament, All \\
Political Parties, National \\
House of Chief
\end{tabular}} & \multirow[b]{4}{*}{$\begin{array}{l}\text { APRM, obj.6 under Socio- } \\
\text { economic development }\end{array}$} \\
\hline & $\begin{array}{l}\text { - Overlap of functions in } \\
\text { MDAs } \\
\text { - Lack of adequate \& } \\
\text { formalized Public - } \\
\text { Civic interface } \\
\end{array}$ & $\begin{array}{l}\text { 3. Rationalize and define } \\
\text { structures, roles and } \\
\text { procedures for state and } \\
\text { non state actors }\end{array}$ & $\begin{array}{l}\text { 3.1 Provide clear mandate and terms of } \\
\text { Reference for institutions }\end{array}$ & & \\
\hline & $\begin{array}{l}\text { Inconsistent } \\
\text { consideration of } \\
\text { environment in public } \\
\text { policy processes } \\
\end{array}$ & $\begin{array}{l}\text { 4. Institutionalize the } \\
\text { mainstreaming of } \\
\text { sustainable development } \\
\text { principles }\end{array}$ & $\begin{array}{l}\text { 4.1 Use of SEA in public policy } \\
\text { processes }\end{array}$ & & \\
\hline & $\begin{array}{l}\text { - Lack of demand and } \\
\text { feedback on M\&E } \\
\text { information }\end{array}$ & $\begin{array}{l}\text { 5. Institutionalize and } \\
\text { internalize policy } \\
\text { formulation, planning, } \\
\text { and M\&E system at all } \\
\text { levels }\end{array}$ & $\begin{array}{l}\text { 5.1 Facilitate National Development Policy and } \\
\text { strategy formulation } \\
\text { 5.2 Facilitate development planning and plan } \\
\text { implementation } \\
\text { 5.3 Strengthen policy formulation and planning } \\
\text { capacity at all levels } \\
\text { 5.4 Strengthen M\&E capacity and coordination } \\
\text { at all levels } \\
\text { 5.5 Establish district based M\&E systems }\end{array}$ & & \\
\hline & $\begin{array}{l}\text { - Strengthening of } \\
\text { institutions - } \\
\text { National, } \\
\text { Decentralised }\end{array}$ & $\begin{array}{l}\text { 6. Implement the } \\
\text { coordination mechanisms } \\
\text { for the social protection } \\
\text { strategy, and increase }\end{array}$ & $\begin{array}{l}\text { 6.1 Support the establishment of inter-agency } \\
\text { task force to oversee the harmonisation of } \\
\text { policies and programmes to support the } \\
\text { vulnerable and excluded groups }\end{array}$ & $\begin{array}{l}\text { MDAs, MMDAs, CBOs } \\
\text { Households, NGOs, DSW }\end{array}$ & $\begin{array}{l}\text { APRM, obj.9 under Political } \\
\text { Governance }\end{array}$ \\
\hline
\end{tabular}




\begin{tabular}{|c|c|c|c|c|c|}
\hline KEY AREA OF FOCUS & ISSUES & POLICY & STRATEGIES & $\begin{array}{c}\text { IMPLEMENTING AND } \\
\text { COLLABORATIVE } \\
\text { AGENCY } \\
\end{array}$ & $\begin{array}{c}\text { GLOBAL / REGIONAL } \\
\text { LINKAGES }\end{array}$ \\
\hline & $\begin{array}{l}\text { Structures, and the } \\
\text { family and } \\
\text { communities } \\
\text { - Commitments to issues } \\
\text { on vulnerability } \\
\text { - Problem of low } \\
\text { resource allocation } \\
\text { - Weak harmonisation } \\
\text { of stakeholder } \\
\text { initiatives } \\
\text { - Limited information } \\
\text { on rights and } \\
\text { responsibilities } \\
\text { among both state and } \\
\text { non-state actors }\end{array}$ & $\begin{array}{l}\text { resource allocation to } \\
\text { social protection }\end{array}$ & \begin{tabular}{|} 
6.2 Assist decentralised agencies to incorporate \\
programmes to vulnerable and excluded \\
groups in district development plans \\
6.3 Promote capacity development in social \\
work and volunteerism \\
6.4 Prepare and adopt a national social policy \\
framework \\
6.5 Assist the decentralised agencies to \\
incorporate and coordinate programmes for \\
the vulnerable and at the district level \\
6.6 Harmonise concepts and definitions relating \\
to vulnerability and exclusion among state \\
and non-state actors \\
6.7 Enhance formulation and implementation of \\
social protection initiatives for the vulnerable \\
and excluded at the micro, meso and macro \\
levels \\
6.8 Facilitate the development of explicit policy \\
actions to provide safety nets designed to \\
meet the needs of different categories of \\
vulnerable and excluded groups
\end{tabular} & & \\
\hline \multirow[t]{2}{*}{\begin{tabular}{|l} 
VII. \\
FIGHTING \\
CORRUPTION AND \\
ECONOMIC \\
CRIMES
\end{tabular}} & $\begin{array}{l}\text { High perception of } \\
\text { corruption in public } \\
\text { service, political } \\
\text { process and the } \\
\text { economy }\end{array}$ & $\begin{array}{c}1 \text { Reduce opportunities for } \\
\text { rent-seeking by political } \\
\text { and economic agents, } \\
\text { and public officials }\end{array}$ & $\begin{aligned} & 1.1 \begin{array}{l}\text { Establish all the institutional structures } \\
\text { necessary for the effective implementation } \\
\text { of the new procurement act. }\end{array} \\
& 1.2 \begin{array}{l}\text { Revise the Guidelines on Asset declaration } \\
\text { to allow for easier investigation and }\end{array} \\
& \text { prosecution of violators } \\
& 1.3 \begin{array}{l}\text { Ensure the passage of the Whistleblower's } \\
\text { bill and the Freedom of information bill }\end{array} \\
& 1.4 \begin{array}{l}\text { Formulate and progressively implement a } \\
\text { fair wage policy }\end{array} \\
&\end{aligned}$ & \multirow[t]{2}{*}{$\begin{array}{l}\text { MOJ, Office of the President, } \\
\text { CHRAJ, SFO, Audit Service, } \\
\text { MMYE, Law enforcement } \\
\text { agencies, the Judiciary, BOG, } \\
\text { Office of Accountability, } \\
\text { Parliament, Chief of Staff, } \\
\text { The Governance Programme }\end{array}$} & \multirow[t]{2}{*}{$\begin{array}{l}\text { APRM, obj. } 7 \text { under Politica } \\
\text { Governance; obj.4 under } \\
\text { Economic Governance }\end{array}$} \\
\hline & $\begin{array}{l}- \text { Weak institutional } \\
\text { capacity to fight to } \\
\text { fight corruption. }\end{array}$ & $\begin{array}{l}\text { 2. Strengthening the existing } \\
\text { anticorruption } \\
\text { institutions }\end{array}$ & $\begin{array}{l}\text { 2.1 Enhance the capacity of the existing anti- } \\
\text { corruption institutions to effectively carry } \\
\text { out their mandates }\end{array}$ & & \\
\hline
\end{tabular}




\begin{tabular}{|c|c|c|c|c|c|}
\hline KEY AREA OF FOCUS & ISSUES & POLICY & STRATEGIES & $\begin{array}{c}\text { IMPLEMENTING AND } \\
\text { COLLABORATIVE } \\
\text { AGENCY } \\
\end{array}$ & $\begin{array}{l}\text { GLOBAL / REGIONAL } \\
\text { LINKAGES }\end{array}$ \\
\hline & $\begin{array}{l}\text { - Weak collaboration } \\
\text { among institutions } \\
\text { charge with } \\
\text { responsibility of } \\
\text { fighting corruption. }\end{array}$ & & \begin{tabular}{|l|} 
2.2 Provide courts with the necessary facilities \\
and personnel to expeditiously deal with \\
corruption cases. \\
2.3 Organize periodic training on economic \\
crimes for the financial intelligence unit of \\
the Ghana Police Service and other anti- \\
corruption agencies \\
2.4 Encourage collaboration activities among \\
agencies responsible for fighting corruption \\
2.5 Encourage Civil Society Groups, including \\
the media to play its watch-dog role \\
effectively.
\end{tabular} & & \\
\hline \multirow[t]{4}{*}{$\begin{array}{l}\text { VIII. WOMEN } \\
\text { EMPOWERMENT }\end{array}$} & \multirow{3}{*}{$\begin{array}{l}\text { - Prevalence of } \\
\text { outmoded customs } \\
\text { inimical to women's } \\
\text { rights } \\
\text { - Lack of Gender } \\
\text { Budgeting } \\
\text { - Weak access to } \\
\text { economic resources } \\
\text { - Inadequate women in } \\
\text { public life }\end{array}$} & \begin{tabular}{|}
1 Enforce existing laws \\
protecting women's \\
rights and introduce new \\
legislations to take care \\
of existing gaps
\end{tabular} & $\begin{array}{l}\text { 1.1 Promote the awareness of existing laws } \\
\text { 1.2 Enhance capacity of appropriate } \\
\text { enforcement agencies } \\
\text { 1.3 Expand coverage of the institutions dealing } \\
\text { with women rights }\end{array}$ & \multirow[t]{3}{*}{$\begin{array}{l}\text { MOWAC, MMYE, } \\
\text { WAJU, DSW, Legal Aid } \\
\text { Board, NCWD, MOH } \\
\text { MOJ, CBOs, NGOs, FBOs, } \\
\text { Traditional Authorities }\end{array}$} & \multirow[t]{3}{*}{$\begin{array}{l}\text { MDG 3, APRM, obj } 8 \text { under } \\
\text { Political Governance; obj.5 } \\
\text { under Socio-economic } \\
\text { development }\end{array}$} \\
\hline & & $\begin{array}{l}\text { 2. Enhance women access } \\
\text { to economic resources } \\
\text { and promote women in } \\
\text { public life } \\
\end{array}$ & $\begin{array}{l}\text { 2.1 Progressively implement affirmative action } \\
\text { for women } \\
\text { 2.2 Expand and sustain micro finance schemes } \\
\text { for women } \\
\text { 2.3 Strengthen institutions dealing with women } \\
\text { and children } \\
\end{array}$ & & \\
\hline & & $\begin{array}{l}\text { 3. Introduce gender } \\
\text { budgeting }\end{array}$ & $\begin{array}{l}\text { 3.1 Incorporate gender analysis in the policy } \\
\text { formulation process }\end{array}$ & & \\
\hline & \begin{tabular}{|l} 
Women affected by \\
violence \\
- Harmful traditional \\
practices- trokosi, \\
widowhood rites, \\
bethrotal systems)
\end{tabular} & $\begin{array}{l}\text { 4. Create an enabling } \\
\text { environment for victims of } \\
\text { violence to access help }\end{array}$ & $\begin{array}{l}\text { 4.1 Intensify and support sensitization } \\
\text { programmes on legal and women rights } \\
\text { especially in the rural areas and among } \\
\text { traditional leaders and FBOs } \\
\text { 4.2 Ensure the passage and implementation of } \\
\text { the Domestic Violence Bills and institute } \\
\text { strict sanctions for perpetuators }\end{array}$ & $\begin{array}{l}\text { MOWAC, MMYE, } \\
\text { WAJU, DSW, Legal Aid } \\
\text { Board, NCWD, MOH } \\
\text { MOJ, CBOs, NGOs, FBOs, } \\
\text { Traditional Authorities }\end{array}$ & MDG 3 \\
\hline
\end{tabular}




\begin{tabular}{|c|c|c|c|c|c|}
\hline KEY AREA OF FOCUS & ISSUES & POLICY & STRATEGIES & $\begin{array}{c}\text { IMPLEMENTING AND } \\
\text { COLLABORATIVE } \\
\text { AGENCY } \\
\end{array}$ & $\begin{array}{l}\text { GLOBAL / REGIONAL } \\
\text { LINKAGES }\end{array}$ \\
\hline & $\begin{array}{ll}\text { Shielding } & \text { of } \\
\text { perpetrators } & \text { of } \\
\text { violence } & \end{array}$ & & $\begin{array}{l}\text { 4.3 Develop community-based response to } \\
\text { violence involving traditional leaders and } \\
\text { FBOs on human rights, gender and ADR }\end{array}$ & & \\
\hline & $\begin{array}{l}\text { Limited governmental } \\
\text { - Inadequate social } \\
\text { support for victims of } \\
\text { violence }\end{array}$ & \begin{tabular}{|l} 
5. Disseminate information \\
about domestic violence, \\
and related legal \\
implications and \\
women's rights
\end{tabular} & \begin{tabular}{|l} 
5.1 Provide shelters and support for victims of \\
violence \\
5.2 Include gender and human rights studies in \\
curriculum of law enforcement agencies and \\
social work institutions \\
5.3 Monitor incidence of domestic violence and \\
other violence against women
\end{tabular} & & \\
\hline & & $\begin{array}{l}\text { 6. Integrate Human Rights } \\
\text { and Gender into the } \\
\text { training programmes for } \\
\text { law enforcement agencies } \\
\text { and social workers }\end{array}$ & 6.1 Establish WAJU desk at all police stations & & \\
\hline \multirow[t]{4}{*}{$\begin{array}{|ll|}\text { IX. } & \text { ENHANCING } \\
& \text { DEVELOPMENT } \\
& \text { COMMUNICATION }\end{array}$} & \multirow[t]{4}{*}{$\begin{array}{c}\text { Outdated information } \\
\text { management system }\end{array}$} & $\begin{array}{l}\text { 1. Promote the development } \\
\text { of modern information } \\
\text { management system } \\
\text { including E-Governance } \\
\text { process }\end{array}$ & $\begin{array}{l}1.1 \text { Develop \& implement Information } \\
\text { management policy }\end{array}$ & \multirow[t]{4}{*}{$\begin{array}{l}\text { NDPC, GSS, NCCE, } \\
\text { Ministry of Information, } \\
\text { Governance Programme, } \\
\text { Office of the President, The } \\
\text { Media, NGOs, CSOs }\end{array}$} & \multirow[t]{4}{*}{$\begin{array}{l}\text { APRM, obj } 3 / 6 \text { under } \\
\text { Political Governance }\end{array}$} \\
\hline & & $\begin{array}{l}\text { 2. Promote timely dispatch } \\
\text { of strategic information } \\
\text { to targeted areas }\end{array}$ & $\begin{array}{l}2.1 \text { Facilitate access and enabling } \\
\text { environment }\end{array}$ & & \\
\hline & & $\begin{array}{l}\text { 3. Promote Development } \\
\text { Communication }\end{array}$ & $\begin{array}{l}\text { 3.1 Involve the marginalized in governance } \\
\text { through access to information } \\
\text { 3.2 Encourage private community radio stations }\end{array}$ & & \\
\hline & & 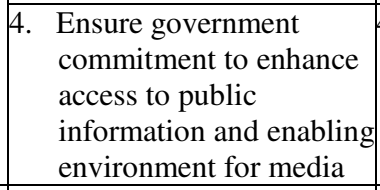 & $\begin{array}{l}\text { 4.1 Effective implementation of public } \\
\text { information law }\end{array}$ & & \\
\hline \begin{tabular}{|ll}
$\mathrm{X}$. & PROMOTING CIVIC \\
& RESPONSIBILITY
\end{tabular} & & $\begin{array}{l}\text { 1. Ensuring higher civic } \\
\text { responsibility and } \\
\text { citizens involvement in } \\
\text { economic development }\end{array}$ & $\begin{array}{l}\text { 1.1 Enforcing rules and regulations } \\
\text { systematically in all spheres, in school, at } \\
\text { work, on the streets, in religious institutions, } \\
\text { etc }\end{array}$ & $\begin{array}{l}\text { MOI, Ghana Police Service, } \\
\text { MTTU, MMDAs, NCCE, } \\
\text { NGOs, National \& Regional } \\
\text { Houses of Chief, Office of }\end{array}$ & $\begin{array}{l}\text { APRM, obj. } 3 \text { under Political } \\
\text { Governance; obj.1 under } \\
\text { Socio-economic } \\
\text { development. }\end{array}$ \\
\hline
\end{tabular}




\begin{tabular}{|c|c|c|c|c|c|}
\hline KEY AREA OF FOCUS & ISSUES & POLICY & STRATEGIES & $\begin{array}{l}\text { IMPLEMENTING AND } \\
\text { COLLABORATIVE } \\
\text { AGENCY }\end{array}$ & $\begin{array}{l}\text { GLOBAL / REGIONAL } \\
\text { LINKAGES }\end{array}$ \\
\hline & & & \begin{tabular}{|l|} 
1.2 Institute rewards for civically responsible \\
behaviour and reprimand unacceptable \\
behaviour \\
1.3 Support formal and informal institutions of \\
socialization and learning to perform their \\
roles as channels of change \\
1.4 Empower traditional authorities to actively \\
participate in ensuring responsible civic \\
behaviours \\
1.5 Strengthen the partnership with the public \\
media to promote civically responsible \\
behaviour
\end{tabular} & $\begin{array}{l}\text { the President, Religious } \\
\text { leaders, MOES, GES, } \\
\text { Traditional Leader, } \\
\text { Governance Programme }\end{array}$ & \\
\hline \multicolumn{6}{|c|}{ ECONOMIC GOVERNANCE } \\
\hline \multirow[t]{3}{*}{$\begin{array}{l}\text { XI. FISCAL POLICY } \\
\text { MANAGEMENT }\end{array}$} & & $\begin{array}{l}\text { 1. Improve Public } \\
\text { Expenditure } \\
\text { Management }\end{array}$ & $\begin{array}{l}\text { 1.1 Develop a more effective data collection } \\
\text { mechanism } \\
\text { 1.2 Transparency in use of statutory funds } \\
\text { 1.3 Enforce budget controls on SOEs }\end{array}$ & \multirow{6}{*}{$\begin{array}{l}\text { MOFEP, Office of the } \\
\text { President, Parliament, BOG, } \\
\text { IRS, CEPS, MOTI, Regional } \\
\text { Integration \& NEPAD, } \\
\text { MMDAs, Audit Service, } \\
\text { Accountant-General Dept., }\end{array}$} & \multirow{3}{*}{$\begin{array}{l}\text { MDG 8, APRM, obj.1/3 } \\
\text { under Economic Governance }\end{array}$} \\
\hline & & $\begin{array}{l}\text { 2. Promote effective Debt } \\
\text { Management }\end{array}$ & $\begin{array}{ll}\text { 2.1 } & \text { Monitor size of domestic debt } \\
\text { 2.2 } & \text { Restructure domestic debt stock } \\
\text { 2.3 } & \text { Reduce stock of domestic debt }\end{array}$ & & \\
\hline & & $\begin{array}{l}\text { 3. Improve fiscal resource } \\
\text { mobilisation }\end{array}$ & $\begin{array}{l}\text { 3.1 Minimise revenue leakages in all collecting } \\
\text { agencies } \\
\text { 3.2 Review and revise existing taxes, fees and } \\
\text { user charges } \\
\text { 3.3 Strengthen revenue collection institutions } \\
\text { 3.4 Strengthen MMDAs for improved tax } \\
\text { collection }\end{array}$ & & \\
\hline \multirow{3}{*}{$\begin{array}{l}\text { XII. MONETARY } \\
\text { POLICY } \\
\text { MANAGEMENT }\end{array}$} & & 1. Price Exchange Stability & 1.1 Improve liquidity management & & \multirow{3}{*}{\begin{tabular}{|l|} 
MDG 8, APRM, obj 1/5 \\
under Economic Governance
\end{tabular}} \\
\hline & & & $\begin{array}{l}\text { 1.2 Establish an effective inter-bank foreign } \\
\text { exchange market }\end{array}$ & & \\
\hline & & $\begin{array}{l}\text { 2. Improving the } \\
\text { institutional, legal and } \\
\text { regulatory framework }\end{array}$ & $\begin{array}{l}\text { 2.1 Revise laws and procedures governing the } \\
\text { Banking sector } \\
\text { 2.2 Conduct regular supervision of banks }\end{array}$ & & \\
\hline
\end{tabular}




\begin{tabular}{|c|c|c|c|c|c|}
\hline KEY AREA OF FOCUS & ISSUES & POLICY & STRATEGIES & $\begin{array}{c}\text { IMPLEMENTING AND } \\
\text { COLLABORATIVE } \\
\text { AGENCY } \\
\end{array}$ & $\begin{array}{l}\text { GLOBAL / REGIONAL } \\
\text { LINKAGES }\end{array}$ \\
\hline & & $\begin{array}{l}\text { 3. Deepen the capital } \\
\text { market }\end{array}$ & $\begin{array}{l}\text { 3.1 Implement schemes to increase long-term } \\
\text { savings/funds } \\
3.2 \text { Expand bond markets }\end{array}$ & \multirow{4}{*}{$\begin{array}{l}\text { MOFEP, Office of the } \\
\text { President, Parliament, BOG, } \\
\text { Financial Institutions, SEC, } \\
\text { NIC, GSE, PEF, SSNIT, } \\
\text { IRS, CEPS, MOTI, Regional } \\
\text { Integration \& NEPAD, } \\
\text { MMDAs, Audit Service, } \\
\text { Accountant-General Dept., } \\
\end{array}$} & \multirow{4}{*}{$\begin{array}{l}\text { MDG 8, APRM, obj.1 under } \\
\text { Economic Governance; obj.2 } \\
\text { under } \quad \text { Socio-economic } \\
\text { development }\end{array}$} \\
\hline & & \multirow[t]{2}{*}{$\begin{array}{l}\text { 4. Strengthening the } \\
\text { financial sector }\end{array}$} & $\begin{array}{l}\text { 4.1 Initiate steps to provide clearer titles over } \\
\text { assets } \\
4.2 \begin{array}{l}\text { Address inefficiencies in legal, } \\
\text { judicial and asset registry systems }\end{array} \\
4.3 \begin{array}{l}\text { Facilitate development of database for } \\
\text { credit management }\end{array} \\
44 \begin{array}{l}\text { Reduce BoG secondary reserve } \\
\text { requirements }\end{array}\end{array}$ & & \\
\hline & & & $\begin{array}{l}\text { 4.5 Promote competition in the financial system } \\
\text { to reduce high interest rate spread and } \\
\text { ensure competitive rates }\end{array}$ & & \\
\hline & & $\begin{array}{l}\text { 5. Create a more diversified } \\
\text { financial sector and } \\
\text { improve access to } \\
\text { financial services }\end{array}$ & $\begin{array}{l}\text { 5.1 Improve the administrative framework for } \\
\text { micro finance } \\
\text { 5.2 Develop micro finance product designed to } \\
\text { address the needs of agriculture } \\
\text { 5.3 Establish a central securities depository for } \\
\text { government securities } \\
\text { 5.4 Enact long-term savings law for private } \\
\text { pension and housing schemes. }\end{array}$ & & \\
\hline \multirow[t]{3}{*}{$\begin{array}{l}\text { XIII. INTERNATIONAL } \\
\text { TRADE } \\
\text { MANAGEMENT }\end{array}$} & & $\begin{array}{l}\text { Improve import } \\
\text { competitiveness }\end{array}$ & 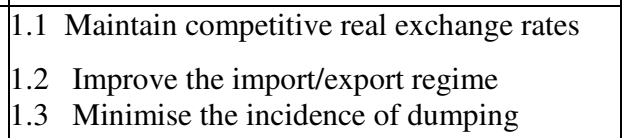 & & \multirow[t]{3}{*}{$\begin{array}{l}\text { MDG 8, APRM, obj.1/5 } \\
\text { under Economic Governance }\end{array}$} \\
\hline & & $\begin{array}{l}\text { 2. Diversify and increase } \\
\text { export base }\end{array}$ & $\begin{array}{l}\text { 2.1 Promote new areas of competitive } \\
\text { advantage } \\
\text { 2.2 Take full advantage of Preferential Access } \\
\text { to markets such as AGOA, EU-ACP } \\
\text { 2.3 Engage fully in Multi-lateral Trade } \\
\text { negotiations }\end{array}$ & & \\
\hline & & $\begin{array}{l}\text { 3. Institute mechanisms to } \\
\text { manage external shock }\end{array}$ & 3.1 Maintain stable reserves & & \\
\hline
\end{tabular}




\begin{tabular}{|c|c|c|c|c|c|}
\hline KEY AREA OF FOCUS & ISSUES & POLICY & STRATEGIES & $\begin{array}{c}\text { IMPLEMENTING AND } \\
\text { COLLABORATIVE } \\
\text { AGENCY }\end{array}$ & $\begin{array}{l}\text { GLOBAL / REGIONAL } \\
\text { LINKAGES }\end{array}$ \\
\hline & & $\begin{array}{l}\text { 4. Accelerate economic } \\
\text { integration with other } \\
\text { regional and/or sub- } \\
\text { regional states }\end{array}$ & $\begin{array}{l}\text { 4.1 Implement the WAMZ programme } \\
\text { 4.2 Work towards establishing a common } \\
\text { customs union } \\
\text { 4.3 Ensure that National Trade Policy reflects } \\
\text { ECOWAS protocols } \\
\text { 4.4 Strengthen links between industrial and } \\
\text { trade policies }\end{array}$ & & \\
\hline \multicolumn{6}{|c|}{ CORPERATE GOVERNANCE } \\
\hline $\begin{array}{l}\text { XIV. GOOD } \\
\text { CORPORATE } \\
\text { GOVERNANCE }\end{array}$ & & $\begin{array}{l}\text { 1. Promote an enabling } \\
\text { environment and } \\
\text { effective regulatory } \\
\text { framework for corporate } \\
\text { management }\end{array}$ & $\begin{array}{l}\text { 1.1 Ensure that corporations act as good } \\
\text { corporate citizens with regard to human } \\
\text { rights, social responsibility and } \\
\text { environmental sustainability } \\
\text { 1.2 Promote the adoption of codes of good } \\
\text { business ethics in achieving the objectives } \\
\text { of the organization } \\
\text { 1.3 Ensure that corporations treat all their } \\
\text { stakeholders in a fair and just manner } \\
\text { 1.4 Provide for accountability of corporations } \\
\text { and directors }\end{array}$ & $\begin{array}{l}\text { CHRAJ, MMYE, PEF, AGI, } \\
\text { SSNIT, GEA, Organised } \\
\text { Labour, EPA, MOFEP, } \\
\text { Auditor-General, PAC, } \\
\text { Judicial Services, SFO, } \\
\text { Economic Crime Unit of } \\
\text { Police, MOI, MOC, NCA, } \\
\text { CSOs, Media }\end{array}$ & $\begin{array}{l}\text { APRM, obj. } 1 / 2 / 3 / 4 / 5 \text { under } \\
\text { Corporate Governance } \\
\\
\text { APRM, obj. } 1 / 2 / 3 / 4 / 5 \text { under } \\
\text { Corporate Governance }\end{array}$ \\
\hline \multicolumn{6}{|c|}{ EVIDENCE-BASED DECISION MAKING } \\
\hline \begin{tabular}{|l|} 
XV. PROMOTING AN \\
EVIDENCE-BASED \\
DECISION MAKING
\end{tabular} & & $\begin{array}{l}\text { 1. Strengthening the data } \\
\text { base for policy } \\
\text { formulation and decision } \\
\text { making }\end{array}$ & $\begin{array}{l}\text { 1.1 Rationalize the production of data within the } \\
\text { statistical system } \\
\text { 1.2 Define the roles and mandates of the } \\
\text { various data producing institutions } \\
\text { 1.3 Adopt common definitions, methods and } \\
\text { classifications } \\
\text { 1.4 Review of the Statistical law and adoption } \\
\text { of a statistical master plan }\end{array}$ & $\begin{array}{l}\text { NDPC, GSS, CSOs, Ministry } \\
\text { of Information, MMDAs, } \\
\text { Office of the President, } \\
\text { NGOs, NCCE, MDAs, } \\
\text { MOFEP, BOG, Research } \\
\text { Institutions, Governance } \\
\text { Programme }\end{array}$ & $\begin{array}{l}\text { APRM, obj.2 under } \\
\text { Economic Governance; } \\
\text { obj.2/6 under Socio- } \\
\text { economic development. }\end{array}$ \\
\hline
\end{tabular}




\begin{tabular}{|c|c|c|c|c|c|}
\hline KEY AREA OF FOCUS & ISSUES & POLICY & STRATEGIES & $\begin{array}{c}\text { IMPLEMENTING AND } \\
\text { COLLABORATIVE } \\
\text { AGENCY }\end{array}$ & $\begin{array}{l}\text { GLOBAL / REGIONAL } \\
\text { LINKAGES }\end{array}$ \\
\hline & & & $\begin{array}{l}1.5 \text { Adopt international standards and good } \\
\text { practices system-wide, including the United } \\
\text { Nations Principles for Official Statistics and } \\
\text { the IMF's General Data Dissemination } \\
\text { Standards }\end{array}$ & $\begin{array}{l}\text { NDPC, GSS, CSOs, Ministry } \\
\text { of Information, MMDAs, } \\
\text { Office of the President, } \\
\text { NGOs, NCCE, MDAs, } \\
\text { MOFEP, BOG, Research } \\
\text { Institutions }\end{array}$ & \\
\hline
\end{tabular}

